\title{
Special Report 4: China's Energy System Revolution
}

\author{
Shi Yaodong and Angus Gillespie
}

Innovation plays a crucial role in China's energy system transition and revolution. At the 6th meeting of the Central Leading Group for Financial and Economic Affairs in June 2014, General Secretary $\mathrm{Xi}$ announced that China would: (i) carry out an energy system revolution to put China's energy development on the fast track; (ii) reform the energy industry into an effective and competitive market system with a market-oriented pricing mechanism; and (iii) transform the government's regulation of the energy industry and improve the energy legislation system.

There have been many system constraints on the sustainable development of China's energy industry

DRC Team Lead of Special Report 4: Shi Yaodong from the Research Department of Industrial Economy, DRC of the State Council of China.

Shell Team Lead of Special Report 4: Angus Gillespie, Former Vice President Group CO2, Shell Global Solutions.

Contributors: Philip Gradwell and Cameron Hepburn from Vivid Economics; Li Weiming, Chen Jianpeng and Zhou Jianqi from DRC of the State Council of China; Liu Xiaoli from the Energy Research Institute, NDRC; and Fan Jingli and Wu Lin from the China University of Mining and Technology.

S. Yaodong $(\square)$

Research Department of Industrial Economy, DRC of the State Council of China, Beijing, China

A. Gillespie

Former Vice President Group CO2, Shell Global

Solutions, The Hague, the Netherlands for a long time. For example, state monopoly in the oil, gas and power sectors has restricted market competition and kept private capital investment low. Government price control of those three sectors has prevented the market from allocating resources efficiently and distorted the prices of some products. To address these constraints, the government has introduced a series of guidelines and reform roadmaps over the past few years. These include the Opinions of the CPC Central Committee and the State Council on Further Deepening the Reform of the Electric Power System (March 2015), the Opinions of the CPC Central Committee and the State Council on Advancing the Reform of the Pricing Mechanism (October 2015), the Opinions on Deepening the Reform of the Oil and Gas System (May 2017), and the Action Plan for Energy System Revolution (July 2017). These guidelines and roadmaps clearly identify the objectives, pathways and mechanisms for deep energy system reform.

With the introduction of these guidelines, action plans and related support measures, ${ }^{1}$ the

\footnotetext{
${ }^{1}$ For example, the supporting documents for power system reform include the Implementation Opinions on Promoting the Reform of Power Transmission and Distribution Pricing Mechanisms, the Implementation Opinions on Promoting the Development of the Power Market, the Implementation Opinions on Building and Consistent Operation of Power Trading Institutions, the Implementation Opinions on the Orderly Deregulation of Power Generation and Consumption Planning, the Implementation Opinions on Promoting Power Retail Reform, and the Guidelines on Strengthening and Regulating the Supervision and Management of Backup Coal-Fired Power Plants.
} 
reform of China's energy institutions and system has made positive progress.

Reforming China's energy system is a formidable task and cannot be achieved overnight. Li Wei, Director of the DRC of China's State Council and Chinese lead of this DRC-Shell collaborative research project, said in a recent speech that in the context of the global energy revolution, there are still some deeply rooted contradictions and problems for China to address before it can deliver a clean, low-carbon, secure and efficient modern energy system. ${ }^{2}$ In Special report 4, we discuss how China can develop and deepen its energy system revolution and institutional innovations, and we put forward a series of constructive policy proposals.

\section{Factors and Trends in Energy System Reform}

\subsection{Energy Supply and Demand: Global Energy Oversupply and Strong Energy Demand Growth in Asia's Emerging Economies}

Historical experience suggests that it is difficult to implement energy system reform at a time of rapidly growing energy demand, as the priority is to ensure energy supply security and meet demand. In recent years, affected by such factors as slowing world economic growth and industrial restructuring, global energy demand has shown little movement. On the other hand, the shale gas revolution and large-scale investment and development in response to high energy prices have resulted in global energy oversupply and lower energy prices. As China's economy enters the new normal of slower growth, demand for energy will decline and lead to overcapacity in the country's energy sectors, including coal, electricity and oil. Thus, it is unlikely that there will be sharp fluctuations in energy demand and

\footnotetext{
${ }^{2}$ Speech made by Director Li Wei at the China Grand Energy Transition Forum 2017, August 19, 2017.
}

large-scale energy supply shortages. To drive energy system reform forward, improvements in energy use efficiency can help strengthen relatively stable internal and external environments.

The annual growth rate in China's energy demand is forecast to fall below $2 \%$ by 2035 , from $8 \%$ in 2000 . This is attributed to China's slowing economic growth, improved energy efficiency and changing patterns of consumption. China's energy demand is increasingly less dependent on energy-intensive industries like steel and cement. Instead, future energy demand will be closely linked to economic restructuring - more structural adjustments mean less energy demand, and vice versa. For example, if China's economic structure shifts closer to that of the USA, energy demand will decrease. As the global economy grows, energy demand will also grow. Almost all new energy supply in 2014-35 will be consumed by rapidly developing economies. According to BP Energy Outlook 2035 (2016), the average annual growth rate in world primary energy demand in 2014-35 will be 1.4\% and world total energy demand will increase by $34 \%$ in the same period. In the new normal economy, China's energy demand will grow slowly but sustainably. In 2025-35, China will account for less than $30 \%$ of the increase in global energy demand, compared to $60 \%$ in the past decade (BP 2016).

The share of oil, natural gas and coal in global energy demand has been stable over the past decade (Fig. 1). In 2016, the share of oil, natural gas and coal production was $38.95 \%, 28.55 \%$ and $32.5 \%$ respectively.

Oil and natural gas production shows slight but steady growth over the past decade, compared to coal, which has declined. As coal-dominated energy producers begin to seek alternative energy sources, the energy system gradually evolves (Fig. 2).

Global primary energy demand did not change significantly in 2006-16 (Fig. 3). Oil had the largest share of global primary energy demand, reaching 33\% in 2016. Although many countries are now reducing their consumption of fossil fuels to lower their $\mathrm{CO}_{2}$ emissions, this did not have much impact on energy demand. Renewable energy is expanding and its 
Fig. 1 Share of oil, natural gas and coal in global energy production. Source BP

Statistical Review of World Energy 2017

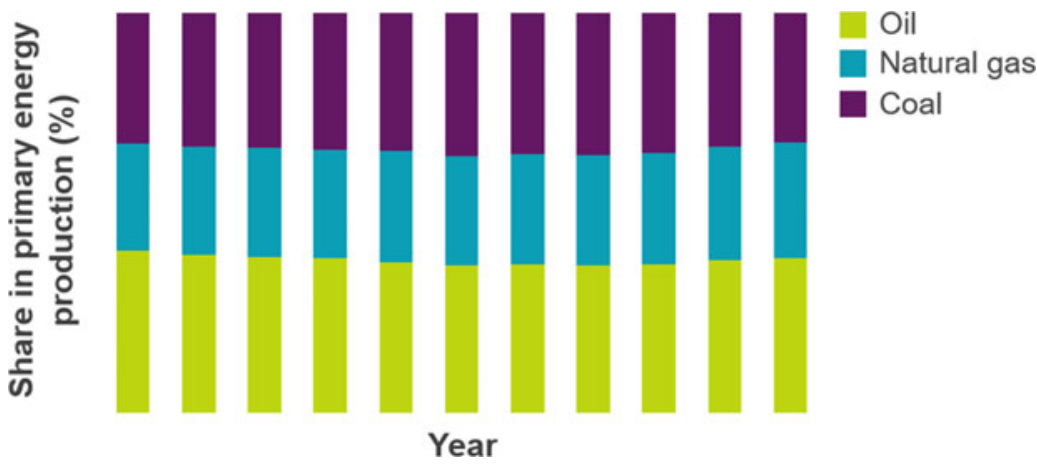

Fig. 2 Global primary energy production. Source BP Statistical Review of World Energy 2017

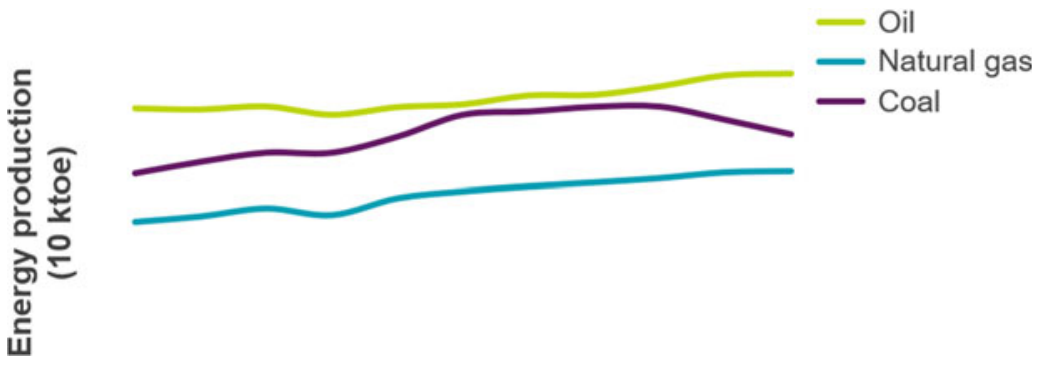

production landscape is changing. In 2016, demand for renewable energy grew by $12 \%$ (including wind, geothermal, solar, biomass, waste-to-energy and biofuels, excluding hydropower). Although this is lower than the average growth rate of $15.7 \%$ in $2006-16$, it still represents the biggest annual increase ever (a rise of 55 Mtoe, which is more than the decline in coal demand). In the same year, China became the world's largest renewable energy producer ahead of the USA. Although renewable energy only accounts for $4 \%$ of global primary energy demand and the average growth rate of some renewable energy sources, including nuclear and hydro, is only $2.64 \%$, new energy is expected to remain the major driver of the energy revolution and will play a major role in driving economic growth in the future.

Figure 4 shows that growth in energy demand to 2035 comes entirely from emerging economies, with China and India accounting for more than half of the increase. In contrast, oil demand in OECD countries will continue to fall steadily. In terms of oil supply, non-OPEC countries are the main source of increased supply, producing
11 million barrels per day (MMbbl/d) compared to $7 \mathrm{MMbbl} / \mathrm{d}$ in OPEC countries. The increase in non-OPEC oil supply comes entirely from the Americas: shale oil from the USA, deep-sea oil from Brazil, and the oil sands of Canada (BP 2016) (Fig. 5).

BP estimates (BP 2016) that the average annual growth rate of global natural gas demand will reach $1.8 \%$ in $2014-35$, making natural gas the fastest growing fossil energy source. This robust growth is the result of focused supply and environmental policy support. The increase in natural gas demand comes mainly from emerging economies, with about 30\% from China and India and more than 20\% from the Middle East. Industry and power generation are behind the increase, whereas in OECD countries the increase is primarily from power generation. World shale gas production is rising. In 2014-35, the average annual growth rate of shale gas production is expected to reach $5.6 \%$, and its share of total natural gas production will be almost $25 \%$. In 2014-25, nearly all the increase in shale gas output will be contributed by the USA. By 2035, China is expected to become the 


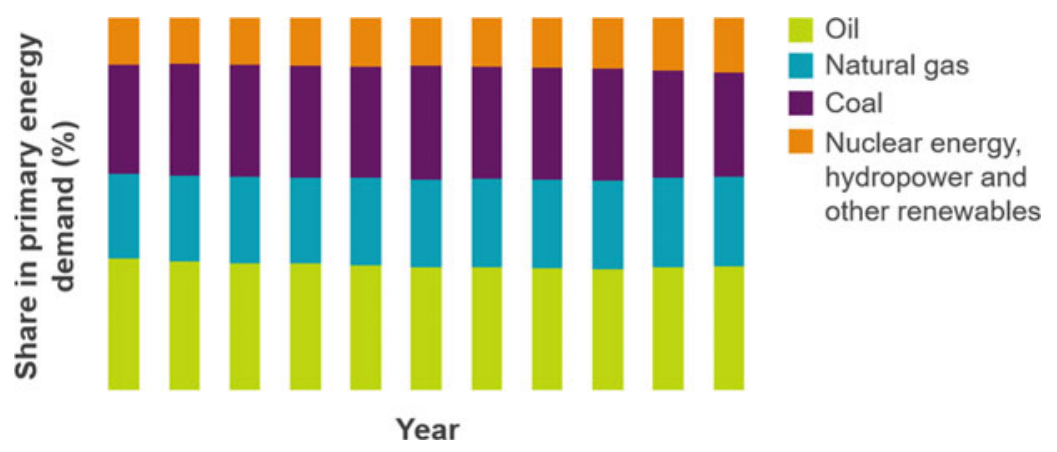

Fig. 3 Share of global primary energy demand. Source BP Statistical Review of World Energy 2017

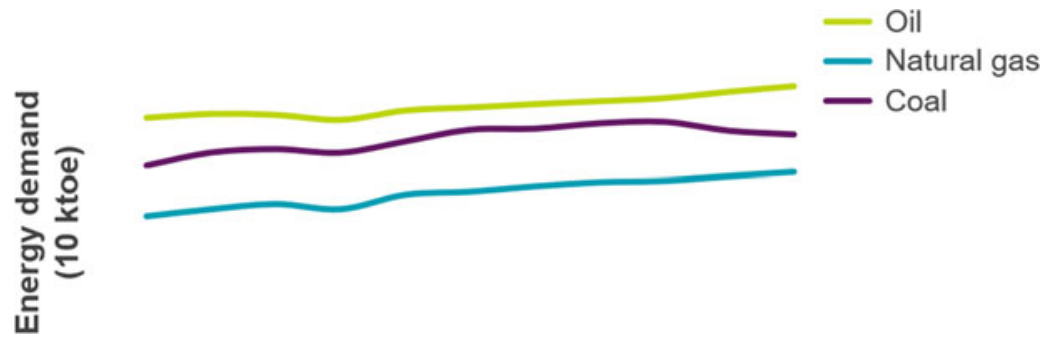

Fig. 4 Global primary energy demand. Note Ktoe = thousand tonnes of oil equivalent. Source BP Statistical Review of World Energy 2017

\section{Demand}

\section{Supply}

\section{$\mathrm{MMbbl} / \mathrm{d}$}

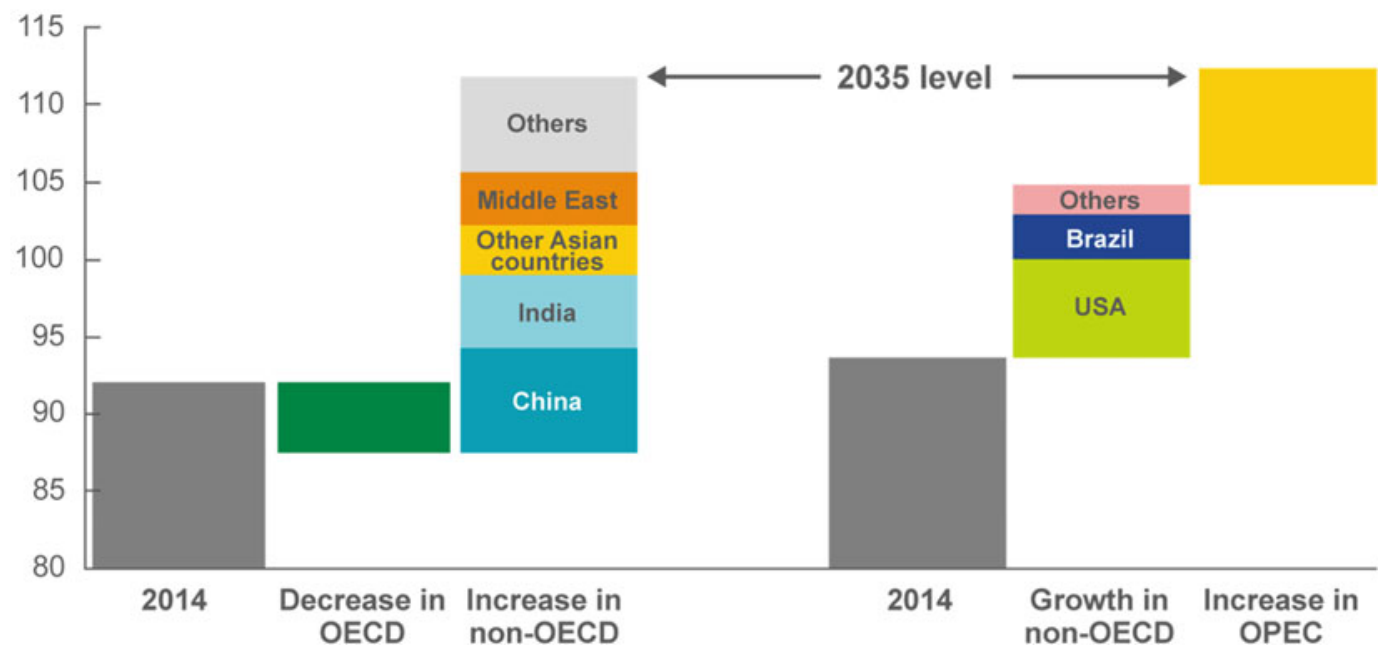

Fig. 5 Global oil demand and supply in 2035. Source BP Energy Outlook 2035 (2016)

largest contributor to increased shale gas production. Global coal demand is forecast to drop sharply to an average annual growth rate of only
$0.5 \%$ in $2014-35$. This is largely due to slowing growth in coal demand and rebalancing of the economy. Even so, China will remain the world's 


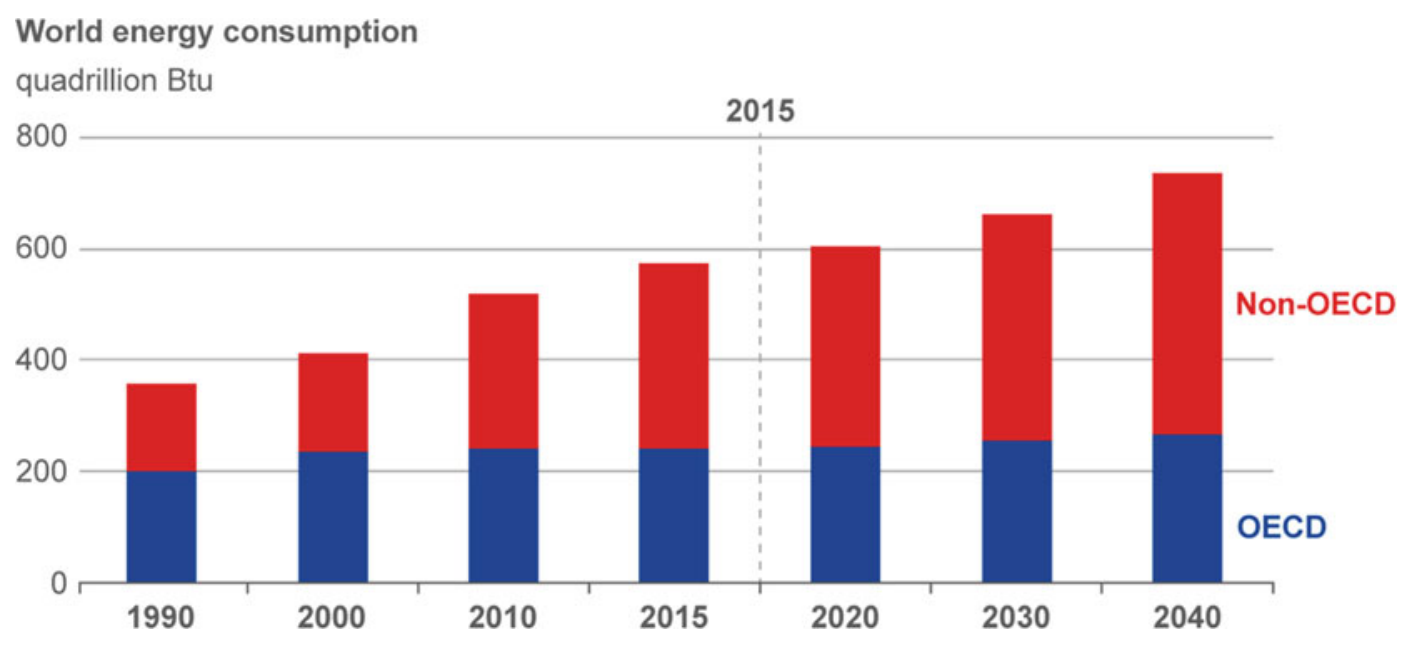

Fig. 6 Energy consumption in OECD and non-OECD countries. Note Btu = British thermal units. Source EIA World Energy Outlook (2017)

largest coal market, consuming almost half of global output in 2035. In the same period, India will register the highest growth in coal demand (435 Mtoe) and become the world's second largest coal consumer ahead of the USA. Although strong growth in coal demand in India and South East Asia can offset lower demand in the USA and the EU, it is unlikely that India and South East Asia will drive the global coal market as China did previously.

Global demand for hydropower and nuclear power will grow steadily at an average rate of $1.8 \%$ and $1.9 \%$ respectively, due mainly to growing demand for energy in Asia. China's unprecedented development of hydropower will come to an end, settling at an average annual growth rate of $1.7 \%$ in 2014-25. Brazil will have the second highest growth rate (after China) and will replace Canada as the world's largest hydropower producer. China's nuclear power demand will grow rapidly, climbing to an average annual growth rate of $11.2 \%$, which is higher than China's growth rate in hydropower over the past two decades. China's demand for nuclear power is forecast to double by 2020 and increase ninefold over the current level by 2035 .

According to the U.S. Energy Information Administration's (EIA) World Energy Outlook 2017, global energy consumption will increase by $28 \%$ between 2015 and 2040 , with more than half of the increase coming from non-OECD countries in Asia, including China and India (Fig. 6). Growth in energy demand from Asia's emerging economies is the result of their strong economic performance. Rising economic growth and growing energy demand will intensify competition for energy supply. It is therefore important that these countries seize the strategic opportunities of the Belt and Road Initiative to drive international energy cooperation and deepen energy system reform.

\subsection{Major Adjustments to the World Energy Landscape: Diversified Energy Supply and Increased Regional Energy Collaboration}

After 2005, the share of shale gas in total US natural gas production increased rapidly-from $5.4 \%$ ( 1 trillion cubic feet) in 2006 to $56 \%$ (15.2 trillion cubic feet) in $2015 .^{3}$ In 2009 , US natural gas production exceeded that of Russia, making it the world's largest natural gas producer. US

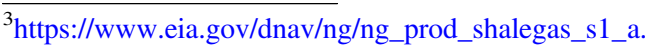
htm.
} 


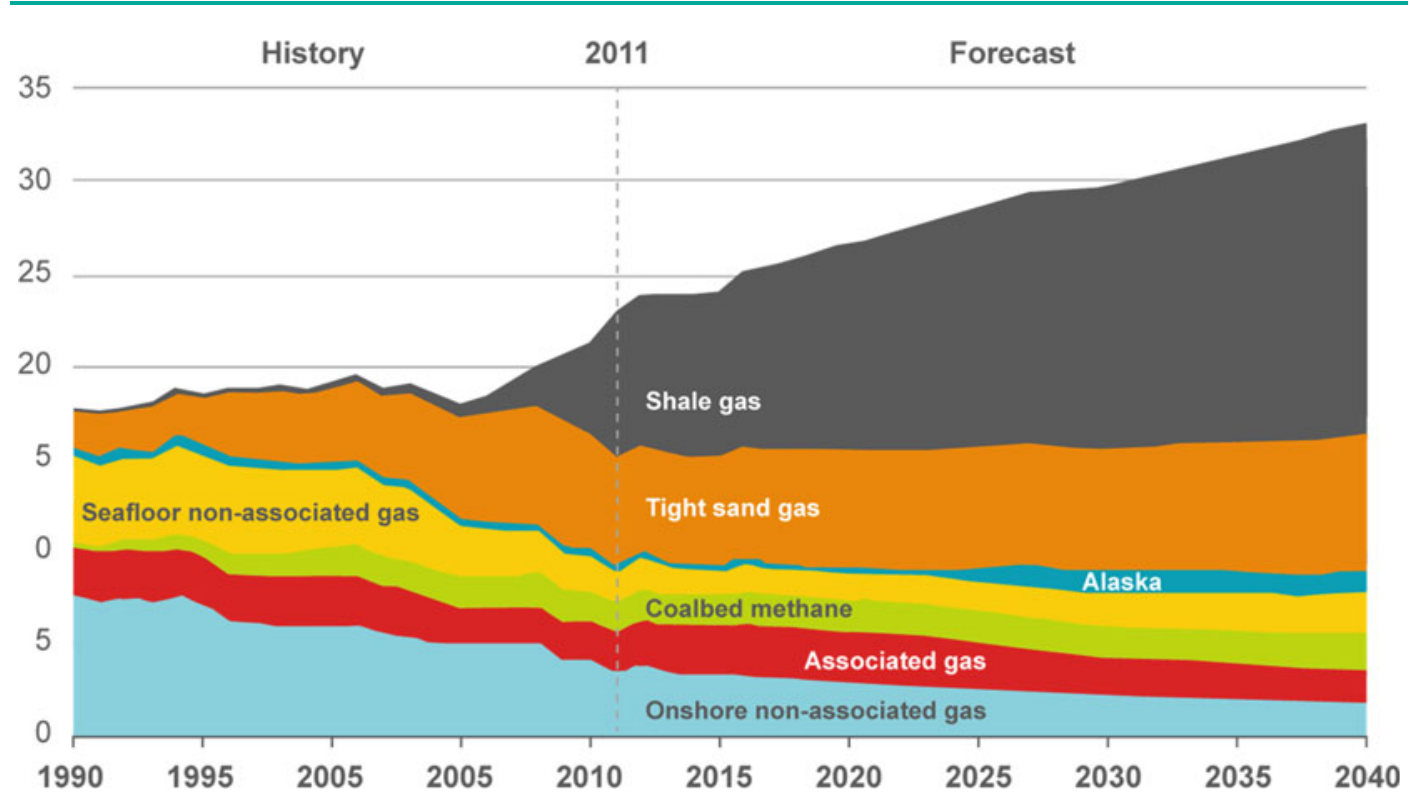

Fig. 7 Natural gas production in the USA (trillion cubic feet). Source IEA (2017)

shale gas production is forecast to exceed 20 trillion cubic feet by 2040 , accounting for more than half of its total natural gas production. ${ }^{4} \mathrm{New}$ proven natural gas reserves in the USA continue to increase and are currently estimated to be 2,300 trillion cubic feet. At the present level of consumption, the reserves are sufficient to last for nearly 100 years (Fig. 7).

With its substantially increased oil and gas production, the USA is likely to turn its long-advocated slogan of energy independence into reality. The USA has reduced its dependence on oil imports from $60 \%$ in 2005 to $25 \%$ in 2016. ${ }^{5}$ The National Intelligence Council predicts that the USA will achieve energy independence by 2030 and become an oil self-sufficient country and a major natural gas exporter. Canada -with proven oil reserves of 172.19 billion barrels in 2015-has $10.1 \%$ of the world's total proven oil reserves, the largest after Venezuela and Saudi Arabia. It also has about $95 \%$ of the world's proven oil sand resources. With abundant conventional and unconventional oil and gas resources, Canada has become a new energy

\footnotetext{
${ }^{4}$ EIA, Short-Term Energy Outlook 2017.

${ }^{5}$ https://www.eia.gov/tools/faqs/faq.php?id=32\&t=6.
}

superpower. According to the International Energy Agency (IEA 2017), Canada's oil production will reach 30-60 MMbbl/d by 2030. The rise of North American energy intensifies the diversification of energy supply.

The US shale gas revolution sparked a shale gas investment boom across the world. In 2011, the USA calculated its domestic shale gas resources and those of 32 other countries. In 2013, it expanded its assessment to include 137 shale formations in 41 countries, including shale oil resources in addition to shale gas. The assessment found that there are highly abundant shale oil and gas resources in the world, corresponding to $10 \%$ of the world's recoverable crude oil reserves and $32 \%$ of the world's recoverable natural gas reserves. Russia has the most abundant shale oil reserves, followed by the USA, China, Argentina and Libya. China has the highest shale gas reserves, with Argentina, Algeria, the USA, Canada, Mexico and Australia also richly endowed. ${ }^{6}$ Currently, Europe and Australia have increased their efforts to explore and exploit shale gas resources, and China is

\footnotetext{
${ }_{6}^{6}$ https://www.eia.gov/analysis/studies/worldshalegas/pdf/ fullreport.pdf.
} 


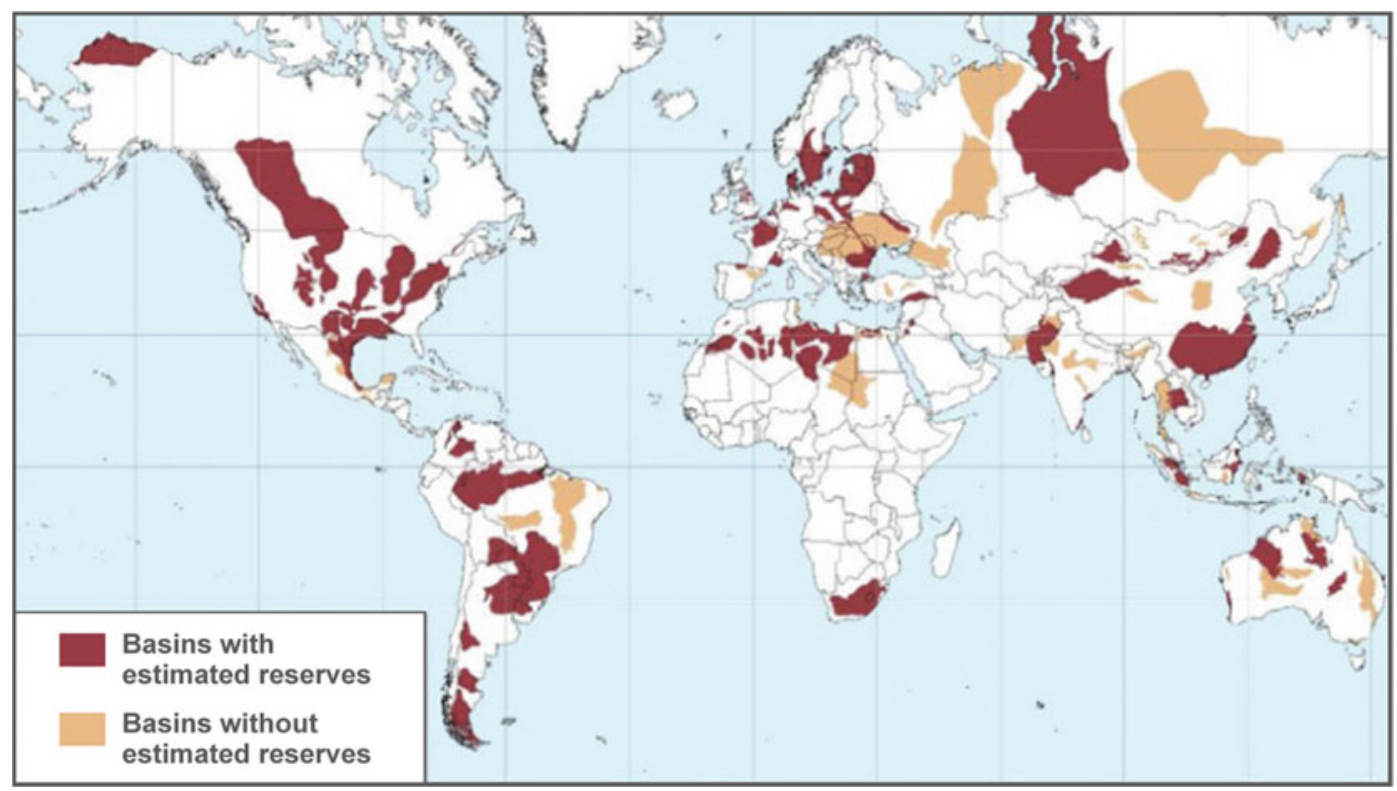

Fig. 8 Distribution of basins with shale oil and gas resources across the world. Source https://www.eia.gov/analysis/ studies/worldshalegas/

starting large-scale commercial development of its shale gas resources. The IEA forecasts that unconventional natural gas will account for about half of world total natural gas production in 2035, with most produced in China, the USA and Australia. In 2035, China's shale gas production will stand at 13 billion cubic feet per day (Fig. 8 and Tables 1 and 2).

The shale gas revolution in the USA has caused a ripple effect in energy and related fields across the world. The impacts of this revolution were first reflected in natural gas prices, which in the USA fell from $\$ 10$ per million British thermal units (MMBtu) in 2005 to around \$3/MMBtu today. In time, as costs rise, the price is expected to increase by about $2.4 \%$ per year, reaching $\$ 7.8 / \mathrm{MMBtu}$ in 2040. Compared with prices in Asia and Europe, the USA will have a clear advantage in prices over the longer term. The IEA estimates that the cost of liquefied
Table 1 Top 10 countries in terms of shale oil reserves in $2015^{\mathrm{a}}$

\begin{tabular}{|l|l|l|}
\hline Ranking & Country & Reserves billion (bbl) \\
\hline 1 & USA & 78 \\
\hline 2 & Russia & 75 \\
\hline 3 & China & 32 \\
\hline 4 & Argentina & 27 \\
\hline 5 & Libya & 26 \\
\hline 6 & UAE & 23 \\
\hline 7 & Chad & 16 \\
\hline 8 & Australia & 16 \\
\hline 9 & Venezuela & 13 \\
\hline 10 & Mexico & 13 \\
\hline
\end{tabular}

ahttps://www.eia.gov/analysis/studies/worldshalegas/ 


\begin{tabular}{llll}
\hline $\begin{array}{l}\text { Table } 2 \text { Top 10 countries } \\
\text { in terms of shale gas }\end{array}$ & Ranking & Country & Reserves (trillion cubic feet) \\
reserves in $2015^{\mathrm{a}}$ & 1 & China & 1115 \\
& 2 & Argentina & 802 \\
& 3 & Algeria & 707 \\
\hline 4 & USA & 623 \\
\hline 5 & Canada & 573 \\
\hline 6 & Mexico & 545 \\
7 & Australia & 429 \\
\hline 8 & South Africa & 390 \\
& 9 & Russia & 285 \\
& 10 & Brazil & 245 \\
& Total & $\mathbf{7 , 5 7 7}$
\end{tabular}

natural gas (LNG) exports from the USA (including the cost of liquefaction, transport and gasification) can be held below \$10/MMBtu, which is still competitive when compared with the current level of \$16/MMBtu and \$12/MMBtu in Asia and Europe respectively. As the USA gradually deregulates natural gas exports, its impact on the world's natural gas market will be increasingly prominent (IEA 2017) (Fig. 9).

As a result of lower natural gas prices, many coal-fired power plants in the USA have switched their fuel from coal to natural gas, resulting in falling coal and electricity prices. This brings a great opportunity to regenerate the manufacturing and chemical industries. Chemical companies that shut down plants in the USA several years ago, due to high natural gas prices, are planning to reopen production facilities and are again using low-price natural gas as a raw material to produce ethylene, synthetic ammonia, chemical fertilisers and diesel fuels.

In short, the large-scale extraction and use of unconventional oil and gas resources make the Americas one of the most important resource exporters after the Middle East, Russia and North Africa. US oil and gas exports will impact energy trade between Europe and Russia for several decades-reducing Europe's dependence on its neighbour and diversifying its energy import structure. To safeguard energy exports, Russia will strengthen energy cooperation with countries in East and South Asia. The reduction in Europe's energy dependence on Russia will further consolidate the political, economic and military alliance between Europe and the USA and Canada. Russia's political and economic cooperation with China, and with emerging economies in Asia, will also grow. China will strengthen its energy cooperation with other countries through the Belt and Road Initiative (BRI). BRI covers two high-quality energy-rich regions: Russia-Central Asia; and the Gulf Region-Western Europe, the former endowed with oil and gas, the latter with advanced energy technologies and widely deployed renewables. Stronger international energy cooperation through BRI will connect Central Asia, North-east Asia, South East Asia, Europe and the Americas, creating regional energy communities to deliver win-win cooperation.

\subsection{Protecting the Environment and Combating Climate Change Are Global Concerns}

The large-scale development and use of fossil energy severely impacts the air, water and environment. Fossil fuel use emits a large amount of 


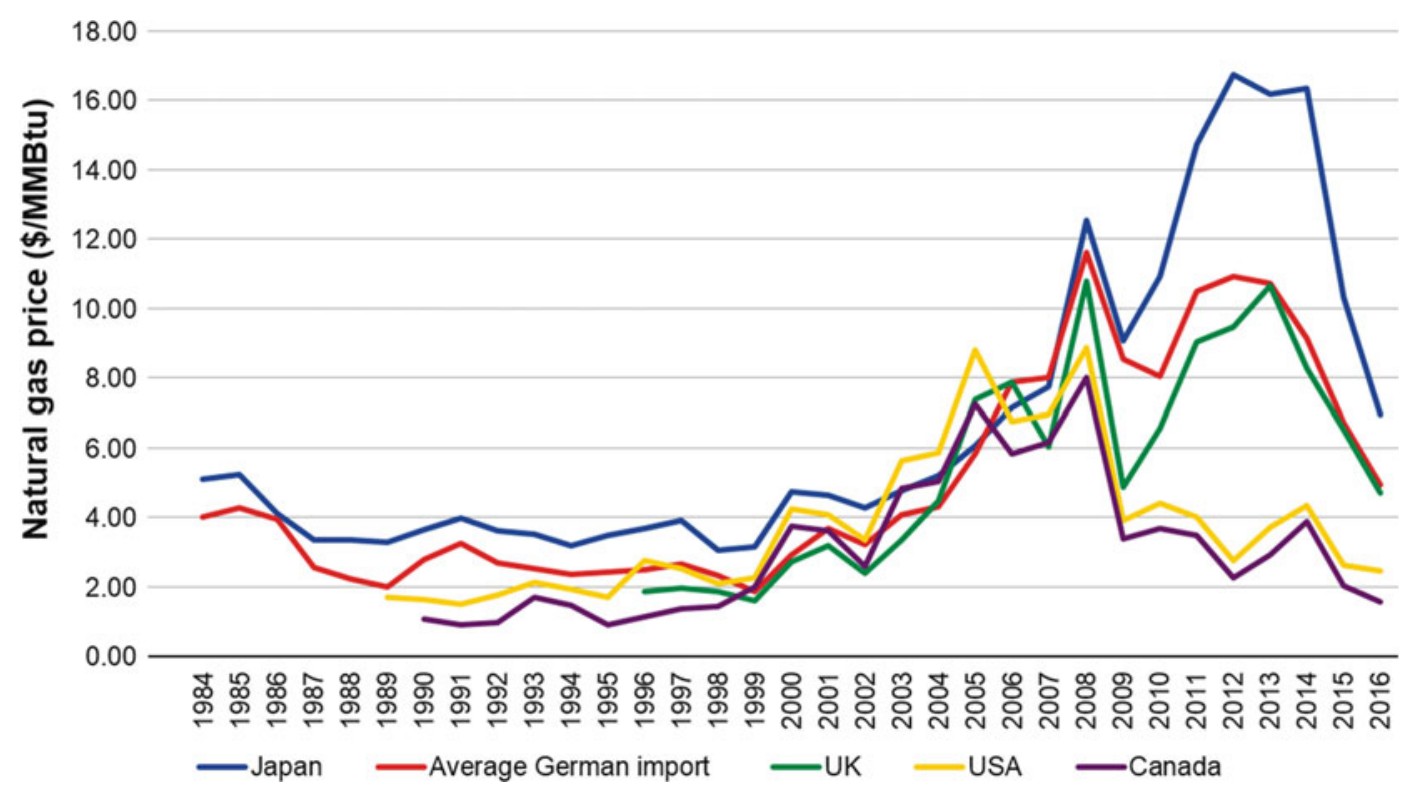

Fig. 9 Price of imported natural gas (\$/MMBtu). Source BP (2017)

pollutants into the air, including carbon dioxide $\left(\mathrm{CO}_{2}\right)$, sulphur dioxide $\left(\mathrm{SO}_{2}\right)$, nitrogen oxides $\left(\mathrm{NO}_{\mathrm{x}}\right)$ and soot. Global $\mathrm{SO}_{2}$ emissions are about 90 million tonnes per year (IEA 2017). They acidify soil and rivers and erode buildings and historical sites. Around $30 \%$ of China's soil surface contains sulphur deposits above the critical level. $\mathrm{NO}_{\mathrm{x}}$ emissions from fossil energy use impact land, rivers, marine ecosystems and the ozone layer. $\mathrm{NO}_{\mathrm{x}}$ emissions from urban traffic and thermal power plants are the main source of PM2.5 atmospheric particulate matter. Increasing amounts of particulate matter from thermal power plants, transport and other industrial sectors cause widespread and severe haze, threatening human health. In addition, fossil energy extraction and use consume water resources and cause severe pollution.

According to the International Energy Agency's World Energy Outlook 2017, 20\% of the world's population live in areas with water shortage. Global water consumption in energy production was 600 billion tonnes, about $15 \%$ of total global water consumption. Its impacts include wastewater discharge from coal production and marine and groundwater pollution from oil and gas exploitation. Large-scale development of conventional energy resources can damage vegetation and landforms. Renewables and other types of new energy also impact the environment, such as visual pollution from wind turbines and the disposal of nuclear waste.

Most $\mathrm{CO}_{2}$ emissions from human activities are from burning fossil fuels. As energy consumption grows, $\mathrm{CO}_{2}$ emissions also increase. According to the Fifth Assessment Report (AR5) of the Intergovernmental Panel on Climate Change (IPCC), the concentration of $\mathrm{CO}_{2}$ in the atmosphere reached 392 parts per million (ppm) in 2012, and the global average temperature rise over the last century was $0.74^{\circ} \mathrm{C}$. The report suggests that global climate warming has become an indisputable fact, which can be evidenced by the rise in atmospheric and sea temperature, large areas of melting snow and ice, and rising sea levels. According to the data monitored by the US National Oceanic and Atmospheric Administration (Fig. 10), global average $\mathrm{CO}_{2}$ concentration exceeded $400 \mathrm{ppm}$ in July 2017 , which is about $40 \%$ higher than 100 years ago. 
Some climate experts believe that the $\mathrm{CO}_{2}$ concentration of $400 \mathrm{ppm}$ represents a critical value that cannot be reversed. When the critical value is exceeded, the global temperature rise will reach $2^{\circ} \mathrm{C}$.

Global warming has negative impacts on the ecosystem. The combined average temperature over global land and ocean surfaces for April 2016 was $1.10^{\circ} \mathrm{C}$ above the 20th century average of $13.7^{\circ} \mathrm{C}$ - the highest temperature departure for April since global records began in 1880 . Sixteen of the 17 warmest years on record have occurred since 2000. Global warming does not just make winters warmer and summers hotter, it also causes major environmental crises, such as glacial retreat in the Qinghai-Tibet Plateau and melting ice and snow in the Antarctic and Arctic. Research indicates that if the global average temperature rise exceeds $2^{\circ} \mathrm{C}$ compared to pre-industrial levels, many species with poor adaptability will die out; if the global average temperature rise exceeds $4^{\circ} \mathrm{C}$, grain yields will fall sharply and fishing productivity will be significantly reduced, exposing global food supply to high risk. ${ }^{7}$ Global warming increases the frequency and intensity of extreme weather conditions, and accelerates the melting and shrinking of glaciers, the largest freshwater reserves on Earth, causing sea levels to rise. Millions of people will be threatened by environmental disasters like floods, droughts, typhoons, water scarcity and the submergence of coastal areas, islands and low-lying littoral cities. According to the World Bank, the losses inflicted by extreme weather conditions are increasing - the average annual loss in the 1980 s was valued at $\$ 5$ million. This has risen to $\$ 200$ billion in the past decade. ${ }^{8}$ Some scientists predict that the average global temperature will rise by at least $3^{\circ} \mathrm{C}$ by the end of this century, which will result in the extinction of a large number of species (Fig. 11).

From the United Nations Framework Convention on Climate Change (UNFCCC) in 1992 to the Kyoto Protocol in 1997 and the Paris

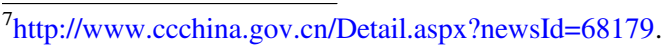

${ }^{8}$ http://news.china.com.cn/world/2013-11/20/content_ 30647909.html.
}

Agreement in 2015, the international community has been increasingly concerned about climate change and made vigorous efforts to reduce greenhouse gas emissions. The Paris Agreement sets ambitious goals for reducing greenhouse gas emissions. It established an approach based on the nationally determined contributions (NDCs) of each signatory country to reduce national emissions and adapt to the effects of climate change; and it reiterates the UNFCCC's principle of the common but differentiated responsibilities of individual countries. The Paris Agreement represents the first consensus reached by the international community to combat climate change together, and the first proportionate response by the world's political system to environmental threats. It also brought politicians and academics together, in agreement and on the same side. However, the process is full of twists and turnsthe Trump administration announced withdrawal from the Paris Agreement in June 2017 and cancelled the Clean Power Plan introduced by the Obama administration in October 2017, both of which obstruct efforts to combat climate change. The Trump administration is also widely criticised by the international community for its regression and non-action about global climate change. To deliver the goal of emissions reduction, all countries must gradually reduce their use of fossil energy. It is, however, extremely difficult to arrange international negotiations on climate change and align developed and developing countries on climate protection goals, emissions reduction responsibilities and financial investments. As the country with the most advanced industry and the highest cumulative carbon emissions per capita, the USA should accept its responsibilities. Its decision to withdraw from the Paris Agreement is disappointing. Despite the intricate political and economic games behind the negotiations on climate change, the trend of international collaboration on combating climate change cannot be reversed (Fig. 12).

The sense of urgency felt by much of the world about controlling environmental pollution and combating climate change provides operational space for energy system change. Pollution like haze and environmental pollution constraints 


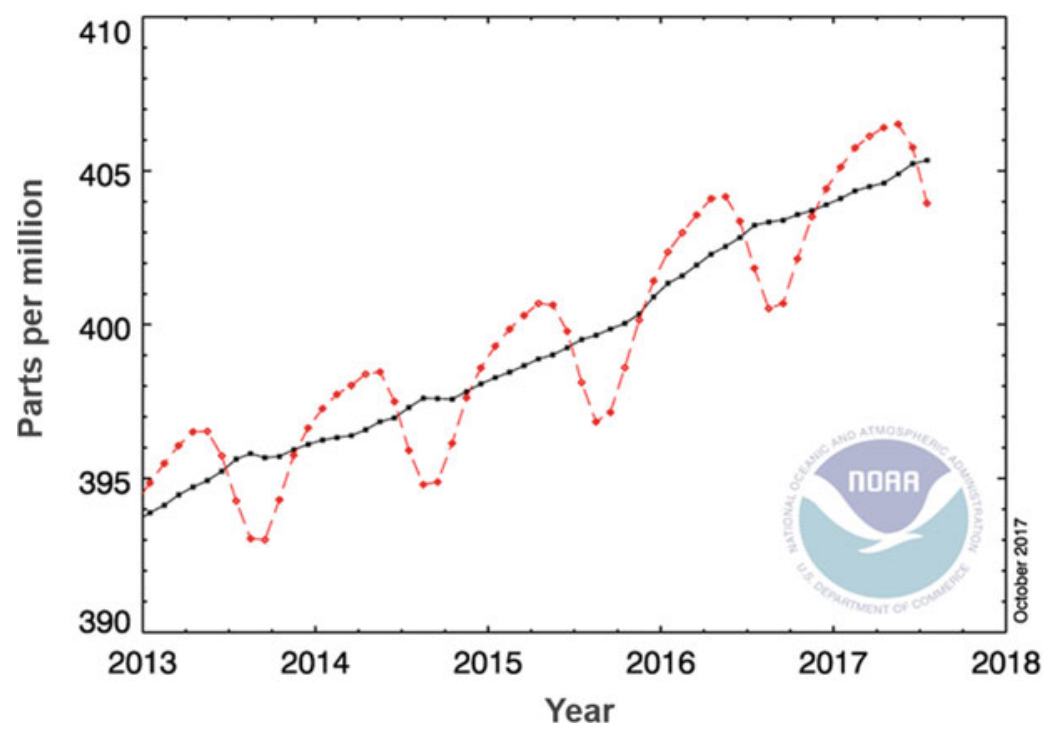

Fig. 10 Global monthly mean $\mathrm{CO}_{2}$ concentration. Source US National Oceanic and Atmospheric Administration, NOAA (2017) (https://www.esrl.noaa.gov/gmd/ccgg/trends/global.html)

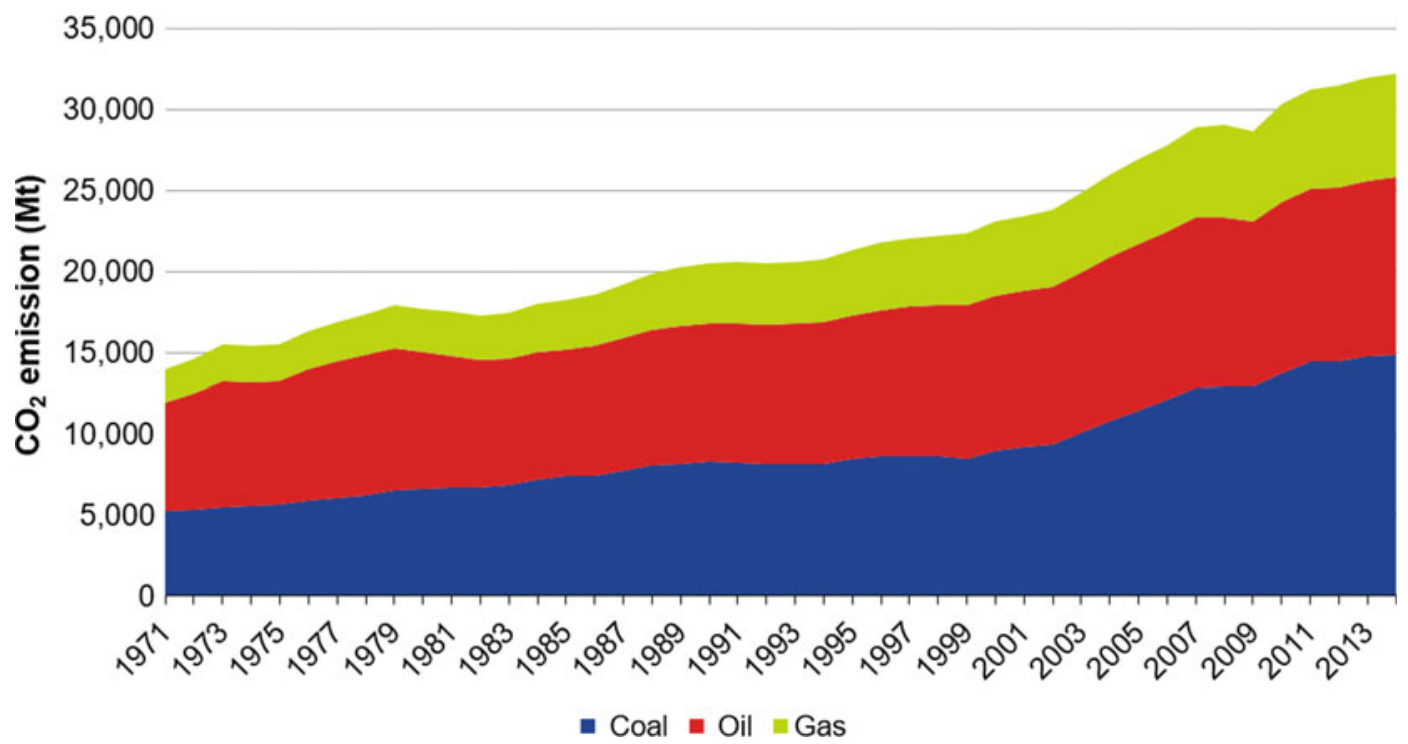

Fig. 11 Global $\mathrm{CO}_{2}$ emissions from fossil fuels. Source IEA (2016)

have made the public aware of the effects of energy consumption on the environment. As a result, the public generally supports energy system reform to control haze and alleviate energy constraints. People are willing to choose cleaner energy consumption and share the cost of environmental protection. As past international experience shows, the public's recognition of clean development can force the government and business to focus on clean development-the Montreal Protocol on substances that deplete the ozone layer is a case in point (Fig. 13).

The green energy era began at the start of the 21 st century. The principal trend in the global 
Fig. 12 GDP, energy consumption and $\mathrm{CO}_{2}$ emissions.

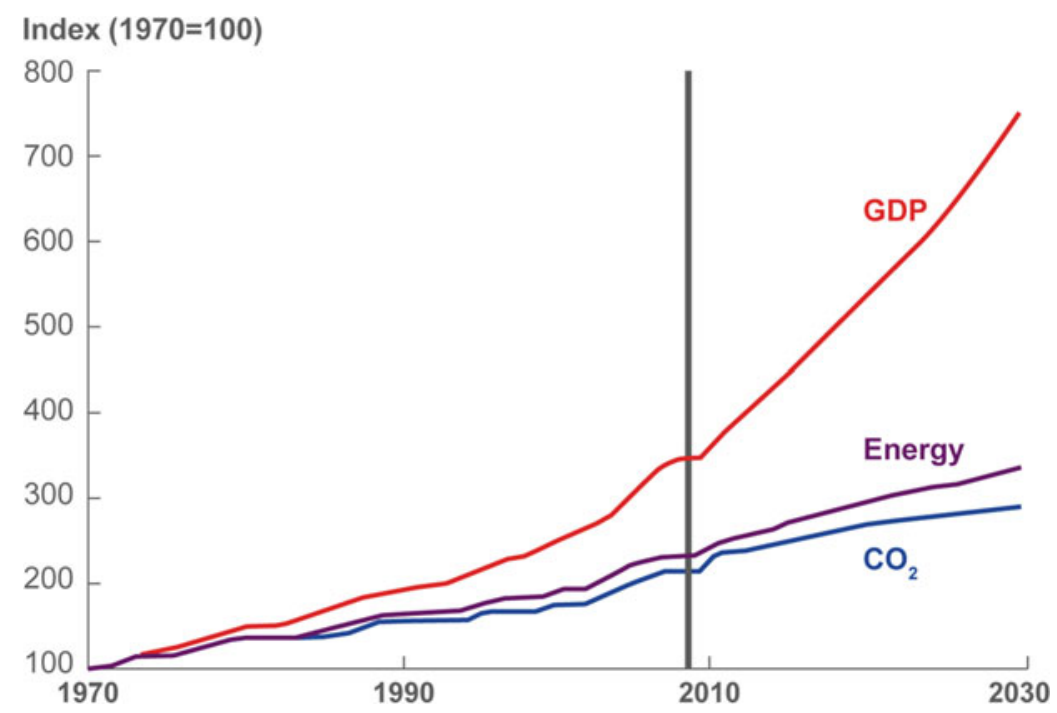

energy transition is the shift from fossil fuels to a sustainable, clean and low-carbon energy system. In developed economies, the share of low-carbon energy in the supply system is increasing. In 1974, Japan issued a new energy development plan to raise investment in developing and using solar, geothermal and hydrogen energy and synthetic natural gas, and identified the development of solar energy as a national strategy. In 2004, Japan introduced its strategic vision of developing new energy technologies, including solar and wind, into a pillar industry valued at JPY 3 trillion. This would include reducing oil use from $50 \%$ to $40 \%$ of its total energy consumption and increasing the share of new energy to $20 \%$. In recent years, European and American countries have adopted a goal-oriented and systematic approach to achieving an energy transition by 2050 . For example, as mentioned in the EU Energy Roadmap 2050, the share of renewables in total energy consumption will be more than $55 \%$ in 2050 . A study by the U.S. Department of Energy said that renewables can meet $80 \%$ of power demand by 2050 .

Clean energy is becoming a megatrend in global energy development. As the world's largest energy consumer, China is already targeting an energy revolution. In energy technology, the Action Plan for Innovation in the Energy Technology Revolution (2016-30) and the 13th
Five-Year Plan (2016-20) for Energy Technology Innovation have defined 15 innovation pathways for China's energy technologies in the medium-to-long term. According to the Strategy of Energy Production and Consumption Revolution (2016-30), by 2020, the year before the 100th anniversary of the Chinese Communist Party, China will fundamentally change its model of extensive growth in energy consumption. Total energy consumption will be held within a 5 Btce limit and the share of coal consumption will be decreased. The share of non-fossil energy will be $15 \%$, and energy consumption per unit of GDP will be $15 \%$ lower than in 2015. By 2030 , the share of non-fossil energy and natural gas in total energy consumption will be around $20 \%$ and $15 \%$ respectively. Increases in energy demand will be met mainly by clean energy.

\subsection{A Sound Legal System Will Secure the Energy Market and Guide the Energy Revolution}

Energy in developed economies is based on a relatively mature market system. A sound legal system across the entire energy value chain gives developed economies a head start in energy development. For instance, Japan introduced a 


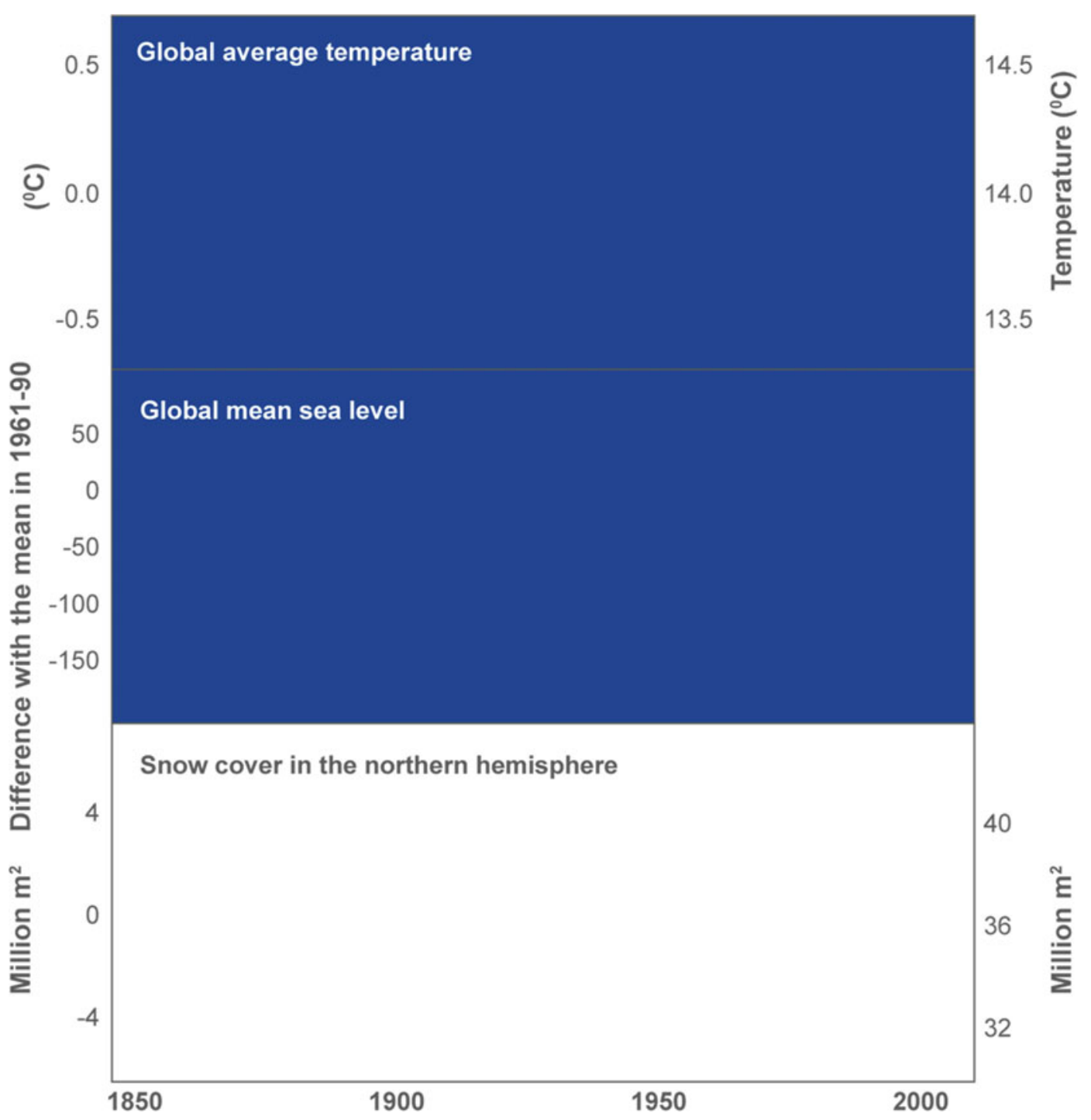

Fig. 13 Change in global average temperature, sea level and snow-cover in the northern hemisphere. Source Intergovernmental Panel on Climate Change (IPCC), Fourth Assessment Report (2007)

series of laws to implement emissions reduction measures and control energy demand growth in all sectors. To lower energy consumption, the USA issued a national energy efficiency policy and regulations and the National Appliance Energy Conservation Act. To reduce emissions, the USA passed the Clean Water Act, the Clean Air Act and the Solid Waste Disposal Act, and others.

Developed economies are at the forefront of new energy legislation. The UK government passed the Climate Change Act 2008 and the Energy Act 2011, which cover green energy options, energy efficiency and low-carbon technologies. The House of Representatives passed the American Clean Energy and Security Act of 2009 (ACES) to drive development of clean energy and energy security in the USA. In Japan in 2011, the House of Councillors and the House of Representatives passed the Act on Special Measures for Renewable Energy to promote new energy technology innovation and reduce 
dependence on nuclear power. Germany introduced the Renewable Energy Sources Act in 2014, which requires the share of new energy consumption to eventually exceed 50\%. Earlier, in March 2009, Germany passed the Renewable Energies Heat Act to increase the share of renewable energy in heat production.

Renewable energy is an irreversible trend. According to the International Renewable Energy Agency, by the beginning of 2016173 countries had set renewable energy development goals and 146 countries had introduced related support policies. For instance, by 2050 Denmark will be free from fossil fuels and in Germany renewable energy will account for $60 \%$ of energy consumption.

China has yet to introduce an energy law to support energy development. In May 2016, the National Energy Administration of China issued the Energy Legislation Plan 2016-20, identifying "five laws and four regulations" as priority projects. These include the Energy Law of the People's Republic of China and laws on electric power, the coal industry, oil and gas, oil and gas pipelines, nuclear power administration, offshore oil and gas pipelines, national petroleum reserves, and energy supervision and administration. As the energy industry develops, the gap between safeguarding energy security and regulating and managing energy is increasingly apparent. To reform the supervision and administrative system of the energy industry in China, it is important to implement the Energy Law of the PRC.

In recent years, China's new energy development has accelerated. Installed wind and solar power capacity is at a world-class level. However, there are still some challenges for China to address, including wind and solar curtailment, destructive exploitation of geothermal energy resources, and management and operational mechanisms for new energy development. Solving these problems will largely depend on adjusting relevant policies and laws and regulations, and by drawing on those of other countries.

\subsection{The Energy Technology Revolution: IT, Smart Technologies and the Energy Internet}

The energy landscape is undergoing major change. This is an age where technological breakthroughs are continually made in energy technologies and the energy system undergoes game-changing evolution. It is the age of systemic change, where the electricity market is increasingly deregulated and existing business and profitability models in the energy industry are shaken. This is the age of the Energy Internet (Internet+), where the Internet and energy are integrated and disruptors spring up to accelerate the game-changing process.

According to Jeremy Rifkin, a renowned American trend expert, the revolutionary combination of communications technologies and energy is breeding the third industrial revolution. Advanced information and communications technologies like the Internet of things (IoT), big data and cloud computing create the Energy Internet by reshaping energy production, transmission, marketing and use. The Energy Internet, with the smart grid as a carrier, is the inevitable result of the extension of Internet development into the energy and other industries. New technologies like cloud computing, IoT, big data and E-commerce connect people with things and enable dispersed components like information and the grid to be consistently managed. In this way, grid production and management can gradually emerge from their decentralised silos into a culture of centralised collaboration, thus improving business, management and innovation. As the integrator of energy and information, the Energy Internet will drive technological and industrial revolution and have a broad and profound impact.

Many governments and businesses are exploring Energy Internet projects. The US FREEDM project is building the Internet of energy: a network of distributed energy resources 
that intelligently manages power using secure communications and advanced power electronics. The German eTelligence project used Internet technologies to build a real-time electricity balancing and trading system, which manages intermittent, fluctuating levels of energy output using load adjustment to integrate new energy sources with the grid. It also provides a real-life example of how energy allocation can be adjusted using a real-time electricity trading system. And in China, the State Grid Corporation has initiated the concept of the "global energy Internet", a globally connected smart grid that is designed to allow clean power transmission through ultra-high voltage transmission systems.

There are many other pilot projects that are focused on achieving optimal integration of distributed energy and microgrids. For instance, GCL's distributed micro-energy grid and ENN's Ubiquitous Energy Network (UEN) are both examples of a complementary regional multi-energy Internet that works across an extended industry chain. GCL has mainly focused on solar photovoltaic and combined heat and power, although it also operates in natural gas and smart energy; while ENN is mainly focused on fuel gas and the processing of fuel gas for power generation and cooling and heating services.

For traditional power grid businesses, the Energy Internet brings significant challenges. In particular, the deregulation of the distribution network and the openness and sharing that are inherent in the Energy Internet will significantly weaken these companies' control of the grid. The availability of more competitive products and services will result in high-value customers leaving traditional power grid companies; this can already be seen in the continual customer loss that major grid companies in other countries have suffered after electricity market reform. Traditional power grid enterprises therefore need to: (i) change their mindset to one of active competition, maintain their strength on the demand side of the distribution network, and proactively develop integrated energy services like combined cooling, heat and power; (ii) develop clean energy on the supply side and in alignment with the relevant national policies; and (iii) focus on and incubate promising and competitive industries to rapidly connect the value chain. In short, traditional power grid companies need to transform themselves and become more competitive in the market.

For traditional power generators and other types of energy company, the era of the Energy Internet provides both opportunities and challenges. Power generation companies can gradually move from being behind the scenes to take centre stage and interact directly with customers. They need, however, to diversify their business portfolio. As demand growth for power slows down, power generation companies will need to adjust their business rapidly, because they are no longer competing solely with other power generation businesses, but with companies along the entire power value chain. To stay ahead in the Energy Internet, traditional power generation companies will need to focus on clean and distributed energy, and proactively develop integrated energy services that provide decision support for the demand-response system. In brief, they should be customer-oriented and target the end-user market.

For new energy companies, the Energy Internet will bring substantial financial benefits; many of these companies have already achieved fame and wealth from it. The conservative approach of the traditional energy companies, which often translates into a wait and see strategy, means that they have yet to show up fully as competitors. New energy companies should, therefore, take advantage of this opportunity and capitalise on their strengths by developing benchmark projects and industry standards, in readiness for a future counter-attack by the energy majors. In short, new energy companies should develop a flexible approach in order to proactively guide industry trends.

For power equipment companies, the Energy Internet undoubtedly poses higher demands on those implementing the Made in China 2025 strategy. For these companies, their top priorities are to address the weak integration of energy and the Internet, and to support and drive improvement in power equipment manufacturing. They 
should also consider collaborating with other companies to jointly develop solutions in the Internet of things and artificial intelligence. In brief, power equipment companies need to modernise and exercise their strengths in intelligent manufacturing.

For Internet and IT companies, big data is an important cornerstone of the Energy Internet. In April 2016, the National Development and Reform Commission (NDRC) issued its Guidelines on Promoting the Development of Internet+ Smart Energy. In these guidelines, the NRDC proposed developing energy big data service applications and outlined the requirements for IT companies and for the integration and secure sharing of big data, business service systems, and industry management and supervision systems. However, Internet and IT companies need to explore how to capture energy big data effectively and integrate it with other big data to maximise data value. In short, Internet and IT companies need to unlock the value of energy data.

\subsection{New Energy Development and Storage Technologies: Cheaper and Better Renewable Energy Accelerates the Growth of a Low-Carbon Power System}

According to Bloomberg New Energy Finance's New Energy Outlook 2017, the cost of solar power and onshore wind power will drop by $66 \%$ and $47 \%$ respectively by 2040 , and the operating cost of renewable energy will be lower than that of most fossil fuel power plants by 2030. As the report indicates, the transition of global power systems towards low-carbon energy will be faster than in previous predictions - the total global carbon emissions from power systems will peak in 2026, and by 2040 will be $4 \%$ lower than in 2016. One of the report's authors says: "Thanks to rapidly decreasing solar and wind power costs and the increasingly important role of various battery technologies, including electric vehicle batteries, in balancing power supply and demand, the green power system represents an irreversible trend across the world". The report also points out that solar and wind power will dominate the future power system. It estimates that by 2040 , $72 \%$ of total global new investment in power generation will be in renewable energy ( $\$ 7.4$ trillion of the $\$ 10.2$ trillion total). Solar power investment will be $\$ 2.8$ trillion and its installed capacity will increase by a factor of 14 , and wind power investment will be $\$ 3.3$ trillion and its installed capacity will rise by a factor of 4 . By 2040, wind and solar power will account for $48 \%$ of global installed capacity and $34 \%$ of global power output, significantly higher than the current levels of $12 \%$ and $5 \%$ respectively.

Solar energy will pose more challenges for coal-fired power generation. Currently, the levelised cost of energy of solar photovoltaic power is only a quarter of the 2009 level and is expected to fall by a further $66 \%$ by 2040 , i.e. the solar power that can be purchased with $\$ 1$ will be 2.3 times that of the current level. In Germany, Australia, the USA, Spain and Italy, the price of solar power is at the same level as coal power.

The cost of offshore wind power is expected to decrease faster than onshore wind power. Thanks to greater experience, intense competition, less risk and the substantial effects of economies of scale in large wind farms, the cost of offshore wind power will fall sharply by $71 \%$ by 2040 . The cost of onshore wind power will drop by $47 \%$, from a level that has declined by $30 \%$ over the past eight years. This is due to lower wind turbine costs, improved efficiency and more streamlined operations and maintenance.

New and flexible energy capacity, such as battery storage, will also facilitate the development of renewable energy. The market for lithium-ion batteries for energy storage systems is projected to grow to at least $\$ 239$ billion by 2040. As a result, there will be increasingly intense competition between utility-scale battery storage and natural gas-fired power generation. As a report from the International Renewable Energy Agency shows, the cost of battery storage for some applications may fall by up to $66 \%$ by 2030. Declining battery prices could also 
increase the installed capacity of battery storage by a factor of 17, creating new business opportunities.

The increasing use of electric vehicles (EVs) will raise demand for electricity as well as help balance the power grid. By 2040, EVs will consume 13 and $12 \%$ of the power output in Europe and the USA respectively. Since EVs can be charged at peak times of renewable energy generation or when the wholesale electricity price is low, the power system will be able to accommodate intermittent energy sources such as solar and wind power better. The development of EVs will drive a reduction of $73 \%$ in the cost of lithium-ion batteries by 2030. At the same time, the use of fixed power storage technologies like EV batteries helps decarbonise energy end-use applications.

Household photovoltaic (PV) systems will become increasingly popular. By 2040, the output from rooftop PV systems will account for 24, $20,15,12,5$ and $5 \%$ of the total power output in Australia, Brazil, Germany, Japan, the USA and India respectively. The development of large renewable energy systems will squeeze the demand for power generated by coal- and natural gas-fired power plants. Even with the increased power demand from EVs, large fossil fuel-fired power plants will be under pressure to maintain their profitability.

\subsection{Accelerating Change in Global Energy Governance: From OPEC and the IEA to Win-Win Cooperation}

Global energy governance in the second half of the 20th century was epitomised by the ongoing struggle between the Organization of Petroleum Exporting Countries (OPEC), representing the interests of oil producers, and the International Energy Agency (IEA) under the Organization for Economic Co-operation and Development (OECD), which represents the interests of Western oil consumers.

In the 21 st century, countries are increasingly concerned about energy security, as a result of which global energy governance has gradually improved. As the most important international energy organisation, the IEA has shifted from its initial goal of "preventing oil supply disruption" to "maintaining and improving system response to oil supply disruptions, promoting reasonable energy policies, strengthening cooperation with non-IEA countries, and industrial and international organisations across the world, operating a permanent international oil market information system, improving the global energy supply and demand structure, driving forward international collaborations on energy technologies through development of alternative energy and improvement of energy utilisation efficiency, and helping integrate environmental and energy policies". To this end, it has taken a series of measures: strengthening exchange and negotiations with OPEC to promote stability in the international oil market; developing cooperation with Russia and emerging economies such as China and India through the G7 platform; and improving energy efficiency and promoting clean energy to address the huge challenges of global energy development and climate change. In 2012, the IEA put forward six basic principles to build an "efficient energy world". These include making the economic benefits of energy efficiency more visible, so that regulation can encourage the promotion of energy-efficient technologies.

Global energy governance has developed as the energy industry has evolved. Over 150 years, the energy industry has become a major driver of progress in the world and a core industry in most major countries. However, as the number of participants in the world energy market gradually increases, global energy governance has become ever-more complicated. Despite the current mainstream message of win-win cooperation, the diverse economic and political features of energy make global governance a difficult task in the long term. It will take several decades for the world's energy consumption to shift from fossil fuels to new energy alternatives, and the global game that currently surrounds fossil energy production, transport and consumption will remain and even intensify while the transition takes place. This can significantly affect international 
energy cooperation. In particular, the inherent structural conflict between energy producers and consumers makes dialogue and collaboration between them difficult. However, sovereign countries will continue to play a dominant and irreplaceable role in global energy governance, and their input and influence will be essential when it comes to building a new global energy governance system and navigating the energy technology revolution.

\subsection{Global Energy Majors Accelerate Their Transformation into Integrated Energy Companies}

In recent years, as environmental problems have become increasingly severe, a global consensus has formed around the shift to low-carbon and clean energy. In response to the need for a change in the overall structure of energy consumption, all countries are increasing their policy support for large-scale development of the new energy sector. As a result, the installed capacity of new energy is continuously increasing, the technical costs are rapidly decreasing and the return on investment is steadily improving.

International oil majors, including BP, Shell and Total, began investing in new energy in the 1990s. However, the profits that were available from continuously rising international oil prices after 2009 meant that they reduced their new energy investments or dropped parts of their new energy businesses altogether. After June 2014, the international oil price plunged and then settled at a sustained low price. At the same time, the oil majors recognised the existential role of climate change and the need for oil and gas companies to respond to societal concerns on climate change and play their part in the transition to a lower carbon world.

$\mathrm{BP}$ is the international oil giant with the deepest and widest footprint in new energy. the company has identified biofuels as a priority in its new energy business. According to BP, by 2035 , the number of vehicles worldwide will grow to 1.8 billion units, double the current level.
By then, despite the relatively sufficient availability of oil, the pressure from climate change and carbon emissions will increase, which BP suggests can be mitigated by biofuels. With more than 40 years of experience in hydrogen production and more than 10 years of experience in operating hydrogen refuelling stations, BP has been named the energy partner of the world's two largest hydrogen demonstration projects in Europe and the USA. BP and the Ministry of Science and Technology of the People's Republic of China have cooperated successfully on hydrogen energy projects, including China's first hydrogen refuelling station. Wind power is one of the largest components in BP's renewable energy business. BP currently operates 14 wind farms in seven states of the USA, with 2,200 MW of capacity.

Turning to Shell, new energy technology now accounts for a fifth of Shell's annual R\&D budget and is expected to become an important growth business. Raízen, a biofuels joint venture between Shell and Cosan, has evolved into the third largest biofuels company in Brazil, producing more than 2 billion litres of bioethanol and more than 20 billion litres of other industrial and transport fuels annually. In hydrogen, Shell plans to build 390 hydrogen retail sites by 2023 , including 230 sites using Shell products. Shell has several wind farms in the USA and the Netherlands, with annual wind power output exceeding $500 \mathrm{MW}$. In 2017, Shell acquired NewMotion, which operates more than $30,000 \mathrm{eV}$ charging stations in western Europe. The acquisition highlights how Shell has strong expectations that this represents the future trend in vehicle energy.

In the context of lower oil prices, Total plans to invest $\$ 500$ million annually in new energy and expects to increase its share of the new energy market to $15-20 \%$ by 2035 . Total's solar energy has been listed among the world's top three in terms of business size. A leading biofuels producer in Europe, Total began its development of biofuels in 1992, including the first generation of ethyl tert-butyl ether from ethanol and vegetable oil methyl ester. Currently, Total is developing the second generation of biofuels. In 2011, Total paid $\$ 1.4$ billion for a $66 \%$ 
shareholding in SunPower, the world's second largest solar panel manufacturer. SunPower made net profits of $\$ 246$ million in 2014 and became a key pillar of Total's business performance. In 2016, Total acquired Saft Groupe, a Francebased battery manufacturer, for $€ 950$ million. This company ranks 15 th in the world in fields like nickel-cadmium batteries, high-performance disposable lithium batteries and lithium-ion satellite batteries.

It is clear that these traditional energy titans have had a profound influence on technological progress, especially in new energy, while carrying out their own strategic readjustments.

\section{Current Developments in China's Energy Industry}

In 2016, China's energy supply and demand situation was generally improving. Structural reform of the supply side was under rapid implementation, and there was steady progress in realigning the energy system. However, the traditional sectors - coal, coal-fired power generation, refining and chemicals-were still running at overcapacity, and the development of clean energy was facing major challenges.

\subsection{Slight Growth in Energy Demand and Significant Progress in Changing the Energy System}

In 2016, China's total energy demand was 4,360 million tonnes of coal equivalent (Mtce), up $1.4 \%$ (60 Mtce) on 2015. This was $2.2 \%$ lower than the average annual growth rate during the 12th Five-Year Plan (2011-15) and 5.3\% lower than that for the 13th Five-Year Plan (2016-20).

The first reason for this change was a sharp decrease in China's coal consumption, especially scattered coal. In 2016, China's total coal consumption was $3,780 \mathrm{Mt}$, down $4.7 \%$ (185 Mt) from 2015. This was the third consecutive decrease since 2014, and it slowed down growth in total energy consumption. Between 2011 and
2015, China's total energy consumption increased by $7.4 \%$, an annual growth rate of less than $1.5 \%$. This was in sharp contrast to the average annual growth rate of $7.9 \%$ between 2000 and 2011. China's energy consumption per unit of GDP fell by $18.2 \%$ between 2011 and 2015, exceeding the goal of the 12th Five-Year Plan (2011-15); it then declined by a further 5\% in 2016. This shows that China is supporting economic and social development, while reducing energy consumption and using less resources. Individual sectors tell a similar story: between January and November 2016, coal consumption in the power and steel industries decreased by $0.4 \%$ and $0.6 \%$ respectively, compared to the same period in 2015; coal consumption in building materials remained at the same level as 2015; coal consumption in chemicals increased by $7.2 \%$; and coal use in other sectors decreased by $10.7 \%$. Coal consumption in power, steel, building materials and chemicals represented $47.9 \%, 16.3 \%, 13.8 \%$ and $7.2 \%$ respectively of total coal use during the same period, up 0.6, 0.1, 0.3 and $0.6 \%$ from 2015, while coal consumption in other sectors accounted for $14.9 \%$ of the total, down $1.5 \%$ from 2015 . The reduction in coal consumption in other sectors, especially of scattered coal, was driven mainly by the policies on air pollution control introduced in the previous two years. From 2016, major projects designed to reduce coal consumption, such as modernising coal-fired boilers and substituting waste heat and shallow geothermal energy for coal in household heating, were developed in the Beijing-TianjinHebei region to reduce coal consumption. The scope of this pilot coal reduction and substitution programme was gradually expanded to include the Yangtze River and Pearl River deltas, as well as Liaoning, Shandong and Henan. The scope was also extended from power projects to non-power projects.

The second influential factor was that China's power consumption grew steadily and the demand for power from service industries and households increased significantly. The National Energy Administration's data show that China's total power consumption was $5,920,000$ gigawatt-hours (GWh) in 2016, up 5\% from 
2015 (an increase of $282,500 \mathrm{GWh}$ ). Specifically, the growth rate of power consumption by the service industries and urban and rural households was $11.2 \%$ and $10.8 \%$ respectively, far higher than the growth rate of $2.9 \%$ in manufacturing. The service industries and urban and rural households accounted for $56 \%$ of the country's total power consumption.

The third factor was that consumption of oil products kept growing, though there was a clear difference between petrol and diesel. In 2016, as China restructured its economy and modernised consumption patterns, use of oil products continued to rise. According to the Bureau of Economic Operations Adjustment of the National Development Reform Commission (NDRC), China's total consumption of oil products was 289 Mt in 2016, up 5\% on 2015. Specifically, petrol consumption grew by $12.3 \%$, due to the rising number of vehicles on the road. At the same time, macroeconomic trends and industrial restructuring led to a decline in diesel consumption, down $1.2 \%$ from 2015 , although there was a gradual increase in demand for industrial diesel. Aviation fuel continued its high growth trend, up $10.4 \%$ on the preceding year but $7 \%$ points lower than previously due to the popularity of high-speed rail. High consumption levels of oil products and significant imports of crude oil meant China's apparent oil consumption reached $556 \mathrm{Mt}$ in 2016, up 5.5\% on the previous year.

The fourth factor was that China's natural gas consumption picked up, though its share of total energy use remained low. Data from the National Bureau of Statistics (NBS) show that China's total apparent natural gas consumption reached 208.6 billion cubic metres in 2016, up 8 or $4.6 \%$ points on 2015 (an increase of 15.5 billion cubic metres). However, natural gas's share of primary energy consumption remained at a low 6.3, only $4 \%$ higher than in the early 21 st century. Driven by a market-oriented natural gas pricing system and new controls on air pollution, natural gas has begun to replace coal projects in many provinces. And on the residential side, a tiered gas pricing mechanism has been launched to encourage the shift to gas. In addition, natural gas consumption in several major sectors has significantly increased. According to the NBS data, the power sector used the most natural gas in 2015; gas consumption in the coal, gas and water production and supply sectors reached 35.27 billion cubic metres, up $30.87 \%$ on 2014 (an increase of 8.106 billion cubic metres).

The fifth factor is a significant increase in the use and share of non-fossil energy. In 2016, use of commercial non-fossil energy was around 541 Mtce, accounting for $12.4 \%$ of China's total energy consumption. Adding non-commercial new energy brings the share to $13.3 \%$, a rise of $1.3 \%$ on 2015 . Initial estimates show that consumption of primary electricity reached about $1,701,000 \mathrm{GWh}$, up $11.2 \%$ (171,000 GWh) on 2015. Non-fossil energy use rose by about 60 Mtce, making it the largest contributor to the increase in consumption. ${ }^{9}$

So, by taking a broad range of measures, China continued to optimise its energy system in 2016. Coal's share of energy consumption decreased for the third consecutive year, and non-fossil energy was the main source of new energy use. Coal's share of primary energy consumption was $62 \%$, down $1.7 \%$ points on 2015 , whereas oil's share was $18.3 \%$, similar to 2015. The share of natural gas and fossil fuels in primary energy consumption was $6.4 \%$ and $13.3 \%$ respectively, up $0.5 \%$ and $1.25 \%$ on 2015 . Changes in China's patterns of energy production and consumption over the past decade have impacted the relationship between supply and demand, driving reform (Fig. 14).

\subsection{Sharp Decrease in Energy Production and Significant Rise in Clean Energy Supply}

In 2016, China's total primary energy production was about 3.46 Btce, down $4.2 \%$ from 2015. Coal and crude oil production sharply decreased,

\footnotetext{
${ }^{9}$ Xiao Jianxin et al., Analysis of China's Energy Development in 2016 and the 2017 Energy Outlook for China, in Energy of China, Issue 3, 2017.
} 


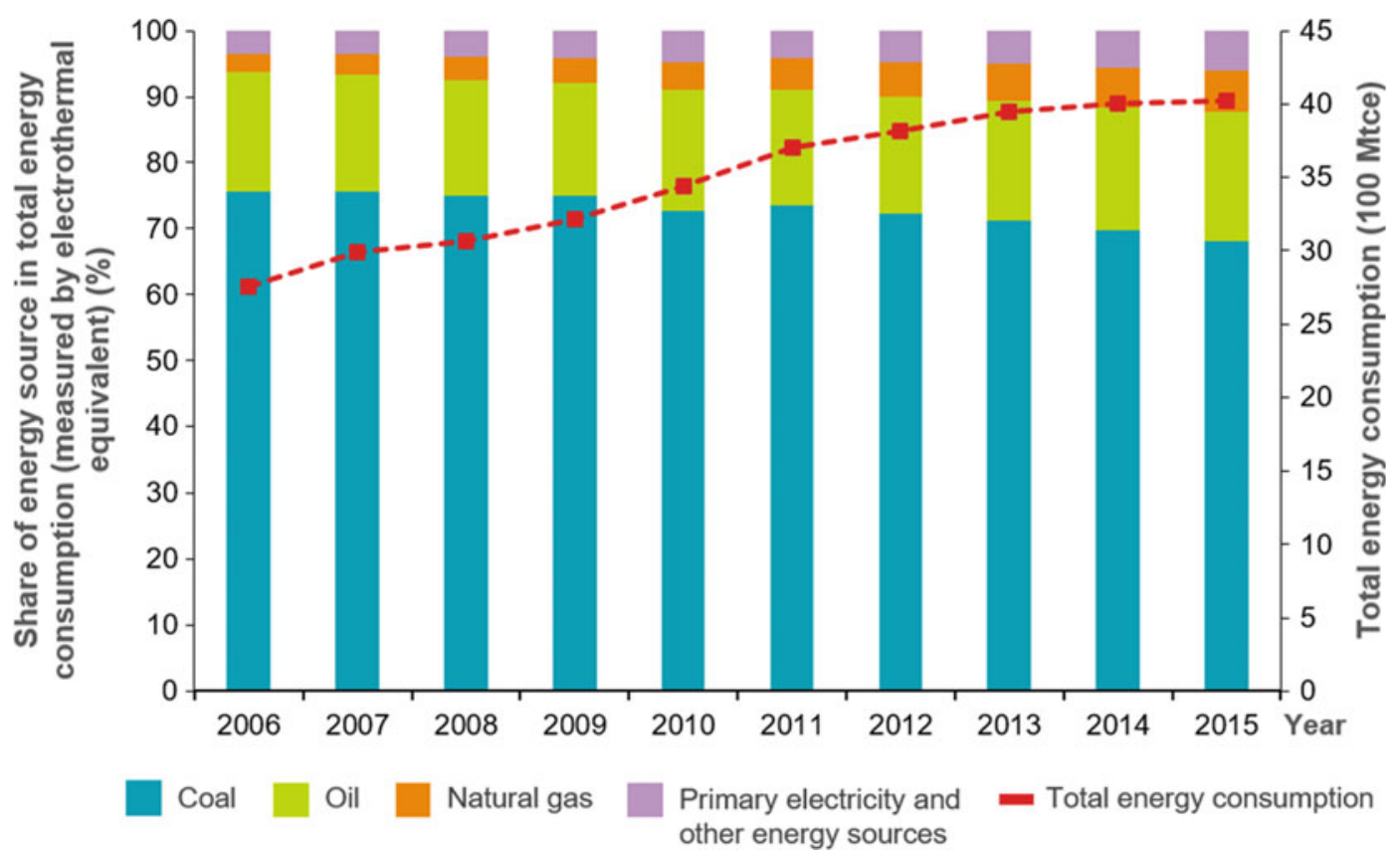

Fig. 14 Total energy consumption and share of various energy sources. Source National Bureau of Statistics of China (2017)

and natural gas and primary electricity slightly increased.

Coal production declined sharply in 2016, with raw coal production at $3.41 \mathrm{Bt}$, down $340 \mathrm{Mt}$ (9\%) on the previous year. This was consistent with the trend of declining coal consumption over the previous three years. There was a slight increase in the second half of the year, as some high-quality, safe and efficient capacity was released in August and September. The State Council of China announced in its Opinions on Alleviating Overcapacity in the Coal Sector to Secure Sound Development that the approval of new coal mines and mine modernisations to create additional capacity would be stopped from March 2016. For any new coal mines that were genuinely essential, the policy was to reduce outdated capacity and replace it with high-quality capacity. Thanks to the efforts to eliminate overcapacity, excess coal capacity was reduced by $290 \mathrm{Mt}$, which also helped stabilise the coal price.

There was also a clear drop in crude oil production, though refined crude oil output maintained its growth rate. In 2016, spurred by lower international oil prices, China's crude oil producers further reduced inefficient production. Data from China's NBS show that crude oil production was $199 \mathrm{Mt}$ in 2016, down $6.9 \%$ on the previous year. This was also the first year since 2010 that crude oil production was less than $300 \mathrm{Mt}$, with the annual decrease exceeding $10 \mathrm{Mt}$ for the first time. At the same time, regulations around the import and use of crude oil were relaxed. As a result, driven by high demand from the vehicle and aviation sectors, China's crude oil processing capacity grew rapidly, reaching $541 \mathrm{Mt}$ (up 3.6\% on the previous year). In particular, crude oil processing capacity in Shandong, a province with several local oil refining companies, was $101 \mathrm{Mt}$, which made Shandong the first province to exceed $100 \mathrm{Mt}$ in crude oil processing capacity. In 2016, China's production of oil products stood at $345 \mathrm{Mt}$, an increase of $2.4 \%$.

Natural gas production, on the other hand, rose slightly, and shale gas output grew rapidly. Coalbed methane (CBM) production also increased. In 2016, due to slower growth in 
domestic natural gas demand and a significant increase in natural gas imports, China's production of conventional natural gas was 136.9 billion cubic metres, up slightly $(1.7 \%)$ on 2015 . Shale gas production maintained strong momentum, with production in 2016 reaching 7 billion cubic metres, up $52.2 \%$ on 2015. CBM developed slowly-CBM ground extraction reached 4.5 billion cubic metres, a slight increase of $1.7 \%$, and CBM use was 4.2 billion cubic metres. Production of coal gas was 1.6 billion cubic metres, up $14.3 \%$ on the previous year. In 2016, the production and use of coalmine gas were 17.9 billion cubic metres and 8.8 billion cubic metres respectively, an increase of 96 and $148 \%$ compared to 2010 .

Installed power capacity continued to grow, and non-fossil energy's share of the power mix increased. According to data from the China Electricity Council, by the end of 2016, China's installed power capacity reached 1,650 gigawatts (GW). Specifically, installed capacity and output of hydropower were $330 \mathrm{GW}$ (up $3.92 \%$ on 2015) and 1,174,800 gigawatt-hours (GWh) (up $5.58 \%$ from 2015). The installed capacity and output of nuclear power were $33.64 \mathrm{GW}$ (up $23.83 \%$ ) and 213,100 GWh (up 24.39\%). The installed capacity and output of grid-connected wind power were $147.47 \mathrm{GW}$ (up 12.79\%) and 240,900 GWh (up 29.78\%). The installed capacity and output of grid-connected solar power were $76.31 \mathrm{GW}$ (up $80.91 \%$ ) and 66,500 GWh (up $68.51 \%$ ). The installed capacity of non-fossil energy, including hydro, nuclear, wind and solar power accounted for $36.6 \%$ of China's total installed power generation, while output from non-fossil energy generating units amounted to $29.14 \%$ of the total. New installed capacity in 2016 reached $120 \mathrm{GW}$, including $48.36 \mathrm{GW}$ of thermal power, 19.3 GW of wind power, 34.54 GW of solar power, 11.7 GW of hydropower and 7.2 GW of nuclear power. Non-fossil energy accounted for $60 \%$ of China's total new installed power capacity, the fourth consecutive year it exceeded $50 \%$. This is clear evidence that China is continuing to optimise its power system. In 2016, China's total power output was 5,990,000 GWh and the share of non-fossil energy was $28.4 \%$, up $1.5 \%$ points on 2015 . The new power output is equivalent to the 2016 output of two Three Gorges hydropower stations..$^{10}$

The breakdown of China's primary energy production in 2006-15 is shown in Fig. 15. Raw coal production gradually declined, but is still the main component in energy production. In 2015, raw coal's share of total primary energy production reached $78.2 \%$, while the share of other energy sources exceeded $10 \%$. Natural gas production increased at an average annual growth rate of $5.27 \%$, reaching $5.3 \%$ of total primary energy production in 2015. The average annual growth rate of primary electricity and other energy sources was $6.94 \%$. The share of other energy sources also increased, the result of China's changing energy system. In the future, the market share of natural gas and renewable energy sources will increase, and their production share could also continue to increase.

China should: (i) develop an energy supply system based on solar, wind, hydro, nuclear and biomass as well as other clean energy sources, complemented by fossil energy such as coal and oil; (ii) encourage energy producers to invest more in clean energy technologies and production, give clean energy priority access to the market, and increase the share of clean energy in the energy supply system; and (iii) implement appropriate taxes and financial policies on fossil fuel energy production and supply, and reduce the development of existing conventional fossil energy resources.

\subsection{Energy Efficiency Policies Gradually Take Effect and Controls on Energy Consumption and Energy Intensity Produce Results}

Energy efficiency is a key component in building a greener civilisation. Energy efficiency is not just about reducing energy use, but also about improving energy productivity, sharpening

\footnotetext{
${ }^{10}$ Xiao Jianxin et al., Analysis of China's Energy Development in 2016 and the 2017 Energy Outlook for China, in Energy of China, Issue 3, 2017.
} 


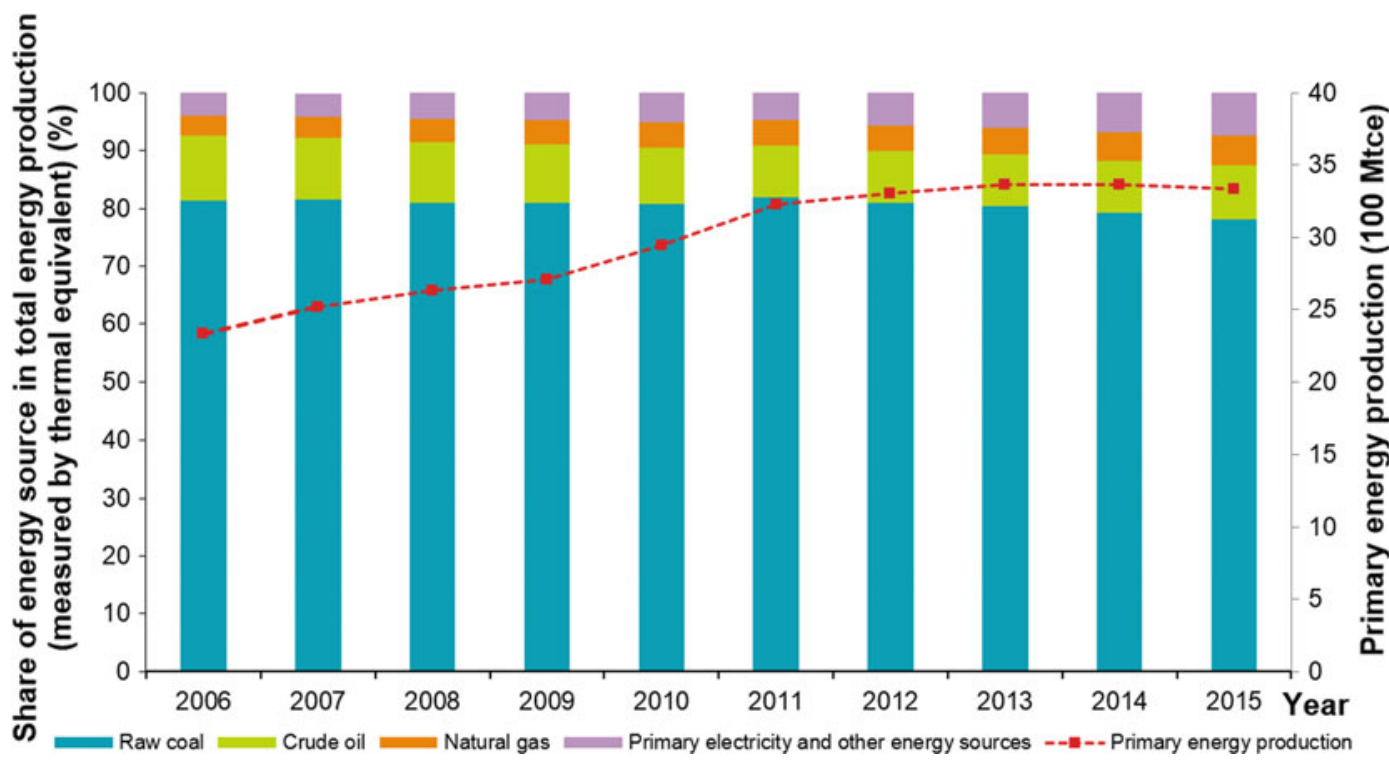

Fig. 15 China's primary energy production and share of various energy sources. Source National Bureau of Statistics of China (2017)

industrial competitiveness and creating an efficient and modern energy system. The measures to achieve this include reshaping patterns of production and living, restructuring the economy, optimising the industrial system, increasing the share of clean energy, and making energy use more efficient. Energy efficiency can pave the way for a green and low-carbon society and help realise the centenary goals to mark the founding of the Communist Party of China in 2021 and the People's Republic of China in 2049. Those two goals are building a moderately prosperous society in all respects by 2021 and transforming China into a modern socialist country that is prosperous, strong, democratic, culturally advanced and harmonious by 2049 .

In 2016 the State Council of China issued the Overall Work Plan for Energy Conservation and Emissions Reduction for the 13th Five-Year Plan (2016-20), outlining targets for energy efficiency: by 2020, the energy consumption per unit of GDP should be RMB 10,000, $15 \%$ lower than in 2015, and total energy consumption should remain less than 5 Btce. Moreover, the goal of controlling total energy consumption and energy intensity would be delegated to the provinces. As part of the 2016 plan, the National Development and Reform Commission (NDRC) and other authorities were entrusted by the State Council to evaluate provincial government success in delivering the energy efficiency goals of the 12th Five-Year Plan (2011-15). The provinces also had to define their 2016 and 2017 targets for controlling total energy consumption and energy intensity. In 2017, NDRC and its partner authorities assessed the provincial governments' progress in fulfilling those targets. Twelve ministries and commissions, including the NDRC, the Ministry of Science and Technology, the Ministry of Industry and Information Technology and the Ministry of Finance, jointly issued the Action Plan for National Energy Saving during the 13th Five-Year Plan (2016-20). The plan defined the top 10 energy-saving measures to achieve the targets, including deploying energy-efficient products and promoting energy saving. The introduction of regulations on energy saving-including the Measures for Energy Conservation Supervision, the Measures for the Energy Conservation Review of Fixed-Asset Investment Projects, the Plan for Developing the Energy Saving Standard System and the 
Measures for the Administration of Energy Efficiency Labels - helped drive energy saving.

With policy support, China began to promote energy efficiency in key sectors. In 2016, the Energy Efficiency Forerunner Programme, designed to make China a leader rather than a follower in energy efficiency, was extended. In the same year, the NDRC and the General Administration of Quality Supervision, Inspection and Quarantine of the People's Republic of China published the Energy Efficiency Forerunner Product Catalogue for household refrigerators, flat-panel TVs and adjustable-speed air conditioners. The NDRC provided investment support to improve energy efficiency in energy-intensive sectors, promote energy conservation, and improve energy use in urban street lighting, airports, stations and ports. China issued the Measures for the Administration of Energy Conservation in Major Energy-Consuming Enterprises, launched the "100-1,000-10,000" energy conservation programme, ${ }^{11}$ and drove the development of an online energy consumption monitoring system of major energy-consuming enterprises. The Ministry of Housing and Urban-Rural Development made great progress in implementing the green building initiative. The Ministry of Transport promoted the development of a modern, integrated transport system and established a green transport network.

Thanks to the efforts made by these stakeholders, China's total energy consumption was effectively controlled in 2016, and the energy consumption per unit of GDP reduced by $5 \%$ compared to the previous year, thus exceeding the targets for 2016. Overall, China reduced energy consumption by 230 Mtce, equivalent to about $500 \mathrm{Mt}$ of $\mathrm{CO}_{2}$ emissions.

\footnotetext{
${ }^{11}$ The "i00, 1,000, 10,000" energy conservation initiative places the top 100 energy-consuming enterprises in China under national regulation, the top 1,000 energy-consuming enterprises under the regulation of their respective provincial governments, and other high energy consuming enterprises under the regulation of lower-level governments.
}

\subsection{Fossil Fuel Energy Prices Rebound and the Electricity Price Continues to Decline}

In 2016, oversupply in the international market slackened and China's energy supply reforms were strengthened. As a result, the price of major energy sources rebounded after levelling out, though there was much variation among them.

The price of coal increased slightly in the first half of 2016, rose significantly in the third quarter (Q3), then stabilised at the end of 2016. The price rise in those six months could be seen in the Bohai-Rim Steam-Coal Price Index (BSPI) for 5,500 kilocalories per $\mathrm{kg}(\mathrm{kcal} / \mathrm{kg})$ thermal coal, which reached RMB 401 per tonne at the end of June, RMB 30/t higher than earlier in the year. Between July and October the price rose quickly, and by the end of October exceeded RMB 600/t, RMB 236/t higher than at the start of the year. At the beginning of Q3, several advanced capacity projects came into operation and dealers released their stockpiles, substantially increasing the amount of coal on the market. Between November and December, the coal price slowly declined, RMB 14/t lower at the end of 2016 than its high point for the year. The coal market then stabilised.

The international oil price rose irregularly after hitting the bottom, and prices of oil products in China increased correspondingly. At the beginning of 2016, Brent and West Texas Intermediate (WTI) prices had plunged to $\$ 27.88$ per barrel (bbl) and $\$ 26.21 / \mathrm{bb}$ respectively, the lowest point of the year, after which they gradually picked up. By the end of 2016, Brent and WTI prices had doubled-both exceeding $\$ 50 / \mathrm{bbl}$. However, due to an easing in both supply and demand, rebalancing was slower than expected. In addition, the lowering costs and improving efficiency of US shale oil also restricted a rise in oil price. In 2016, of the 25 adjustment cycles for oil products in China, there were five downward adjustments, 10 upward adjustments and 10 non-adjustments. The annual cumulative price rises of petrol and diesel were RMB 1,015/t and RMB 975/t.

The international natural gas price remained at a low level, while that of imported natural gas 
significantly declined. In 2016, the gas price in international markets dropped - the average annual Port Henry price, UK National Balancing Price (NBP) and Japan Liquefied Natural Gas Import price were $2.49 / \$$ per million British thermal units (Mbtu), \$4.64/Mbtu and \$6.8/Mbtu respectively, down 5\%,30\% and 36\% respectively on the previous year, and the price differences between the three indexes narrowed. According to statistics from the General Administration of Customs, China's average natural gas import price was $\$ 305 / \mathrm{t}$ in 2016 , down $27 \%$ on 2015. In particular, the average price of imported pipeline gas and imported LNG were \$270/t and $\$ 343 /$ t, 31 and 24\% lower than in 2015 .

The electricity price continued to decline, which helped lower the cost to the real economy. In January 2016, China introduced the coal-electricity price linkage mechanism, and lowered the feed-in tariff for coal-fired generating units and the retail price for general industrial and commercial use by RMB $0.03 / \mathrm{kWh}$, helping businesses to reduce their electricity expenditure by about RMB 22.5 billion. The feed-in tariff for renewable energy decreased: the benchmark feed-in tariff for onshore wind power in Class 1, 2 and 3 resource-rich areas was decreased by RMB $0.03 / \mathrm{kWh}$, and in Class 4 resource-rich areas by RMB $0.01 / \mathrm{kWh}$. The benchmark feed-in tariff for solar photovoltaic power in Class 1 and 2 resource-rich areas was decreased by RMB $0.1 / \mathrm{kWh}$, and in Class 3 resource-rich areas by RMB $0.02 / \mathrm{kWh}$. The pilot reform of power transmission and distribution pricing passed the strict cost supervision and review test, reducing power transmission and distribution prices by $16.3 \%$.

\subsection{Imports of Major Energy Sources Grow Rapidly and Oil and Gas Imports Hit a Record High}

In the context of lower international energy prices, China's imports of coal, crude oil and natural gas grew rapidly in 2016, with growth rates exceeding $10 \%$. As a result, China's dependence on oil and gas imports rapidly increased. Exports of oil products also grew significantly.

The strong rebound in China's coal price stimulated a significant increase in coal imports. International coal prices, affected by trends in bulk energy commodities like oil, rose only slightly. Meanwhile, lower shipping prices made imported coal more price-competitive in China's south-east coastal areas. All these factors led to coal imports increasing from May 2016 onwards, with total coal imports in 2016 reaching $256 \mathrm{Mt}$, up $25.2 \%$ from 2015 , while coal exports were $8.78 \mathrm{Mt}$. Net coal imports were $247 \mathrm{Mt}, 48 \mathrm{Mt}$ (24.2\%) higher than in 2015.

Due to a build-up in oil reserves and changes in the regulations regarding the right to import crude oil, China's crude oil imports grew sharply to $381 \mathrm{Mt}$ in 2016, equal to that of the USA. This figure was $45 \mathrm{Mt}$ higher than in 2015, reflecting an annual growth rate of $13.6 \%$. Driven by this significant growth, China's dependence on oil imports hit a record high of $64.4,3.9 \%$ points higher than in 2015.

Despite the limited growth in domestic demand, China's annual net exports of oil products reached $32.55 \mathrm{Mt}$, a substantial increase of 11.2 Mt compared to 2015. Exports of oil products accounted for $10.7 \%$ of China's total crude oil processing capacity, and $17.9 \%$ of the total net oil product exports of the Asia-Pacific region in $2016,5.2 \%$ points higher than in 2015 . China became the third largest exporter of oil products in Asia-Pacific, after Japan and South Korea.

In 2016, due to lower international natural gas prices, rising natural gas demand in China and many new long-term contracts, China's natural gas imports resumed their high growth, though this came at the cost of lower production at domestic gas fields. Data issued by the National Bureau of Statistics of China show that natural gas imports were about 74.5 billion cubic metres in 2016, an increase of $21.9 \%$ on the previous year. LNG imports increased particularly sharply, by 11 billion cubic metres. In addition, China's dependence on natural gas imports reached $34.2 \%$, up $3.1 \%$ points. 


\subsection{Variations in Energy Company Profitability and Demands that the Petrochemical and Power Sectors Develop Sustainably}

In 2016, the diverging price trends of major energy sources caused business performance to vary in the different energy sectors. In particular, coal companies significantly improved their operating performance, while upstream oil and gas companies made losses and midstream oil and gas companies enjoyed steady profits. The profitability of coal-fired power plants declined and non-fossil energy companies registered losses.

In the first half of 2016, a slight rise in the coal price helped to improve the performance of coal companies. Between January and April, the coal mining and coal washing and preparation sector reported total profits of RMB 960 million, down $92 \%$ on the same period in 2015. From May onwards, however, coal company profits increased month by month. In 2016, the cumulative profits of the coal mining and coal washing and preparation sector reached RMB 109.09 billion, up $223.6 \%$ on 2015 . In contrast, the total profits of the mining industry decreased by $27.5 \%$ against 2015. Total profits of the coal mining and preparation sector were $60 \%$ those of the mining industry, significantly improving the performance of coal companies.

The performance of oil and gas companies varied greatly-oil and gas exploration and development suffered losses but refining and chemicals made huge profits. According to the CNPC Economics \& Technology Research Institute, due to lower international oil prices, the profits of China National Petroleum Corporation (CNPC), which has a large share of the upstream oil and gas exploration and production business, decreased sharply by $94.34 \%$ in 2016 , while China National Offshore Oil Corporation (CNOOC), which is also in the upstream business, suffered a huge loss of RMB 7.735 billion in the first half of 2016. Benefiting from national legislation on oil products, China Petroleum \& Chemical Corporation (or Sinopec), which has a higher share of the refining and chemical businesses, reported profit growth of $11.2 \%$. In the context of lower oil prices, the performance of international and Chinese oil companies was weaker. As a result, reducing investments and costs and improving operational efficiency was a common remedy for most oil companies.

In 2016, the profit margins of coal power companies were squeezed significantly due to lower feed-in tariffs, rising coal prices, a sharply decreasing electricity price and lower output. According to statistics from the China Electricity Council, between January and November 2016, the total profits made by the top five Chinese power generation groups amounted to RMB 54.2 billion, down $45 \%$ on the same period in 2015. In particular, the profits of coal power businesses dropped by $67.4 \%$. Preliminary estimates show that the reduction in profits in China's coal power sector resulting from lower feed-in tariffs, rising coal prices and lower output were RMB 110 billion, RMB 7 billion and RMB 7.4 billion respectively.

Due to difficulties connecting renewable energy to the grid, non-fossil energy companies suffered large losses. In 2016, the restrictions on connecting non-fossil energy to the grid became a severe problem - about $150,000 \mathrm{GWh}$ of clean power was not used effectively, equivalent to a reduction in turnover of RMB 60-80 billion. This undoubtedly affected the profitability of non-fossil energy companies. In addition, lower renewable energy subsidies also resulted in higher financial losses for these businesses. Initial estimates show that the gap that renewable energy subsidies failed to cover in 2016 exceeded RMB 60 billion. $^{12}$

\subsection{Coalbed Methane Is Developing Well, but Challenges Need to Be Addressed Urgently}

On November 24, 2016, the National Energy Administration of China released the 13th

\footnotetext{
${ }^{12}$ Xiao Jianxin et al., Analysis of China's Energy Development in 2016 and the 2017 Energy Outlook for China, in Energy of China, Issue 3, 2017.
} 
Five-Year Plan (2016-20) for Coalbed Methane (CBM) Development and Use. The 3rd Five-Year Plan (1966-70) for the CBM sector is the guideline for China's exploration and use of CBM during the 13th Five-Year Plan. The 13th Five-Year Plan is the decisive stage in building a moderately prosperous society in all respects and a critical period for adjusting the energy system towards diversified energy supply and clean energy. The CBM sector faces both opportunities and challenges, but the opportunities tend to outweigh the challenges.

On the one hand, the external environment is generally favourable. China has implemented the necessary energy supply structural reforms to: (i) increase the share of non-fossil energy and natural gas in total energy production and demand; (ii) raise the share of natural gas in total primary energy demand to $10 \%$; and (iii) encourage the development of CBM. China has also implemented an innovation strategy and accelerated the local development of critical technologies and equipment. As a result, the technological bottlenecks constraining CBM development are expected to disappear. As China introduces increasingly strict requirements for safety in coal mines, the safe extraction of coalmine gas is a fundamental means to prevent gas explosions. China has made a solemn commitment to the international community to decrease $\mathrm{CO}_{2}$ emissions per unit of GDP by $40-45 \%$ by 2020, and that $\mathrm{CO}_{2}$ emissions will peak around 2030. These factors bring a hard-won opportunity for the rapid development of the CBM sector.

On the other hand, the sector still has some challenges that need to be addressed urgently. $\mathrm{CBM}$ is still in its infancy. The size of the market is small and competition is weak. In recent years, the price of CBM has dropped significantly due to the adjustment of natural gas prices, which offsets the positive effects of subsidies. Moreover, gradually rising production costs and slowing investment in CBM exploration and development have created a large gap between the production and use of CBM. In some regions, CBM does not have open and fair access to natural gas pipelines, and the transmission and distribution facilities of some CBM projects are inadequate. The large number of potentially dangerous mines in China increases the difficulty of extracting gas. In addition, the gas extracted from coal mines is of low concentration and very difficult to use. China therefore needs to make vigorous efforts to address these challenges during the 13th Five-Year Plan (2016-20).

\subsection{Steadily Promote Energy Development in the Belt and Road Initiative}

In September and October 2013, during his visits to Kazakhstan and Indonesia, President Xi Jinping proposed building the Silk Road Economic Belt and the 21st Century Maritime Silk Road, which together form the Belt and Road Initiative (BRI).

Energy cooperation is an important part of the BRI, which connects energy consumption markets in Europe and Asia with major energy exporters in the Middle East, Central Asia and Russia. The BRI covers two high-quality fossil energy-rich regions-Russia-Central Asia and the Persian or Arabian Gulf - as well as Western Europe, which has advanced energy technologies and widely deployed green energy. Building the BRI with other countries can promote stability in the energy market in Eurasia and drive the transition to green energy.

In March 2016, the Outline of the 13th Five-Year Plan (2016-20) for the National Economic and Social Development of the People's Republic of China was published. The BRI was included in the Five-Year Plan because it is an important means to coordinate regional development in China and it opens up and actively involves China in global governance.

The 13th Five-Year Plan (2016-20) for the Development of the Energy Industry states that China will: (i) take the domestic and the international markets into consideration and use all available resources to implement its energy cooperation strategy; (ii) seize the major opportunities of the BRI to interconnect energy infrastructure, expand international cooperation 
on capacity sharing and actively participate in global energy governance; (iii) speed up the development of energy cooperation projects to interconnect energy infrastructure in BRI countries and regions; and (iv) conduct research on cross-border transmission systems and collaborate on power grid modernisation.

The 13th Five-Year Plan (2016-20) for the Development of the Power Sector states that China will: (i) use all available domestic and international resources to promote international cooperation on power system equipment, technologies, standards and engineering services; and (ii) drive the building of interconnected power grids and encourage Chinese power companies to participate in the construction and operation of overseas power projects.

The 13th Five-Year Plan (2016-20) for the Development of the Coal Sector states that China will: (i) strengthen international cooperation on coal to sharpen the competitiveness of China's coal sector; (ii) steadily develop international coal trading to promote the development and use of overseas coal resources and expand overseas engineering, procurement and construction projects and technical services; and (iii) promote international win-win cooperation on coal capacity to develop overseas coal resources, build support infrastructure and invest in upstream and downstream coal businesses.

The 13th Five-Year Plan (2016-20) for the Development of the Oil Sector states that China will: (i) improve the quality and benefits of international cooperation on oil; (ii) optimise the pace of investment and asset portfolio; diversify overseas investments, investors and modes of cooperation; and integrate energy and financethus boosting the Going Global strategy of Chinese oil enterprises; (iii) optimise and promote oil and gas cooperation with Russia, the Middle East, Africa, the Americas and Asia-Pacific; and (iv) collaborate on building interconnected infrastructure in BRI countries.

The 13th Five-Year Plan (2016-20) for the Development of the Natural Gas Sector states that China will: (i) implement the BRI and strengthen cooperation with natural gas producers to develop a diversified supply system and safeguard natural gas supply security; (ii) establish a multi-level coordination regime to ensure supply security and safety with countries with cross-border natural gas pipelines; and (iii) cooperate with natural gas consumers in North-east Asia to create a regional natural gas market and improve China's right to speak on natural gas pricing.

The 13th Five-Year Plan (2016-20) for the Development of the Renewable Energy Sector states that China will: (i) develop the renewable energy value chain to sharpen the international competitiveness of China's renewable energy sector and play an active role in driving the global energy transition; and (ii) combine the development plans and construction demands of BRI countries to deliver signature collaborative projects in a timely fashion, thus encouraging a joint Going Global strategy for renewable energy consulting, design, contracting, equipment supply and operating companies.

\subsection{Strongly Promote Energy Reform}

\subsubsection{Supply-Side Structural Reform of the Coal Sector Will Cut Overcapacity}

China has introduced policies to identify the measures necessary to cut overcapacity in the coal sector. In early February 2016, the State Council of China issued Document No. 7, which set the goal of shutting down surplus coal production facilities. Between March and July the authorities introduced eight policies to identify the support measures needed to reposition surplus workers, administer funds for bonuses and subsidies, manage land and mines for new capacity, and set environmental constraints. Despite the sharp slowdown in demand for coal, China's coal sector still has strong market potential in the medium and long terms, according to the Research Report on Overcapacity Cutting and Development Strategies in China's Coal Sector, 2017-21. The coal sector should, therefore, grasp the opportunities to implement structural reform of coal supply, seek policy support, shut down outdated capacity and 
cut overcapacity, thereby transforming and modernising the industry.

China has made major progress in shutting down coal production facilities. With the help of support policies, China has placed strict controls on unsafe production, overcapacity and the illegal construction of mines, and has introduced reward and subsidy measures. As a result, 290 Mt of cumulative coal capacity was cut in 2016, which is almost $60 \%$ of the overcapacity scheduled for removal during the 13th Five-Year Plan (2016-20). As stated in the Report on the Work of the Government published in March 2017, China will also shut down at least $150 \mathrm{Mt}$ of coal production facilities and reduce steel production capacity by around $50 \mathrm{Mt}$. At the same time, China will suspend or cancel $50 \mathrm{GW}$ of coal-fired power generation capacity.

China made limited progress in 2016 in restructuring the coal industry and reducing production capacity. The main reasons for this are: (i) the companies to be merged had great difficulty guaranteeing re-employment for workers; and (ii) companies to be restructured lacked funds in the first half of 2016; when those funds were made available in the second half of the year they were considerably lower than expected, which slowed down the restructuring process.

Reducing overproduction is an important part of the goal of "cutting overcapacity, reducing excess inventory, deleveraging, lowering costs and strengthening areas of weakness" in order to structurally reform the coal industry. In accordance with the decisions of the Central Committee of the Communist Party of China and the State Council, China's coal sector made further efforts to reform the industry and cut overcapacity. Various measures were taken, including restricting new capacity, shutting down outdated production facilities and excess capacity in an orderly manner, controlling illegal mine construction and expansion, and reducing production. As a result, coal production declined, reducing oversupply to some extent.

From July 2016, as the excess coal inventory lessened and coal demand grew, the coal price rose rapidly and some regions faced shortages.
The reasons for the shortages were several. They include rising thermal power output, increased storage of coal for winter, better control of over-the-limit road transport and adjustments to the railway network, reduced overcapacity, production controls and curtailing illegal production. However, it should be noted that coal demand did not increase sharply: coal consumption in the first 11 months of the year declined by $1.6 \%$ against the previous year. There are still many coal mines that are a safety risk or close to resource depletion, use outdated technologies and equipment, do not conform with safe production conditions and coal industry policies, or have a production capacity of less than 300,000 tonnes per year, all of which make cutting coal overcapacity a challenge.

\subsubsection{Electricity System Reform Measures Are in Place and Making Significant Progress}

A multi-level pilot project was rolled out across China in 2016 (excluding Xizang). Twenty-one provinces implemented a pilot scheme for comprehensive electricity system reform, nine provinces and the Xinjiang Production and Construction Corps launched a pilot system to reform power retailing, and three provinces piloted grid connections for renewable energy.

The power transmission and distribution price reforms covered provincial power grids. In 2016, China introduced the Measures on Supervision and Review of Power Transmission and Distribution Prices with the aim of identifying and reducing unneeded assets and unreasonable costs in grid companies and establishing an incentive and restraint mechanism. In addition, China disclosed the power transmission and distribution prices of 12 provincial grids; the average historical grid cost reduction ratio stood at $16.3 \%$. Power generation and power consumption underwent orderly deregulation. The formation of electricity trading institutions was basically completed in 2016. It involved creating a medium-to-long-term electricity trading mechanism in 28 provinces to pilot cross-provincial 
trading, along with arrangements for direct trading between power users and power generation companies. In 2016, the amount of electricity traded exceeded 1 million $\mathrm{GWh}$, accounting for about $19 \%$ of China's total power consumption.

In addition, China established an access and exiting mechanism for market participants and a new regulatory system, developed a pilot reform scheme for power distribution services, and included coal-fired backup power plants within the scope of the regulations.

\subsubsection{Oil Sector Reform Features "Comprehensive Promotion, Major Breakthroughs and Priority Trials"}

First, a pilot programme was launched to reform the management of oil and gas mining rights. In 2015, Xinjiang piloted open bidding for the exploration of conventional oil and gas blocks. And in October 2016, Xinjiang was identified as the pilot province for comprehensive energy reform, with the focus on deregulating market access to the oil and gas sector.

Second, the reforms deregulating the right to use imported crude oil and the right to import crude oil took effect. In 2016, an increasing number of non-state enterprises were awarded the necessary permits to import and use crude oil, and the quota for imported crude oil was increased significantly. To address issues like quota reselling, China implemented new allocation principles, along with various other adjustments and a strict assessment regime. This effectively guaranteed the fair allocation of imported crude oil and maintained sound market development.

Third, overcapacity cutting policies were extended to the refining and chemical sectors to improve oil product quality. In 2016, China introduced several policies-including the Guidelines on Adjusting the Structure, Promoting the Transformation and Increasing the Profits of the Petrochemical Industry; and the Development Plan for the Petrochemical and Chemical
Industries, 2016-20 - to solve the problem of production overcapacity in refining and chemicals. Tax incentives were also introduced to increase oil product exports and reduce domestic output of oil products. In addition, oil product quality was further improved - in 2016, 11 provinces in east China supplied China V petrol and diesel; this was extended across China in 2017.

Fourth, the oil product pricing system was improved to reflect market developments. In 2016 , in the context of sharply falling international crude oil prices and various difficulties affecting domestic oil and gas production, China adjusted the oil product pricing system and lowered the limit for oil product price regulation. This will mitigate risks that may arise from any future increase in oil product prices.

Fifth, China accelerated the reform of state-owned oil enterprises and encouraged the participation of private capital. In 2016, CNPC restructured its engineering and construction businesses, Sinopec restructured its regional oil engineering services, and CNOOC integrated its refining and chemical companies. In addition, state-owned oil enterprises allowed private capital to become stakeholders, thereby creating mixed ownership businesses. A case in point is Sinopec, which sold a 50\% stake in Sichuan-toEast China Gas Pipeline Co., Ltd.

\subsubsection{The Natural Gas Sector Is Reformed and Achieves Remarkable Success}

First, there was progress in reforming natural gas pricing into a market-oriented system. In 2015, China delivered the goals of the three-step transition in natural gas pricing reform. In 2016, China took natural gas pricing reform even further by identifying pricing policies for gas storage facilities, promoting market-oriented natural gas pricing for chemical fertilisers, and by piloting reform of the city-gate gas price in Fujian. The price of non-residential gas, which accounts for more than $80 \%$ of China's total natural gas consumption, was almost all 
negotiated between the supply and demand parties, apart from a small amount of residential gas necessary to maintain people's living standards. The market-oriented pricing system drove down the price of natural gas, reducing the cost of gas use for companies.

Second, regulation of the natural gas transmission tariff and distribution fee has been steadily strengthened. Following the principle of "deregulating gas sources and retailing, and controlling gas transmission and distribution", China introduced several policies to regulate natural gas transmission and distribution. These included measures for administering the gas pipeline transmission tariff and for supervising and reviewing pricing costs, which required the cross-provincial gas pipeline operating companies to establish independent accounting processes before June 1, 2017. China also effected measures for the supervision and administration of local gas transmission tariffs and distribution fees, requiring all provinces to introduce the necessary support policies to reduce end-use gas prices.

\subsubsection{Policies to Promote the Development of Renewable Energy Are Introduced and an Assessment System Is Developed}

First, in 2016, a guiding framework for renewable energy development and use was introduced. China quantified the share of non-fossil energy for the first time and clearly defined the requirements to develop, connect and measure renewable energy in all provinces.

Second, a system was developed to guarantee the purchase of wind and solar power. In 2016, China issued the Measures to Guarantee the Purchase of Electricity Generated by Renewable Energy and made public the volume of wind and solar power purchased in all provinces. This was an important institutional change to help reform the legal and power systems, and a significant starting point to guarantee grid connection of renewable energy and ensure market access for new energy in the future.

Third, the green certificate and trading system for renewable energy was formed. The green certificate is an evidence-based means for evaluating how well power supply companies are delivering their planned share of non-hydro renewable energy. As electricity system reform continues and a carbon trading system is developed, market conditions for the green certificate and trading system will gradually improve, and the green certificate will become a channel to secure new funding for renewable energy projects.

\subsubsection{Reform of State-Owned Energy Enterprises Accelerates}

First, China has developed the " $1+N$ " policy. " 1 " refers to the Guidelines on Deepening Reform of State-owned Enterprises (2016). Specifically, 10 pilot reform projects were implemented in accordance with the Guidelines and led by the State-owned Enterprise Reform Steering Group under the State Council. "N" stands for the support pillars, which include the development of a mixed ownership economy, improvement of the state-owned asset management system, supervision of state-owned assets to prevent their erosion, development of a robust legal system, introduction of equity and dividend incentives, separation of social responsibilities previously undertaken by state-owned enterprises (SOE), supervision and management of state-owned asset transactions, SOE restructuring, illegal operations, investment accountability, employee stock ownership pilot projects, and so on.

Second, China is improving corporate governance by forming pilot boards of directors. The scope of the pilot includes China Baowu Steel Group, State Development \& Investment Corporation (SDIC) and China General Nuclear Power Corporation (CGN). A system for recruiting managers and professional executives will be piloted at centrally run enterprises and their subsidiaries, including SDIC and China Railway Signal \& Communication (CRSC). 
These pilots will be extended to include eight other SOEs-China Shenhua, Baowu, China Minmetals Corporation (CMC), China Merchants Group (CMG), China Communications Construction Company Limited (CCCC), China Poly Group, China Cheng Tong and China Reform Holdings Corporation Limited.

Third, China is using mergers and acquisitions to integrate enterprises. In May 2015, with approval from the State Council, China Power Investment Corporation (CPIC) and State Nuclear Power Technology Corporation merged to form State Power Investment Corporation (SPIC), with assets of more than RMB 700 billion and annual operating revenues of around RMB 200 billion. SPIC broke the monopoly in nuclear power of China National Nuclear Corporation (CNNC) and China General Nuclear Power Group (CGN) and made SPIC one of the country's top-three nuclear power groups, integrating upstream and downstream businesses. In the future, SPIC plans an initial public offering, with the ambition to become China's largest nuclear power group.

\section{The Current Energy System and Existing Problems}

\subsection{Energy Legislation System}

\subsubsection{Current Developments}

China's legal framework for the energy system has started to take shape, providing the legal basis and guarantees for energy development and government administration. Energy law enforcement is an important part of China's energy administration. However, legal supervision and compliance remain in their early stages.

\section{(1) The energy law framework is taking shape}

China's energy legislation is complex in structure and scattered in content. It is a mixture of old and new laws and regulations.

The elements of China's energy legislation system comprise laws, administrative regulations, departmental regulations, mandatory standards and specifications, local laws and regulations, and international conventions. The legislative hierarchy consists of national institutions and the State Council, below which are departments, local institutions with legislative powers, and local government.

The participants involved in the energy system include producers, traders, consumers, government at all levels and other energy market entities. The provisions regarding the rights and responsibilities of energy market participants are scattered across different energy laws and regulations.

China's energy legislation system covers exploration and production, processing and conversion, distribution, transport and use. The system is an integral part of the much larger ambition to build an ecological civilisation and robust legal system. Provisions relating to downstream energy are linked to environmental protection and combating climate change.

\section{(2) Energy law enforcement has become an important part of energy administration}

Energy law enforcement is an important part of China's energy administration.

The main energy law enforcement entities include national and local authorities for development and reform (pricing), land and resources, environmental protection and safety. Departments and administrative bodies relating to commerce, customs and quality supervision also play a role.

Enforcement mainly takes the form of traditional law enforcement and administrative methods like supervision. Central government is generally better than local government at enforcement. The number of enforcement agents necessary to cover a sector as large as energy makes it difficult to find good-quality personnel who satisfy professional requirements.

Results are typically related to capability. Because the basis for enforcement is sometimes unclear, it can be difficult to enforce legislation effectively over national energy infrastructure. Enforcement by local government often meets intervention from other parties. 
(3) Legal supervision and compliance in the energy sector is still at an early stage

The development of a judicial system for energy law is just beginning. Due to the long-standing pattern of administrative enforcement, energy cases resolved by the judicial system are rare, and the final decision tends to be one of administrative action.

Energy law compliance currently relies more on self-discipline. The development of a system requiring compliance with energy law is still at an early stage and the existing self-governing industry organisations continue to play an important role.

Legal supervision is still in its infancy. The activities of non-governmental organisations play a role, but the development of a consistent legal supervisory system still has a long way to go.

\subsubsection{Analysis of Existing Problems}

In general, the inconsistency and lack of coordination in China's energy law and regulatory system need to be addressed. Problems such as dependency on administrative enforcement, a lack of judicial practices, inadequate punishment and slack law enforcement exist. In addition, poor coordination between the energy legislation system and energy reform is set to become a major barrier to China's energy revolution.

\section{(1) Current problems in China's energy law and regulatory system}

The fact that a fundamental energy law and specific laws for key energy sectors have been lacking for a long time has impeded the sustainable development of China's energy industry. The Energy Law of the People's Republic of China (PRC) should be the foundation of the energy industry and the bedrock of the entire energy legislative system. Currently, however, the Energy Law of the PRC is in draft form only.

At the same time, the long absence of laws in key energy sectors has resulted in ineffective non-law-based regulation of construction, management and operations. Currently, there are no specific laws for the oil and gas sectors, or for energy utilities and energy product marketing and services.

Some regulations still bear the hallmarks of a planned economy, and others are poorly adapted to the needs of a market economy. For example, the Electric Power Law of the PRC lacks rules for electricity trading, power generation mechanisms and power system development. The Coal Industry Law of the PRC has many provisions that are ill-adapted to the current state of the coal sector, and which need to be amended and improved as soon as possible. In addition, China's energy laws and regulations are excessively based on principles and can be impractical. Many energy laws and regulations do not have the necessary support regulations for implementation. Their impracticality is due mainly to lack of clarity on rights and responsibilities. It is, therefore, necessary to define the rights and responsibilities of government and market participants in each part of the energy value chain. In addition, there are departmental regulations that are clearly intended to suit the interests of the department or authority concerned.

The provisions regarding specific services in China's energy industry are scattered among different laws and administrative, local and departmental regulations. As such, their effectiveness varies. In the absence of consistent guidelines, differences between the laws and regulations of different jurisdictions create inconsistencies in regulating the same energy services.

\section{(2) Energy law enforcement is decentralised and relies on administrative processes}

Constrained by the energy legislation and administrative system, China's energy law enforcement relies strongly on administrative processes. Even in those areas of energy law instituted since China's reform and opening-up, only rarely are energy issues resolved through judicial channels. Energy issues with a clear law enforcement basis and defined rights and responsibilities are mainly resolved through energy regulation (see below). Some policy goals are realised through administrative enforcement, 
for example by shutting down overcapacity, and these actions tend to be taken by local government. Technically speaking, these measures do not have a legal basis; their main purpose is to implement government policy.

China's energy law enforcement is decentralised and spread among different levels of government and departments. Enforcement is mainly the responsibility of the authority for energy policymaking, regulation and administration. The right to enforce energy law relating to the economy is decentralised to the National Development and Reform Commission and the National Energy Administration; and the right to enforce energy law with regard to society is with the Ministry of Environmental Protection, as well as those authorities responsible for quality and safe production. The enforcement of energy law also involves the relevant agencies of local government. China's energy and environmental law enforcement are separate, especially in the upstream and midstream energy sectors.

China lacks personnel and expertise in its energy law enforcement force, especially at grassroots-level energy administration, where enforcement teams are often too small and lack professionalism and independence. This results in incomplete or slack enforcement, no deterrence for severe violations or only minor penalties for infringements, rules and regulations that are ignored, and an absence of regulation of enforcement institutions.

Energy law enforcement is not carried out on a regular basis, and there is a severe lack of enforcement while activities are taking place. Instead, China's energy law enforcement is limited to unannounced or scheduled inspections and the post hoc results of energy activities.

At the same time, punishments for activities that break the energy laws are inadequate. China's energy law enforcement focuses more on correcting behaviour, and the punishments for violations tend to be light. In the economic enforcement field, the penalty for violating fair competition is far less than the illegal profits that may have been made. In the social enforcement field, the excessively light punishments for non-compliant emissions are far lower than the cost of controlling those emissions.

\section{(3) Poor coordination between the energy legislation system and energy reform}

The slow development of energy legislation has hindered energy system reform. Some of China's key energy laws were developed in the early years and not amended for a long time, so they are poorly adapted to the requirements of modern energy development. Held back by the constraints of these energy laws, reform at different levels of the energy industry has achieved only limited improvement of the energy system. Despite local successes, the ideal situation, in which energy legislation is aligned with energy reform, has not been realised, and so the reforms have had no effective legal basis.

The values underlying some energy laws are not aligned with the direction of energy system reform. From the market's perspective, some of China's existing energy laws were based on a guiding principle of "meeting demand with sufficient supply", and this clear supply-oriented bias makes the laws increasingly ill-suited for market-oriented energy supply and demand. From the government's perspective, the existing energy laws and regulations are unclear regarding the roles, rights and responsibilities of the government, and contain only very limited descriptions of the relationship between the government's functions (including planning, supervision and regulation) and the market.

The lack of clear definitions of rights and responsibilities in the energy laws results in energy system reforms lacking a legal basis. Specifically, government bodies in the energy sector do not have clear powers that they can use to act, and energy market participants do not have clear descriptions of their rights and responsibilities. These gaps stifle effective planning, operation and regulation in these natural monopolies. 


\subsection{The Energy Administration System}

\subsubsection{Current Developments}

In general, China's energy administration system has become relatively centralised in the upstream and midstream sectors, with coordinated administration now a regular practice. Energy regulation and policies are becoming increasingly important, although it is still difficult to distinguish between regulation and intervention. Energy planning is gradually transitioning to a market-oriented system from a planned economy approach. Energy strategies are increasingly valued and the energy reserve system is undergoing improvement.

\section{(1) Centralisation of upstream and midstream energy administration}

Gradually, China's energy administration has shifted from a decentralised to a relatively centralised format.

The National Energy Administration (NEA) is China's most important energy administration body. As a national vice-ministerial organisation under the National Development and Reform Commission (NDRC), the NEA oversees such key energy sectors as power, coal, oil, natural gas, nuclear power and renewable energy. Its main responsibilities include: (i) preparing drafts of energy-related laws and regulations, formulating and implementing energy development strategies, plans and policies, promoting and drafting energy system reform, and coordinating major issues in energy development and reform; (ii) engaging the relevant personnel to develop energy industry policies and related standards, and approving fixed-asset investment projects in the energy industry; (iii) guiding and promoting technological progress in the energy sector; (iv) managing nuclear power development, including the development and implementation of plans and standards, carrying out nuclear power-related R\&D and organising emergency management of nuclear power plants; (v) taking charge of energy conservation and ensuring comprehensive resource use in the energy industry; (vi) conducting energy forecasting, releasing information and participating in operational coordination and emergency preparations; (vii) supervising and regulating the power market; (viii) licencing, supervising and managing power production safety, reliability and emergency response; (ix) taking the lead in promoting international energy cooperation, and reviewing or approving major overseas energy investment projects; and (x) participating in energy policymaking in areas such as resources, finance and taxation, environmental protection, climate change, and making recommendations on energy pricing and imports and exports.

The NEA has 12 departments and employs 240 executive staff, including 42 leaders. The NEA departments and their main responsibilities are listed in Table 3. The NEA's internal organisational integration involves two major changes.

First, Market Supervision and Electric Power Safety have become two new departments. Electric Power Safety covers the responsibilities of the former State Electricity Regulatory Commission (SERC), and Market Supervision expands the responsibilities of Electric Power Safety to include new energy, coal and oil and gas, as well as promoting market-oriented energy development. Thanks to the responsibilities added by the new Market Supervision department, the NEA will gradually play a dominant role in energy system reform and the formation of an energy market.

Second, the former Policies and Regulations functions of the NEA and SERC have been combined to form Legal and Institutional Reform, which is mainly responsible for research on major issues in energy law, regulations, supervision and institutional reform.

China's local energy administration system comprises two levels - six regional energy bureaus and 12 local energy offices. However, as the local energy administration system was formed by merging the electricity regulatory agencies under the former SERC into the NEA, the main responsibility of China's regional 
Table 3 NEA internal organisation

\begin{tabular}{l|l} 
Name & Main responsibilities \\
\hline General Office & $\begin{array}{l}\text { Administrative affairs; disclosure of government affairs; security and confidentiality; } \\
\text { petitions; energy statistics; forecasts and early warning; coordination of the National }\end{array}$ \\
Energy Commission Office
\end{tabular}

Conservation and Scientific Providing guidance on energy conservation and the use of resources by the energy Equipment

Electric Power

Nuclear Power

Coal

Oil and Gas

New and Renewable Energy

Market Supervision

Electric Power Safety

International Cooperation

Party Committee (HR) industry; work related to technological progress and equipment; developing energy industry standards (excluding coal)

Developing and implementing plans and policies on thermal generation and power grids; electricity system reform; coordinating and balancing power supply and demand.

Preparing and implementing nuclear power development plans and policies; emergency management of nuclear power plants

Developing and implementing plans and policies on coal development, coalbed methane (CBM) and the conversion of coal into clean energy products; work related to the reform of the coal sector; managing stakeholders in CBM development; shutting down outdated coal production facilities; the management and use of CBM

Developing and implementing plans and policies on oil and gas development and refining; work related to the reform of the oil and gas sector; management of national oil and gas reserves; supervision and management of commercial oil and gas reserves

Providing guidance for and coordination of new, renewable and rural energy development; developing and implementing plans and policies for new energy, hydropower, biomass energy and other renewable energy sources

Preparing plans for power market development and regional power markets; regulating the power market and power distribution, supply and non-competitive power generation services; handling disputes in the power market; conducting research and providing proposals on electricity tariffs; supervising and reviewing the electricity tariff criteria for ancillary services; recommending policies on universal power services and supervising their implementation; and regulating fair access to oil and gas pipeline facilities

Developing policies on the safety of non-nuclear power plants, the construction of power system projects and supervising project quality and safety; supervising and managing power safety and production, reliability and emergency response; supervising and managing the safety of hydropower dams; investigating and handling accidents in power production and engaging the participation of relevant stakeholders

Promoting international energy exchange and cooperation; conducting negotiations and signing agreements with foreign energy authorities and the International Energy Agency; developing energy opening-up strategies, plans and policies; coordinating overseas energy development and use

Personnel and organisational management, team building, discipline and supervisory work in the NEA and regional energy administrations directly under it; party work in the NEA and the Beijing-based organisation directly under it 
energy bureaus and local energy offices is still regulating the power sector.

The NDRC and the State Council are responsible for the approval of major energy projects (including infrastructure); and the NDRC, under the control of the central government, is responsible for energy pricing (mainly in the upstream and midstream sectors) and its supervision and management. The development and reform department under local government is responsible for the approval of local energy projects, and the local development and reform (pricing) department is responsible for local energy pricing (mainly with regard to downstream use).

Some government administration functions related to energy have been assigned to other departments. For example, the Ministry of Land and Resources administers the mining rights for oil, natural gas and natural uranium; the central and local land and resources authorities administer the coal mining rights under their jurisdiction; the State Administration of Coal Mine Safety is responsible for safety in coal exploration and development, and the State Administration of Work Safety is responsible for safety in conventional energy production; and customs authorities administer energy imports and exports. In addition, the State-owned Assets Supervision and Administration Commission (SASAC) invests in large state-owned energy enterprises.

Coordinated administration has become normal practice. Some major energy policies are jointly released by the NDRC and NEA. Basically, the NEA can coordinate the administration of all energy sources, except nuclear power and coal, which have special requirements for safety. To undertake overall administration of China's energy system, the NEA must coordinate with the NDRC and local government, and effectively perform its governmental functions of planning, regulation and supervision (Table 4 ).

Table 4 China's energy administration institutions and their responsibilities (2014)

Institution
National Energy Commission (NEC)
National Development and Reform
Commission (NDRC)
National Energy Administration
(NEA)
The Ministry of Land and Resources
The Ministry of Water Resources
The Ministry of Industry and
Information Technology

The Ministry of Science and Technology

The Ministry of Finance

The Ministry of Construction

The Ministry of Agriculture

The Ministry of Transport

The Ministry of Environmental Protection

\section{Responsibilities}

National energy development strategies and major issues and activities

Overall plans, addressing climate change, and statistics; energy conservation, clean energy development mechanism, development and use of new and renewable energy, and demonstration and promotion of energy conservation and emissions reduction

Information, strategies, plans, strategic reserves, emergency management of nuclear accidents, institutional reform and international cooperation; energy equipment and technology, energy industry events

Resource management (mining rights)

Rural hydropower strategy, plans, institutional reform, international cooperation and information; small hydropower projects, rural power grids and technologies

Emergency management of nuclear accidents, nuclear industrial planning and international cooperation; nuclear research, major technologies and equipment, energy conservation and emissions reduction; fuel efficiency of motor vehicles and development of new energy vehicles

Technical research, research on basic science; development and implementation of science and technology plans, and promotion of oil and gas pipeline technology advances

Fuel tax, and financial and tax policies related to renewable energy development, gas use and energy-efficient products

Energy-efficient buildings and urban sewage and biogas

Promotion of biogas, biomass energy and solar energy

Planning and implementation of green transport

Control of emissions from energy-consuming machines and tools, and pollution 
(2) Energy regulation and policies play an increasingly important role

Government regulation and policies are playing an increasingly important role. The government has promoted a shift in energy production by: (i) introducing an assessment system for energy conservation and emissions reduction; (ii) restraining total energy consumption by shutting down outdated production facilities and cutting overcapacity; and (iii) stimulating the development of new and clean energy with tax incentives. Although these are all government-led mandatory policies, they have delivered genuinely strong results to date. The ability of government regulations and policies to incentivise or disincentivise the energy industry is critical to the efforts to create an ecological civilisation and promote sustainable energy development.

However, government is still intervening in market access. The government has imposed selective control of the energy sector and set many access thresholds in terms of investment scale, site choice, equipment level and product sourcing for energy development projects. Compared with large enterprises and foreign-owned companies, small and medium-sized enterprises and domestic companies are faced with high restrictions on access.

\section{(3) Energy planning promotes balance and adapts to economic and social development}

Planning is an important government function in the energy system and is increasingly adapted to economic and social development.

Energy planning has been shifting from "meeting demand with sufficient supply" to balancing supply and demand. China's energy market has entered an era of diversified competition, where energy substitution occurs at multiple levels and supply and demand are changing rapidly. The previous energy market, driven by supply, has changed, with the demand side now playing an increasingly important role.

Energy planning functions have also changed, from mandatory to directive. Previously, energy planning started from the supply side and focused on state-owned energy enterprises in key sectors. With the reform of the energy market and enterprises, the mandatory planning function is gradually weakening and energy plans are rapidly assuming a more directive role.

Energy planning has gradually become scientific, consistent and democratic. The practices in the 12th and 13th Five-Year Plans (2011-15 and 2016-20 respectively) prove that the government values research during the early stages of energy planning and seeks opinions from all walks of life, striving to ensure that energy plans are in the common interests of all stakeholders.

\section{(4) Energy strategies are valued factors in decision-making}

China values energy strategies and considers them an important basis for decision-making. Both central and local government develop strategies for each energy source and each part of the energy value chain, as well as medium- and long-term strategies for some key sectors. China's Strategic Action Plan on Energy Development (2014-20) of the General Office of the State Council describes the major actions and safeguards required to implement energy strategies.

(5) Energy reserves are valued and emergency response stocks have improved

Energy reserves are the responsibility of the energy administration under the central government. Reserves of fossil fuels are mainly physical (energy products) and cannot respond quickly to ongoing events. In terms of energy source, China's reserves are mainly oil and coal. The oil reserve is of strategic significance. Due to China's high self-sufficiency in coal, coal reserves are not kept at strategic levels. In addition, natural gas reserves are mainly used for balancing gas supply with demand, so natural gas storage facilities are small and used for peak shaving.

National strategic oil reserves are the responsibility of the National Energy Administration (NEA). China has built a national oil reserve centre. The NEA is responsible for building and 
managing national oil reserve bases, collection and storage, rotation and use of strategic oil reserves, and monitoring supply and demand in international and domestic markets.

Natural gas reserves are used mainly to adjust gas supply. China's gas reserves have difficulty meeting normal demand. Due to the small scale of gas reserve storage facilities and absence of a peak-shaving gas pricing mechanism, the peak-shaving capability of gas reserves is below international levels. At the end of 2014, the increased production of residential gas and weak downstream gas demand resulted in higher inventories at several liquefied natural gas terminals, but there is still not enough space to store more spot gas.

Coal reserves are not as crucial as oil reserves. China has begun building an emergency coal reserve system. Many provinces are building emergency coal reserves, and large coal enterprises, utilities and ports already have emergency coal reserves. Currently, China's thermal power plants consider a coal stock of 15 days to be normal and of seven days to be a warning. The thermal coal stock of a power generation company should not be less than 20 days. In terms of administration, China's emergency coal reserve system is mainly the responsibility of the National Development and Reform Commission (NDRC), the Ministry of Finance and government departments for transport, railway and energy. Organisations like the China National Coal Association (CNCA) and State Grid provide coal market monitoring, early warning services and information support. The enterprises responsible for emergency coal reserves build dedicated storage facilities. Overall planning and regulation of emergency coal reserves are carried out by national government and specific task fulfilment is the responsibility of enterprises and ports.

In the event of a severe natural disaster or emergency, the NDRC and the Ministry of Finance make decisions on using reserves based on applications from provincial governments or suggestions from organisations like the CNCA or State Grid. NDRC and the Ministry of Finance then give the order to use the emergency reserves to the relevant enterprises that hold the reserves. Since normal production and operation are ongoing, reserves are rotated so that used stocks are replaced with new, and at least one rotation per quarter takes place.

Enterprises that undertake coal emergency reserve tasks can apply for bank loans, and the national government can grant subsidies for newly built reserve facilities and reconstruction or expansion projects. For enterprises that have fulfilled their emergency reserve tasks, the central finance department will pay interest on their loans or on the capital they have invested in the emergency reserves, as well as subsidise other costs such as site occupancy and storage charges.

China's energy emergency reserve system is designed to respond to energy emergencies, ensure secure and stable energy supply, and make short-term decisions on energy security. At the centre of emergency management is the "inter-ministerial coordination mechanism for ensuring coal, electricity, oil and transport security". China's energy emergency reserve system is decentralised and short term, with the relevant central enterprises performing the emergency management function. First, the NDRC has the largest say in energy emergency management and also has administrative responsibility for energy regulations. Second, the responsibilities of the NEA include ensuring energy emergency supply, managing oil reserves, guiding implementation of administrative measures by national oil companies, and emergency management of the power sector, which was previously the main responsibility of the former SERC. Third, the State Administration of Work Safety is responsible for leading production safety and emergency rescue work in key energy sectors, such as coal and petrochemicals. In addition, the State Administration of Science, Technology and Industry for National Defence is responsible for emergencies in nuclear power. The general administration office and the energy authority of local governments cooperate with the central government in carrying out energy emergency management. China's energy emergency management has played an important role in addressing energy emergencies, such as the 2008 
snow disaster in south China, conflicts between the coal and power sectors, and regional oil and gas shortages.

\subsubsection{Analysis of Existing Problems}

China's existing administrative system lacks consistency and the level is low. Problems such as decentralised administration, unclear rights and liabilities, and overlapping functions remain. Administrative coordination between various departments regarding strategy, planning and policy is poor. The culture of putting approval ahead of public service has not fundamentally changed. In addition, the management of energy reserves and emergencies lacks public engagement.

\section{(1) Inconsistent administrative oversight and no independent high-level institution}

There are many agencies that have some responsibility for energy administration, but they lack a centralised organisation. In many places they suffer from overlapping remits, where different departments have joint administrative responsibility for specific areas, which can be highly problematic. The National Energy Commission was established to improve energy strategy and overall coordination, but its role has been restricted by the way its organisational structure was set up, and it does not coordinate the administrative activities of the various departments effectively. The National Energy Administration (NEA) is responsible for overall energy planning and development, as well as for supervising the energy industry as a whole, but the administrative functions for specific energy sectors are decentralised to the Ministry of Industry and Information Technology, the Ministry of Water Resources, the Ministry of Agriculture, the State Administration of Work Safety, the Ministry of Environmental Protection and the Ministry of Commerce. This administrative approach of "divided policies from various sources" not only increases the cost of coordination, but also results in unclear responsibilities, conflicting authorities and inefficient administration.
Definitions of rights and liabilities in the energy sector are unclear, both horizontally (between departments of the central government) and vertically (between central and local government). The first problem is that China's energy-related administrative institutions perform their functions in accordance with the Plan on Defining Functions, Internal Organisation and Staffing, and therefore the power granted to them is not based on law. The absence of a fundamental energy law means that the rights and liabilities of energy administrative institutions also lack a legal basis. The next difficulty is that the body framing energy regulation is a subsidiary of the institution that administers those same regulations, and this non-independent approach, which bundles administration and regulation together, hinders effective energy law enforcement. Another problem is that local energy regulation is vulnerable to pressure from local government. Finally, the administrative systems in various energy sectors have their own specific features (except for oil and gas). In those energy sectors that adopt a hierarchical administrative approach, there is a clear lack of coordination between central and local administrative institutions.

The NEA is a vice-ministerial department. It therefore ranks below other resource administration departments that are ministries, such as the Ministry of Water Resources and the Ministry of Land and Resources. For some major energy decisions, the NEA still needs to seek approval from the National Development and Reform Commission (NDRC). All this makes it difficult for the NEA to play its coordinating role effectively. A typical example where overall oversight is needed is regulating energy volume and energy prices. The NEA is mainly responsible for energy volume and the NDRC controls the administration of energy pricing, and this separation does not sit well with the strong link between the two areas. Inevitably, conflicts arise between the measures for adjusting volume and those for adjusting price, and as a result the policies introduced by both departments tend not to deliver good results. 
(2) Outdated approach to administration and overcomplicated approval processes

Due to the typically large scale of investment required in the upstream and midstream sectors of the energy industry, and the need for productivity allocation and cross-provincial coordination, the requirement that the administrative function be vertically hierarchical and horizontally decentralised creates an overcomplicated approval process. Moreover, there are some specific requirements that make it difficult to access non-state-owned capital. Central enterprises entering this field also need to handle their relationship with local government, for whom the conflict between administration and interests is difficult to manage.

There is also a lack of public services in the energy sector, which can be clearly seen in the provisions for information disclosure. First, there is insufficient disclosure of government information, including missing or inadequate updates regarding administrative licencing and laws and regulations, as well as too little disclosure of documents and notices that have a direct impact on the development of the energy industry. Second, the mandatory information disclosure system for natural monopolies like oil and gas pipelines has not been established, and information disclosure platforms are absent. Third, there is no administrative system for making data public, especially in basic research. As a case in point, the system for collecting and submitting data on oil and gas resources was introduced in China several years ago, but due to slack enforcement the relevant administration has had difficulty obtaining and managing these data. The delay in building databases and disclosing information has severely affected the integration of mining rights administration processes.

\section{(3) Poor and uncoordinated energy plans make it difficult to balance supply and demand}

The coordination between energy plans at different levels and in different sectors is poor. Some energy plans are conditional on each other.
Other energy plans (especially local plans) do not take energy supply and demand sufficiently into account. The energy plans for some sectors have not been effectively implemented or even completed for some time. Coordination between central and local energy plans is poor. Typically, energy plans are more often completed on the supply side and poorly implemented on the demand side. The evaluation of energy plans and their implementation is far behind schedule.

Planning for supply and demand balancing tends to consider volume ahead of how price affects energy demand. Although changes in the scale and structure of energy demand are assessed within the context of socioeconomic development, the current (government-led) pricing mechanisms for oil, gas and electricity make it hard for price changes to reflect market supply and demand. When energy plans are implemented, price tends to severely restrict the market's role. Moreover, the administration of energy volume and price are separate responsibilities of the NEA and NDRC respectively, which also contributes to the tension between volume and price when energy supply and demand are considered.

The lack of coordination between plans for power consumption and generation has become increasingly acute, which can be clearly seen in generating equipment availability. In 2014, the average availability of several types of generating equipment in China hit a record low. In addition to weak power demand due to the sluggish economy, the distribution of power generating units also caused problems. For example, the start-up of Unit 2 of the Hongyan River nuclear power plant was postponed even though it was ready, because the power supply capacity of the north-eastern power grid had not been properly considered at the planning stage. The lead time for nuclear power plant construction increases the likelihood of mismatches between installed power capacity and power demand.

\section{(4) Energy strategies lack national support and an implementation mechanism}

China lacks national medium- and long-term energy strategies. Despite the introduction of the 
Strategic Action Plan on Energy Development (2014-20), national energy strategies are unclear. Local and national energy strategies are not coordinated, and the guidance provided by energy strategies lacks relevance for energy plans. In addition, there is no strategy implementation mechanism or policy support.

The energy revolution needs clear goals and a roadmap, coordinated safety measures and relatively stable policies. The energy revolution and medium- and long-term energy strategies are carried out by means of dynamic economic and social development and synchronised reforms, including those of government, finance, science and technology. Some of these dynamically developing reforms are interdependent.

\section{(5) The energy reserve and emergency response systems need to be updated}

China's energy reserves commonly suffer from several problems, exemplified by oil and coal reserves. These problems are: (i) a powerful legislative guarantee for strategic reserves is lacking - there is no clear legal definition of the boundary between government and market, or of the rights and liabilities of the various energy industry participants, regarding levels of reserves of different energy sources; (ii) an incomplete administration system - the storage and release conditions for energy reserves need to be improved: price is the key, but the necessary supervisory system is absent; (iii) the method for holding reserves needs to be improved-static energy reserves result in excessively high costs and relatively limited reserve size; (iv) poor levels of IT functionality in energy reserve administration, leading to insufficient disclosure of information, especially on reserve capacity and volume; (v) inefficient reserve storage facilities - the logistics of energy reserves still need to be improved; and (vi) physical reserves are concentrated in large central energy enterprises, while commercial oil and gas reserves are growing slowly.

China's energy emergency management is designed mainly for domestic, local and short-lived, unexpected energy incidents; it would have great difficulty responding effectively to global energy events that had wider or deeper implications. First, China's energy emergency management is limited to guaranteeing supply in the case of an emergency. Second, China's energy emergency management is decentralised and lacks consistent national management and coordination. It is very much set up for emergencies involving a specific energy source or a particular part of the energy value chain and is inadequate for responding to global energy events that involve several energy sources. Moreover, the geographical scope of energy emergency response is limited to China, and no international energy emergency management has been set up. Third, the development of an energy emergency material guarantee system is inadequate. China's oil reserves still have some way to go to meet the International Energy Agency's 90-day oil stock security criteria, and the size and capacity of the power grids and the natural gas pipeline network do not meet emergency demand levels. Fourth, energy reserve and emergencyrelated legislation is still lacking, and related systems need to be improved, including the use and storage of energy reserves, supervision, evaluation, IT-based administration and funding systems.

China's energy reserve and emergency management suffer from poor information disclosure and public engagement. As there is no information disclosure system, participants in the energy sector have difficulty obtaining information in a timely fashion. Since commercial energy reserves are not mandatory and a reasonable pricing mechanism for energy reserves has yet to be established, private capital is not motivated to enter the field.

\subsection{Energy Market and Circulation System}

\subsubsection{Current Developments}

China's energy market and circulation system are still very much a monopoly. This is rooted in the energy system and institutions and is reflected in network facilities. China's energy market system 
is still in its early stages. The level of marketisation varies for different energy sources - the coal sector has completed its market-oriented reform; the downstream oil and gas sector is highly deregulated, but upstream still suffers from severe monopoly problems; and the market-oriented reform of power transmission, distribution and retail is urgently needed. In addition, the institutional barrier in natural monopolies has become a major hurdle in the reform of the energy circulation system.

\section{(1) Slightly more competition in the oil and gas market, but resource monopoly remains}

As a result of the 1998 reform and restructuring of the oil and gas sector, and the related reform and policy measures that followed, an energy production and circulation system has taken shape, covering upstream and downstream, domestic and overseas trading, and production, transmission and sales. The market consists of the top four oil groups - China National Petroleum Corporation (CNPC), China Petroleum \& Chemical Corporation (Sinopec), China National Offshore Oil Corporation (CNOOC) and Yanchang Petroleum-alongside various other oil and gas enterprises of different ownership types and sizes, with the top four dominating and forming in effect an oligopolistic or monopolistic competition landscape.

Competition in refining and chemicals, wholesale and retail, has increased. In recent years, state-owned oil enterprises such as CNOOC and Sinochem, which have crude oil resources, have rapidly enlarged their refining presence, intensifying the competition. Because CNOOC and Sinochem have limited downstream distribution resources, the construction and operation of refineries backed by CNOOC and Sinochem investment will increase competition in the energy wholesale and retail sectors.

At the same time, easier entry terms into wholesale oil products have helped diversify market participants. CNOOC, Sinochem and some private oil and gas companies have all been awarded an oil product wholesale licence. Compared with the early 21 st century, the competition landscape of the wholesale oil product market has evolved, and competition has gradually intensified.

CNPC, Sinopec and CNOOC have retained their resource monopoly, restricting the development of other market players. In terms of market structure, domestic crude oil and gas resources are concentrated in state-owned oil enterprises, especially CNPC and CNOOC. Wholesale is dominated by CNPC, Sinopec and CNOOC, but in recent years competition in refining, oil production and natural gas wholesale markets has intensified somewhat. There are numerous players in the energy retail market, but because the resource market is dominated by CNPC, Sinopec and CNOOC, private companies dealing in oil products and natural gas other than the top four oil groups do not have a complete vertical presence throughout the market, and they rely on the top four oil groups for resources and even marketing.

\section{(2) Electricity market reform has started and needs to be deepened}

China's electricity market has more than a decade of experience, during which time small reforms in different parts of the electricity value chain have been continuously carried out and have delivered good results. In 2002, China separated generation from the power grid, and gradually developed pricing mechanisms in power generation, transmission, distribution and sales. In 2004, China introduced the benchmark feed-in tariff policy and began to set and announce regularly the feed-in tariff for new generating units in each province.

The main problems in China's electricity sector are reflected in its market structure. In power generation a pattern of diversified competition has taken shape. The vast majority of power generation enterprises are state-owned and state-controlled, including the top five large power generation corporations (China Huaneng, China Datang, China Huadian, China Guodian and State Power Investment Corporation, SPIC) 
and the top four small power generation groups (State Development \& Investment Corporation, SDIC; Guohua Electric Power; CR Power; and China General Nuclear Power Group, CGN). The installed capacity of these companies accounts for $60 \%$ of the country's total. There are also some power generation enterprises that are wholly owned or controlled by local government. At the same time, power transmission, distribution and sales have not yet been deregulated, and power supplies in all provinces come mainly from local monopoly power grid enterprises. Electricity sales from central grid enterprises account for more than $80 \%$ of the country's total electricity demand. Independent market-oriented trading has not yet been established in China's electricity market - competition has been introduced in power generation, but monopolies remain in transmission, distribution and sales. Grid companies with power transmission and distribution networks have a monopoly in both wholesale and retail. Finally, power generation plans are developed in coordination with government at all levels and with power plants and grids. This has created an administrative system influenced by multiple factors, such as regulation policies, energy conservation and emissions reduction, and the requirements of administrators.

The new electricity market reform plan has been released in the Opinions on Further Deepening the Reform of the Electric Power System. The goal of "establishing and improving the market mechanism in the power sector that features 'legal basis, separation of government and enterprises, compliant market participants, fair trading, reasonable prices and effective supervision" stated in the Opinions echoes actual requirements. The priorities and pathway of electricity market reform can be summarised as "deregulating a new power distribution and sales market, deregulating electricity prices other than transmission and distribution tariffs, and deregulating power generation other than that for safe and efficient power operation and supply reliability, and others. The reform framework is defined as "deregulating power generation, sales and end use, and control of power transmission and distribution", which is basically what would be expected. Generally, this round of electricity market reform has been carried out with a common-sense approach and has taken both the requirements of reform and the principle of practicality into consideration. Compared with "Document No. 5", released in 2002, the Opinions is of more practical significance.

(3) Coal sector market reforms are complete, though the long-term contract price for thermal coal needs to be tested in the market

The coal sector has ended its dual-track price system and completed its market-oriented reform. Apart from thermal coal, China's coal market was already market-based. In 2013, the cancellation of priority contracts and the ending of the dual-track price system for thermal coal completed the market reform of the coal sector. Although the contradiction between marketoriented coal and planned electricity appears to have been resolved, the long-term contract price for thermal coal, reached through difficult negotiations and compromise between all parties involved, has yet to be tested in the market.

\subsubsection{Analysis of Existing Problems}

China's energy circulation system is largely monopolistic. Administrative monopoly is prominent in investment access and resource acquisition in upstream primary energy. The fact that there is only a limited number of market participants in the oil and gas sector (especially in upstream and midstream) affects the overall efficiency of the sector.

\section{(1) The upstream and downstream oil and gas monopoly affects the overall efficiency of the value chain}

The monopoly in upstream oil and gas persists. Despite mutual penetration of each other's dominant market areas by CNPC, Sinopec and CNOOC, the "separation of upstream and downstream, separate administration of domestic and overseas trading, and separation of offshore and onshore oil and gas" in the oil and gas sector, 
which was formed at the end of the 20th century, has remained relatively stable, and China's current regulations and administration reinforce this situation.

First, the unequal status of different market participants makes access difficult for non-state-owned investors, so it is hard to create a fair market environment. This is not conducive to improving the overall efficiency of the oil and gas sector or sharpening the competitiveness of oil and gas enterprises, nor does it help increase the exploration and development of domestic oil and gas resources.

Second, local monopoly markets form between upstream, midstream and downstream, and within each part of the oil and gas value chain, which leads to market separation and makes it difficult to establish a consistent and open market system.

Third, various market structures - a national oil and gas exploration and mining rights trading market, a pipeline capacity trading market, a reserves market and a futures trading marketare all yet to be established. As a result, the market has very little scope to play a role in allocating resources; resource use efficiency could therefore be improved. As a large oil and gas consumer, China does not have enough say in international oil and gas pricing.

\section{(2) Many interrelated problems hinder the development of the electricity market}

The Opinions is just a guideline. If the requirements stated in the Opinions are truly to be implemented and the reform goals achieved, then support policies and regulations, along with implementation documentation, are needed. Problems to be solved in the power sector include: (i) the relationship between power grid enterprises and relatively independent electricity trading institutions urgently needs to be defined; (ii) power transmission and distribution tariffs need to be set independently; (iii) market-oriented power generation and sales prices, other than those for public goods, need to be phased in; (iv) cross-subsidies for electricity prices need to be gradually decreased; (v) the bilateral trading market needs to be kick-started by increased market participation and a cross-provincial market mechanism; (vi) power sales reform needs to be steadily promoted and power distribution and sale services need to be deregulated to admit private capital in an orderly manner; and (vii) the results of reform need to be safeguarded by legislation.

\section{(3) Barriers in the coal market and severe decentralised administration remain}

Of all the energy sectors, coal has the most relaxed administration. However, despite the substantially reduced level of government intervention in the coal market, there are still many problems in the sector. First, the involvement of multiple departments in its administration and the complexity of coal circulation results in high costs. Second, there are acute transport bottlenecks, such as poor allocation of transport capacity. Third, coal logistics management is inadequate, and there are still no emerging coal circulation companies and logistics centres. Fourth, supervision of the coal circulation process is poor and there is a serious problem with pollution. In addition, poor quality control is holding back the sustainable development of the coal market.

There are still many obstacles in coal circulation. First, coal logistics generally divides into west-to-east and north-to-east coal transport, and any imbalance in economic transformation may reinforce such supply and demand differences. Second, rail transport plays a more important role in the coal logistics system, which is of greater significance for coal transport in Xinjiang and eastern Inner Mongolia. Third, water transport is an important method of north-to-south coal transport. The coal volume transported by water increases year by year, and the established directions of coal flow are undergoing change.

The coal sector features the loosest administration of all primary energy sources. Central government, local government and coal associations all play a role in the administration of coal. Although administrative streamlining has allowed some tasks to be erased or delegated to 
local government, there has been no obvious improvement in decentralised administration.

\subsection{Energy Pricing System}

\subsubsection{Current Developments}

The government continues to intervene in energy pricing. In each part of the energy value chain the pricing guidance reflects market dynamics poorly. Overall, there are many problems in China's energy pricing system: in price formation, composition and regulation, and in the coordinated administration of production and pricing. Pricing in upstream primary energy has gradually been deregulated, but government intervention remains influential in the pricing of energy products for major end users. The ground has been prepared for market-oriented pricing reform in the oil and coal sectors, but gas pricing reform still needs more work. The energy tax and finance systems and policies play an important role at some stages of reform and have a positive impact on end-user energy prices.

\section{(1) Problems with China's energy pricing systems severely constrain energy system reform}

China has been steadily promoting energy pricing reform for years, but deeply rooted contradictions have not been resolved. Distortions in pricing cause resources to be miscalculated, structural imbalances and extensive overdevelopment. Although the policy of "replacing pricing reform with adjustment" has had partial success, prices and price adjustments that work in the short term have not developed into a long-term pricing mechanism and a workable pricing settlement for the entire energy system.

Energy pricing reflects the various drawbacks in China's energy system and is a core component of energy system reform. Unreasonable energy product prices and slow-moving pricing reform severely constrain the smooth transition to a new development process and a change in overall economic structure. Administratively, energy planning and balancing supply and demand are mainly the responsibilities of the NEA, while energy pricing and administration are the responsibilities of the NDRC. This administrative separation of production volumes and pricing is the major cause of China's energy pricing problems, many of which are outlined in the following paragraphs.

First, due to the unfair pricing mechanism and the government's forceful intervention in pricing, prices do not reflect the true value of energy products. Market-oriented pricing in competitive energy fields and related areas is not common practice. For historical reasons and due to the specific characteristics of energy resources, the prices of China's energy products have been set or strictly controlled by the government for a long time. As a result, energy prices cannot effectively reflect supply and demand and the scarcity of energy resources, which restricts the role of price in resource allocation.

Second, pricing calculations and taxation are unreasonable and full-cost accounting is not well implemented. In the current price calculation of energy resource products, cost items are entered at a low level that does not provide reasonable compensation for the energy resource production process. Neither do they reflect the cost of controlling environmental pollution in the resource development process nor the cost of safe production. Moreover, external costs are not internalised. Inconsistent taxation and energy costs do not reflect the price relationships of energy products, resulting in users lacking any cost constraints for some energy products. This is detrimental to the correct alignment of the energy system.

Third, the incomplete price regulation system, poor regulatory expertise and inadequate information disclosure hinder effective price regulation. When the price regulatory body regulates prices in natural monopolies it tends to lack real-time cost information and feedback; its price and cost accounting and supervisory capability are, therefore, weak. Moreover, there are insufficient levels of personnel, finance, materials and IT in the price regulatory body, and inadequate transparency of price regulation and public engagement. At the same time, lack of 
transparency and cross-subsidies due to monopolistic pricing are the main reasons why effective supervision is difficult to deliver. Some energy sources and links in the energy value chain completely lack cost and price regulation, resulting in a hardened price monopoly in natural monopolies like power grids and oil and gas pipeline networks.

Fourth, the disconnect in energy pricing results in intermittent price transmission and obvious contradictions between pricing in different links of the energy value chain, which affects the ability of the market to allocate energy resources effectively. This phenomenon is especially evident in the power sector, for example in the disconnect between the sales price and cost of generation, and between the power transmission and distribution tariffs and the feed-in tariff. In addition, the links with international and domestic market pricing are weak. Government pricing does not respond promptly to market dynamics, and China also lacks a voice in international energy pricing.

Fifth, separating production volumes and price amplifies the shortcomings in China's energy pricing system. Energy planning and balancing supply and demand are mainly the responsibility of the NEA, and energy pricing and administration are the responsibility of the NDRC. This administrative system, which separates production volume and price, is the major cause of China's energy pricing problems. When supply is tight, the effects of the separation are not obvious, but in the context of diversified energy supply and demand, especially during the transition to market-oriented energy pricing, the administrative separation is increasingly ill-adapted to the requirements of energy development.

(2) Deregulation of upstream pricing is gradual, but government intervention continues

Pricing in China's upstream energy sector has gradually been deregulated. The deregulation of pricing in the coal and oil industries has been implemented in phases: upstream coal pricing has been deregulated for years, and the crude oil price is independently determined and based on the international oil price. The implementation of netback pricing has made the upstream natural gas wellhead price redundant. Power generation pricing has evolved from a price based on each generating unit to a benchmark price, and government interventions are gradually decreasing.

Government intervention still occurs in downstream energy, especially in the pricing of major end-use energy products. Natural gas and electricity end-user prices in particular are still controlled by local government, due to the reliance of these two energy sources on natural monopoly networks and facilities and the public service attribute associated with them.

\section{(3) Pricing reform in the oil and coal sectors is completed, but hurdles remain in elec- tricity and gas}

Oil pricing has become market oriented. China's crude oil prices are now negotiated or independently determined by oil-producing enterprises, based on the international oil price. The price of crude oil supplied by national oil companies is negotiated by the buyer and seller on the principle that the cost of delivering domestic onshore crude oil to refineries should be equivalent to the cost of delivering imported crude oil from international markets to refineries. The price of crude oil supplied to local refineries from national oil companies is set by referring to the price of mutually supplied crude oil between two oil groups. The price of crude oil produced by CNOOC and other companies is independently determined by the corresponding producer with reference to the international oil price.

The pricing of oil products is linked to international oil prices, but a degree of government intervention remains. Having connected the government-guided moving-average price with the international oil price, the government can influence end-user oil prices more through tax policies. In March 2013, the government announced an improved oil product pricing mechanism, whereby the price adjustment cycle of oil products would be shortened from 22 to 10 
working days, and the price adjustment restriction of $\pm 4 \%$ of the energy source's average price in the international market would be cancelled. In general, China's current oil product pricing mechanism follows the basic principle of following the international oil price, but to ensure a relatively stable domestic oil price it implements the government-guided pricing approach. The existing oil product pricing mechanism covers the following five aspects: (i) differentiated oil product prices - either government-guided price or government-controlled price; (ii) adjustment of petrol and diesel prices based on changes in the international crude oil market price every 10 working days; (iii) adjustment of oil processing profit margins and thus oil product prices, based on changes in the international crude oil price; (iv) the NDRC sets the ceiling retail price of petrol and diesel for all provinces and major cities; and (v) defines the difference between wholesale and retail prices.

A dynamic price adjustment mechanism that reflects market supply and demand and the scarcity of resources has been preliminarily established in the natural gas sector. China has gradually implemented the netback pricing approach for pipeline gas since 2011, but the price of pipeline gas has been restricted by gas source price and limits on pipeline transmission and distribution. The implementation of the netback pricing approach represents a major step in rationalising the relationship between the natural gas price and the alternative energy price. China's natural gas market is still supplier-dominated and non-competitive, and the gas end-user price is determined by such factors as gas source prices, government-controlled long-distance gas transmission tariffs and local government-controlled gas distribution fees and sale prices. Hence, compared to alternative energy sources, the competitiveness of the natural gas price is uncertain. Liquefied natural gas (LNG) pricing has been reformed and is market-oriented, but the price of LNG entering the pipeline network as peak-shaving gas remains unclear.
Due to the complicated network of interests associated with the price of electricity, the market-oriented reform of electricity pricing has been much discussed, but without reaching a conclusion. China's electricity price is currently considered both from the power generation side and from the demand side. China's current electricity price system covers mainly feed-in tariffs, transmission and distribution tariffs and the power sale price. On the generation side, different power generation companies set different feed-in tariffs in light of local conditions, and the NDRC sets the benchmark feed-in tariff. On the supply side, local government sets different prices according to the type of end user - a dual pricing system (including basic price and meter price) is generally applied to large industrial users, and a tiered electricity pricing system is applied to residential users.

Coal pricing has been market-oriented for a while. The double-track price system used for thermal coal pricing was ended along with priority contracts in 2013. The publication of the Guideline of the General Office of the State Council on Deepening the Market-Oriented Reform of Thermal Coal marked the official ending of the dual-track price system, which had been in place for more than 20 years. The NDRC no longer sets the annual framework for allocating rail transport capacity for cross-provincial coal to local governments.

\subsubsection{Analysis of Problems}

In general, the government still intervenes heavily in energy pricing in China, and there is insufficient guidance on end-user energy pricing. Energy prices reflect poorly market supply and demand and the attributes of each energy commodity. The current energy pricing system struggles to reflect the interactive relationship between production volume and price, and there is insufficient transparency in pricing. In addition, the energy tax and subsidy systems fail to provide useful guidance on energy production and consumption. 

(1) Transparency and timeliness in the oil
product pricing system

Despite the quasi-market-oriented nature of oil product pricing, the contradiction between operating a transparent pricing system and allowing for delayed price adjustments has not been solved. The risk-free arbitrage behaviour that this gap allows clearly generates instability in market supply, which in turn has an impact on the stability of the oil product market, especially when oil prices fluctuate wildly. A market-based oil product pricing mechanism will address these problems and allow the government to still intervene through tax and other means.

\section{(2) There is no market-oriented gas pricing mechanism; the price of gas does not reflect its actual value}

There is no market-oriented gas pricing mechanism, and the difference in gas price between regions is unjustified. In general, the price of gas does not properly reflect the attributes of natural gas as a commodity. Gas pricing reform can be completed independently, but it should be coordinated with pipeline network reform.

The price determined by netback pricing is unreasonable - it is obviously too high, and the ceiling city-gate gas price defined by current policies has become the de facto gas source price in each province. As research indicates, this price level is about $30 \%$ higher than the total cost of gas, so there is a great amount of profit built in. However, the high price squeezes the profit margin of downstream industries and discourages any significant increase in gas's share of total energy consumption.

Gas price adjustment policies are incomplete and the residential gas price is low. The gas price adjustment policies introduced in Beijing, Hebei and Shanghai in 2011 do not affect the residential gas price, allowing it to stay at a low level. This results in an underlying expectation among residents that low-cost gas will be available. In contrast, the price of industrial gas is higher than that of residential gas.
The gas pricing system is incomplete and distorted. There is no clear pricing mechanism and no administrative system that differentiates between peak and off-peak consumption, gas prices that allow supply cut-off at any time and tiered gas prices. There are no specific requirements on how to calculate cost and price or to determine who is responsible for supervision, which makes it difficult to set prices.

\section{(3) Electricity pricing is a major problem in energy pricing reform}

Electricity pricing reform is dependent on electricity system reform. Two main problems need to be addressed.

The first problem is the arbitrary pricing mechanism. On the grid connection side, the feed-in tariff is decided by the government. Without market competition, it is difficult to motivate power enterprises. On the power transmission and distribution side, power grid operators do not decide transmission and distribution tariffs; their revenue is generated by the difference between the power wholesale price and the feed-in tariff. On the sales side, wholesale prices do not reflect user demands and result in limited options for consumers. Cross-provincial power supply lacks a mechanism that can motivate both the supplier and the buyer. In general, electricity prices in China are decided by administrative bodies and do not reflect the real supply and demand relationship and production costs. A scientifically based pricing mechanism has yet to be established.

The second problem is the large cross-subsidies. On the grid connection side, the hydropower feed-in tariff is significantly higher than that for other types of power generation. On the wholesale side, the subsidies for different types of use overlap. For instance, urban areas subsidise rural areas, industrial and commercial users subsidise residential and agricultural users, users of high voltage subsidise users of low voltage, and consumers of large loads subsidise those of low loads. As a result, the electricity retail price does not reflect the true cost of power 
supply and fails to guide consumers to use electricity efficiently. The existence of cross-subsidies also hinders market-oriented reform in power generation and sales.

In addition, although coal pricing has become market-oriented, the price does not include externalities, so it needs to be adjusted through institutional reforms such as an environmental tax and resource tax.

\subsection{Energy Regulation System}

\subsubsection{Current Developments}

China's energy regulation system is not independent or sufficiently professional, and its supervision capabilities are inadequate to safeguard fair market operation. The organisational structure of China's energy regulation system is mostly situated at lower administrative levels, and the rights and liabilities it sets out are unclearly defined and decentralised. The system prioritises economic regulation. It bundles administration and regulation together, resulting in weak supervision and enforcement that require improvement.

\section{(1) Regulatory functions are decentralised and multi-level}

Generally, China's energy regulation system is: (i) decentralised across several authorities, with both a horizontal division of labour (regulating market access, investment, cost and price, etc.) and a vertical division of labour (regulating the value chain of the different energy sources); (ii) multi-level (including the State Council, central ministries and commissions, and local government); and (iii) features separate economic regulation and societal supervision.

Economic regulation of the energy sector is at a high administrative level, being mainly the responsibility of the central government. China's economic and social supervisory functions for oil and gas, coal, electricity and nuclear power are decentralised across various departments and authorities, whereas the economic regulatory functions for the energy value chain are mainly concentrated in central government. For example, the regulatory functions for market access, cost and pricing in the power sector are in the hands of different departments, including the NDRC, the Ministry of Finance and the NEA. A single economic regulatory function may involve different departments. For example, the supervision of electricity investment involves the NDRC, the NEA and local government bodies.

Significant regulatory functions are mainly undertaken by the NDRC and the NEA. As a macroeconomic management agency, the NDRC also coordinates China's economic and social development and the regulatory means to enact it. The establishment of the NEA in 2013 highlights how energy regulation has been strengthened. Its supervisory activities focus on "improving the energy regulation and administrative system, strengthening energy regulation and administration, controlling total energy consumption, developing the energy market and maintaining energy market order" (see Table 5).

\section{(2) Economic regulation has been prioritised and social supervision is gradually being improved}

The energy sector is a priority for government regulation, but China's energy regulation is still in the early stages of transition away from planned supervision and administration. Energy regulation prioritises economic regulation, while the social supervision of energy use remains relatively weak. Currently, economic and social supervision are separate.

In general, energy regulation in China means economic regulation. Economic regulation consists mainly of supervising market access, pricing, investment, costs and market trading conduct. These functions are mainly decentralised to departments like the NDRC and NEA. China has strict supervision of market access and investment, but the supervision of trading conduct is not very effective. Economic regulation takes place at a higher level, and (with the exception of coal) is typically implemented by central government. 
Table 5 China's energy regulation institutions and their responsibilities (2014)

Institution
NDRC
NEA
The Ministry of Water Resources
The Ministry of Finance
The State Administration of Work Safety (the State
Administration of Coal Mine Safety)
The State Administration of Science, Technology and
Industry for National Defence under the Ministry of
Industry and Information Technology
The National Nuclear Safety Administration under the
Ministry of Environmental Protection
The General Administration of Quality Supervision,
Inspection and Quarantine
The Ministry of Commerce

Institution

Responsibilities

Supervision of pricing and investment (access)

Technical standards, supervision of investment (access), market (order), electricity safety and universal service

Technical standards for hydropower in rural areas

Energy-related financial norms and accounting regulations

Supervision of energy-related (production) safety

Review and management of the import and export of nuclear materials, regulation of nuclear materials (circulation)

Supervision of environmental and nuclear safety

Quality standards and product standards

Criteria for oil product market access and supervision of the oil product market

Source Based on the Plan on Defining Functions, Internal Organisation and Staffing, and official websites

China is attaching increasing importance to social supervision in the energy sector. The supervisory functions for the environment, safety and health involve externalities and public goods, and tend to be centralised in departments or administrative institutions such as those for environmental protection and safety at work. Social supervision, however, tends to follow the guiding principles of local administration.

\section{(3) Administration and regulation have been bundled together, but regulation is weak}

China's institutional organisation of energy regulation generally bundles administration and regulation together. This reflects the relationship between energy regulation and other energy administrative functions. For example, supervision, planning, policy, regulation and public services are centralised in one department, like the NDRC or NEA. These departments are responsible not only for developing investment, operation and administrative policies in energy sectors like power, natural gas and coal, but also for supervising the implementation of these policies. Despite the relative independence of these organisations and the formation of some supervisory departments and bureaus, regulation is still weaker than other functions, such as planning and policy.

In the long term, however, especially as the energy pricing mechanism gradually improves, the separation of administration and regulation will continue. Regardless of which approach to administration and regulation is taken, bundled or separated, the following tasks need to be undertaken: increase energy regulation; gradually raise the access threshold to the energy market; improve technical standards, environmental requirements and safety standards; and improve the management of energy projects and the safety supervision of energy enterprises. In addition, the scope of energy regulation should be enlarged and the supervision of costs in sectors with a natural monopoly should be increased.

\section{(4) The energy regulation system has taken shape}

China's energy law and regulation system has taken shape. Energy-related laws, administrative regulations, departmental regulations, normative 
documents and mandatory standards and specifications form the legal basis for energy regulation, and they all play their part in modifying and regulating energy development.

The legal foundation of China's energy regulation system is spread across various energy laws and regulations, with some parts of the energy sector subject to several different energy laws and regulations. The laws that can be used as the basis for energy regulation include the Mineral Resources Law of the PRC, the Electric Power Law of the PRC, the Coal Industry Law of the PRC and the Energy Conservation Law of the PRC. There are also some provisions on energy regulation in other related laws, such as the Water Law of the PRC, the Environmental Protection Law of the PRC, the Law of the PRC on Prevention and Control of Radioactive Pollution and the Production Safety Law of the PRC. Beyond this, the departmental regulations passed by the State Council and by ministries and commissions serve as the basis for supervision of various energy sectors, for example the Regulation on Electric Power Supervision (2005) and the Regulation on the Emergency Response to and Investigation and Handling of Electric Power Safety Accidents (2011). The former State Electricity Regulatory Commission (SERC) introduced more than 60 regulations on supervision and more than 160 normative documents. Finally, the mandatory standards and specifications set the limits and procedures for key energy sectors, so they provide the most direct basis for supervision.

\subsubsection{Analysis of Problems}

In general, China's energy regulation lacks independence, is positioned at a low administrative level, needs higher standards of professionalism, and has difficulty carrying out the supervision needed of a modern energy market. As a result, there is not enough consistent and effective supervision in key energy sectors, especially in natural monopolies.

\section{(1) Supervisory agencies are positioned at a lower administrative level and they are not independent}

First, there is currently no independent high-level energy regulatory agency. An approach that bundles administration and regulation together has been in use for years. During this time there has been no independent, dedicated agency responsible for energy regulation. This lack of independence has severely restricted how energy regulation is carried out.

Second, the existing energy regulation agencies are at a lower administrative level. Among the major agencies that perform energy regulation, the NEA is at the department/bureau level and the NDRC is at the division level. Only the National Nuclear Safety Administration is relatively independent; it is a national agency administered by the Ministry of Environmental Protection on behalf of the central government. However, the special nature of nuclear safety supervision makes it different to most other types of energy regulation.

Third, there is no national agency that consistently carries out energy regulation. The decentralised nature of supervision has prevented the synergies from the energy regulation system as a whole being realised, so that often a situation arises where many parties have responsibility for something, but none of them delivers anything. When the NEA was formed in 2013 it was given the energy regulation function, but there are more than 10 national government departments involved in energy sector supervision for oil and gas, power, coal, nuclear power, renewable energy and others.

Fourth, when it comes to supervisory efficiency, the excessively decentralised regulatory function increases the difficulty of coordinating supervisory activities, which compromises efficiency to some extent. The contradictions and conflicts between various departments, and between central and local government, are 
unavoidable. To give one example, if the supervision of pricing, cost and quality was well coordinated it would help to deliver optimal results; but in reality pricing supervision is the responsibility of the NDRC, cost supervision is the responsibility of the Ministry of Finance and NEA, and the NEA is also responsible for supervising service quality and standards. This division of functions runs counter to a logical solution, which is to supervise pricing, cost and service quality together. The current administrative silos and the non-sharing of information undoubtedly affect the efficiency of supervision and the effective implementation of China's energy policies.

(2) Consistent and effective supervision is absent in key energy sectors, especially in upstream and the midstream

First, consistent and effective supervision is absent in key energy sectors. Thanks to independent, professional and consistent supervision, the former State Electricity Regulatory Commission (SERC) achieved good results in the supervision of electricity. In other key energy sectors, including oil, gas and coal, the decentralised, fragmented and inconsistent supervision available does not deliver a professional service, with knock-on effects in the various energy sectors.

Second, supervision is particularly inadequate in some key links of the energy value chain, such as in natural monopolies. For example, there is no effective supervision of dominant enterprises that might abuse their market rights in the oil, gas and power sectors.

Third, there is a large rift between energy regulation and environmental supervision. In the renewable energy sector, supervision of the resource and environmental problems caused by renewable energy development has yet to be introduced. And when it comes to social supervision of oil and gas exploration and development, the energy and environment supervision authorities do not play a significant role, with the result that action on these issues depends on the self-discipline of oil and gas companies.

\section{(3) An incomplete basis for supervision makes it difficult to meet the requirements of modern energy regulation}

There are many reasons for China's incomplete energy regulation system. Large gaps in legislation and delays in ratifying laws and regulations in key energy sectors make it difficult to meet modern energy regulation requirements.

First, the absence of significant energy laws and regulations has resulted in an incomplete regulatory system. The most important energy law is still awaited - the Energy Law of the PRC was prepared at the end of 2007, but the date of its release is still uncertain. In addition, there are no energy regulatory laws, so there is no high-level legal basis for defining energy regulation rights and liabilities. In addition, laws for some key energy sectors are missing. For example, the long-term absence of the Oil and Gas Law of the PRC and the Atomic Energy Law of the PRC has left gaps in energy consumption legislation.

Second, obsolete laws and delayed amendments have failed to meet the requirements of energy development and supervision. Based on obsolete legislative concepts, some energy laws, such as the Coal Industry Law of the PRC and the Electric Power Law of the PRC, are essentially traditional administrative regulations. Legislation in the oil and gas sector is emergency response-oriented, temporary and out of date. Moreover, the amendment of some energyrelated legislation is slow. A case in point is the amendment of the Mineral Resources Law of the PRC, which, due to theoretical disagreements and the involvement of other non-energy sectors, has still not been finalised after years of discussions.

Third, the absence of essential implementation and support regulations leads to poor operability. For example, oil and gas legislation, such as the Coal Industry Law of the PRC, suffers from unclear regulatory boundaries, unclear definition of rights and liabilities, and uncertainty regarding its scope and conditions. The lack of implementation and support regulations results in legislation that is ineffective and unsuited to practical implementation. 
(4) Inadequate and unprofessional government supervision

The NEA has built a dedicated supervisory department that aims to extend the successful experience gained in electricity supervision to other energy sectors, especially fossil fuels. The oil, gas and power sectors are strikingly different in terms of technical and economic characteristics and supervisory demands. China's oil and gas supervision is still in its infancy and the gap between it and the advanced supervision found elsewhere in the world is wider than in electricity supervision. Coal supervision, however, has Chinese characteristics, which make it hard to apply the experience and practices of electricity supervision to fossil energy.

In addition to the two dedicated supervisory departments of the NEA, the agency under the former SERC - that was merged into the NEA and positioned as a dedicated supervisory department - has found it difficult to address the supervisory requirements of multiple energy sources. Furthermore, China's energy regulation organisations suffer from inadequate funding and low-level equipment, technology and IT capability.

Finally, given non-existent social supervision, non-governmental organisations that try to fill the breach have no legal status within energy regulation, and it is difficult for them to obtain useful information and access the necessary communication channels.

\section{China's Energy System Transformation: Progress, Conflict and System Design}

\subsection{The Urgent Need for Energy System Transformation}

Energy supply pressure is mounting. Energy consumption in China has been increasing steadily. As a result of its continued economic momentum and the declining energy consumption of the major mature economies, China has overtaken the USA to become the largest energy consumer in the world. Energy supply in China, rich in coal but short of oil and gas, is limited, unable to meet growing demand. This has led to an expanding gap between supply and demand, which shows no sign of improvement. While striving to address its energy security, China is becoming more and more dependent on oil and gas imports. Meanwhile, the sources of these imports are relatively concentrated geographically and susceptible to global turbulence, increasing the risk to energy security. In the future, unsustainable energy supply will give rise to uncertainty in energy development, bringing about an energy security challenge that cannot be ignored.

China's energy product pricing mechanism is ineffective. Market signals do not accurately reflect the supply-demand relationship and resource scarcity, as well as externality costs such as environmental pollution. Energy pricing that is not market-led, including lower energy prices imposed by regulation, leads to excessive energy consumption and impedes the effective allocation of scarce resources. For a long time, China's economy has been dominated by energy-intensive secondary industries, which account for a large amount of the total energy consumed by industry. China's energy intensity is 1.55 times the global average (2016), significantly impairing the efficiency of the country's economic growth.

Massive energy consumption brings severe environmental pollution and environmental damage. The direct effects can be seen in the greenhouse gas emissions from unnecessary energy use that pollute the environment, damage biodiversity and impact the climate, as evidenced by the frequent occurrence of extreme weather, such as acid rain and haze. In a time of global decarbonisation, high pollutant emissions seriously impair China's image in the world and restrict its potential for exports, employment, revenues, investment and economic growth.

China's energy system needs to adapt to a new productivity trend. China has become the world's largest energy producer and consumer, with an energy system comprising coal, electricity, oil, gas, new energy and renewables, as well as 
significantly improved technical sophistication and energy use for living and production. However, a few factors, including inadequate market competition and pricing mechanisms, an outdated energy legislation system and inefficient regulation, have all restricted the growth of China's energy industry. It is imperative that the Chinese economy shifts from being resource/energy/ pollution-intensive to a healthier, innovationdriven mode of growth, and that it moves away from quantity and speed to quality.

Transformation of the energy system, as an instrumental part of the energy revolution, means pursuing goals in five different areas: energy availability guarantees, environmental pollution controls, economic restructuring, price shock absorption, and energy security.

First, energy system transformation can lead to improved energy availability. Energy underpins the development and security of a nation. Given an energy portfolio that features an abundance of coal and very little oil and gas, as well as insufficient use of nuclear, wind and solar power, a more streamlined energy system is vital to increase the use of new energy and provide long-term energy supply stability in China.

Second, energy system transformation alleviates environmental pressure on the energy industry. With energy consumption increasing, pollutant emissions from China's energy sector are becoming a critical challenge. Especially in recent years, climate change and the environmental impact of the energy sector have drawn much attention. In China, extreme weather, such as acid rain and haze, has become a major threat to people's health. Energy system transformation will, therefore, improve efficiency in the sector and promote clean and green initiatives, which will reduce the resource and environmental pressure on the sector.

Third, energy system transformation facilitates economic restructuring. China's extensive economic growth over the past three decades has resulted in a rigid energy consumption structure as well as waste and the inefficient use of energy sources. Given this context, energy transformation provides an effective path to optimise the economy: the efficient use of energy sources will promote economic restructuring and ensure sustained efficient operation of the economy.

Fourth, energy system transformation can alleviate the impact of energy prices on businesses and people. An efficient energy pricing system accurately reflects the supply-demand relationship and guides sensible production and consumption and promotes the efficient use of resources. If it is to succeed, energy system transformation must take into account resource scarcity, affordability, social fairness and sustainability.

Fifth, energy system transformation helps improve energy security. Against the backdrop of an increasingly complex global political and economic landscape, energy security is essential for the smooth operation of the Chinese economy, as well as for the sustained progress of Chinese society. Using market mechanisms, energy system transformation leverages pricing to balance energy supply and demand, ultimately contributing to national energy security.

\subsection{Status Quo and Major Conflicts in China's Energy System}

Since opening up, China has implemented a series of transformative initiatives in energy development and exploitation, market access, pricing, investment and financing, international trade, and administration. The time when only government invested in the energy sector has gradually changed. The old system of planning and administration, where demand was dependent on availability, has also changed, to cover supply and demand as well. There has been solid progress in transforming the energy pricing mechanism, and an energy market has taken initial shape. A few energy sectors are no longer under central control, and the institutional climate for energy development has improved, which plays an instrumental role in guaranteeing supplydemand balance and driving social and economic development. Specifically, reforms like price control removal, administration-enterprise unbundling and empowering enterprises to become market participants have revitalised the 
coal market, leading to a golden decade (200212) for coal. Initiatives such as restructuring the three national oil and gas companies in 1998, and loosening market access and price control have improved the oil and gas sectors and made China one of the 10 largest oil producers. The initiatives to set up two grid companies, five power generation groups and the China Power Regulatory Commission in 2002 have essentially broken the hold of the monopolies. As a result, issues that were common in the planning era (such as administration-enterprise bundling and gridgeneration conglomerates) have been resolved, allowing competition between multiple participants in the power generation market. All these initiatives have effectively released the potential for productivity improvements and given impetus to the development of China's energy industry.

Despite all this, it should be noted that, in the context of the global energy industry and in the drive to deepen reforms, the current energy regime does not satisfy the demands on energy production. Neither does it support the consumption revolution nor drive the development of the socialist market economy. Some deep conflicts and issues still need to be addressed urgently, as summarised below.

\subsubsection{A Modern Energy Market System Has yet to Take Shape}

Since opening up, China has shifted from a planned market economy to a socialist market economy and has carried out a series of institutional reforms in investment, taxation and pricing. Despite the reform initiatives in the energy industry, there are still several challenges to be addressed, including slow progress in some sectors, the unclear boundary between administration and business, government intervention in economic activities, unfair competition between market participants of different legal status, and the absence of consistent market access criteria. Other concerns include the government's control of coal and oil exploration and mining rights, imperfect administration, and poorly regulated market flow. An open, transparent and well-regulated energy market access system has yet to take shape. The coal, oil and power markets are highly fragmented: the system for assessing and approving new entrants is more like an administrative procedure, with approval more likely to be given to large state-owned enterprises, which poses higher barriers for privately owned and foreign companies. Energy production is still under government control, by means of power output and oil and gas production scheduling. Even now, more than three decades after opening up, it is thought-provoking to realise that sometimes a market participant can decide neither price nor production volumes. There are other administrative and regulatory challenges that need to be addressed: the imperfect energy market mechanism and taxation system; the financial and taxation policies that are poorly suited to encouraging the development of new and renewable energy; and the restricted range of incentives to support development of the energy industry, including subsidies, financial discounts and tax incentives. Also, in the context of global economic integration, China still needs to integrate itself properly with the global energy market and use its international influence to shape regional energy markets.

The organisational structure of the energy industry is still less than optimal, constraining effective competition in some critical areas. In general, there are major differences in industrial organisation between different types of energy (especially in energy supply), including market barriers to private capital, a lack of competition in some sectors and excessive competition in others, and even surplus capacity. In the oil and gas sector, the three leading national oil companies maintain obvious first-mover advantages in onshore oil and gas production and pipeline operation and management (CNPC), petrochemicals and oil products (Sinopec), and offshore oil and gas exploration and production (CNOOC), while each of them still demonstrates shortcomings in value chain integration. Effective competition is still required in some major areas to improve the overall efficiency of the industry. Another major concern is the increasingly obvious overcapacity in the refining segment.

In short, the energy system challenges that need to be addressed are: imperfect market 
system, monopoly in some segments, pipeline-operation bundling, dispatch-operation bundling and competition restrictions. Most energy companies in China are large state-owned enterprises, with few private investors, giving an unbalanced mix of market participants. The government still controls the licencing of coal, oil and gas exploration and mining rights, and the rules necessary to ensure consistent market access and fair market competition are still not in place. So, depending on their legal status, companies are not competing on the same level playing field. Grid operators still have holdings along the entire value chain of power transmission, distribution and sales, and a fair and well-regulated market competition mechanism has still not been put in place. Integrated operations encompassing exploration, development, refining, transmission, imports and sales have more or less been realised in the oil and gas industry, but the industry still does not allow diverse participants to compete in individual sections of the value chain. A spot and futures market for oil and gas products has not been established, and regional international energy markets are less and less influential in the wider world.

\subsubsection{The Energy Pricing Mechanism Is Still Imperfect}

The deregulation initiative has made slower progress and there is still no fair pricing mechanism - the price of oil products, gas and electricity is still decided by the government. The price structure is unjustified. The cost of infrastructure like pipelines is not systematically checked, and externality costs related to the environment have not been internalised. Price distortion remains: electricity and gas prices for residential use have been below cost for some time, and cross-subsidies abound. The energy taxation system is still imperfect, and the structure and levels of resource taxation are unreasonable. Other concerns to be addressed include: poorly aligned fiscal and taxation policies for coal, oil, gas and renewable energy; a restricted range of incentives to support development of the new energy industry, including subsidies, financial discounts and tax incentives; and incomplete pricing, fiscal and taxation systems that fail to reflect the supply-demand relationship in the energy products market, the scarcity of energy products, and their environmental impact.

The government still intervenes in the energy market and it is still impossible to deploy energy resources by means of price. In a market system, the most efficient information is the price signalprecise and flexible price signals can successfully adjust supply and demand, provide guidance for investment and optimise resource allocation. With the exception of coal, there is still no market-based pricing mechanism for other types of energy - grid and sales tariffs are still decided by the government, and the price for oil products is still not decided by market competition, though it has been aligned with the international market. Current energy prices in China do not reflect supply and demand, resource scarcity and environmental impact, or provide guidance for consumption, investment and resource allocation. Over the course of a decade of reform, the monopoly in the coal sector has been broken up to enable competition. However, state-owned enterprises still maintain their dominance in the oil and gas and power transmission and distribution sectors, and a diversified range of market participants has still not materialised. The enterprises active in these sectors are less motivated to improve productivity, and their resource allocation is inefficient.

\subsubsection{Government Administration Still Needs to Be Improved}

The relationship between government and the market still needs to be improved and the government needs to accelerate its transition to a different role. On the one hand, the government intervenes too much in the market and its administration is too specific, especially when it comes to project approval. The procedure for project approval is relatively complex and some of the initiatives to shift approval from upper- to lower-level government have failed to achieve the desired results. On the other hand, there has not been enough research on energy strategy, which is not clearly aligned with the goals of the 
Two Centenaries. ${ }^{13}$ Energy planning is less scientific, authoritative and actionable than it should be, and the alignment between different plans is poor. Project approval tends not to be aligned with implementation.

Even though reforms have been carried out in the energy industry, progress in some areas is slow. The boundary between administration and business is less clear than it should be, and the government intervenes too much in energy-related economic activities. Other concerns to be addressed include the impossibility of achieving fair competition between market participants of different legal status, the absence of consistent market access criteria, the over-representation of state-owned capital, and the lack of efficient market-led pricing mechanisms. In 2002 China replaced the examination and approval system with the verification system, with the aim of clarifying the obligations of the government and business, streamlining the process, and regulating investment. However, in the real world, the verification system looks very much like administrative approval, which, compared with practices in other developed countries still has several flaws. In addition, project verification is usually more favourable to large state-owned enterprises, while setting higher entry barriers for privately run businesses.

\subsubsection{Imperfect Regulation by Government}

The regulatory system for energy is still not independent, and the regulatory responsibilities for market entry, pricing, investment, costing and transaction management are spread across different authorities, including the development and reform commissions and the energy administrators. The regulatory function is still weak, and the regulation of oil, gas, coal, new energy and the Energy Internet is clearly inadequate. There

\footnotetext{
${ }^{13}$ The Two Centenaries mark the founding of the Communist Party of China (in 2021) and the People's Republic of China (in 2049). The goals are to build a moderately prosperous society in all respects by 2021 and transform China into a modern socialist country that is prosperous, strong, democratic, culturally advanced and harmonious by 2049 .
}

is no effective rules-based regulation of the market. Industry regulation of oil and gas pipeline safety, the transfer and assignment of mining rights, fair third-party access, scientific resource development, clean production and reasonable energy consumption is incomplete. In addition, the competence of professional regulators is poor. In particular, regulation of technical matters and of compliance with standards and specifications barely meets the needs of conventional and new energy, nor of the energy transition.

There is a lack of independent and professional regulators. The existing decentralised regulatory system, characterised by the integration of administration and regulation, fails to achieve the results expected, especially in market regulation.

The level of coordination and alignment between different regulatory departments is poor -regulatory goals, effectiveness and speed across different departments and between central and local government are inconsistent. Decentralisation results in some regulatory functions being absent or inadequate. Another concern is the focus on market access approval without attaching sufficient importance to post-access regulation. In other words, the government focuses its regulatory efforts on project identification and approval, not on regulating project execution and post-project delivery. In addition, the government addresses economic aspects, such as investment approval, product and service price, and production scale, but fails to regulate externalities like resource conservation, safety, the environment and quality. Other challenges include an inadequate legal foundation and a lack of strict and scientific energy regulatory standards.

Monopolies in midstream transmission are not clearly identified, and their regulation is inadequate, especially of power grids and gas pipelines. Grid operators monopolise power purchase and sale. The building of a regional power market has progressed slowly, power tariff reform is sluggish, and the separation of transmission and distribution and the bidding mechanism for grid connections have yet to be implemented. Gas transmission still awaits effective regulation and 
fair access is difficult. National oil companies still monopolise investment and construction of the pipeline network, while bundling and intra-company transactions continue in gas transmission, distribution and sales. In some regions there are still pipeline monopolies.

\subsubsection{Incomplete Legislative System}

China's energy legislation system is incomplete, as evidenced by the lack of a fundamental energy law, the delayed adoption and revision of other laws, and the incomplete scope and poor operability of the system. Provisions are spread across laws, administrative regulations, regional regulations and departmental rules, with varying degrees of enforcement. Due to the lack of consistent legislative guidelines and fundamental principles, the links between specific regulations at different administrative levels are absent. Some departments legislate regulations for the benefit of the department itself. Other notable concerns include an excessive reliance on administrative enforcement and inadequate punishment for infringements.

China is now confronted with severe resource and environmental constraints, pressure to reduce greenhouse gas emissions, and the challenges of maintaining energy security and driving the energy technology revolution. China's initiative to combat climate change requires that its carbon emissions peak around 2030. While energy consumption will still rise in the future, the abundant clean energy resources of hydro, wind and solar have not been exploited effectively. This suggests there is huge scope for adjustment in the energy system. The dependence of oil and gas on imports is $70 \%$ and $40 \%$ respectively, and China is the largest importer of oil and gas from the Middle East, making energy security a challenge. The development of emerging technologies like the Energy Internet will radically change the industry. This will force the government to change its regulatory and administrative practices, and drive innovation in industrial organisation and government administration, which in turn will set new demands on the energy revolution.

In brief, to solve the above issues and address emerging situations and challenges, it is necessary to transform China's energy system urgently. In this critical window, when international energy prices are low, China will waste no time in initiating its energy system revolution, based on the consensus of all stakeholders.

\subsection{System Design for China's Energy System Revolution (2030)}

\subsubsection{Guiding Ideas}

In the spirit of the 18th and 16th National Congress of the Communist Party of China in 2012 and 2002 respectively, China should embark on its energy system revolution with the goal of building an ecological civilisation. This should focus on accelerating energy transition in line with the development concepts of "Innovation, Coordination, Green, Openness and Sharing". The market should play a decisive role in resource allocation, while the government should carry out its administrative and regulatory roles better in order to break down the barriers to energy sustainability and shape a modern, open, complete and competitive energy system. Such a system will prioritise renewables and gas, ensure the well-coordinated development of centralised and distributed energy, soundly balance supply and demand, and improve energy efficiency, all for the benefit of the national economy, people's livelihoods and the environment.

\subsubsection{Fundamental Principles}

\section{(1) Market orientation}

Taking into account industry characteristics and laws, China will distinguish between areas of natural monopoly and areas of competition and give participants equal access to the market. Efforts will be channelled towards creating an 
"effective market + efficient administration", with the focus on building the market, enhancing market regulation, maintaining market order, ensuring fair competition, mobilising and motivating market participants and shaping a modern energy market system.

\section{(2) Access criteria}

While loosening the restrictions on market access, China will introduce substantive standards for safety, the environment and energy efficiency. China will also transform and modernise the energy mix to alleviate the harmful effects of energy production and consumption on the environment and release the benefits of reform as much as possible.

\section{(3) Energy security}

Given the fact that it is a large energy consumer and importer, China will maintain its energy security by integrating international and local markets, sharing international resources, competing globally and playing an active role in global energy governance.

\section{(4) Public benefits}

China will carry out its transformation of the energy system with a well-coordinated package of goals and with the aim of providing clear economic and social benefits-including providing the public with clean, affordable and high-quality energy and ensuring a reliable energy supply.

\subsubsection{Strategic Goals}

\section{(1) Market system perfection}

China will create an open and modern energy market system, underpinned by comprehensive legislation and orderly competition. A market competition landscape-where huge energy companies act as the backbone and a diversified mix of energy production, transmission and sales companies of different legal statuses and sizes coexist - will effectively address concerns about inequality among market participants, market segmentation and disorderly competition.

\section{(2) Pricing mechanism perfection}

Prices in competitive segments will be decided by the market. Prices in natural monopoly segments will largely be supervised and regulated by the government. Together, these will create a pricing mechanism and fiscal and taxation system that accurately reflect the supply-demand relationship, resource scarcity and environmental impact, and address concerns about unfair price policies and pricing mechanisms.

\section{(3) Government administration improvement}

The boundary between government and market will be clarified and an industry strategy, overall plan, regulations and standards, and high-level energy administration bodies for energy reserves and emergency response will be created. Following the tenet that "Things prohibited by laws cannot be done, things not prohibited by laws can be done, and duties enforced by laws must be performed" will address the challenges caused by the absence of unified and independent high-level energy administration bodies.

\section{(4) Effective market regulation}

Unified, independent and professional market regulators will be set up to form a modern energy regulatory system. The new system will have a clearly defined responsibility matrix, and will pursue fairness and equality, transparency and efficiency, and effective regulation, thereby addressing problems such as the bundling of administration and regulation, decentralised or missing regulatory functions and poorly enforced regulations.

\section{(5) Complete legislative system}

A complete, well-structured, well-aligned and unified system of energy law will be created, with associated regulations, standards and laws 
for power, coal, oil and gas. This will support national energy security and sustainability, and address existing problems, such as the lack of unified fundamental principles that underpin legislation, and the lack of coordination, consistency and cohesion in the current energy legal system.

\subsubsection{Strategic Priorities}

\section{(1) Creating a modern energy market system}

Natural monopoly segments will be separated from competition-based segments, and the market access mechanism will be improved to encourage diversified participants to invest in different segments of the energy industry in an orderly manner. Trading regimes for the energy market will be introduced or improved, and a modern hierarchical energy market system, including links between the national market and multiple regional markets, will be formed. Power system operators capable of performing dispatching and transactions independently will be established to separate the power transmission and distribution businesses. Oil and gas and coal exploration and mining rights will be acquirable only through bidding and market competition. Oil and gas pipeline operators will be encouraged to gain exclusive rights, pipeline transport services will be completely separated from sales, and fair third-party access to pipelines and other infrastructure will be allowed. Deployment of a global Energy Internet that connects everything and comprehensive energy service markets will be accelerated. An energy system that facilitates neutral peer-to-peer interconnection between centralised and distributed energy sources, as well as between energy storage and load devices, will be deployed.

\section{(2) Reshaping the energy market pricing mechanism}

A scientific pricing mechanism for monopoly segments will be created, combining constraints and incentives, and based on cost supervision and audits. By introducing scientific, transparent and consistent regulation, monopoly segments will be encouraged to undertake healthy and sustainable development and to reduce their costs. Prices in competition-based segments will be deregulated and shift to a market-led pricing mechanism. Performance-based, complete, independent and incentive-guided power transmission and distribution pricing systems will be created. Pricing reform in inter-provincial and local power transmission will be introduced. Studies will be conducted to determine the correct tariffs for regional distribution grids, and the formation of a complete power transmission and distribution regulatory system will be accelerated. Studies will be conducted on methods that can be used to publish power transmission and distribution fees and price information, as well as methods to determine and distribute voltagebased costs. The price of oil products and gas will be deregulated and determined by market competition. Apart from the gas distribution network, charging for the use of other oil and gas pipeline infrastructure will be decided by the market. Subsidy and assistance mechanisms will target people in need and industries serving the public good. Cross-subsidies will be eliminated and an energy price regulation regime will be perfected to establish a reasonable price ratio between different types of energy.

\section{(3) Creating an efficient energy administra- tion regime}

A central regulatory body for state-owned natural resources and the environment will be formed to oversee land use, environmental conservation and recovery, pollutant emissions and enforcement. Planning, policy, standards and incentives will be used to administer energy industry development in a holistic manner. The boundary between government and market will be clarified, and complete lists defining powers and duties will be created. Approved plans will be carried out effectively, approval criteria clearly defined, approval procedures streamlined and administrative approval powers revoked or delegated, all of which will reduce government intervention on specific issues. Renewable energy integration 
and curtailment will be thoroughly addressed, and inter-provincial transmission will be incorporated into the national strategy for long-term power transmission and use. Power generation will be completely deregulated and new energy generation in all regions will be guaranteed the sale of a minimum number of hours per year. Peak shaving and standby auxiliary service market mechanisms will be completed, motivating improvements to fossil power flexibility and the deployment of new peak shaving and energy storage facilities. Spot energy markets will be formed to benefit from the lower marginal cost of renewable energy.

\section{(4) Creating an effective energy regulation system}

China will separate administration from regulation, establishing independent and professional regulators, and building on the dual-level (central and regional) regulatory system. The responsibilities of regulators will be clearly defined, focusing on economic aspects, while regulation of the societal dimension will be enhanced to ensure fair competition in natural monopoly segments like pipeline infrastructure. Regulatory capacity and efficiency will be improved to maintain fairness in market competition.

\section{(5) Creating a modern energy legislation system}

China will adopt its Energy Law to provide a legal basis for the creation and revision of other energy-related laws and regulations. The Electric Power Law will be revised, the Oil and Gas Law will be researched and drafted, and the Coal Law will be improved, all of which will provide a legal basis for the creation, implementation, assessment, supervision and adjustment of power, coal, oil and gas strategies. The Energy Conservation Law and Renewable Energy Law will be implemented, while consistent regulatory, coordination, holistic decision-making and public consultation mechanisms will be formed or improved. Studies will be carried out on formulating the Energy Regulation Provisions, and energy regulatory rules, methods and procedures will be created.

\section{Reforming the Oil and Gas Sector}

\subsection{Progress in the Reform of China's Oil and Gas Sector}

The pace of market-oriented reform of China's oil and gas sector accelerated after the 18th National Congress of the Communist Party of China in 2012. A series of reform policies and measures covering upstream access, market-based pricing, pipeline network reform, market regulation, and management of crude oil imports and exports was introduced. The Central Committee of the Communist Party of China and the State Council unveiled the Opinions on Deepening the Reform of the Oil and Gas Industry in May 2017, which defines the direction, targets, methods and tasks of reform. The move to reform the oil and gas industries energised the market, enabling it to allocate oil and gas resources fairly and create a favourable policy environment for the sustainable and steady development of China's oil and gas industries.

\subsubsection{Pilot Mining Rights Reform of Upstream Resources Has Made Great Progress}

Due to the long-term monopoly in oil and gas exploration and production in China, mining rights are highly concentrated in several large state-owned oil and gas corporations, making it difficult for private capital to gain access to upstream resources. Because the mining rights transfer and exit system is defective, the mining rights market cannot operate efficiently, and barriers to trade are common, leading to low oil and gas exploration, poor exploitation efficiency and insufficient investment. To resolve these problems, the Chinese government has launched pilot oil and gas mining rights management reform programmes. 
Public tender was applied to shale gas blocks. Following the first round of public tenders to attract private investment to shale gas in 2011, the Ministry of Land and Resources initiated the second round in September 2012. The two rounds of public tendering involved 24 shale gas blocks, covering a total area of 20,002 square kilometres in Chongqing, Guizhou, Hubei, Hunan, Jiangxi, Zhejiang, Anhui and Henan. There were successful bids for 21 blocks. The bid winners include: large state-owned enterprises like China Huadian Corporation and China Shenhua Energy Company; energy groups invested in by local government, such as Chongqing Energy Investment Group and Tongren Energy Investment Group; and two private enterprises (Huaying Shanxi Energy Investment Company and Beijing Titan Source Natural Gas Resources Technology).

There were breakthroughs in mining rights reform in conventional oil and gas blocks. The Ministry of Land and Resources initiated public tenders for six conventional oil and gas blocks in Xinjiang in 2015. Thirteen enterprises submitted bids, including state-owned oil companies, local energy corporations and publicly traded petrochemical companies. At the end of 2017, the Ministry of Land and Resources commissioned the Xinjiang Land and Resources Trading Centre to list the mining rights for five oil and gas blocks in Xinjiang for public transfer. The transfer term was set at five years, two years longer than that specified in the 2015 tender. Private companies were also allowed to take part in this pilot reform of upstream oil and gas. The objective was to expand investment in oil and gas exploration and exploitation and diversify upstream investors. Awarding the blocks by public tender broke the state-owned oil companies' monopoly over upstream exploration and exploitation, helping the reform process to make substantial progress.

Competitive bidding was also used to transfer shale gas and coalbed methane exploration blocks. Guizhou and Shanxi provinces signed agreements with the Ministry of Land and
Resources to develop shale gas and coalbed methane resources. On the instructions of the Ministry of Land and Resources, the Guizhou Provincial Government auctioned the Zheng'an block, where Anye Well 1 is located, in August 2017 to accelerate the exploration and production of shale gas. Besides Guizhou, other provinces and regions also selected shale gas exploration blocks for transfer through competitive bidding. The Department of Land and Resources of Shanxi Province transferred the mining rights for 10 coalbed methane blocks (covering a total area of 2,043 square kilometres) through public bidding in November 2017 to seven local enterprises, including Shanxi Blue Flame Coalbed Methane Group. This was the first batch of coalbed methane transferred in China after the reform of the mining rights system. It motivated local governments and energised the market.

Many support policies have been introduced to deepen mining rights reform. The Reform Scheme of the Transfer System of Mining Rights and Plan for the Reform of the Mineral Resource Royalty System was adopted in December 2016. Its purpose was to promote the transfer of mining rights through competitive bidding, restrict the transfer of mining rights through private agreement and build a new mineral resources royalty system with Chinese characteristics. As stated in the 13th Five-Year Plan (2016-20) for Natural Gas, the transfer of exploration blocks through competitive bidding to eligible market participants in a fair and open manner would help create an exploration and production system dominated by large state-owned oil and gas enterprises, but which would also include private companies.

\subsubsection{Market-Oriented Pricing Reform is Progressing Rapidly}

In China, the natural gas price is administered at different levels. The city-gate price is administered by the price authorities under the National Development and Reform Commission (NDRC), and the sales price after the city-gate station is administered by local government pricing 
authorities. Gas price is composed of ex-plant price, city-gate price $^{14}$ and end-user price. ${ }^{15}$ Ex-plant price, trunk pipeline transmission tariff and city-gate benchmark price are set by the NDRC. The local pipeline gas distribution fee is set by the provincial government's pricing authorities, as is the urban end-user price.

Gas price deregulation in China has been making steady progress since the 18th National Congress of the Communist Party of China in 2012. Following the principle of "maintaining the administration of pipeline transmission tariffs in a natural monopoly and deregulating gas sources and prices", a complete price regulatory system covering the natural gas value chain from trans-provincial long-distance pipelines and provincial short-distance pipelines to city/town gas distribution pipelines has been established.

The non-residential gas price was fully reformed, step by step, through pilot implementation in selected regions. The three steps of gas price deregulation were completed during the 12th Five-Year Plan (2011-15). Pilots for gas pricing mechanism reform were first carried out in 2011 in Guangdong and Guangxi. Measures included shifting gas price management from factory to city-gate, capping the maximum price, changing the pricing method from cost-plus to netback, and building a dynamic adjustment mechanism linking gas price to the price of fuel oil, liquefied petroleum gas and other alternative energy sources. The new gas pricing mechanism, based on the knowledge gained from the two pilots in Guangdong and Guangxi, was introduced nationwide in 2013. The price of stock gas and incremental gas was adjusted separately. The price of incremental gas was first linked to the price of alternative energy. Then the price of stock gas was linked to the price of alternative energy in three steps. At the beginning of 2015, the price of stock gas and incremental gas was loosely tied to conditions in domestic and

\footnotetext{
$\overline{{ }^{14} \text { City-gate price }=\text { ex-plant }}$ price + pipeline transmission tariff.

${ }^{15}$ End-user price $=$ city-gate price + local pipeline gas distribution fee.
}

overseas markets. In this way, the non-residential gas price was fully reformed.

The residential gas price has been gradually adjusted. In order to take people's well-being into account, China used a dual pricing system for residential and non-residential city-gate gas prices. The residential city-gate price had not been adjusted since 2010, which meant that the average residential city-gate gas price was about $20 \%$ lower than the non-residential price. With changing domestic and international markets, deepening reform of non-residential gas prices and inconsistent pricing mechanisms for residential and non-residential gas, the gas price became increasingly difficult to manage and was a constraint on gas supply security. To address the residential and non-residential city-gate gas dual pricing system, the NDRC released the Circular on Adjusting Residential City-Gate Gas Price in May 2018. This changed the ceiling price administration system into a benchmark price administration system. It stated that the residential gas price should be linked to the non-residential city-gate gas benchmark price, and that the supplier and buyer should be allowed to negotiate a city-gate price that is no more than $120 \%$ of the base level (with no lower limit). Given the difference between residential and non-residential gas prices in some provinces, the national pricing authority allows them to reform residential gas price stepwise. The price increase in residential gas price may not exceed RMB 0.35 per cubic metre in 2018, and the remaining price difference should be adjusted a year later. At this point, residential and non-residential gas are linked by both the pricing mechanism and price level, and the price of gas in competitive parts of the value chain is decided by the market.

The price of shale gas, coalbed methane, coal-to-gas and other types of unconventional gas were deregulated and allowed to fluctuate in 2013, as was the price of liquefied natural gas in September 2014 and the price of gas supplied directly to users (except fertiliser companies) in April 2015. The price of gas used for chemical fertilisers, and the gas storage purchase, sale and service price were deregulated one by one in 
2016. A pilot reform of the city-gate price was also carried out in Fujian province.

After several years of reform, the marketisation of the residential gas price had clearly improved. Before the reform, the residential gas price was managed by the government. After the reform, the price of non-residential gas (which accounts for more than $80 \%$ of China's total gas consumption) was determined by the market, of which $50 \%$ was completely determined by the market. For the remaining $30 \%$, a flexible mechanism, whereby the price may be $20 \%$ higher than the maximum gate station price, was applied.

A price regulation system covering all nodes in the gas transmission and distribution networks was created by reforming the pipeline transmission pricing mechanism. To resolve the long-term absence in China of clear and sophisticated gas pipeline transmission pricing and supervisory and review mechanisms, the NDRC issued the Measures for the Administration of Natural Gas Pipeline Transport Prices (tentative) and the Measures for the Supervision and Review of Natural Gas Pipeline Transport Pricing Costs (tentative) in October 2016. These measures specify the scope and objectives of price regulation, the methods and procedures of price management, as well as some key indicators based on the principle of "allowable cost + reasonable profit". As a result, a new gas pipeline transmission pricing method has been established. The price no longer differs from one pipeline to another. Rather, it is assessed and then fixed, based on the cost of transmission (made public by the government) and the pricing formula. Pipeline transmission costs that are not part of the tariff are clear to all parties. This standardises pricing and provides clear and verifiable charging criteria for third parties wanting access to the transmission network.

Because the price regulation rules for gas distribution are not yet complete, the gas distribution price varies between regions, with some regions charging a higher price than others. The NDRC issued the Guiding Opinions on Strengthening Regulation of Gas Distribution in June 2017, which defines the methods for setting the gas distribution price. It also defines the key indicators and parameters and the requirements needed to improve regulation, build cost constraints and create motivation mechanisms, as well as requiring disclosure of business information. The Guiding Opinions established the price regulation framework for downstream urban gas distribution, thereby building a complete price regulation system covering all parts of the gas system, from transmission to distribution. In addition to alleviating the cost burden on users by lowering the high distribution price in some regions, the Guiding Opinions lays a solid foundation for the future separation of distribution and sales and the opening of the gas distribution network to third parties.

In the first half of 2017, the NDRC reviewed the pricing of 13 trans-provincial gas pipeline transmission companies. The pipeline transmission price had decreased by around $15 \%$ on average, saving businesses using downstream gas about RMB 10 billion. Shaanxi, Jiangsu, Zhejiang, Hebei, Yunnan and Jiangxi developed their own transmission and distribution price regulations, as required by central government, and reduced their pipeline transmission and gas distribution prices, cutting the cost for businesses by more than RMB 4 billion. Supervision and review of transmission and distribution prices enabled pipeline transmission companies to reduce costs and increase efficiency, benefitting gas users. Most importantly, the process opened the pipeline network and marketised gas trading. After the long-distance pipeline transmission price had been reviewed and fixed, two pipeline transmission companies immediately opened their pipelines to third parties.

\subsubsection{Access to Infrastructure Was Further Deregulated}

Systemic shortcomings severely impede the efficient use of infrastructure and fair competition among market participants. To resolve these problems, the NDRC and the NEA issued the Measures for the Administration of Natural Gas Infrastructure Construction and Operation and the Measures for the Supervision and Administration of the Fair Opening of Oil and Gas 
Pipeline Network Facilities (tentative) in April 2014. The measures state that: "the state shall encourage and support various kinds of capital to participate in the investment and construction of natural gas infrastructure included in integrated planning"; "third parties shall be allowed to use gas infrastructure, including liquefied natural gas (LNG) terminals"; "oil and gas pipeline network operators shall, in the case of spare network capacity, share their pipeline network facilities equally with third-party market participants and provide transport, storage, gasification, liquefaction, compression and other services"; and "oil and gas pipeline network facility operators shall use facility capacity to the full, ensure services are maintained for existing users, and provide access to the facilities for new users in a fair and non-discriminatory manner". After these measures were declared, some oil companies provided third parties with access to their LNG terminals. For example, CNPC provided Beijing Gas Group with access to its Dalian and Tangshan LNG terminals and the YongqingTangshan-Qinhuangdao pipeline, thereby providing unloading, storage, gasification and transmission services for imported LNG (450 million cubic metres of gas was transmitted in 2016). CNPC's Caofeidian terminal received 15,000 tonnes of LNG imported by China Gas from Nigeria. Sinopec transmitted 210 million cubic metres of natural gas for Kunlun Gas, China Gas, China Resources Gas and Shanxi Guohua Energy. CNOOC transmitted 54 million cubic metres of natural gas in its Guangdong gas pipelines for China Resources Jiangmen and ENN Dongguan.

To improve the supervision and regulation of fair access to oil and gas pipeline facilities and to provide information that could form the basis for fair access, the NEA issued the Notice on Information Disclosure of Access to Oil and Gas Pipeline Facilities in September 2016. The notice specifies the parties required to disclose information, the information to be disclosed, the methods of disclosure and the arrangements for supervision and regulation. CNOOC, Sinopec and CNPC published on their websites the information required on all their infrastructure, including long-distance pipelines and LNG terminals. Some provinces, including Shanxi, also disclosed information on their pipelines to the public. After three years, gas infrastructure information was transparent, providing the basis for fair access to, and supervision and regulation of, the facilities.

\subsubsection{Reform of the Right to Import Crude Oil and the Right to Use It}

Crude oil is imported to China by state-owned and non-state-owned trading companies. Permits for state-owned trading companies are issued by the State Council. Those companies with permits include Sinopec, CNPC, CNOOC and Sinochem. Import volumes are not limited. Non-state-owned trading companies are managed by quota. Their import volumes are capped. Permits and import volumes are managed by the Ministry of Commerce. Crude oil imported by non-state-owned trading companies can enter approved refineries only. There were more than 20 non-stateoperated trading companies before 2012, importing around $10 \%$ of China's total imported crude oil. China began to deregulate crude oil import rights in 2012, granting them to state-owned enterprises like China National Chemical Corporation, and in 2014 to private companies like Xingjiang Guanghui Petroleum.

China began to speed up reform in 2015, by extending the right to import and use crude oil to approved Chinese refineries. The NDRC issued the Notice on Issues Concerning Use Management of Imported Crude Oil in February 2015. This allows crude oil processing companies that meet energy consumption, quality, environmental and safety conditions to use imported crude oil, on condition that they shut down outdated capacity or construct gas storage facilities of a certain size. The notice marks the point when crude oil import rights were officially opened up and the eradication of oil and gas monopolies began to gain pace. In 2018, 32 local refineries (excluding those operated by Sinochem) were granted permits to import more than 90 million tonnes of crude oil. The Ministry of Commerce issued the Circular on the Application by Crude 
Oil Processing Enterprises for Non-State-Owned Trading and Import Qualification in July 2015. The circular allows non-state companies approved to import, export and refine oil products - and which meet energy consumption, quality, environmental, safety and storage conditions - to apply for approval to import crude oil. Up to August 2016, 16 companies had obtained the right to import crude oil, importing 62.57 million tonnes in total.

Further deregulation adjusted the original oil import-export management system and laid an institutional foundation for the formation of a transparent and open oil refining market featuring orderly competition and diversified market participants. The move brought new opportunities to small and medium-sized oil companies in trade, financing and logistics. The utilisation rate of private refineries was improved significantly. Statistics show that average capacity utilisation of Shandong's refineries increased from $41.2 \%$ in June 2015 to $60 \%$ in the first half of 2017 .

\subsubsection{Oil and Gas Exchanges Were Steadily Established}

The introduction of natural gas exchanges is an important means to reform the natural gas pricing mechanism and strengthen China's voice in international natural gas pricing. The role of natural gas exchanges is repeatedly mentioned in government documents, such as the 13th Five-Year Plan (2016-20) for Natural Gas, the Notice on Clarifying the Price Policies for Gas Storage Facilities, the Notice on the Policies Regarding City-Gate Station Price in Fujian Province and the Notice on Promoting Deregulation of the Price of Gas Used for Chemical Fertiliser Production. Gas suppliers and users are encouraged to participate in oil and gas exchanges and other platforms to establish a transparent gas price through trading.

The Chinese government accelerated the introduction of natural gas markets, successfully building two trading platforms, one in Shanghai and the other in Chongqing. The Shanghai Petroleum \& Gas Exchange, founded in December 2014, was put into trial operation in July 2015 and official operation in November 2016.
Unilateral gas trading volume exceeded 6.5 billion cubic metres in 2015 and 15 billion cubic metres in 2016, accounting for around 8\% of total gas consumption in China. The volume was expected to exceed 50 billion cubic metres in 2017. LNG bidding for 12 coastal provinces and cities is now conducted through the Shanghai Petroleum \& Gas Exchange, and 174,800 tonnes of LNG have been traded in total. The price reached by bidding fully reflects local LNG supply and demand. The Shanghai Petroleum \& Gas Exchange carried out the first round of bidding for pipeline gas in September 2017. The exchange plays an important role in aligning supply with demand and establishing a reasonable price. With its influence growing, the Shanghai Petroleum \& Gas Exchange attracts wide attention in and outside China.

Chongqing Petroleum and Gas Exchange was unveiled in January 2017 and put into trial operation in April 2018. Some provinces and cities, including Xinjiang, Zhongwei, Shenzhen and Hubei, are actively researching the formation of regional natural gas exchanges.

Natural gas exchanges are important outcomes of oil and gas price deregulation. They provide influential support for the deepening of reform. Though their size is not yet large, their role of allocating resources in a market-oriented and optimal fashion and in providing equal competition opportunities to downstream users is now widely recognised.

China has created an oil futures market. Despite China's position as the world's largest crude oil importer, the second largest oil consumer and the fourth largest oil producer, China has inadequate influence in the crude oil market, and suffers from the Asian premium of paying more for crude oil from the Middle East than European or US refiners. The development of oil futures provides a method of price discovery and drives the reform of China's oil products pricing system. It can also help eliminate the Asian premium, hedge against oil finance risks and promote RMB internationalisation. Crude oil futures were officially listed on the Shanghai International Energy Exchange (INE), a unit of the Shanghai Futures Exchange, in March 2018. 
It is the first futures market on the Chinese mainland open to outside investors.

\subsection{Major Problems in the Existing Oil and Gas System and Mechanisms}

Following the intensive introduction and implementation of reform policies and measures after the 18th National Congress of the Communist Party of China in 2012, China's oil and gas market-oriented reform made great progress. Measures include improving the oil and gas pricing mechanism, marketising the allocation of oil and gas resources, enhancing oil and gas supply capacity, and improving oil and gas resource use. However, there are still some underlying institutional problems in the oil and gas sector that urgently need to be addressed.

\subsubsection{Unsound Market System and Inadequate Market Competition}

First, the administrative monopoly is strong in exploration and production, restricting the extent to which oil and gas production capacity can be improved. Oil and gas exploration and production is a monopoly in China. According to the Administrative Measures for Registration of Mineral Resources Prospecting Blocks and the Administrative Measures for Registration of Mineral Resources Exploitation issued by the State Council in 1998, the companies engaged in exploration and exploitation of oil and gas resources are subject to mandatory approval by the State Council. So far CNPC, Sinopec, $\mathrm{CNOOC}$ and Yanchang Petroleum have been approved. Oil and gas mining rights need to be registered, which has been a long-term policy. The mining rights of the four companies cover all favourable blocks. At present, China's registered oil and gas exploration rights cover 4 million square kilometres of land, of which 3.9 million square kilometres belong to CNPC, Sinopec and CNOOC. Registered oil and gas exploitation rights cover about 118,000 square kilometres of land, of which 117,000 square kilometres $(99 \%$ of all registered exploitation rights) are owned by CNPC, Sinopec and CNOOC. In recent years, China began to explore the transfer of mining rights through competitive bidding for shale gas and coalbed methane exploration blocks and carried out pilot public bidding for conventional oil and gas blocks in Xinjiang. However, oil and gas mining rights are still highly concentrated in a few large state-owned oil and gas companies, leading to limited market competition, a low degree of marketisation and inefficient operation. Since the procedures for transfer and exit from oil and gas mining rights are not mature, and since supervision and follow-up measures are absent, it is difficult for private capital to enter the market. A diversified upstream market based on orderly competition has yet to be formed. As a result, there is insufficient investment in oil and gas resource exploration and exploitation and the potential for increased output and lower costs is restricted. Furthermore, enclosed gas blocks are not exploited. This prevents blocks of potential resources from being fully exploited.

Second, the lack of diversity in infrastructure investors and insufficiently deregulated investment access result in infrastructure construction lagging behind market development. In China, trunk gas pipelines and branch pipelines are mainly invested in and built by CNPC, Sinopec and CNOOC. Regional branch pipelines are mainly invested in and built by CNPC, Sinopec, CNOOC and local capital. CNPC's gas pipelines account for more than $70 \%$ of total gas pipeline investment. Because of this lack of diversity in pipeline investors, China's gas pipeline construction does not match demand. During the 12th Five-Year Plan (2011-15), China constructed about 25,800 kilometres of trunk and feeder gas pipelines, accounting for only $58.5 \%$ of the planned $44,000 \mathrm{~km}$ target. Although pipeline investment and construction are not so far behind that they hinder gas supply, it is still difficult for private natural gas companies to enter the market, due to constraints like insufficiently deregulated investment access and long project approval processes. As a result, it is hard to unlock the huge potential in gas pipeline investment and construction-the quantity and 
speed of pipeline construction does not meet demand, and the efficiency and economic benefits of pipeline investment and construction need to be improved. Some provinces with their own pipeline companies want gas pipelines to be built and operated by these companies in a centralised manner, excluding other companies from investing in and constructing gas pipelines in their province. In other provinces that do not have such policies, the monopoly policy is exercised during project approval. Gas storage facilities also lack diversity. The country's 12 gas storage facilities are owned by CNPC and Sinopec. Six private gas companies have jointly constructed one town gas storage facility, but it is yet to be provided with working gas.

Third, gas infrastructure is highly integrated, which hinders downstream market development. China's gas sector has not yet separated transmission from distribution and sales. As a result, the highly integrated upstream, midstream and downstream monopoly business model dominates. For example, about $98 \%$ of upstream gas is supplied by CNPC, Sinopec and CNOOC. These three companies have built about $95 \%$ of trunk oil and gas pipelines and account for $90 \%$ of the receiving capacity at China's 17 liquefied natural gas (LNG) terminals. They are also the principal actors in gas production, purchase and sales. As pipeline construction and investment needs to have gas sources and a market, the upstream monopoly creates a barrier for pipeline investment that prevents other participants from entering the field. In addition, the upstream monopoly restricts direct gas purchase transactions with large users and hinders growth in imported gas, which has a negative impact on the development of the downstream natural gas market.

Fourth, most of China's trunk gas pipelines are owned by CNPC, Sinopec and CNOOC, but they are poorly interconnected. And most provincial pipelines were built jointly by provincial state-owned enterprises and the three oil and gas titans. Typically controlled by provincial state-owned companies, the provincial pipelines are not interconnected with national trunk pipelines. Access to pipelines and fair services is difficult for newcomers, even for state-owned enterprises supervised and managed by central government. Why? Under the vertically integrated model of operation, pipelines help large oil and gas companies integrate exploration with imports and sales. Large oil and gas companies with upstream resources do not want to lose the lucrative midstream pipeline transmission market and be restricted in their sales activities. There is not enough pressure on them to open pipeline infrastructure to others. Also, large oil and gas companies view LNG terminals as gas supply points, rather than public infrastructure. There is, therefore, a conflict of interest between maintaining the price of gas high over the long term, providing third-party access to infrastructure, and performing the duty of ensuring supply. The existing oil and gas system can meet the demands of market-oriented reform, but it has become a bottleneck impeding the rapid, healthy and sustainable development of the natural gas industry.

\subsubsection{The Market's Ability to Determine Price Is Insufficient}

First, market-oriented pricing has not been implemented in competition-based sectors. The price of most oil products and natural gas is currently set by the government, rather than by the market. Since the conflict between the transparency of the oil products pricing mechanism and the hysteresis of price adjustments has not been resolved, the oil product price mechanism cannot fully reflect supply and demand in China, or the scarcity of resources or environmental impact. As a result, it cannot effectively stimulate or restrain the efficient development and reasonable consumption of oil and gas resources. As for the natural gas pricing mechanism, the current city-gate price is a benchmark price set by government, including ex-plant price (imported gas price) and the pipeline transmission tariff. This pricing model, with its two links, impedes third-party access to pipeline facilities. Although the Circular on Adjusting the Residential City-Gate Gas Price of May 2018 stated that China would gradually unify the residential 
and non-residential city-gate gas prices to eliminate cross-subsidies, the residential gas price is still lower than the cost of gas supply. Furthermore, cross-subsidies have still not been completely eradicated. In some regions, price adjustment lags behind the city-gate price, so changes in the upstream market are not reflected in price in a timely fashion.

Second, the gas price system needs to be improved. On the supply side, the construction of gas storage in China has lagged far behind market development for some time. This is due to the high investment cost of underground gas storage, a shortage of options for recovering investment in cushion gas, the absence of a peak-shaving gas price, and the failure to establish a market-oriented pricing mechanism for gas storage services and peak-shaving gas capacity. As indicated in the Report on the Oil and Gas Industry in and Outside China 2017, up to the end of 2017, China had constructed 12 gas storage facilities (clusters), the peak-shaving capacity of which stood at 10 billion cubic metres. The working gas capacity of 8 billion cubic metres accounted for $3.4 \%$ of China's gas consumption that year, much lower than the global average of $12 \%$. In developed countries, the working capacity of gas storage accounts for $20-30 \%$ of their total gas consumption. The severe shortage of gas storage peak-shaving capacity was an important cause of the national gas shortage at the end of 2017. On the demand side, the absence of interruptible and peak and off-peak gas prices dampens the motivation to expand the interruptible user base.

Third, natural gas exchanges help push market reform of the gas pricing mechanism and restore the commodity attributes of gas. Although the Shanghai Petroleum \& Gas Exchange has started operations and the Chongqing Oil and Gas Exchange will start soon, China's natural gas exchanges are still in their infancy. Spot trading has begun with small quantities, but futures trading has yet to start. The gas trading volume of the Shanghai Petroleum \& Gas Exchange exceeded 15 billion cubic metres in 2017, about $6.3 \%$ of China's total gas consumption. There is a large gap between China and the USA and
Europe. Only a small volume of gas is traded via competitive bidding. At the Shanghai Petroleum \& Gas Exchange, pipeline gas is traded mainly by reference to the provincial city-gate price set by the NDRC. Competitive bidding is limited to low-volume LNG trading. Deals are mainly concluded by negotiation, with trading models still being explored. The services offered by the exchanges need to be diversified and the trading system needs to be improved. The following challenges remain: gas pricing policy factors that restrict trading, the absence of a competitive upstream market, and pipeline networks and infrastructure that do not provide fair access to third parties. This means that the natural gas exchanges can only trade in volume; they cannot determine benchmark prices. As such, it is difficult for them to replace government-set benchmark prices in the short term.

\subsubsection{Poor Government Administration and Supervision}

China has made great progress in reforming oil and gas management, but administration and supervision still need to be improved.

As regards resource development and use, oil and gas supply security and environmental protection, too much attention is paid to reviewing and managing market access qualifications, and not enough to overseeing project implementation and effects. Public services for information management and modernisation technologies are not in place. Important information is sometimes not disclosed in advance or on time. The government intervenes too much in the market. Government management is too low-level and specific, such as focusing on investment approval, price setting and output control. The power, duties and interests of central and local government are not balanced. The central government has strong power and limited duties, and local government has little power and unlimited duties, leading to inefficient administration and poor outcomes.

Oil and gas strategies have been missing for a long time. Industry plans and arrangements (major projects), policies, standards and specifications, and laws and regulations are not aligned 
and harmonious, so synergies cannot be created. For example, the positioning of natural gas development strategies is not clear, and the scepticism about the cleanness of natural gas needs to be addressed. Plans for the oil and gas sector, limited to seeking advice, are not harmonious with other plans, such as those for land, the sea and natural reserves. Key content is not well aligned. In addition, national oil and gas pipeline construction plans do not incorporate local government plans for land and urban and rural development, making coordination during implementation difficult. And industry associations do not play their roles to the required extent.

The regulatory system is incomplete. First, the functions and duties of oil and gas authorities are decentralised. The policy goals of central and local government departments are different and their work rate is not aligned, making coordination difficult. Second, regulatory activities do not have a clear interface. Their efficiency is poor and their effects are weak. The absence of relevant laws and regulations means that there is insufficient basis for effective problem solving. For instance, China has not yet developed an energy law, an oil and gas law or natural gas law, and the policies related to opening pipeline networks and gas infrastructure to third parties are issued by ministries or commissions in the form of circulars or measures. Third, there is not enough diversification in the regulators and the means of regulation, making it difficult to implement reforms that call for "administrative streamlining, delegation of powers and service optimisation". Government regulators rely mainly on standard administrative methods and peer-to-peer supervision and review.

\subsection{Objectives of Oil and Gas Industry Reform}

\subsubsection{The Idea Behind the Reform}

Reform of China's oil and gas industry is guided by Xi Jinping's Thoughts on Socialism with Chinese Characteristics for a New Era, the 19th National Congress of the Communist Party of
China in 2017, the 2nd and 3rd Plenary Sessions of the 19th Central Committee of the Communist Party of China in 2017, and the development concepts of "Innovation, Coordination, Green, Openness and Sharing". The reforms should be implemented across the whole oil and gas value chain in an orderly manner, with the focus on supply-side structural reform, including exploration and production, pipeline transmission, circulation, refining and chemicals, enterprise reform, government regulation, and the enactment, amendment and abolition of oil and gas regulations. The relationship between the market and government should be clarified to enable the market to play a decisive role in resource allocation and the government to play a more efficient role.

\subsubsection{Basic Principles}

The market's decisive role in resource allocation should be given full play. Industry characteristics and the laws of market development should be followed. Barriers to entry and monopolies in the oil and gas industry should be eliminated to enable eligible market participants to enter competition-based sectors. This will improve competition and efficiency, energise the market and raise oil and gas supply capacity. In addition, government should play a more efficient role in macroeconomic regulation, market supervision and regulation, and service provision.

Oil and gas is an integral part of the nation's economy. Reform of the oil and gas sector has a direct impact on economic development, resource security and environmental safety, people's livelihoods and social stability. Its positive and adverse impacts on the social economy should be fully considered. Industry characteristics and the laws of the market economy should be followed to reform upstream, midstream and downstream in an orderly and problem-oriented manner. An overall reform plan that clearly defines the direction and goals of reform should be developed, targeting breakthroughs at key points of the plan and implementing pilot projects to gain experience and test solutions.

China is a large oil and gas producer and consumer. Ensuring national energy security 
under open conditions should be the first objective. Domestic and international markets and resources should be planned in a holistic manner. The survey, assessment and exploration of domestic oil and gas resources should be strengthened, and the resources developed in an orderly and cost-effective way to improve China's domestic supply capacity. China should also actively develop overseas resources to diversify imported oil and gas supply, thus lowering risk and enhancing supply security.

Different targets and interests should be acknowledged. Economic returns and social benefits should be combined organically. Public interest should be better protected. Oil and gas supply capacity and quality should be improved to make high-quality, clean and affordable oil and gas resources widely available to the public.

\subsubsection{Objectives of Reform}

Market-oriented reform of the oil and gas value chains should be accelerated, as required by the Central Committee of the Communist Party of China and the State Council in the Opinions on Deepening the Reform of the Oil and Gas System. This will be achieved by capitalising on the strategic opportunity to deepen reform of the oil and gas sector, thanks to the abundant supply resources available in the international oil and gas market and low oil and gas prices. The goal is to build a modern oil and gas market that has been opened up in an orderly fashion, featuring fair competition, effective regulation and governed by laws. By 2030 the market will play a decisive role in allocating oil and gas resources and government will play a more efficient role. Oil and gas supply capacity and efficiency of use should be improved rapidly, and the substitution of energy types should be realised as soon as possible. In this way, economical oil and gas resources will be available to people, and the strategic objectives of energy production and consumption will have been achieved.

More effort should be channelled into restoring the commodity attributes of oil and gas to allow prices to be determined by supply and demand. Government focus will shift, from intervening in operations and setting prices for oil and gas producers to developing strategies, plans, policies and rules to create a fair market. Government should strengthen its regulations on market access, transactions, monopolised segments, pricing and costs. It should also improve the standards, rules and procedures of the regulatory process to create a standardised, orderly, open and transparent supervisory and regulatory system.

Oil and gas supply capacity and energy efficiency will be improved. Reform of the whole value chain should be deepened to make the competition-based segments of oil and gas companies more dynamic. Technical innovation should be pushed to reduce production costs and improve supply capacity. Other targets include: using domestic as well as overseas resources; mitigating market risk; improving transmission and service; improving oil and gas use efficiency; ensuring strategic oil and gas security; and operating safely and cleanly along the whole value chain.

The substitution of energy types should be achieved as soon as possible. Petroleum consumption should be guided. The proportion of natural gas should be increased significantly to develop natural gas into one of the main energy sources as soon as possible, thereby achieving the strategic objectives of energy production and consumption.

\subsubsection{Pathways to Reform in the Oil and Gas Sector}

To achieve the above objectives, oil and gas sector reform should be as follows.

(1) Reform the oil and gas mining rights management system and establish a mining rights market

Reform of the oil and gas mining rights management system should "be market-oriented, diversify investors in an orderly manner, strengthen supervision and regulation, and improve the tax and fee system".

To ensure orderly, stable, efficient and green exploration and production and the efficient allocation and use of oil and gas resources, 
management of mining rights should be performed at a high administrative level. China can use the lessons learned from the trial implementation of the competitive transfer model for shale gas and coalbed methane (CBM) exploration blocks in provinces like Guizhou and Shanxi. These were jointly sponsored by the provincial government concerned and the relevant ministry. Provinces should be selected to delegate shale gas and CBM mining rights to local government, thus motivating local government to drive the exploration and development of shale gas and CBM resources throughout the country. To eliminate the uneven distribution of tax revenues between central and local government, the mechanism by which oil and gas benefits are shared by government needs to be improved to ensure that resource development benefits local people.

The Mining Rights Transfer System Reform Plan issued by the State Council in 2017 clearly states that China's mining rights (including oil and gas exploration and exploitation) will shift from agreements to public auction. The plan requires that all mining rights transfers are made through listing and that agreement-based transfers will be restricted. The price of mining rights transfers will be determined by the market. This competitive transfer approach will be fully implemented in China's oil and gas exploration blocks. It is suggested that the relevant authorities develop support policies for the national mineral resources royalty system as soon as possible, and that differentiated benchmarks be set for onshore and offshore oil and gas exploration blocks and unconventional oil and gas resources.

The experience gleaned from the pilot auction of exploration rights for the first and second batches of conventional oil and gas blocks in Xinjiang should be extended to other provinces. Companies registered in the People's Republic of China that have a Chinese entity as their controlling shareholder, have sufficient financial resources and a sound financial and accounting system, and can independently bear legal liabilities, are allowed to hold oil and gas mining rights, thus breaking the upstream monopoly.
However, bid winners should be selected on their financial and technical strength, rather than on the level of investment committed, to ensure that blocks are transferred to companies that are truly interested in oil and gas and to avoid the need for passive supervision later. The lessons learned from the auction of shale gas and oil and gas exploration rights in Xinjiang, as well as the pilot reform of CBM mining rights in Shanxi, should be studied. Small and medium-sized enterprises with different ownership systems should be allowed to exploit the abundant oil and gas reserves owned by CNPC, Sinopec and CNOOC that have not been used and for which there is no development plan in the short term. Non-public enterprises and capital, as well as companies with superior technical strength, are encouraged to form joint ventures and bid for oil and gas mining rights. Finally, an exploration and exploitation system involving diverse participants should be created through mining rights reform, enabling the market to determine resource allocation.

The lowest limit of investment for oil and gas exploration blocks should be set at different levels in different regions for different mineral varieties and for different phases of exploration. Given the low cost of ownership of exploration rights, and to encourage more companies to exit from idle blocks and attract other investors into exploration, the upper limit of exploration investment should be raised for the first and second years and lifted completely for the third year. However, the upper limit of exploration investment and exploration royalties for difficult and high-risk blocks could be reduced. For example, exploration and exploitation of unconventional oil and gas resources are far more difficult than for conventional resources. A lower exploration investment threshold and exploration royalty should be applied to unconventional oil and gas blocks based on geological conditions and/or difficulty and the time required for exploration. The cost of owning oil and gas block mining rights and the amount to be paid to central government in the form of royalties should be set at a suitable level. Mining rights should be rationalised and the tax and fee system reformed. 
Block circulation includes the transfer of exited and existing blocks and circulation between businesses. First, measures to restrict block exit should be developed to improve the exit mechanism, including: (i) economic means to raise the charges for holding exploration rights; and (ii) administrative means to force mandatory exit of a proportion of the same basin whenever an exploration right is extended. It is suggested that differentiation be applied according to the difficulty of exploring in different regions. For example, the lower limit of exploration rights investment for the Tarim and Sichuan Basins, which have complex geological conditions and a long drilling period, should be different from other basins or regions. The years in which such blocks are under assessment should be extended appropriately. Second, the measures to administer transfer of existing blocks should be improved. Such measures exist already, but there are no relevant assessment agencies or detailed rules of implementation and no precedent for oil and gas block transfer. It is suggested that rules on the paid use of reserves and valuation methods that are fair, reasonable and consistent with international practice should be studied and developed, and that world-class reserve assessment agencies should be cultivated to create conditions for mining rights circulation and reserves trading. Third, circulation of existing blocks should be accelerated. After analysing successful circulation cases, such as that of Daqing Oil Field entering the Tadong Block, the four major oil and gas companies (Sinopec, CNPC, CNOOC and Sinochem) should be allowed to transfer blocks and trade reserves among themselves using market-oriented approaches to revitalise mining rights resources.

To encourage businesses to exit idle blocks and make room for other investors, the initial investment of those exiting businesses should be compensated. If a licence holder exits and the exploration right is taken by another company, that company should provide compensation for the previous investment of the licence holder. Compensation criteria could be investment in seismic exploration, research or drilling.
China will cancel the franchise of the three major state-owned oil and gas enterprises for onshore cooperation with foreign businesses and allow other Chinese companies to cooperate with foreign businesses under government regulations. Companies should be motivated-and capital, advanced technologies and management experience leveraged - to improve China's ability to supply oil and gas, especially unconventional resources. The franchise for offshore cooperation should also be steadily deregulated. Pilot reforms could be carried out, initially with CNPC and Sinopec. After which the criteria for awarding offshore oil and gas mining rights should be researched by examining these pilot reforms. Subsequent laws and regulations should be introduced step by step.

While granting access to upstream resources, China should improve management and share geological data. It is suggested that the government should form a national geological data organisation, giving it the right to set up an oil and gas geological data submission system and empowering it to require businesses (including national oil companies) to submit geological data. Non-confidential geological data should be made available to all companies to facilitate data and information sharing.

(2) Accelerate reform of the oil and gas pipeline network and build an independent and diversified system of oil and gas infrastructure

The guiding principle behind the reform of the oil and gas pipeline network is: "drive the independence of trunk pipelines of large state-owned oil and gas companies step by step to unbundle pipeline transmission and sales; improve the mechanism for fair access to the oil and gas pipeline network to make trunk pipelines and intra- and inter-provincial pipeline networks open to third-party market participants". China will focus on addressing the main factors constraining the development of its natural gas industry: infrastructure construction, undiversified construction companies and operators, low 
level of pipeline interconnection, bundled transmission and sales, and ineffective implementation of third-party fair access. China is striving to achieve independence for oil and gas pipelines and create a nationwide pipeline network by 2020 to support an oil and gas production, supply, storage and sales system, and deliver the ultimate goal of a coordinated oil and gas value chain by 2030 .

Pipelines and other infrastructure link upstream to downstream in the oil and gas sector. The reform of the pipeline network, and its effect on upstream-downstream reform, has attracted widespread attention. The experience of countries with a mature natural gas market suggests that natural monopolies like pipelines should be separated from upstream and downstream businesses, and that pipeline companies should divest their bundled sales services. Pipeline companies should operate independently and only provide a transmission service, thus helping to create a competitive and efficient oil and gas market. The independence of oil and gas pipelines not only provides the strongest guarantee for fair access to infrastructure, it also eases supervision of pipeline transmission costs, accelerates the formation of an efficient pipeline service market and helps marketise the whole industry.

In recent years, factors such as low oil and gas prices, slower growth in gas consumption, a significant decline in the operating revenues of CNPC, Sinopec and CNOOC, and the upcoming pipeline reform have reduced pipeline infrastructure construction and made investment in upstream exploration and production less attractive. If reform is not accelerated, it will restrict the construction of gas pipelines and have an adverse effect on gas supply security. On the other hand, as oil and gas system reform deepens, private enterprise will enter the upstream market to explore and exploit resources, import oil and gas, invest in infrastructure and develop the natural gas trading market. As a result, third-party demands for fair access to infrastructure, especially gas pipelines, will increase. Independent operation of pipelines will undoubtedly facilitate fair access and promote sector-wide market-oriented reform. The
DRC-Shell work stream believes that China urgently needs to speed up reform of infrastructure, including the trunk pipelines of large state-owned oil and gas enterprises, and introduce the plan to reform China's oil and gas pipeline network as early as possible. This will create pipeline independence and develop pipeline services, thereby ensuring rapid development of the natural gas market.

The reform of local pipeline networks should be vigorously encouraged. Laws and regulations should be improved to ensure fair access. Judging from international experience, a third-party fair access policy can balance the financial interests of midstream pipeline owners, upstream producers and downstream consumers, and attract capital to invest in infrastructure construction. To encourage private capital to invest in the construction of China's oil and gas infrastructure and to improve the use of existing infrastructure and thus the efficiency of the entire sector, it is suggested that infrastructure operators (including trunk oil and gas pipelines, intra- and inter-provincial pipeline networks, LNG terminals and underground gas storage facilities) should provide transmission services to third parties on a non-discriminatory basis. To ensure third-party access, the national energy administration should improve the Measures for Regulation of Fair and Open Access to Oil and Gas Pipeline Networks and the Measures for Administration of Natural Gas Infrastructure Construction and Operation, and develop the Rules for Implementation of Fair Access to Natural Gas Infrastructure. In so doing it should define: how infrastructure operators can provide independent services like pipeline transmission to all users in a fair and just manner; how they should disclose information; and define the legal liability for breach of fairness and openness, thus laying an institutional foundation for fair access to pipelines. An efficient system should be created in which regulators can review and approve the qualifications of prospective upstream and downstream users applying to operate infrastructure or gain access. Companies failing to grant fair access or discriminating against third parties should be penalised and publicised. 
Restrictions should be gradually eliminated to diversify investment. According to the Medium and Long-term Plan for Oil and Gas Pipeline Networks, issued by the NDRC and NEA in 2017 , by 2025 China's total length of oil and gas pipelines will be 240,000 kilometres. This includes $77,000 \mathrm{~km}$ of crude oil and oil product pipelines, which increases by $29,000 \mathrm{~km}$ the $27,000 \mathrm{~km}$ of crude oil pipelines and 21,000 km of oil product pipelines at the end of the 12th Five-Year Plan (2011-15), and 163,000 km of gas pipelines (an annual increase of $10,000 \mathrm{~km}$ on the $64,000 \mathrm{~km}$ of gas pipelines at the end of the 12th Five-Year Plan). The next 10-15 years will see oil and gas pipeline construction peak. Because the construction of oil and gas pipelines is capital-intensive, and China needs to build many pipelines, a policy that restricts investment to CNPC, Sinopec and CNOOC will restrain China's pipeline development and slow the growth of its natural gas market. Restrictions on private capital funding pipeline construction should, therefore, be progressively eliminated, motivating the private sector to invest in pipeline construction and operation. To this end, the following aspects should be reformed. First, the infrastructure investment project approval system should be reformed by softening the review terms and criteria and by streamlining the approval procedure, thereby attracting private capital to invest in and construct gas infrastructure included in the national and provincial plans. Second, new pipeline investment that is open to third parties should, if reasonable, be prioritised for approval. Third, low-interest or interest-free loans or subsidies should be offered to those companies building key interconnecting pipelines with low return on investment, to increase their returns without raising users' costs. Fourth, investors should be allowed to invest in, construct, operate and manage LNG terminals and gas storage facilities as independent legal entities. This will diversify ownership and operation of LNG terminals and gas storage facilities and speed up their construction.

Government should — based on the pipeline needs for crude oil, natural gas and refined oil products_-plan pipeline deployment and create standards for investment, construction, operation and pricing. In particular, provincial and inter-provincial pipelines should be interconnected to support regulations. Unified standards should be developed for natural gas from different sources feeding into the pipeline network to ensure stable quality, usability and safety. The pressure grade of newly built pipelines should be carefully determined by referring to proven experience from other countries. Unified design and manufacturing parameters for gas usage facilities and gas volume measurement criteria should be defined to ensure technical interconnectivity.

Supervision and approval of transmission and distribution tariffs should be improved to reduce transmission and distribution costs. First, in accordance with the principle of China "maintaining administration over pipeline transmission tariffs in natural monopolies and deregulating gas source and sale prices", a pricing system that is based on "allowable cost + reasonable profit" and which combines constraints and incentives should be established. Pricing administration, cost supervision and review, and price regulation of gas pipeline transmission and urban gas distribution should be improved This will allow independent gas transmission tariffs and distribution fees to be set accurately, remove unreasonable costs and charges at pipeline nodes, and lower the costs of long-distance pipelines, intraand inter-provincial pipelines and gas distribution pipelines. Second, financial independence in the gas distribution, gas sales and engineering services of urban gas utilities should be promoted. Third, large users that meet the conditions for direct supply should be allowed to purchase gas from a provincial pipeline network, local branch pipeline or city gas franchise. Given insufficient pipeline capacity, the absence of third-party access and the excessive pipeline transmission tariff, large users that meet the conditions should be allowed to construct pipelines for direct supply, thus forcing provincial pipelines to lower costs, be competitive and improve efficiency. Fourth, under the guidance of the national gas market regulator, independent gas market regulations should be established at 
the provincial level to implement independent supervision of fair access to gas pipelines, regulate prices and quality of products and services, and maintain an orderly gas market.

Local pipeline reform is a key part of China's market-oriented reform of the oil and gas pipeline network. Local reform should be carried out alongside long-distance pipeline reform, or the latter will be one step short of success. Reform measures for local pipeline networks include establishing independent gas pipeline companies, unbundling pipeline transmission and gas sales, and allowing fair third-party access to infrastructure. First, the creation of independent provincial pipeline companies and the unbundling of pipeline transmission and gas sales should be accelerated. Provincial pipeline companies should not operate gas sources or purchase or sell gas. They should only provide a gas transmission service. Second, provincial pipeline companies must allow fair and non-discriminatory access to pipelines to third parties, and provide all users with pipeline transmission, gasification, liquefaction and compression services. Third, local pipeline construction should be deregulated to encourage private capital to construct gas infrastructure included in the provincial plan. The rate of construction of intra-provincial pipelines should be planned, taking into account oil and gas resources and demand. The principle of "adapting pipelines and storage tanks to local conditions" should be followed to allow storage to play a dominant role in cities with lower gas demand, thus avoiding unnecessary pipeline construction. Fourth, intra-provincial pipeline interconnection should be promoted by developing consistent technical pipeline standards and by setting a reasonable lowest load indicator when estimating the transmission tariff for connecting pipelines, thereby ensuring gas supply security. Fifth, in provinces with excessive transmission and distribution, reform should reduce the number of nodes to lower gas transmission and distribution costs. Users should be encouraged to negotiate prices direct with gas source companies to encourage fair competition on the supply side.

\section{(3) Promote oil and gas pricing reform and create natural gas exchange centres}

In accordance with the principle of "maintaining administration over pipeline transmission tariffs in natural monopolies and deregulating gas source and sale prices", China's oil and gas pricing reform should: (i) improve the oil product pricing mechanism and allow the market to play the decisive role; and (ii) gradually deregulate gas source and sale prices, improve the price protection mechanism for low-income groups and establish a market-oriented oil and gas pricing mechanism. The government should only regulate those pipeline transmission and distribution tariffs under natural monopoly, and restrict price intervention to abnormal oil and gas price fluctuations and to emergencies. This would enable the government to transition its role from pricing to regulation and ultimately to marketise oil and gas prices.

The oil product price mechanism should be further improved. After several rounds of price mechanism reform, China's pricing system for refined oil products has become increasingly market-oriented. In the current and future international energy market, with abundant oil supply and rapid development of alternative energy sources, the external conditions for marketoriented oil product pricing are good. China's oil product market is characterised by three features. First, market participants are diversified. Private refining and chemical companies, oil product businesses and service stations have developed rapidly, and their market penetration matches that of the three state-owned enterprises: CNPC, Sinopec and CNOOC. As the crude oil import quota is gradually deregulated, the quota granted to local refineries, including private ones, has exceeded 100 million tonnes, allowing oil product sources to diversify. Second, there is regular market competition. Excess oil refining capacity has intensified competition in the oil product market. This means that governmentguided crude oil and oil product prices have declined in significance. Third, there are regular price adjustments. As the market-oriented pricing 
mechanism for crude oil and oil products continuously improves and China's economy grows, affordability for people and businesses has significantly improved, and oil product price adjustments are no longer a sensitive issue. The correct conditions for market-oriented oil product pricing now exist. It is suggested that domestic oil product pricing should be fully deregulated by 2020 , and that supply and demand should play the decisive role in pricing. In addition, the regulation of price, oil quality and tax revenue should be strengthened, and the anti-monopoly law enforcement system improved, thus preventing monopoly pricing and maintaining a fair and orderly market.

China has adopted the netback pricing approach to administer city-gate benchmark prices across the country, reformed gas transmission and distribution pricing, and unified residential and non-residential gas prices, laying a good foundation for a gas pricing mechanism where price is determined by market competition. It is suggested that market-oriented reform should progress steadily in stages and that the principles of "pilot implementation followed by extensive deployment", "incremental capacity increases" and "deregulating while rationalising the industry" should be followed, in order to deliver the goal of open, fair, competitive and orderly market-oriented gas pricing reform.

In the short term: first, the pricing system should be improved. After unifying the residential and non-residential benchmark city-gate prices, all provincial pricing authorities should improve the measures for administering residential tiered gas pricing. This will allow them to define the consumption volume and price level of each tier, and establish an upstream and downstream linked price mechanism. Second, pricing policies like interruptible gas prices, peak and off-peak prices and peak-shaving prices should be introduced as soon as possible. To ensure stable gas supply, especially in winter in north China, an interruptible gas price should be set to increase the number of interruptible users and offset the lack of gas storage facilities. China should guide construction of gas storage facilities by defining peak and off-peak prices for different gas-consuming areas and times and encourage users to adopt peak-shaving. The requirements for establishing a gas storage peak-shaving ancillary service market, as stated in the Opinions on Accelerating Gas Storage Facility Construction and Improving the Gas Storage Peak-Shaving Ancillary Service Market, which were issued in April 2018, should be implemented. Purchase and sale prices by gas storage facilities should be determined by market competition, and the cost of constructing gas storage facilities owned by city gas companies should be lowered. Third, modification of metering and billing methods should be accelerated. Volume-based billing should be replaced by calorific value. This would help solve the difficulty of feeding natural gas of different quality from different sources into pipelines and of opening infrastructure to third-party access, and it would align with the international gas trading system. Measures to prevent illegal billing behaviour should be improved in terms of technology and management. Fourth, China should explore how to set up pilot projects to deregulate end-user gas prices. After summarising the lessons learned from Fujian's city-gate price deregulation pilot, additional pilots to deregulate end-user gas prices should be started in provinces like Sichuan, Chongqing and Jiangsu to facilitate later national deregulation of end-user gas prices.

In the medium to long term, once upstream operators are diversified, third-party access to infrastructure has been achieved, and prices at gas exchanges reflect supply and demand, China should stop controlling city-gate prices and deregulate gas source and end-user prices, allowing them to be determined by supply and demand. The pricing authority should only regulate the transmission costs and tariffs of inter-provincial long-distance pipelines, branch pipelines, intra-provincial pipelines and distribution pipelines under natural monopoly, thus achieving the goal of fair, competitive and orderly gas price reform.

The introduction of gas trading markets should be accelerated. In the short and medium terms, the Shanghai Petroleum \& Gas Exchange, Chongqing Petroleum \& Gas Exchange and 
other regional gas exchanges should form China's gas spot price index. First, unconventional gas (coalbed methane and shale gas), whose pricing is completely market-oriented, should compete with one another through platform trading. Companies should be encouraged to trade surplus capacity in pipelines, LNG terminals and gas storage facilities at the exchanges to increase the economic benefits for infrastructure operators and reflect the value of peak-shaving. Second, market trading participants_-including gas suppliers, independent traders, large users and local gas companies - should be fostered to drive trading growth stably. Third, nonresidential gas should be traded at the exchanges to ensure openness and transparency within two to three years. Fourth, regional exchanges should be established in an orderly manner, while accelerating the development of the Shanghai and Chongqing petroleum and gas exchanges. These regional gas exchanges should be developed in accordance with the principle of "different focus, mutual support, moderate competition and coordinated development". They should be located in the main consumption centres and infrastructure hubs, including Xinjiang, Shenzhen, Beijing, Tianjin, Hebei, Zhongwei and Hubei. Fifth, spot and medium- and long-term trading should be encouraged through listing and competitive bidding. This will promote competition between different types of gas and allow price to reflect fully the following: market demand and supply; price fluctuations in alternative energy sources; seasonal, peak and off-peak price differences; and other market factors - enabling China to create a gas spot price index as soon as possible. In the long term, the Shanghai Petroleum \& Gas Exchange should become an international gas exchange open to the Asia-Pacific region and even the world. Gas futures, gas options and other financial products should be launched once the spot gas market is large enough and market participants in upstream and downstream oil and gas are diversified and compete, and infrastructure is interconnected and open. Later, an integrated natural gas exchange-where financial transactions and spot trading complement each other and develop hand in hand-should be built to shape Chinese and even Asia-Pacific gas spot and futures price indexes and to influence the global gas market.

\section{(4) Fiscal and taxation policies for the oil and gas sector need to be improved}

The aim of fiscal and taxation reform includes clarifying the interests of different stakeholders, supporting and guiding the development of unconventional and deep-water oil and gas resources, adjusting the distribution of tax revenues between central and local government, promoting the development and use of green resources, and building a fiscal and taxation system that balances the interests of different stakeholders.

Tight gas subsidy policies should be introduced as soon as possible. The geological reserve of China's tight gas resources is 25-30 trillion cubic metres, equivalent to $45-50 \%$ of China's conventional gas reserves. Moreover, $50 \%$ of these tight gas resources can be exploited, so it is the most practical available natural gas resource and has great development potential. However, tight gas development relies on hydraulic fracturing technology to deliver industrial capacity, and its development costs are two to four times that of conventional gas. Moreover, its single well production is low and steady production is for a short time only. The government has suggested that it grant a subsidy of RMB 0.2 per cubic metre for newly opened tight gas wells.

Shale gas will remain a key contributor to China's gas output growth in the future. Given this, subsidies for shale gas exploitation are important for China's development of shale gas. It is suggested that differentiated subsidies for shale gas resources should be researched. For instance, subsidies for shale gas resources in marine facies in south China should differ, depending on whether they are efficiently or inefficiently extractable at a depth above or below 3,500 $\mathrm{m}$.

To reduce China's increasing reliance on imported oil and gas and enhance domestic 
supply security, the government should introduce differentiated tax policies for unconventional, deep-water, low and enhanced recovery of oil and gas to encourage companies to invest in the development of these resources.

The mechanism for sharing oil and gas tax revenues and royalties between central and local government should be adjusted. Due to decentralisation and the unreliability of local taxation, funds for local oil and gas development are limited. As China's economy develops, local governments are subject to increasingly strong demands to support local economic growth and raise people's living standards with the tax revenues from oil resource development. It is therefore suggested that the tax mechanism for oil and gas revenues and royalties be reformed to ensure that resource development benefits local people. Environmental compensation mechanisms should be established to levy a carbon or environment tax on resource development and use to increase local revenues.

A risk exploration fund should be established to develop strategic oil and gas fields. The government could use RMB 3-5 billion from oil tax revenues to establish a risk fund, which could be used for high-risk exploration led by the government. The government can engage oil companies to carry out initial exploration and drilling in high-risk fields by commissioning their services. If recoverable resources are discovered the field can be transferred through competitive bidding, and the earnings added to the risk fund to create a long-term mechanism.

Fiscal and taxation policies to support the construction of gas storage facilities should be developed. The delays in gas storage construction have become one of the major constraints to China's gas supply security. It is suggested that in provinces that lack the capacity to fulfil gas storage peak-shaving tasks, the government can invest in gas storage construction in several ways, such as by allocating funds from the central government budget. The VAT rate for gas storage should be lower, and a tax refund could be given for the first five years to support early-stage construction of gas storage facilities.

\section{(5) Standardise government administration and create an effective oil and gas regu- latory system}

For the government to exercise its role in market supervision, regulation and services to the full and achieve the reform objectives for the oil and gas sector, government functions should be transformed and the methods of regulation overhauled.

First, government administration should be standardised. Government should intervene less in the market and in business activities. Administration should focus on the development of strategies, plans, policies and market rules and the creation of a fair and impartial industry. Second, plans for the oil and gas industry should be developed in a scientific way. They should be linked to economic and financial development, land use, infrastructure construction, environmental protection, safety, transport and technological innovation. A plan development mechanism should be established to make planning more scientific and authoritative. Plans should have a dynamic adjustment mechanism, and environmental impact assessments should be improved in accordance with relevant laws. Third, the development of industry standards should be accelerated. Macro-management based on planning, policies and standards should be applied to the oil and gas sector. Fourth, government services should be optimised. Energy information and geological data sharing platforms should be built. The government's role of driving technological innovation should be emphasised.

An effective oil and gas regulatory system should be created. China should: (i) separate administration and regulation, and form independent, unified and specialised regulatory authorities, and improve the regulatory system at the national and provincial levels; (ii) consider setting up an independent centralised energy regulatory system within the National People's Congress to define regulatory responsibilities (mainly economic regulation), improve social regulation and ensure fair competition in natural 
monopolies like pipelines; and (iii) improve the efficiency of government regulation, prioritising regulations for processes and activities like fair market access, trading behaviour, natural monopolies, taxes, pricing, safety and environmental protection, and combining legal tools, administrative means, specifications and public engagement to enable collaborative regulation.

To enable the market to play the decisive role in resource allocation and the government to play a more efficient role, those parts of existing laws that are outdated or conflict with the oil and gas sector or hinder its reform should be repealed or modified to facilitate oil and gas mining rights reform. For example, those parts not suitable for a market system in the Mineral Resources Law of the People's Republic of China, the Rules for the Implementation of the Mineral Resources Law of the People's Republic of China, the Regulations on Registering Mineral Resource Exploitation, the Administrative Measures for the Registration of Mineral Resource Exploration Blocks, the Measures for the Registration Administration of Mineral Resource Exploration, the Environmental Protection Law of the People's Republic of China and other laws and regulations should be amended as soon as possible. In addition, it is suggested that the Oil Law and Gas Law be studied and used as soon as possible to: (i) standardise the business activities of the companies and public bodies active in the oil and gas sector; (ii) standardise the supervisory and administrative activities of government and the actions of other stakeholders; (iii) improve the development, use and conservation of oil and gas resources; and (iv) enable the healthy development of the oil and gas sector and other related sectors. The development of energy regulations should be completed as soon as possible to define regulators' roles, functions and responsibilities, regulatory procedures and the decision-making mechanism; standardise information disclosure and the dispute settlement mechanism; and define the penalties for violations. All these actions will give legal support to supervisory and regulatory work and help them become authoritative.

\section{Reforming the Coal Sector}

\subsection{Progress and Trends in Global Coal Industry Reform}

\subsubsection{More and More Countries Have Adopted a Coal Exit Strategy}

Reducing emissions from coal combustion has become an important aspect of cooperative global governance. The international community has maintained a high degree of unanimity regarding the global fight against environmental pollution and climate change. The Paris Agreement was adopted with the unanimous agreement of 195 countries. The USA officially announced its withdrawal from the Paris Agreement in June 2017 and submitted withdrawal documents to the United Nations in August 2017, receiving widespread criticism. Reducing pollutant emissions is an irreversible trend and an important issue in global governance. The USA's withdrawal has not yet had a material impact on global emissions reduction and will not shake the worldwide determination for global climate governance or change the development course of clean energy. Coal is a fossil fuel energy with a high carbon content. Reducing coal consumption has therefore become a focus of global emissions-reduction cooperation.

Most European countries have begun to phase out coal-fired power plants. Eurelectric-the sector association for the European electricity industry, which has around 3,500 member companies - and the European power industry will not "invest in or construct new coal-fired power plants after 2020". This plan is supported by 26 EU member states. Leaders of EU countries reached consensus in October 2014 regarding the objective of "reducing greenhouse gas emissions by $40 \%$ over 1990" and agreed to disinvest gradually in the coal industry and end subsidies for fossil energy. For example, France stopped providing financial support for overseas-owned coal-fired power plants without carbon capture and sequestration in May 2015. Major financial institutions no longer invest in coal mining 
projects. The Norway Sovereign Fund began to disinvest in coal companies in June 2015. Scotland shut down its last coal-fired power plant in March 2016. England, Finland, Portugal and Austria plan to phase out coal-fired power plants by 2025, 2029, 2030 and 2025 respectively. In addition, EU countries plan to cancel coal-related subsidies by 2018. Austria, England, Belgium and Finland have all taken power industry decarbonisation measures.

All OECD member states strictly control subsidies for coal-fired power plants. Thirty-four OECD member states reached agreement in November 2015 to restrict export credits for coal-fired power plants using older technology, granting allowances only to "coal-fired power plants that meet the strictest environmental standards", and tightening financial support for the coal industry.

The USA, Canada and other countries have gradually weakened policies supporting the coal industry. The USA began to restrict the export of coal technologies before the OECD. Major banks in the USA have cancelled financial support for coal projects, as have the Export-Import Bank of the United States, the World Bank and the European Investment Bank. Canada backed carbon capture and sequestration technologies for coal-fired power plants in August 2011. It is possible that it will completely phase out coal-fired power plants by 2050. Many regions in Canada have introduced decarbonisation measures for the power industry.

Many countries levy resource taxes. Denmark, Finland, Sweden and Norway are pioneers in these taxes. In Canada, the Alberta government began to levy CAD $20(\$ 15)$ on every tonne of carbon emitted from January 1, 2017. France started to levy a carbon tax on coal power in 2017.

In summary, the policies for exiting coal can be divided into two categories: (i) restrictive policies on the supply side to reduce coal production; and (ii) policies on the user side that set targets for the transition to new energy as a means to reduce coal demand.

\subsubsection{The Strategic Positioning of Coal Differs from Country to Country}

Many countries are heavily dependent on coal. For example, in Germany, coal accounts for more than $20 \%$ of the energy mix and coal-fired power for more than $40 \%$ of the power mix. In South Korea, the figures are around $30 \%$ and almost $40 \%$ respectively; and in India, they are higher-about $50 \%$ and $60 \%$ respectively. China is one of a minority of coal-based countries. Coal accounts for around $63 \%$ of China's energy mix, and coal-fired power for more than $70 \%$ of its power mix. A few countries may become more dependent on coal, instead of less. Japan is an example. Coal accounts for about $25 \%$ now, in both its energy mix and power mix. By 2030, the share of coal in its energy mix and power mix is likely to increase to $30 \%$ and $26 \%$ respectively.

To ensure energy supply security, some countries increase their use of coal. For example, Japan made a new energy plan after the Fukushima nuclear accident, which involves building 41 coal-fired power plants over the next decade to ensure energy security. To meet increasing energy demand and improve economic development, India plans to increase coal output year by year, and has introduced support policies on the environment, land approval and on granting exploitation rights to private capital.

The positioning of the coal industry differs from country to country. Most countries are actively reducing emissions from coal combustion and optimising their energy and power mix in many ways. But their attitudes on whether to exit or continue to use coal are different, mainly influenced by their resource endowment, industrial structure and phase of development. Significantly decreasing coal's share of the energy mix is impossible for many countries in the short and medium terms. For example, in Germany and the USA, the coal-exiting policy has been ignored by coal and other traditional industries. Japan has increased its coal power to ensure energy security. In keeping with its phase of development, India's coal consumption is 
increasing rapidly, and its coal policies are aimed at stimulating coal supply.

\subsubsection{Clean Energy Is Rapidly Replacing Coal, Thanks to Incentives for Users}

Countries aiming to abandon coal, even though they may be highly dependent on it in the short and medium terms or increasing their use of it, might yet actively take part in global emissions reduction governance and issue the necessary policies to encourage power generation with clean energy. North America is expected to increase the share of clean energy consumption to $50 \%$ by 2025. Argentina plans to invest $\$ 2.1$ billion in wind, solar, biomass power and small hydropower stations. Sweden plans to make $100 \%$ of its energy green by 2040 . Germany encourages distributed energy through a high level of energy efficiency tax refunds and through financial support for energy-efficiency equipment. It is estimated that the proportion of renewable power in total electricity consumption will increase to 40$45 \%$ by 2025 , and to $55-60 \%$ by 2035 . England supports distributed power projects through subsidies, credit loans and intelligent metering. Italy supports distributed power projects through an energy tax, credit loans, high prices, consumption subsidies and other preferential policies - the feed-in tariff for distributed power is $50 \%$ higher than the domestic retail price. In Chile, the proportion of new energy will reach $50 \%$ by 2035 and $70 \%$ by 2050 .

The cost of generating power with clean energy decreases gradually as technologies improve. Meanwhile, the environmental cost of traditional fossil energy is increasing. For that reason, and to promote the development of the clean energy industry, some developed countries have begun to end subsidies for power generation with clean energy. For example, Germany ended its policy for a preferential feed-in tariff for renewable power in June 2016. The European Union began to limit subsidies from member states to the renewables industry in 2017. In the future, governments will increasingly use market mechanisms as the clean energy industry matures. The policies facilitating the replacement of coal by clean energy will gradually change into incentives to make power generation efficient.

\subsubsection{Government Support for the Coal Industry Still Exists}

Many countries once dominated by coal still have a large coal industry, with many coal workers. Support policies of different types are, therefore, still needed from government. The USA, for instance, launched in 2015 the Partnership for Opportunity and Workforce and Economic Revitalization (POWER) initiative, which helps coal communities adapt to the new energy landscape and reposition their economies. The key points in the Federal Government's America First Energy Plan include ensuring self-sufficiency in energy, revoking the Climate Action Plan of the previous administration, and supporting and promoting the clean development of coal. These policies will help revitalise the coal industry. In addition to building more coal-fired power plants, Japan introduced policies to increase investment in scientific research on energy saving and emissions reduction for coal combustion and support the modernisation of coal-fired power plants.

Government support focuses on technical innovation, energy saving and emissions reduction. After analysing different countries' coal support policies, we found that governments support innovation in coal combustion technologies, rather than simply supporting expansion of coal's share of the energy mix, to encourage energy saving and emissions reduction. Replacing coal with clean energy will take a long time, and coal power is characterised by low-cost and proven technologies. That is why many countries strongly support energy-saving and emissions-reduction technologies in the coal sector, while optimising their energy and power mix. They hope to achieve low-carbon use of high-carbon energy by minimising the emissions from coal combustion. 


\subsubsection{Coal Companies Are Folding, Merging or Being Sold}

Coal companies are going bankrupt. Others are merging or being sold. The rapid replacement of coal by clean energy, the global economic recession after the global financial crisis of 2008, and China's declining coal demand since 2014 have led to oversupply in the international coal market. In the USA, Patriot Coal, Walter Energy, Alpha Natural and Arch Coal filed for bankruptcy in 2012, 2015, 2015 and 2016 respectively. Peabody Energy, the largest coal company in the world and engaged in coal exploitation for 100 years, joined the list of insolvent coal companies in April 2015. For coal companies that had not filed for bankruptcy, the situation is frustrating: most of them have been brought to the verge of bankruptcy due to long-term losses. For example, Murray Energy in the USA announced a mass layoff programme in 2016 to reduce its losses, and the net loss of New World Resources, the largest private coal company in eastern Europe, was around €233.6 million in 2015. In 2015, more than $80 \%$ of Chinese coal companies made a loss. The Chinese economy improved in 2017. Output of domestic raw coal picked up. Output from January to September increased by $5.7 \%$ over the previous year, which is $16.2 \%$ points higher than in 2016. But low efficiency, debt, state-owned enterprise reform and other structural problems in China's coal industries remain. Merging and restructuring large coal companies is on the agenda again, and a new trend of vertical integration has emerged. Shenhua Group, the largest coal company in China, and China Guodian Corporation merged to form China Energy Investment Corporation Limited in 2017. Some local state-owned coal companies are also exploring horizontal and vertical integration, aiming to sharpen their competitive edge through resource optimisation and reorganisation.

International consortia have divested their coal businesses. Total of France, the fifth largest energy company in the world, ended its coal production and sales activities in 2015. The total value of the coal assets divested by the Anglo-Australian coal mining giant Rio Tinto since 2013 is more than $\$ 4.7$ billion, and it sold $40 \%$ of its holding in Australia's Bengalla coal mine for more than $\$ 600$ million. In addition to divesting $60 \%$ of its assets in 2016, global mining company Anglo American sold 51\% of its holding in Dawson coal mine and $70 \%$ of its interest in Foxleigh coal mine, both in Queensland, Australia. Vattenfall, wholly owned by the Swedish government and the third largest energy supplier in Germany, announced in 2016 that it would gradually retreat from the German coal market. In the same year, the largest sovereign wealth fund in the world, the Norwegian Oil Fund, sold its shares in 52 coal-related companies.

Some coal companies have seized the opportunity to expand their business. Exxaro Resources of South Africa acquired coal assets from Total of France for $\$ 472$ million in 2014, $\$ 45$ million lower than their value the previous year. Indonesia's state-owned coal company Bukit Asam entered Australia's coal market in 2016 by acquiring one of Rio Tinto's largest coal mines in Australia.

Bankruptcy and merger and acquisition are commercial activities, as well as means of government gaining control. Asset restructuring of international coal companies, an unavoidable result of the industry's descent, is changing the structure of the global coal industry.

\subsection{Progress, Status and Assessment of China's Energy System Reform}

\subsubsection{Reform Has Progressed Despite the Industry's Downturn}

The years 2010-16 were a transitional period for China's coal industry, with industrial growth dropping from high to medium and institutional reform deepening. The golden decade for China's coal industry was 2002-12, when annual coal output increased on average by almost $10 \%$. The growth rate of the Chinese economy slowed down in 2012, leading to overcapacity in the coal industry. Shortage was rapidly replaced by oversupply. The growth rate of coal output 
dropped substantially to $0.74 \%$ in 2013 , then declined into negative growth for three years from 2014, before re-entering positive growth in 2017. In the context of the downturn, coal industry reform has made progress in many aspects.

China has been using dual coal pricing for a long time. Coal traded by sellers and buyers using a market-based pricing mechanism, through which the price fluctuates in line with market conditions, is called market coal. Previously, coal producers and thermal power plants on the state's list of key enterprises traded coal at an annual national coal fair price under a planning mechanism called planned coal. During the golden decade, the price of planned coal was RMB 200 lower than that of market coal, resulting in years of coal power combat. China unified the two prices in 2013, which marketised the coal market.

An important component of China's administrative system reform is "administrative streamlining and decentralisation, the combination of deregulation and regulation, and service optimisation". Coal authorities ended the Coal Production Permit and the Approval Needed to Found Coal Businesses in 2013. Many local governments also introduced the reform policies, delegating approval and improving administrative supervision and management. Administrative supervision and management is becoming increasingly market-oriented and IT-based. Government functions focus more and more on industrial services.

Overcapacity in China's coal industry emerged during the 12th Five-Year Plan (201115), reaching a peak in 2015. From November 2011 to January 2016, the Bohai-Rim Steam-Coal Price Index (BSPI) dropped by $56.51 \%$ from RMB 853/tonne to RMB 371/tonne. According to data from the National Bureau of Statistics of China, the profit margin of the coal mining and washing sectors decreased from $14.06 \%$ in May 2011 to $1.76 \%$ in December 2015, and to its lowest point of $1.55 \%$ in August 2015. In 2015, more than $90 \%$ of large and medium-sized coal companies made a loss. China's coal industry, characterised by its long history, large size and huge number of employees, was an important pillar of the national economy. A fast and substantial downturn in the industry brings financial and social risks and threatens the overall stability of the Chinese economy. The coal industry therefore became a key sector for China's supply-side structural reform under the new normal of slower economic growth. The structural reform of the coal industry is focused on reducing capacity, optimising supply and achieving the reform objectives of reducing inefficient supply and increasing efficient supply. The State Council issued the Opinions on Reducing Overcapacity in the Coal Industry to Achieve Development by Solving the Difficulties in February 2016, which set out the objective of reducing capacity in the coal industry. China cut coal capacity by 290 million tonnes in 2016, exceeding the target of 250 million tonnes. China will strive to meet the capacity reduction target of 150 million tonnes in 2017.

Coal mine safety management has always been an important area of coal industry reform. Since 2010, reform has focused on shutting down or reorganising small coal mines, reforming safety management and increasing safety investment. First, small coal mines that did not meet safety requirements were shut down. More than 3,000 small coal mines, each with an annual output of less than 300,000 tonnes, were closed by the end of 2015 . The second measure was to merge small coal mines that met safety requirements with large companies. Shanxi Province implemented the plan between 2009 and 2012, shutting down 1,545 mines. Other major coal producing provinces also merged large companies with small coal mines. Henan merged and restructured 466 small coal mines in 2010. Hebei began to regulate small coal mines in 2011, shutting down 237 during the 12th Five-Year Plan (2011-15) through merger, restructuring and integration of resources. Shandong launched a programme to merge and restructure small coal mines in 2012; by 2015 there were 52 fewer coal mines than in 2010. The third measure was to increase investment in safety. This became part of management procedures and was well promoted and well implemented. Reform was based 
on management and supervision at each level and on clearly defining responsibilities, including those of regulators, government and coal companies. In particular, the responsibilities of company management were clarified.

Emissions of air pollutants from coal use are strictly controlled. The Chinese government has improved its air pollution prevention work in recent years. Coal combustion is one of the main sources of air pollutants, so coal-fired power plants and steel companies are two important areas of government supervision.

The government began to build a national monitoring system of pollution sources in 2010 and has been improving it ever since. Once the system was completed, the government passed the Environmental Protection Law (which provides strict and comprehensive regulation) in January 2015, and the Atmospheric Pollution Prevention and Control Law in January 2016, which codifies emissions regulation. Also, in 2012 and 2015, the government substantially raised emission standards for the steel industry. Hebei province, a major steel producer, imposed limits and substantially raised emission standards in 2014 by incentivising coal-fired power plants to implement super-clean emission standards. Finally, there has been a push to reduce coal consumption. Air contamination in Beijing, Tianjin and Hebei is a serious problem. Reducing regional coal consumption is an important method of governance. Beijing is implementing the coal-to-gas programme. Beijing, Tianjin, Langfang and Baoding plan to introduce coal-free zones by October 2017. Shijiazhuang, Tangshan, Handan and Anyang have adopted temporary policies to limit steel production capacity to $50 \%$ in the cold season.

Tax reform of the coal industry since 2010 is centred on two measures. First, reform of the coal resource tax, which aims to move from a fee system to a tax system, as well as encouraging more efficient use of resources. Second, changing business tax into value-added tax. Unlike the reform of the coal resource tax, the business tax to VAT reform is a national reform, not just a coal industry reform. It involves paying VAT instead of business tax on taxable items. The business tax to VAT programme, launched in May 2016, has been fully implemented in the coal industry, just as it has in other sectors. The tax reform programme, which aims to relieve the tax burden on small and medium-sized companies and eliminate double taxation on large and medium-sized companies, is another example of tax reform in China following the tax sharing reform of 1994.

The reform of state-owned coal companies has been accelerated. The extensive losses of China's coal industry were caused by oversupply, the heavy debt burden of state-owned coal companies and the weak profitability of most non-coal businesses. The Chinese government therefore regards speeding up the reform of state-owned coal companies as an important way to help the industry become profitable. In addition, accelerating the reform of state-owned enterprises is an important aspect of the coal industry's supply-side structural reform.

The first stage was to restructure state-owned capital investment corporations through pilot programmes. Central and local state-owned coal companies have become pilot reform targets for state-owned capital investment corporations. The plan is now being developed and implemented. The state-owned capital management system and mechanism are being transformed, as is the organisational structure.

The second stage was to integrate, merge and restructure resources. Some major coal suppliers in Shanxi, Shaanxi, Heilongjiang and Hebei formed large local state-owned coal enterprises before 2010 by integrating state-owned coal resources. Henan further integrated its coal resources after 2010. To improve the safety and efficiency of coal mines, state-owned coal companies were encouraged to integrate private coal resources. The coal companies owned by central government began to integrate resources during the 13th Five-Year Plan (2016-20). The State-Owned Assets Supervision and Administration Commission under the State Council introduced new policies in 2016. These require companies owned by central government that are marginally involved in the coal industry to exit the industry and transfer their resources to coal 
enterprises owned by central government. For example, Shenhua Group and China Guodian Corporation merged into China Energy Investment in 2017.

The third stage was to remove state-owned coal companies of their social responsibilities, which were a legacy from the previous round of reform of state-owned enterprises. To relieve the burden on coal companies during the economic downturn, government at all levels began to remove these responsibilities from coal companies and made great progress in doing so.

The fourth stage was to reduce coal capacity. Local governments and state-owned coal companies actively shut down old mines and zombie capacity.

The final stage was to promote mixed ownership. As planned by state-owned enterprise reform, state-owned coal companies are exploring ways to carry out mixed ownership reform and are expected to make progress during the 13th Five-Year Plan (2016-20).

\subsubsection{Reforms Are Characterised by Marketisation and More Administration}

Deregulating the coal price, abolishing coal production permits and requiring companies to obtain approval to start a coal business are significant steps towards market-based reform. The coal market's competitive attributes have been strengthened. Intermediary coal service organisations are more mature. To meet the need for market competition, the authorities made regulations more market-oriented. First, laws, regulations, rules, policies and standards were customised for the coal market. Second, a market information system was developed to monitor and analyse the coal market in real time. Third, plans, guidance and support policies for coal trading, logistics and reserves were introduced to marketise the coal industry.

As circulation becomes more market-oriented, the government is improving its administrative means to regulate the coal industry, especially regarding capacity reduction and price stabilisation. At first, in 2016, China put more effort into capacity reduction. The State Council announced in January 2016 that capacity reduction should "first take place in the steel and coal industries", and that "coal capacity should be reduced significantly" through "the rule of law and marketisation". To implement the capacity reduction plan, the State Council published the Opinions on Reducing Overcapacity in the Coal Industry to Achieve Development by Solving the Difficulties in February 2016. After which, support documents from government departments for human resources, finance, safety supervision, land, quality inspection, taxes, and environmental protection were issued. The provinces, cities and autonomous regions that are major coal and steel producers also set targets, plans and measures for capacity reduction. Strongly driven by policies, the coal industry achieved its capacity reduction objectives ahead of schedule in 2016.

Administration played a leading role in capacity reduction during the market recovery in 2016. This was enabled by the following five factors: (i) the macroeconomy reported slower but stable growth; (ii) market-driven capacity closures and output reduction during the earlier downturn reduced supply; (iii) legal measures forced some outdated capacity to be shut down; (iv) the government strictly controlled the addition of new capacity; and (v) some production restrictions adopted in 2016, such as limiting mine operations to 276 working days a year, controlled output during the rapid price recovery. Factor (i) was the foundation. Factors (ii) and (iii) were essential, but the policies of tightening supply were more crucial and accelerated the recovery of the coal market. China's output of raw coal in 2016 was $9.4 \%$ lower than in the previous year. The government paid close attention to price fluctuations and took the necessary measures to stabilise the coal price. Once coal capacity reduction had delivered results, the coal price went up. To stabilise the price, the government actively influenced long-term agreements with key accounts, under which coal was traded at a price lower than the market price, restraining price rises. Finally, the government strengthened the administrative regulatory regime for safety, making it a priority to regulate the people in charge of coal companies. 
State-owned coal companies have started to reform themselves in accordance with China's state-owned capital management system. Measures include reforming state-owned capital investment corporations, introducing mixed ownership, organisational restructuring and developing market mechanisms. Centrally run state-owned coal companies have made breakthroughs in vertical integration along the value chain. Local state-owned coal companies are exiting from inefficient mines, transforming state-owned capital investment corporations and restructuring.

After the economic downturn, China's coal companies developed expertise in energy industry trends and began to transform and optimise their business structure in two aspects: (i) exiting inefficient coal, coal-fired power generation, coal chemicals and coal machinery, and reorganising internal resources to allow them to exit those fields; (ii) planning for new emerging business, developing modern services and intelligent manufacturing, and using $\mathrm{R} \& \mathrm{D}$ and other resources to make the necessary breakthroughs.

The tax burden on the coal industry is still heavy. After the business tax to VAT reform was carried out, the taxes on some business areas of coal companies decreased, such as in equipment manufacturing. But for other business areas, the tax burden increased because there were fewer allowable deductions. Overall, businesses are paying more taxes since the business tax to VAT reform. After the coal resource tax was reformed, the tax rate on price and resource-related charges differed from region to region. It is not unusual to find coal companies for whom tax liabilities have increased under both reforms.

\subsubsection{China's Coal Industry Reform Still Faces Many Difficulties}

Market-oriented reform conflicts with administrative measures, as revealed in the following four cases.

First, there is a conflict between the government's regulatory function and business governance. Government regulates macro-aspects of the economy and should not intervene at the micro level of business operation and management. Government and business are on two different levels of administrative, social and economic governance. They should cooperate. The introduction of market-based reform requires the boundary between government and the market to be defined. Only by keeping government within bounds and allowing businesses to perform can the market's decisive role be unleashed. If the administrative process is not well controlled, the boundary between government regulation and business governance can become blurred, with the government crossing the line and intervening in business operations. This could be seen during the drive to stabilise the coal price and improve safety. Government authorities were encouraging large coal companies to trade with key accounts at a contractual price, which meddles in the coal companies' business and works against the market-oriented coal pricing mechanism. The process of improving coal companies' safety implicitly regards them as targets for administrative management, which conflicts with their responsibilities as market players and hinders the reform of the state-owned capital management system.

Second, there is a conflict between the target to reduce production capacity in the medium to long term and the current supply shortage. Coal industry losses changed into industry-wide profitability in 2017, making it more difficult to make further capacity reductions. One cause of the supply shortage is that the government's compulsory measures make it harder for the market to meet demand. Capacity reduction should therefore continue. However, improvements in the business environment and the universality of the government's capacity reduction policies still allow inefficient and uncompetitive production capacity.

Third, there is a conflict between reducing and exiting inefficient supply and increasing efficient supply. Staff relocation and debt repayment are the inevitable challenges of capacity reduction. Local government and financial institutions have introduced some protective measures to mitigate social and financial risks. Despite being 
uncompetitive, some inefficient mines have been operating for a long time. In addition, the government's administrative regulatory system has played an important role in capacity reduction since 2016, though its inflexibility has restricted the development of efficient capacity to some extent.

Fourth, there is a conflict between market-oriented regulations and government administration. The government has emphasised the market's decisive role and deepened reform along the lines of "administrative streamlining and decentralisation, the combination of deregulation and regulation, and service optimisation". However, macro-control of the coal market is still dominated by administrative processes. To achieve their environmental and safety objectives, some local governments were inflexible in their administrative guidance, which was not based on law and resulted in unnecessary financial losses for compliant enterprises. There are also problems with the coal contract price encouraged by government. The government abolished dual coal prices with the aim of deregulating coal pricing and forming a market-oriented coal pricing mechanism. Trading coal with key accounts at a contractual price lower than the market price is consistent with the laws of economics. However, if the contractual price does not follow the price trend, or differs greatly from the market price, it could be concluded that the contractual price has been affected by the government's macro-control, rather than being determined by supply and demand. If the contractual price is similar to the old planned price, then clearly the government has not created an effective market-oriented mechanism for coal pricing.

China's coal circulation regulatory system under the new normal of slower economic growth faces new challenges. The market is now the vector for transactions, which has a profound influence on the coal industry.

First, a modern coal circulation regulatory system is not yet in place. The parties engaged in coal circulation are numerous, decentralised and small. These factors make government regulation more difficult. The current regulatory system cannot cover all parties for the following reasons: (i) policy constraint is not effective for each party involved in circulation. Regulations on trading and coal quality cannot fully supervise and restrain complex markets; (ii) coal circulation regulations are not clearly distributed between central and local government, making the regulatory system messier and more complicated; and (iii) development of the auxiliary coal market has lagged behind. This dates back to the start of the reform regime and is characterised by poor contractual performance, scattered market information, an unsound credit rating mechanism and the absence of financial regulation.

Second, there is no market-based carrier optimising supply and demand through the coal circulation regulatory system. Coal circulation regulation needs to allow an existing market-oriented coal pricing mechanism to play its role and stabilise market price fluctuations. However, there is currently no effective carrier. The way to stabilise price fluctuations is by improving supply and demand in a market-based way, rather than intervening in businesses' production and operations, which disturbs the market pricing mechanism. The current coal circulation regulatory system enables regulators to keep track of coal market dynamics but does not allow them to optimise supply and demand.

Third, the regulatory regime transforms coal circulation. Supply-side optimisation has a profound impact on coal circulation. Future coal circulation will not be limited to coal trading and the transport of coal from one place to another but will expand into higher levels of circulation. For instance, the value added to raw coal during circulation will increase, logistics will be modernised and capital and information flow services improved. A coal circulation regulatory regime should not only standardise and manage circulation, it should guide the transformation of circulation. However, the current coal circulation regime does not cover higher levels of circulation services. Such a regime has not yet been designed.

Fourth, China needs a coal circulation regulatory system that meets the demand for green and low-carbon energy. To meet this new 
requirement, the coal circulation regulatory system prioritised three things: the standardisation of coal quality, restricting the use of bulk coal, and the introduction of policies that support the use of clean coal. Clean coal is a highly beneficial way to transform China's coal production and consumption and create new industry trends. However, the clean coal regulatory regime is not systematic enough in its approach and needs to be aligned with China's coal circulation system. Restrictions and incentives are needed: (i) the industrial heating sector needs to be reformed and aligned with the use of clean coal; (ii) restrictive regulations are not strictly enforced, giving some businesses and consumers opportunities to break them; and (iii) the incentives to drive technical innovation in clean coal and modernise industrial and public sector equipment are not in place, nor are consumption subsidies.

It is difficult to reform state-owned coal enterprises due to the large number of people employed in the industry and the heavy debt burden that many companies carry, both of which restrict innovation and transformation. The reform of China's coal industry is strongly related to the reform of state-owned coal companies, which play an important role in China's coal industry. The top 10 coal companies in China, in terms of coal output, are all owned by the state. They produced around 1 billion tonnes of coal between January and September 2017, accounting for more than $60 \%$ of raw coal output by large national coal companies. Large state-owned coal companies - characterised by their large size, diverse business activities and long history - have inefficient production capacity that they need to exit. For many companies, inefficient capacity has become a serious problem, leading to surplus workers and a high debt-to-asset ratio. These companies enter a vicious cycle where the heavier the personnel and debt burdens, the more difficult it is for them to exit inefficient capacity. The recovery of the Chinese economy in 2017 played an unusual role by acting as a buffer, allowing state-owned coal companies the time and space to transform and innovate. A strong internal organisation is a precondition for such transformation and innovation. Internal weaknesses need to be eliminated first. Only then can business creativity be stimulated through institutional and mechanism innovation within the larger reform of the coal industry. The reform of state-owned coal companies poses many questions, such as: What will happen to the workers? How can the company repay its debts? Where will the money come from? There is currently no answer to these questions, which is slowing down the process of industry-wide reform.

\subsubsection{Evaluating China's Coal Industry Reform}

The coal industry is a pioneer in market-oriented reform. Reform started in the 1980s, and has never stopped, but has had different characteristics during different periods. As the Chinese economy moved from a high growth rate to the new normal of lower growth, and environmental governance became more intense, a supply shortage of coal was replaced by oversupply. At present, supply is tight because of the initiatives on capacity and emissions reduction. Changes in the market have accelerated the reform of the coal industry. However, difficulties in business operation and the pressure to prevent air pollution have pushed the government to strengthen its macro-control.

The reform of China's coal industry has the following characteristics: it is an advanced market, with better regulations and deepener reform.

At first, the marketisation of the coal industry made steady progress. Coal authorities abolished various policies, including dual coal prices, the coal production permit and the need for approval to start a coal business. At the same time, coal companies actively explored transitioning from coal producer to energy supplier. The logistics, information flow and capital services for the coal market were improved. Driven by government and businesses, the coal market became more and more sophisticated. 
Next, the government strengthened its macro-control. The government's plans to reduce production capacity achieved remarkable results in a short time. It not only reduced overcapacity but improved the business environment of the coal industry as well. The government also, by combining capacity reduction with emissions reduction and focusing on restricting new capacity and even exiting coal, promoted supply-side reform. To suppress the recovery of the coal price, the government took other measures as well, such as encouraging coal companies to agree low-price contracts with key accounts.

Finally, the reform of state-owned enterprises deepened. To help state-owned enterprises escape the conflicts and issues that urgently needed to be addressed, the government eliminated deep-rooted institutional and mechanism problems. The papers regarding reform of state-owned enterprises were adopted after 2015, gradually forming the $1+\mathrm{N}$ policy. The State-Owned Enterprise Reform Leading Group of the State Council carried out the Ten Pilot Reform Programmes in 2016, which summarise the present round of state-owned enterprise reform. The reform of state-owned coal companies has focused on state-owned capital investment corporations, introducing mixed ownership, divesting coal operations from centrally administered state-owned enterprises whose core business is not coal, and on restructuring and merging companies. The reform of centrally administered coal companies is now making rapid progress, whereas that of local state-owned coal companies is slower.

The coal market experienced a significant downturn after 2010 and was faced with unprecedented environmental pressure. On the one hand, a supply shortage turned into oversupply, which benefitted market-oriented reform. Dual coal prices were abolished. On the other hand, the downturn resulted in financial losses for the industry. Stabilising growth and mitigating risk were especially urgent. Given market and environmental pressure, administrative regulation became essential. As a result, the reform of China's coal industry after 2010 progressed in marketisation and government administration. Administration played a more important role after 2016, not only in reducing production capacity and improving environmental protection, but also in stabilising the coal price once supply and demand had been optimised. The government achieved remarkable results in the short term.

The coal industry regained profitability in 2016. However, the drawbacks of administrative regulation reform were becoming increasingly evident. Coal supply and demand depends on several factors. Reducing production capacity tends to lead to a supply shortage in some regions and in certain types of coal, and exiting mines affects people's livelihoods, even though it helps reduce emissions. Trading with key accounts at a contractual price should be encouraged. Once the price difference between contractual price and market price reaches a certain threshold, a dual price system could reappear. The goal of reform is to build a sophisticated coal market, rather than reduce capacity and stabilise prices. The government's reform measures were indispensable, but an administrative mechanism cannot replace the market mechanism or prevent it from fulfilling its basic functions of optimising the system and determining price. The administrative mechanism should be combined organically with the market mechanism. Therefore, in the long term, China needs to build a coal market system that is aligned with the long-term objectives of marketisation and that manages the relationship between the market and government.

\subsection{Guidelines and Pathways for Future Reform}

\subsubsection{Guidelines}

The revolution in the coal industry needs to resolve the principal contradictions constraining its further development. Reform is the most important path. The journey begins by gaining a clear understanding of the coal industry's role in China's economic and social development, and of how China is striving to achieve its long-term 
objectives of building a market-oriented, efficient and sophisticated coal industry management system by facilitating revolution through reform and being problem-oriented. There are six aspects to consider: (i) handle the relationship between the long-term target of creating a sophisticated management system and the shortand medium-term policies of the coal industry, while protecting the transformation process from disturbance by an emergency; (ii) the government's basic regulatory functions in the coal industry are to avoid price fluctuations and mitigate risk, as the coal sector is of fundamental importance for jobs and economic growth; (iii) once a sophisticated coal market system has been created, control the degree of government administrative regulation and ensure it does not cross the boundary between government and market; (iv) allow the domino effect of reform to take effect at carefully defined breakthrough points of the coal market system; (v) redefine the powers and responsibilities of coal mine safety management, and improve and standardise coal company governance; and (vi) use state-owned capital to optimise the coal industry and improve the industry's operations.

\subsubsection{Handle the Relationship Between the Long-Term Management System and the Short- and Medium-Term Policies of the Coal Industry}

Coal industry reform should have long-term objectives, but the market deals in short- and medium-term cycles. This makes it difficult to combine long-term system reform with short- and medium-term regulation. Supply shortages will not persist in China's coal market in the long run. Moderate oversupply is the target, which is also conducive to improving the coal market system. Shifting from supply shortage to moderate oversupply is a long process, during which labour pains are inevitable. China's coal market entered a downward trend in 2012, reaching the bottom of the cycle in 2015. Markets have the ability to self-regulate. From 2012 to 2015, with an imbalance between supply and demand, many small- and medium-sized coal companies that were not competitive left the market. In 2015, the coal industry made large financial losses. If no other measure other than self-regulation had been used, more coal companies would have shut down. To reduce coal capacity, the government implemented many policies and measures, which were successful after about a year. Then the coal market was short of supply. Compared with the historical price, the coal price in 2016-17 did not rise sharply, reaching only the historical mid-range, though this had a great impact on the bulk raw materials market. Stabilising the coal price was on the government's agenda again. The goal of ensuring safety also involved a conflict between long-term objectives and short- and medium-term performance. In the long term, coal mine safety needs to be managed by law. Only with a sophisticated legal system could a long-acting safety management mechanism be built. But in the short and medium terms, the government officials in charge could strengthen the rulebook to improve coal mine safety management and shift more responsibility onto businesses. During the reform of the coal industry, the central government set long-term reform objectives. However, when the administrative authorities introduced the policies and measures, they did so in response to short- and medium-term problems. It is not unusual for short- and medium-term policies and measures, even emergency policies and measures, to conflict with long-term reform objectives. Therefore, to achieve the long-term reform of the coal industry, the relationship between the long-term coal management system and short- and medium-term emergency policies should be properly managed. Specifically, institutional reform of the coal industry needs to achieve long-term objectives. Short and medium-term government regulation is essential, but it should not be used at the expense of long-term institutional reform. Although short-and medium-term regulation that runs counter to long-term reform can deliver results quickly, it will generate new bottlenecks that hinder the long-term reform process. 


\subsubsection{The Government's Regulatory Function Needs to Be Defined Clearly}

Coal will remain China's main energy source for a long time to come, although its share of energy consumption will decline. Forecasting of future consumption trends suggests that the coal industry's role in the Chinese economy will change. Its function of supporting energy supply, the economy and society will remain, but its status as a pillar industry will weaken. Coal, which is abundant in China, is a low-cost energy that will continue to account for a high proportion of the country's energy consumption. The coal industry has many workers and assets and high levels of debt. What happens in the coal industry has a strong chain effect on midstream and downstream industrial enterprises and the service sectors. Stability in the coal industry is important.

As China's main energy source, coal stabilises and supports the economy and society. The government therefore needs to impose macroregulation on short- and medium-term fluctuations in the coal market to minimise economic, social and safety risks. The two functions are related. If the coal price is stable, economic and social risks are low. However, even if the price is steady, coal mine closures, unemployment, insolvency and other economic and social risks still exist. In addition, safety should be prioritised.

\subsubsection{Controlling Administrative Regulation by Market and Legal Means}

Administrative regulation focuses on short- and medium-term problem-solving and tends to pursue short-term performance at the cost of long-term objectives. The root cause of this is that administrative regulation is not well controlled. Government directly intervenes in the production and operation of coal companies, crossing the line between government and the market. But the status of the coal industry has changed. It has opened up. Government regulation of the coal market should also change in alignment with ongoing coal industry reform, replacing administrative regulation with market and law-based regulation.

To control administrative regulation successfully requires a sophisticated coal industry system to be in place. Only with complete standards and laws can the government's use of market and legal regulation be fully developed. So, to make the most of market and law-based regulation, the coal market system must be improved continuously.

\subsubsection{The Coal Market System Should Be Developed at Carefully Defined Points}

China's coal market made great progress after 2010. Once dual coal prices were abolished, the pricing mechanism became more marketoriented. Some regional and local coal markets are becoming increasingly mature. Coal transport, trading, finance and information services are becoming more and more professional. The shortage of rail capacity has improved radically. But the coal market system still has some shortcomings, such as incomplete inventory standards, noncompliant inventory management, multiple information systems and inaccurate delivery of finished products. These are problems related to coal circulation, which clearly indicate that China's coal circulation system is unsophisticated and that the necessary means to regulate circulation are not in place. A sophisticated coal market system is the precondition for government macro-regulation using market and legal means. So, the coal market system needs to be further improved to lay a foundation for institutional reform of the coal industry. The key is to select accurate breakthrough points. Inventory standards, inventory management, unified information systems (the key) and accurate delivery of finished products are four areas to be improved. Coal market information, as an important enabler of government regulation of coal circulation, includes coal trading, inventory, flow and demand, and could engage the other three areas to improve the current coal market system. 


\subsubsection{Adjusting the Powers and Responsibilities of Coal Mine Safety Management}

Minimising safety risks is a key part of the government's macro-control. Safety management of coal mines is special. The coal mines of many large and medium-sized coal companies and groups are owned by subsidiaries. The state-owned Assets Supervision and Administration Commission administers the rights of investors in state-owned coal companies. Coal mine safety management responsibilities in the Production Safety Law conflict with those in the Company Law. According to the latter, the main responsibility of shareholders is not safety management. The direction of coal industry reform is towards marketisation and legalisation. Another priority for coal industry reform is to align the Production Safety Law with market law. Current legislation on the powers and responsibilities of coal mine safety management are not consistent with China's ongoing state-owned capital management system reform. In the long term, the powers and responsibilities of coal mine safety management need to be redefined. They could be adjusted moderately to alleviate investors' administrative management burden.

\subsubsection{The Role of State-Owned Capital Is to Optimise the Coal Industry}

Improving the state-owned capital management system is a priority for China's reform of state-owned enterprises. Many state-owned coal companies are now defined as state-owned capital investment corporations. This redefines asset management as capital management, and industrial asset operation as industrial capital investment. These changes will have a significant impact on the future structure of the coal industry, leading to two major reform tasks: standardisation of corporate governance and the introduction of mixed ownership. Adjusting the powers and responsibilities of coal mine safety management is one way to standardise corporate governance. Mixed ownership reform and the flow of state-owned capital are complementary. In the future, the state-owned capital of state-owned coal companies will optimise and improve coal industry operations.

\subsection{Policy Suggestions for Deepening Coal Industry Reform}

\subsubsection{Optimise Macro-Regulatory Institutions}

China's reform of the coal industry relies on effecting change in government functions. Only through administrative streamlining and decentralisation, a combination of deregulation and regulation, and service optimisation, can government authorities achieve the institutional objectives of reform. Government functions should focus on guidance and services, which are closely related to the basic functions of the coal market.

Guidance can be used in two ways: to guide government regulators on the strategic frontline of ensuring economic growth; and to help optimise the coal market by constraining and stimulating the regulatory system. The market, which is a bridge between upstream and downstream, should guide the transformation of coal production and consumption.

Service has several purposes: to help government regulators integrate decision-making and public services into a macro-control platform for the coal market; to facilitate macro-control by the central government; and to ensure that production and consumption develop harmoniously and that circulated resources are shared.

Related policy suggestions include: (i) harnessing the promising opportunities unearthed by the reform of party and state institutions to reorganise government's macro-regulatory authority and optimise its functions; (ii) enhancing the government's macro-strategies for the energy industry (including coal), and the functions of monitoring, forecasting, early warning and law-related regulation of the coal market; and (iii) reducing administrative micro-management. 


\subsubsection{Improve the Regulatory System}

The first challenge for China's coal industry reform is that the regulatory system is not sufficiently sophisticated. Building a coal circulation regulation system in line with China's national characteristics is an important area for institutional innovation.

Coal circulation regulations should be aligned with a regulatory system that combines centralisation and decentralisation, encourages centrallocal collaboration, and strengthens self-regulation. Multiple authorities, at different levels and covering different types of participant-including regulatory and other government authorities, central and local government, administrations and associations - should take part.

The regulatory regime should cover various functions of the coal market, including coal quality, commercial fields, logistics, capital, and information flow. Multi-functional supervision is limited rather than universal. This means that it should regulate key processes such as quality standards, environmental protection, contractual performance, credit supervision, risk supervision, and coal mine safety supervision.

Coal mine safety regulations need to be aligned with the reform of the state-owned capital management system and should take advantage of IT and intelligent technology. Regulators should consider redrawing the boundary of corporate governance to relieve shareholders and investors of the burden of administrative management.

\subsubsection{Build a Modern Market Information Network}

Institutional reform of the coal industry is impossible without the support of IT and communications technologies. The purpose of building a coal market information network is very clear: it is to create a coal market macro-control platform to provide data for government regulation. Suggestions are outlined below.

First, a data system that integrates production data and capacity regulation information should be built. It should pool production data from different sectors and form a 3D real-time capacity data network, providing technical support and scientific references for capacity governance by government. The transition from a data system in which designated companies upload their data at intervals, to one in which business and regional data is transferred in real time, will enable the data network to spot companies forging data or information in a timely fashion. Moreover, the common practice in developed economies of penalising companies that forge information should be followed. Social groups and individuals should be incentivised to engage in capacity supervision, and safe whistle-blowing channels should be provided to supplement governance.

Second, coal circulation should become increasingly intelligent to ensure logistics and processing are visible, important coal market information is collected, and key performance indicators of the regulatory system are measured.

Third, intelligent development should be aligned with the introduction of integrated coal logistics parks, and centralised real-time data acquisition points should be set up at different nodes in the coal circulation system.

Fourth, vertical and horizontal barriers in administration should be eliminated, and the data interfaces of the regulatory platform should enable data to be gathered from different administrations and local government authorities.

Fifth, coal industry associations and big data companies should collaborate to create an intelligent coal market information network that uses big data to make coal circulation regulation more market-oriented.

\subsubsection{Accelerate Coal Circulation Reform}

Reform of China's coal circulation lasted more than 30 years, achieving great outcomes. But coal circulation reform was not carried out systematically, except in some areas, such as coal pricing mechanism reform, coal market system building and coal regulatory reform.

Under the new normal of slower economic growth, the coal market has experienced fundamental change. Coal circulation reform was faced with external and internal pressures. One of the objectives of regulatory innovation is to 
speed up reform, including the reform of coal circulation. The regulatory system acts on the external part of the industry. The internal impetus for coal industry reform should be developed. Given the fundamental role of the coal industry in the economy and society, central government should focus on coal circulation reform. Suggestions are outlined below.

First, the optimisation and transformation of coal supply in China should be coordinated with air pollution prevention, the energy demand revolution and the development of traditional industries like steel in order to study coal circulation reform systematically. Details of the reform should reflect the global nature of coal circulation, including logistics and the flow of capital and information. The objective of coal circulation regulation reform can only be turned into actions through design excellence and systematic implementation.

Second, the parties involved in circulation should be encouraged to innovate. Reform of the coal industry needs to stimulate the industry's development. This should be in the form of technical and methodological innovation, including clean coal processing technologies, logistics, process visualisation, information integration and new circulation methods. The launch of new pilot projects should be considered.

\subsubsection{Deepen the Reform of State-Owned Coal Companies}

China should seize the policy opportunities of supply-side reform and state-owned capital management reform in order to speed up the optimisation of capital stock and eliminate inefficient capacity. At the same time, efforts should be made to promote the two-way flow of capital, coordinate exit and entry into the market, optimise the internal structure of the coal industry, improve the operations of coal companies, and accelerate innovation and transition through reform.

Staff and debt are the two main barriers to exiting inefficient capital stock in traditional enterprises. The challenge of repositioning staff can be addressed, but the debt barrier is more difficult to surmount. Debt is the priority when it comes to exiting inefficient capital stock. The policies to reduce debt and make short-term debt repayments focus on debt-for-equity swaps. This shows that exiting inefficient capital stock can be combined with swapping debt for equity.

The current challenges include: (i) Inefficient capital that needs to be exited cannot rely on debt-for-equity swaps. In the past, assets undergoing a debt-for-equity swap could rapidly enter a new round of the profit cycle, but inefficient assets with high debt now have little market value. Financial institutions typically issue a debt-for-equity swap based on profit expectations for assets with potential profitability, not for inefficient assets without any prospect of profitable development; (ii) the entity that issues the debt-for-equity swap is the parent company of a group, not the subsidiary operating the inefficient asset. In the early 21 st century, a group would have relatively undiversified businesses, and the group would be the principal debtor. The case is different now: a large group typically has a diversified business portfolio, and the debtor of an inefficient asset is usually the subsidiary that operates the asset. If the debt-for-equity swap is carried out within the group, it does not solve the challenge of exiting the debts of inefficient assets. Suggestions are outlined below.

First, the purpose of debt-for-equity swaps should be made clear-it is to spin off inefficient assets and lower the asset to debt ratio of companies, and, more importantly, to improve the operational efficiency of the real economy.

Second, an inefficient asset disposal platform should be established. Inefficient assets can be packaged and optimised or reorganised by business group or region to facilitate consistent implementation of the debt-for-equity swap policy.

Third, exit channels in financial institutions should be innovated. The financial policies for cutting overcapacity can be leveraged, and the opportunities to reform state-owned capital investment and introduce mixed ownership can be used to innovate financial capital exit channels in a market-oriented manner. 


\section{Market-Oriented Reform of the Power Industry}

\subsection{Review of International Experience}

Vivid Economics, a UK think tank, and a Shell International team of experts summarised the global market-oriented reform of the power industry and made suggestions for the future reform of China's power industry.

\subsubsection{The Evolution and Effects of Power Market Deregulation}

China and the World: Economic Transformation through Structural Reform, prepared by Dr. Mallika Ishwaran, Senior Economist, Shell International, for the 2017 China Development Forum, summarises the reform of the global power market. The paper points out that power market reform has evolved over several decades. Liberalised power markets, such as those of the USA and UK, were initially designed to meet the dual objectives of energy affordability and energy security (the energy dilemma). Starting with the UK in the 1990s, many countries have liberalised their power markets, based on standard market design criteria involving privatisation, competitive wholesale power generation and retail power supply markets, fair third-party access to transmission and distribution networks, and unbundling the ownership of transmission and distribution networks from power generation and retail supply. Liberalisation has been premised on encouraging competition-and competitive pricing - as a way to reduce electricity prices and develop diversity in supply sources to ensure supply security (Fig. 16). ${ }^{16}$

The first phase of power market liberalisation started in 1990 with the UK. This entailed unbundling power generation and retailing activities from the natural monopoly of

\footnotetext{
${ }^{16}$ Structural Power Market Reform to Support a Decarbonised Economy, March 2017. Prepared by Dr. Mallika Ishwaran, Senior Economist, Shell International, for the 2017 China Development Forum on China and the World: Economic Transformation through Structural Reform.
}

transmission and distribution. In parallel, a process of privatisation also occurred, particularly in the competitive segments of the supply chain. This form of liberalisation spread to Norway, Chile, Argentina, New Zealand and Australia in 1991, and began to spread across the USA from California in 1994. The European Commission published directives in 1996 that encouraged more countries across Europe to liberalise.

Following the 1990s liberalisation, notions of a standard market design began to coalesce around maximising the role of competition, rather than around government involvement, in order to optimise dispatch and investment in power generation and retail. Whereas the costs of production for power generation and the supply of electricity to the consumer could be minimised through competition, grid infrastructure, as a natural monopoly, was best delivered through the regulation of a single company.

Phase 2 of power market liberalisation came in the 2000s. This second phase of reform began with increasing focus on regional integration, harmonisation and environmental objectives. The European Commission and US Federal Energy Regulatory Commission began to promote standard market designs by attempting to prescribe best practice and facilitate trade across borders. The challenge of addressing climate change has meant that the energy dilemma facing policymakers has evolved into an energy trilemmadelivering affordable, secure and decarbonised electricity. Current liberalised power markets, which were designed to deliver energy dilemma objectives, have struggled to cope. The novelty and high initial cost of renewables has required generous government subsidies (undermining affordability) and their contrasting economics with fossil fuel generation has reduced the ability of the wholesale power market to incentivise investment and balance demand and supply (undermining security of supply).

Consequently, power markets across the world are in a state of flux, as countries have started decarbonising their power supply and the levels of renewables penetration have increased. Germany, which has led the way in renewables adoption, has nonetheless struggled to decarbonise energy 


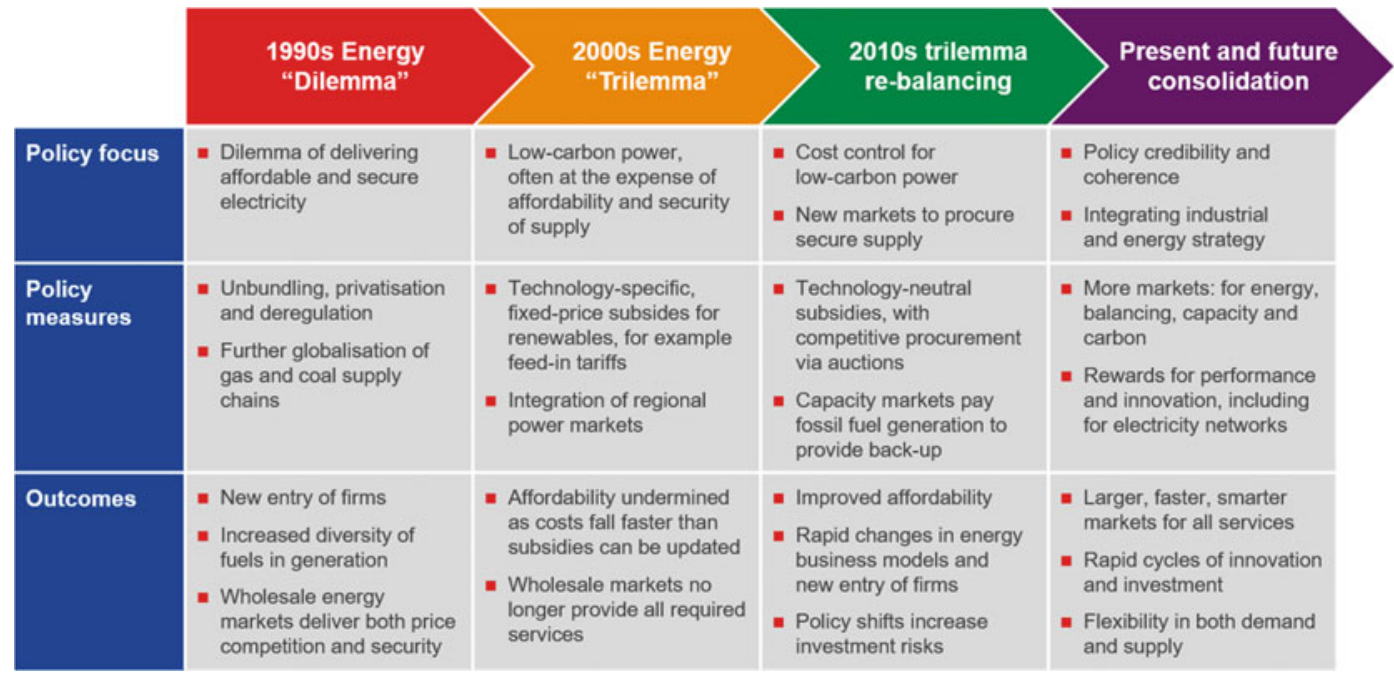

Fig. 16 The evolution of power market policy focus, measures and outcomes. Source Structural Power Market Reform to Support a Decarbonised Economy, Mallika Ishwaran, Shell International, March 2017

supply, because coal plants remain a low-cost source of secure supply.

The UK implemented phase 1 of its power market reform in the mid-2000s but has had to rapidly update policy to bring costs under control and maintain sufficient supply. This has created uncertainty for the up to $£ 100$ billion of planned investment in power generation from 2015 to 2020 (60\% of UK infrastructure spending in the period).

In recent years, innovation in market reform has begun to address the challenges of balancing the energy trilemma. These have focused on auctioning renewable subsidies and capacity payments to control costs and on incentivising new solutions to provide flexibility and improve network management.

Further reform will be needed to deliver a net zero emissions power system. The supply of flexible power is not yet sufficient, and demand for flexibility will increase as more energy end-uses are electrified, such as transport, which will likely increase peak loads. Currently, options such as batteries require multiple revenue streams to be economically viable, requiring changes to how value is distributed across the electricity supply chain. At the same time, the manufacture of renewable power equipment and the addition of a technology layer on top of energy assets, such as with smart meters and the Internet of things, links the transition to a net zero emissions energy system with broader industrial strategy aims.

The efficient coordination of an increasingly complex net zero emissions power system will be most efficiently delivered through greater use of markets. However, due to the challenges of low-carbon power, the appropriate market structures will be different from the historical standard market design. ${ }^{17}$

\subsubsection{Overcome the Market Challenges of Renewable Power}

Another important task during global energy system reform is to overcome the market challenges of renewable power. Variable renewables, such as solar and wind, are a crucial part of a net zero emissions power system, but they have characteristics that undermine the efficient operation of liberalised power markets as currently configured.

\footnotetext{
${ }^{17}$ Structural Power Market Reform to Support A Decarbonised Economy, March 2017. Prepared by Dr. Mallika Ishwaran, Senior Economist, Shell International, for the 2017 China Development Forum on China and the World: Economic Transformation through Structural Reform.
} 
Variability. A key feature of many low-carbon power technologies is that they are variable generators. This means that they generate on an as-available basis rather than on demand, i.e. they require the sun to be shining or the wind to be blowing in order to generate power. Flexible power generation and/or storage capacity is required to make up for this variability and to accommodate renewables into the power grid in a way that maintains security of supply. Furthermore, variable renewables, such as wind and solar, may frequently deviate from forecast levels even when the sun is shining and the wind is blowing, requiring greater short-term balancing between electricity demand and supply to correct for forecast errors. Power systems are already designed to manage variability. However, with greater renewables penetration, the demand for more frequent and greater levels of balancing are also likely to increase.

Low operating costs. Variable renewables, such as wind and solar, have zero or a very low marginal cost of operation once they have been built. This, combined with their variable nature (or intermittency), is already impacting the efficiency of existing liberalised wholesale power markets and the ability of these markets to deliver long-term investment in capacity. Specifically, renewable energy generators, bidding in the wholesale power market at their operating (or marginal) costs, have lowered average power prices. At the lower average price, conventional plants have found it difficult to recover their costs, and additional incentives have been required to invest in long-term capacity necessary to manage intermittency. This has reduced the ability of wholesale power markets to deliver energy security alongside the other two trilemma objectives.

Locational constraints. Renewables tend to be less flexible in terms of their location compared to conventional (fossil-based) power plants, requiring investment in grid expansion to accommodate and integrate them into the power system. They can be located far from demand centres, with optimal sites for wind and solar only coincidentally located close to urban areas and with network infrastructure required to connect supply with demand. Small-scale renewables, such as roof-top solar, may sell power into local distribution networks, but network investment is required to allow these new two-way flows of power without congestion.

Table 6 summarises the evolution of liberalised power markets and the new market signals necessary to accommodate a significant increase in renewables' share of the power mix.

\subsubsection{Build Efficient Net Zero Emissions Power Markets}

Most countries are likely to iterate towards efficient power market structures and policies based on the cost reductions and efficiency gains they are likely to provide, both in terms of cheaper investment and electricity. These benefits are only likely to increase with greater electrification

Table 6 Additional power market incentives required in a net zero emissions world

\begin{tabular}{ll} 
Characteristics of an NZE electricity system & Required signals \\
\hline $\begin{array}{l}\text { Low operating costs - renewables bid low in energy } \\
\text { market, reducing prices }\end{array}$ & Revenue stream to invest in capacity \\
$\begin{array}{l}\text { Variability - output changes and is not necessarily } \\
\text { available on demand }\end{array}$ & $\begin{array}{l}\text { Strong scarcity signals with high temporal resolution to } \\
\text { incentivise flexibility }\end{array}$ \\
$\begin{array}{l}\text { Locational constraints - generation may not be near } \\
\text { demand }\end{array}$ & Strong locational signals; sufficient grid investment \\
\hline
\end{tabular}

Note $\mathrm{NZE}=$ net zero emissions

Source Structural Power Market Reform to Support a Decarbonised Economy 


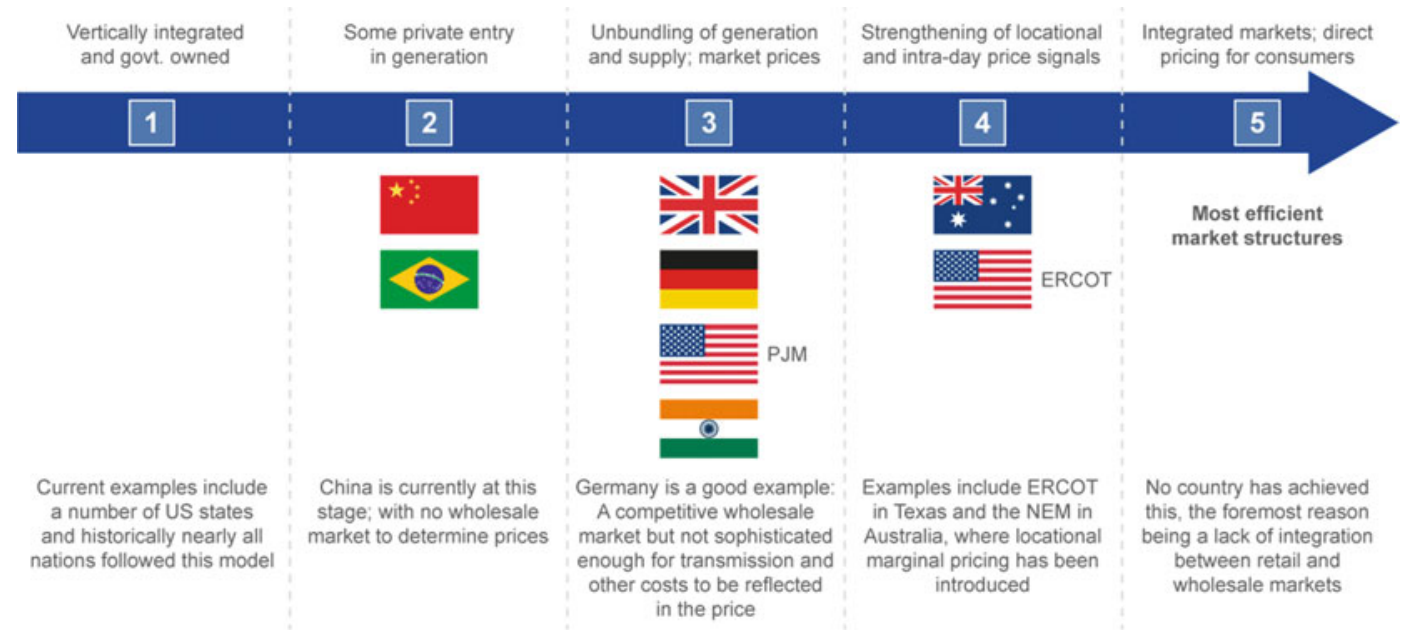

Fig. 17 Progress towards efficient power market structures. Source Vivid Economics

of energy use and decarbonisation of electricity supply.

Progress towards efficient net zero emissions power markets will depend on a country's circumstances, such as its level of economic development and its domestic energy resource endowments. Looking at a range of seven countries across this spectrum (Australia, Brazil, China, Germany, India, England and the USA), most are making progress. For example, unbundling along the supply chain to increase competition and using market prices (Fig. 17). However, currently these price signals are not very sophisticated. Only in Australia and the Electric Reliability Council of Texas (ERCOT) in the USA do prices provide strong locational and temporal signals, and in no market are consumers exposed to real-time prices. China and Brazil are the furthest behind, with limited competition between state-owned enterprises.

In terms of progress towards decarbonisation, government action, rather than market competition between fuels, currently drives decarbonisation (Fig. 18). Governments tend to decide the level of renewables by fixing the level of available subsidies, but then look to allocate these subsidies competitively. The most efficient pathway for decarbonising the power sector is for the level of renewables to be determined through a strong carbon price and ensuing market competition. Only the UK gets close, with its contracts for difference and carbon price floor. Germany and China, while delivering high levels of decarbonisation, are doing so through strong government involvement and at a high cost.

Efficient management of the power grid is currently delivered according to regulatory directives, rather than incentives (Fig. 19). Arrangements for grid management vary considerably across countries, with none basing investment on economic incentives. Instead, all seven countries regulate grid provision, with varying degrees of oversight. The UK and Germany are closest to being efficient, with performance-based regulation that rewards efficiency. At the other end of the spectrum, Brazil, India, and China reward grid provision on a cost-plus basis, which gives little incentive for reducing costs. Australia and PJM and ERCOT in the USA are in the middle of this spectrum, with independent oversight and benchmarking of cost estimates, which provide indirect pressure for efficient grid management.

Finally, policy credibility depends on the broader political, institutional and public environment. Even with efficient power market structures and policies, the ability to attract investment depends on policy risk and whether 


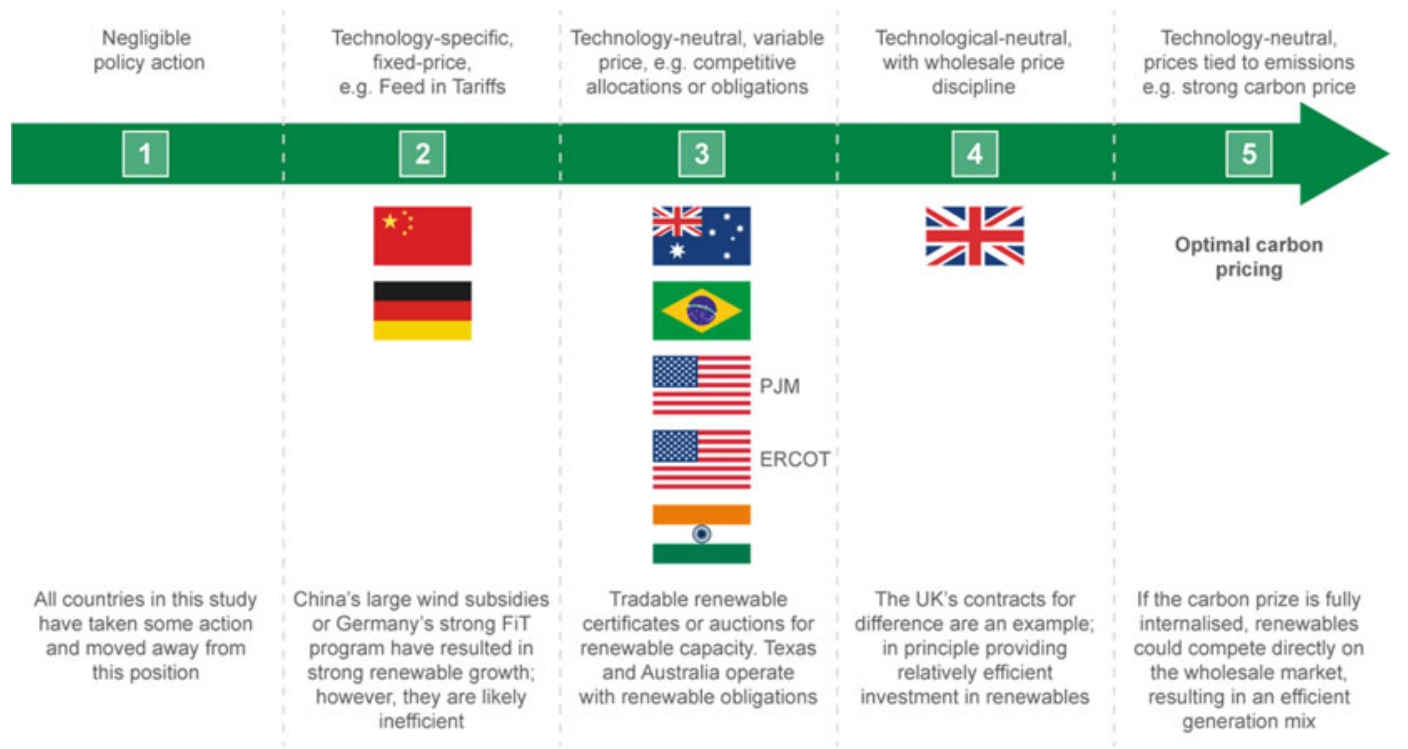

Fig. 18 Progress towards carbon pricing and market competition between fuel sources. Source Vivid Economics

\begin{tabular}{c|c|c|c|c|c|c|c|}
$\begin{array}{c}\text { Vertically integrated } \\
\text { and govt. owned }\end{array}$ & $\begin{array}{c}\text { Unbundled with cost } \\
\text { based regulation }\end{array}$ & $\begin{array}{c}\text { Unbundling and } \\
\text { independent oversight }\end{array}$ \\
economic incentives
\end{tabular}

Fig. 19 Progress towards efficient management of the power grid. Source Vivid Economics

there is an expectation that particular arrangements will persist, or at least change predictably. If policy is seen as credible, this will minimise the perceived risk of investment. Credibility is a quality of the policy environment, which depends on institutional capacity, political predictability, public support and the coordination of objectives across power market services. Governments can also take additional measures to increase credibility and reduce investment risk, such as passing primary legislation (as the UK did with the 2008 Climate Change Act), writing legal contracts, providing guarantees and releasing information on the performance of first-of-a-kind investments.

The pressure on policymakers to ensure that power markets function efficiently in delivering affordable, reliable and low-carbon electricity is only going to increase with higher levels of renewables penetration and greater reliance on 
electricity as an energy carrier. From a policymaker's perspective, there are two key characteristics of well-functioning and efficient power markets in a net zero emissions world ${ }^{18}$ :

- market structures that provide efficient price signals, both for near-term electricity dispatch and for long-term investment in the sector; and

- energy and environmental policies that correct for market failures and support the efficient operation of power markets.

These two factors are necessary for the efficient operation of net zero emissions power markets, without which meeting the energy trilemma objectives becomes significantly more challenging and expensive. For example, in an environment of rapidly declining technology costs, markets are better placed than policymakers to competitively and efficiently procure the necessary investments. However, policymakers have a fundamental role in providing the necessary regulatory and policy frameworks to underpin the efficient operation of these markets.

\subsubsection{Market Structures for Providing Efficient Price Signals}

The price signal from wholesale and retail power markets for conventional generation covers the range of energy provision services: supply of electricity, investment in generation capacity, and balance between the demand and supply of electricity. Variable renewables only provide energy and do so intermittently. This increases the importance of capacity and balancing, with markets potentially being required for these services as they are no longer provided as part of the bundle that has traditionally been provided by a single generation asset and paid for through wholesale and retail electricity prices.

The three requirements for efficient price signals are discussed below (see also the left-hand side of Fig. 20).

\footnotetext{
${ }^{18}$ Structural Power Market Reform to Support A Decarbonised Economy.
}

Efficient electricity markets. Through continued liberalisation of wholesale and retail power markets (including spatially larger and integrated markets that maximise the diversity of supply) to increase competition and security of supply, and through greater time-of-use and locational pricing with shorter settlement periods to increase the strength and specificity of the price signal for efficient electricity dispatch.

Investment in capacity. Through a technology-neutral capacity market (including both supply and demand measures and sufficient penalties to ensure delivery of contracted capacity), where efficient price signals for new investment in capacity are generated through competition among providers of this capacity. By themselves, short-term price signals from wholesale and retail markets are not likely to be enough to incentivise investment in long-term capacity at high levels of renewable energy penetration, thus requiring capacity markets.

Competitive balancing services. Short-term, grid-specific balancing and flexibility services may also be required to accommodate renewables. These would be required to supplement the price signal from wholesale and retail markets, which may be constrained by political economy considerations to protect end users from unexpected price spikes or due to forecast errors. Procuring these services competitively will provide them at the least possible cost and encourage the innovative use of new technologies, such as batteries and technologies that enable demand-side response. The need for such a market could decline as the time required to dispatch from a power plant decreases, and wholesale and retail power markets become more instantaneous.

\subsubsection{Energy and Environmental Policies that Correct for Market Failures}

Efficient policy approaches and frameworks to correct for market failures are also needed to support the efficient operation of power markets. Three key characteristics of the required policy framework are described below (see also the right-hand side of Fig. 20). 


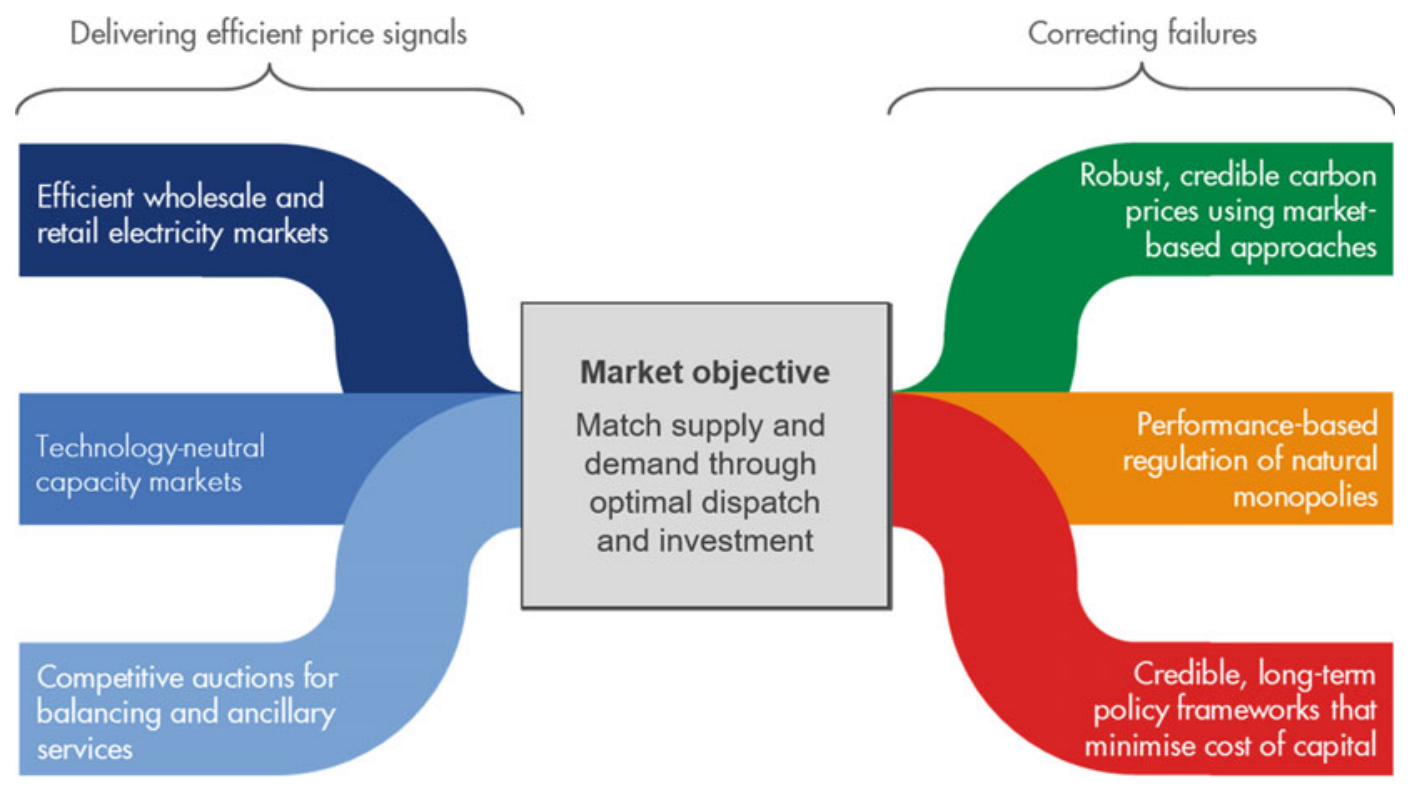

Fig. 20 Efficient power market structures and policies for a net zero emissions world

- The optimal way to incentivise low-carbon generation or encourage energy efficiency is through a robust and credible carbon price, preferably through market-based approaches such as a carbon tax or emissions trading. In its absence, there is likely to be a proliferation of a patchwork of more expensive and less effective policies, such as renewable energy subsidies and mandated performance standards.

- The natural monopoly of power transmission and distribution networks is most efficiently dealt with through independent ownership by a single company whose performance is regulated by an independent regulator. While this is a well-developed area of regulatory economics and policy, it will need to evolve to accommodate consumers that both demand and supply electricity; create flexible infrastructure with natural monopoly characteristics, such as large-scale storage and interconnectors; provide the returns needed for investment in grid extension and expansion to integrate renewables; and grant incentives for innovation in smarter grids.

- Maintaining a stable, predictable and credible policy framework across the range of energy and environmental policies that affect power markets is essential in order to minimise the cost of capital and incentivise the necessary long-term investments in the sector. Minimising policy risk is even more critical on the path to a net zero emissions world, given the long-term, large-scale and capital-intensive nature of the required investments. For example, the recent cycle of iterative power sector reform and learning has unsettled investors, even as the technology has matured to the point of mass deployment. A balance should be struck between the need for policymakers to respond to new circumstances and the need for stable revenues over long asset lifetimes, for example by making policies predictable, with changes announced well in advance and conditional on specified changes in circumstance. 


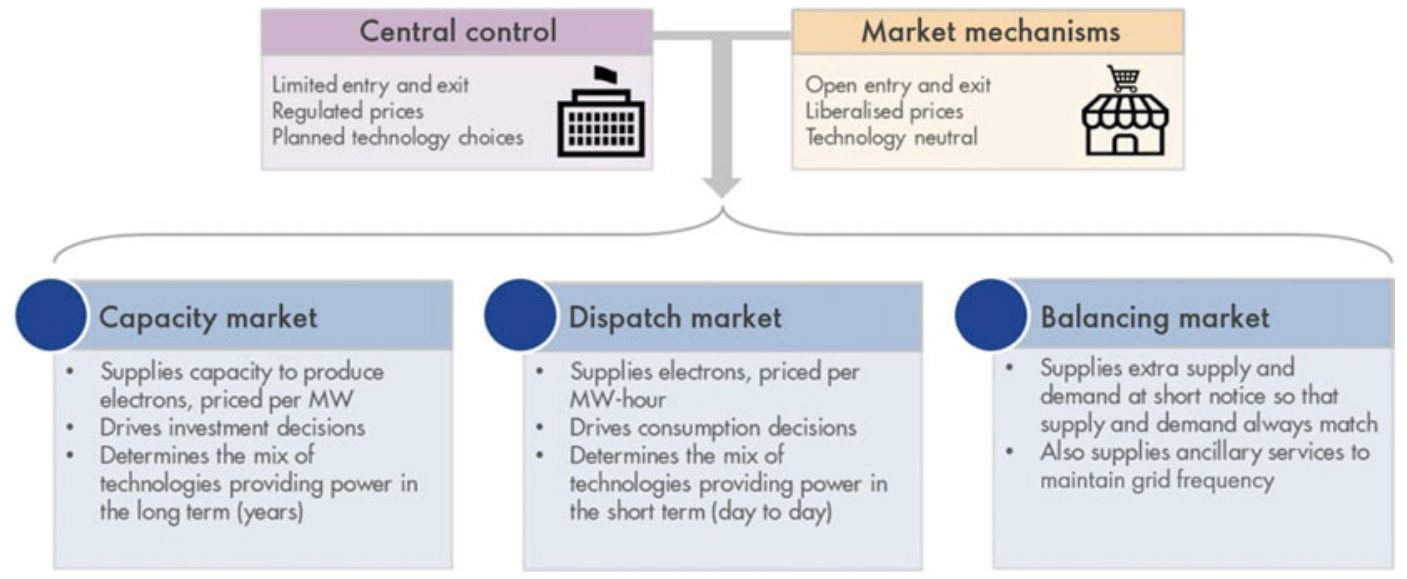

Fig. 21 The power system comprises three markets, which can be managed through central control or market mechanisms. Source Low Carbon Power Markets:

\subsection{Use of Central Control or Market Mechanisms in Seven Countries $^{19}$}

Vivid Economics prepared a report summarising international experience in power market reform for the DRC-Shell Markets Work Stream. The report describes the choices made in seven countries on managing their power systems by central control or market mechanisms. Management of power systems in Australia, Brazil, China, Germany, India, the UK and the USA (PJM, covering 13 states in the north-east, and ERCOT in Texas) are compared, based on the framework outlined in Fig. 21 and the major market features listed in Fig. 22.

Power market structure. Most countries are slowly moving away from central control to market mechanisms, as shown in Fig. 22. This trend is expected to accelerate with the increasing penetration of renewables. While no country has achieved completely liberalised and integrated markets, most countries have been evolving in this direction over the past three decades. We

\footnotetext{
${ }^{19}$ This part is prepared by Vivid Economics. See Low Carbon Power Markets: Lessons from International Experience prepared by Vivid Economics for DRC-Shell Markets Work Stream, April 2017.
}

Lessons from International Experience, prepared by Vivid Economics for the DRC-Shell Markets Work Stream, April 2017

observe three main archetypes of market structure:

- centrally controlled power markets with limited entry in generation (China, Brazil). China currently belongs to this group with no competitive wholesale market;

- unbundling of generation and supply; wholesale market prices (the UK, PJM in the USA, Germany and India). Germany is a good example of this: the country has a competitive wholesale market, but it is not sophisticated enough to reflect adequately transmission and other costs in market prices. Therefore, some government intervention is necessary; and

- increased market liberalisation and strengthening locational and price signals. In rare cases, for example ERCOT in Texas and NEM in Australia, locational marginal pricing has been introduced.

Market power. In order to ensure efficient investment and operation of grid infrastructure (natural monopolies), most countries currently use direct regulation, rather than incentive-based instruments, as shown in Fig. 23. For grids, options for regulation can be plotted along a spectrum, from government-owned and operated 


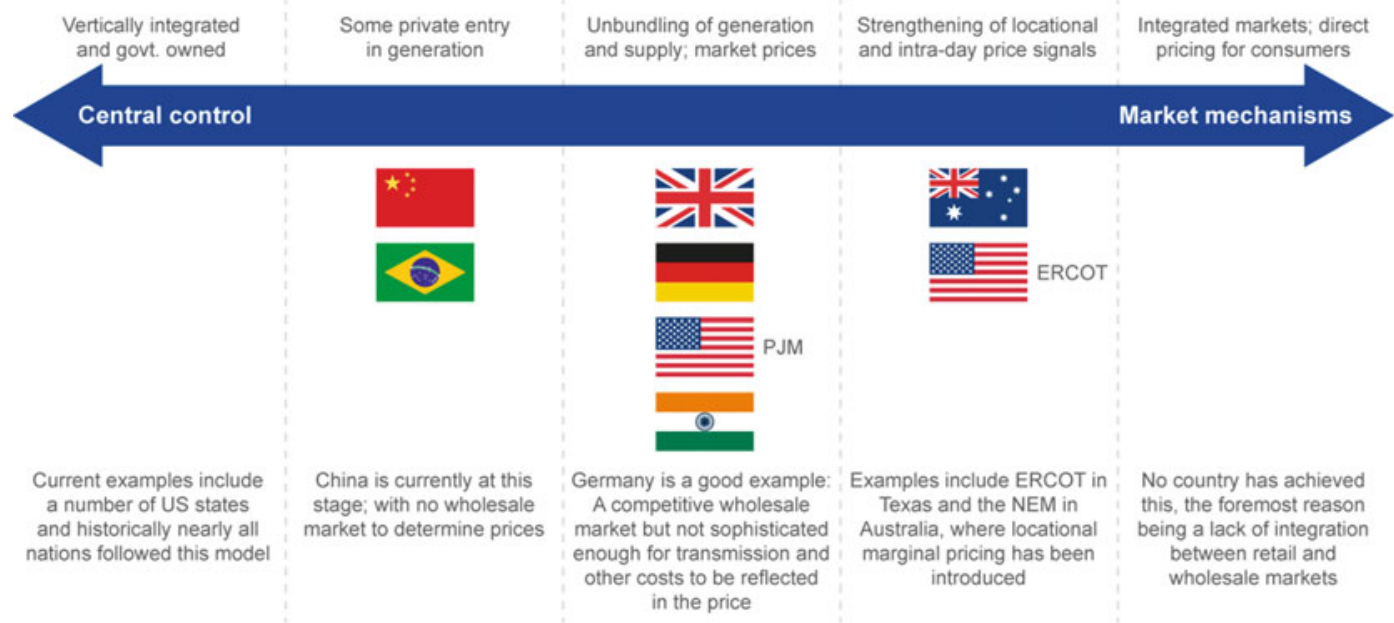

Fig. 22 Most countries are slowly moving from central to market mechanisms; this is expected to accelerate with decarbonisation. Source Low Carbon Power Markets:
Lessons from International Experience, prepared by Vivid Economics for the DRC-Shell Markets Work Stream, April 2017

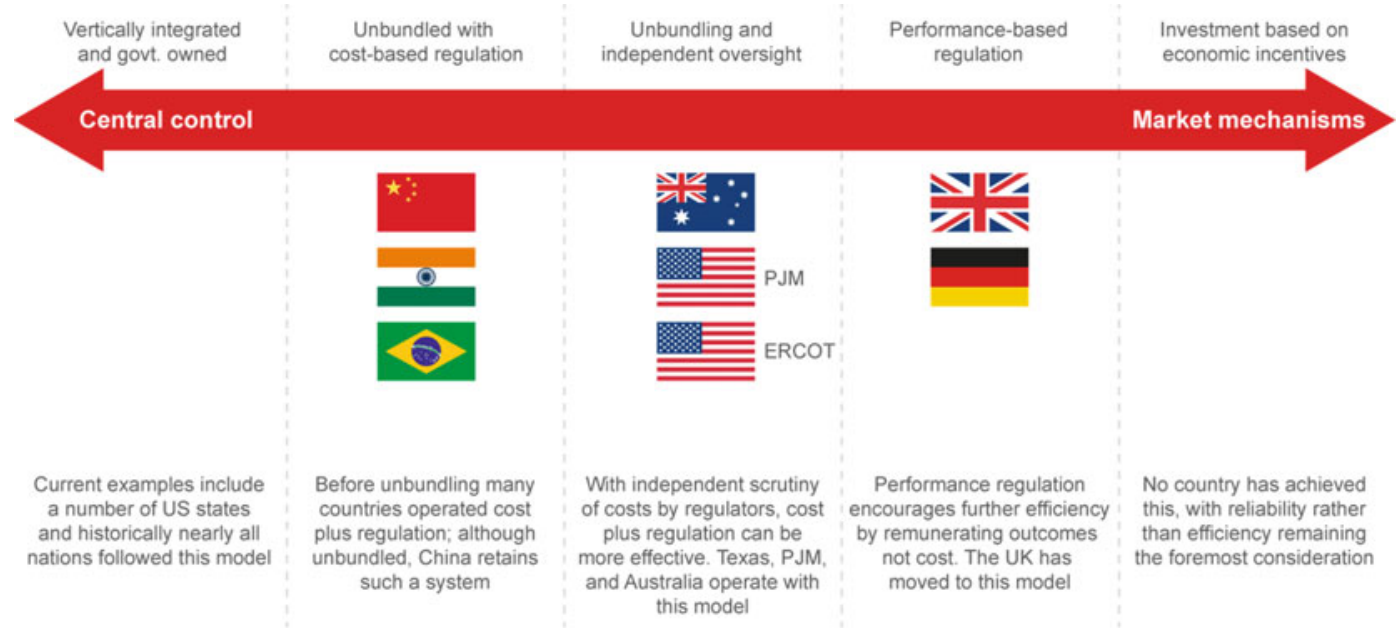

Fig. 23 Market power is mainly managed through regulation, rather than incentives, especially the power grid. Source Low Carbon Power Markets: Lessons from

to an unbundled sector with an independent service operator, where the government regulates the cost of service provision. To avoid moral hazard, performance- or incentive-based regulation can be introduced. However, as Fig. 23 suggests, the most advanced countries on the liberalisation spectrum (Germany and the UK) have opted for performance-based regulation, such as the UK price caps. China is at the other end of the spectrum-although the Chinese
International Experience, prepared by Vivid Economics for the DRC-Shell Markets Work Stream, April 2017

sector is unbundled, the country still operates cost-plus regulation.

Decarbonisation. The move to lower emissions is currently driven by central control, rather than by market mechanisms, as shown in Fig. 24. Given political constraints to the roll-out of carbon pricing, other options that preserve competition while directing investment to cleaner generation have been introduced. On the more liberalised part of the spectrum, those options 


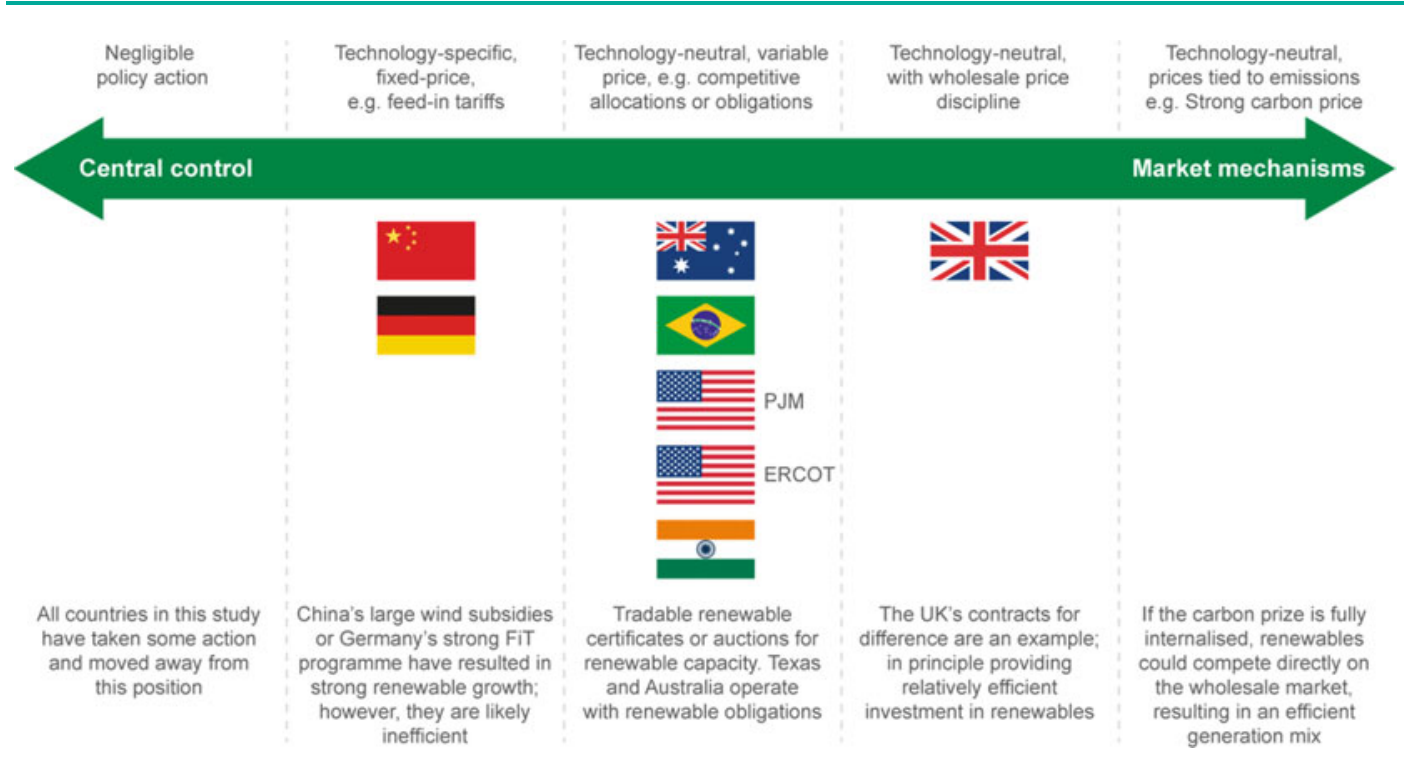

Fig. 24 Decarbonisation in most countries is driven by central control, rather than by market mechanisms. Source Low Carbon Power Markets: Lessons from International

include auctions for low-carbon electricity generation contracts, such as those currently in operation in Brazil and the UK. At the other end of the spectrum, China has adopted the more traditional way, which involves incentivising renewable investment through targeted fixed price measures, such as subsidies.

Policy credibility depends on the broader political, institutional and public environment. Even in a liberalised market, policy is important as it sets the market arrangements. The ability to attract investment depends on policy risk and whether there is an expectation that particular arrangements will persist, or at least change predictably. If policy is seen as credible then the perceived risk of investment will be minimised. Credibility does not have a scale from central control to market mechanisms but is a general quality of the policy environment. It depends on institutional capacity, political predictability, public support and the coordination of objectives across electricity market services. Governments can also take additional measures to increase credibility and reduce investment risk, such as passing primary legislation, writing legal contracts, providing guarantees and releasing
Experience, prepared by Vivid Economics for the DRC-Shell Markets Work Stream, April 2017

information on the performance of first-of-a-kind investments.

\subsection{Global Trends of Power System Transformation}

More and more countries have shifted the focus of energy development to clean energy in recent years, accelerating the global development of renewables and further optimising the energy consumption mix. Green, low-carbon, clean and efficient energy development has become a major trend and many countries have taken new measures regarding the market system, market mechanisms and regulation policies.

\subsubsection{Adapt to the Energy Transition and Innovate a New Market System and Mechanisms}

Increasing the share of renewables in the energy mix and deepening the energy transition imposes new challenges on the conventional power market system. In many countries, the power market system is already optimised and the types of energy traded is comprehensive. Those systems 
are better able to achieve the objectives of allocating international resources efficiently, making the power market competitive, channelling investment into new and low-carbon power generation, meeting consumer demand, and facilitating the use of new technologies.

The European Union published the New Energy Market Design report in 2015, according to which a new power market mechanism to create the European Energy Union will be built. It includes developing an international short- and long-term power market capable of attracting investment, perfecting a market mechanism suitable for renewables, improving the transnational capacity mechanism and strengthening the coordination between wholesale and retail markets. Regional cooperation will be strengthened, an integrated power market will be built and the energy supply security of the whole European Union will be achieved.

To achieve more flexible and efficient power supply and ensure power security, Germany passed the Electricity Market Act in 2016 to help build Electricity Market 2.0. The act focuses on renewables. It strengthens the procedure for adjusting the price signal, expands the balancing market, encourages supply-side management, and builds a fair power transmission tariff mechanism and capacity standby mechanism.

Great Britain launched a new round of power market-oriented reform focusing on low-carbon development in 2014 by holding the first contract for difference and capacity market auctions and amending the relevant rules and trading mechanism. California improved its real-time market, replacing the hour-ahead market with the 15-min market, and launched the energy imbalance market to adapt to the output of renewables.

\subsubsection{Build Large Resource Application Platforms by Expanding the Market}

To promote the development of renewables, diversify energy supply and ensure energy security, transregional and transnational resource allocation is urgently needed. The scope of the power market has expanded again and again, as with the Southwest Power Pool (SPP) in the USA.
Western Area Power Administration, Basin Electric Power Cooperative and Heartland joined the SPP in 2015, and power transaction volumes between the USA and Canada increased. EU member states have continued to strengthen regional cooperation on energy. Latvia, Estonia and Lithuania signed the Baltic Energy Market Interconnection Plan in 2015. The five major power exchanges in Europe signed an agreement to develop a unified European transnational intra-day trading platform, the purpose of which is to optimise the intra-day transnational and transregional trading plan and promote an integrated European power market. Sixteen grid operators in Europe announced an integrated day-ahead market for grids in central and western Europe, and in central and eastern Europe. Six countries in the western Balkans signed a memorandum of understanding on regional power market cooperation. A power market trading platform has started to facilitate the integration of the power markets and grids of countries in the Union for the Mediterranean. The European Union and Turkey strengthened their cooperation on energy market integration and renewables development.

\subsubsection{Pay Close Attention to the Construction of Energy Infrastructure that Helps Create Large Power Markets}

With the expansion of the power market and the large-scale development and use of clean energy, many countries are investing in the development or modernisation of transnational grids to support wide power transactions and optimise resource allocation:

- Grain Belt Express, a cross-state high-voltage transmission project in the USA, was approved by several states. The project, costing $\$ 2$ billion and $1,255 \mathrm{~km}$ in length, aims to integrate and transmit the wind power resources of Kansas;

- the European Union announced that transnational transmission capacity of each member state will account for at least $10 \%$ of its installed capacity by 2020 , and $15 \%$ by 2030 ; 
- transmission lines connecting the Iberian Peninsula, Baltic Sea region, Ireland and Great Britain will be built. To this end, the EU set up the South-west Europe High-level Working Party to encourage Spain, France and Portugal to construct energy infrastructure through technical support and regular monitoring, and to strengthen interconnections between the peninsula and other parts of the EU;

- two new transmission lines connecting Lithuania, Poland and Sweden are under construction to interconnect the Baltic states with Sweden and Poland for the first time;

- the EuroAsia Interconnector, a high-voltage transmission project that will connect the power grids of Israel, Greece and Cyprus with continental Europe, is under construction;

- to adapt to the rapid development of natural gas and wind power generation, Australia continues to invest heavily in cross-regional interconnections. As estimated by the Australian Energy Market Operator, Australia needs to invest AUD 24 billion in the transmission network by 2030 and AUD 120 billion in the power distribution network; and

- Russia has promoted the construction of an energy bridge with North Korea, while accelerating connection to the grids of surrounding countries like Azerbaijan, Belarus, Estonia, Georgia, Kazakhstan, Latvia, Lithuania, Mongolia and Ukraine.

\subsubsection{Build a Strong Regulatory Mechanism to Ensure Effective Competition in the Power Market}

As power market reform moved forward, countries gradually realised that strong regulation is an important condition for effective competition. Increasing the powers of the regulators and improving the content and methods of regulation has been an important trend in power market reform in recent years.

- The US Federal Energy Regulatory Commission (FERC) issued policies and regulations to improve wholesale power, capacity and auxiliary service market pricing, and regulates the demand-response resources entering the market in accordance with the latest measures for demand-side management.

- As suggested by Germany's Electricity Market 2.0, the German Federal Network Agency (Bundesnetzagentur) should issue regulatory measures and publish reports on the wholesale market at least once every two years, making the regulation of market abuse and monopoly actions more open and transparent.

- An amendment to Japan's Electricity Business Act was adopted at the plenary session of the House of Councillors. The act defines the plan for phase 3 of reform and states that an independent electricity regulatory commission will be formed.

- Australia released its national energy market reform roadmap, according to which regulating investment by grid operators and determining a reasonable rate of return for them is an important part of the reform.

- FERC issued rules on market supervision, regulation and analysis and strengthened power market information disclosure. This requires regional power wholesale markets to make power sales and transmission information public within a specified time, make power market prices more transparent and ensure users pay a reasonable price.

- To promote the development of low-carbon power and provide users with affordable electricity, the UK announced a plan for a new round of reform measures that includes price support for low-carbon energy through contracts for difference and a capacity market for procuring flexibility to balance the intermittency of variable renewables like wind and solar. This should improve investment in low-carbon energy and increase capacity. The government is also considering adjusting the transmission tariff mechanism to reflect the tariff for different types of generation, including prosumers supplying distributed renewable generation to the grid and consuming electricity from the grid during times of low or no renewables generation. 


\subsection{An Evaluation of Progress in China's Power System Reform}

\subsubsection{The Problems Facing Electricity System Reform}

As far as policy background is concerned, the Decisions of the Central Committee of the Communist Party of China on Major Issues Concerning Comprehensively Deepening Reforms was adopted in November 2013 at the third plenary session of the 18th Central Committee. The Decisions clearly state that "economic restructuring is still the focus of deepening reform comprehensively. Appropriate handling of the relationship between the government and the market is still the core issue of economic reform, which will enable the market to play a decisive role in allocating resources and the government to play its role better... In natural monopoly industries, in which state-owned capital continues to be the controlling shareholder, we will carry out reform focusing on the separation of government administration from enterprise management; the separation of government administration from state assets management, franchise operation and government oversight; the separation of infrastructure networks from operations; and relax control of competitive businesses based on the characteristics of different industries; and make resource allocation more market-oriented... and improve the mechanism whereby prices are determined mainly by the market. Any price that can be determined by the market must be left to the market, and the government should not improperly intervene. We will push ahead with pricing reforms of water, oil, natural gas, electricity, transport, telecommunications and other sectors, while relaxing price control in competitive areas".

At the sixth meeting of the Leading Group for Financial and Economic Affairs held in June 2014, the Four Energy Revolutions were mentioned for the first time, i.e. the revolutions in energy demand, energy supply, energy technologies and of the energy system. Regarding the revolution of the energy system, it is stated explicitly that "the commodity attributes of energy should be restored. A market structure and market system featuring effective competition, and a mechanism whereby energy price is determined mainly by the market, should be built".

Since the electricity system reform of 2002, which separated generation from transmission, the absence of many power market mechanisms has continued to hinder progress. These missing mechanisms include: a trading mechanism, the absence of which reduces resource use efficiency; a market-oriented pricing mechanism, which is missing because price relationships are not rational; government functions have not been fully defined, which prevents the regulatory system from regulating the power market effectively; nationwide and sector-wide planning and coordination mechanisms are not in place; the development and use of new energy and renewables is encountering difficulties due to an incomplete market development mechanism; law-making and amendments are lagging behind, restricting power marketisation and its healthy development; and the market credit system is developing slowly.

After observing and comparing China's power industry management system with that of OECD countries, Vivid Economics pointed out that the institutional framework for China's power industry is very complex. No agency has complete control over the power industry or the authority to coordinate other agencies' actions. Unlike regulators in OECD countries, the power regulatory function in China is exercised by the National Energy Administration (NEA), which is administered in turn by the National Development and Reform Commission. The NEA is not an independent body. A problem arises from such a management system: planning and pricing decisions at the central and local levels may be influenced by political objectives. This top-down planning approach for power grids and the lack of coordination with provincial and regional grid companies may lead to inefficient investment decisions and poor coordination between generation and transmission investments. These investment patterns create pockets of generation where electricity supply is abundant, but other 
areas where it is scarce, due to limited transmission capacity. As a result, while China has significant renewable generation capacity, large volumes of renewable energy are curtailed, increasing overall electricity costs and carbon emissions. ${ }^{20}$

According to Vivid Economics, the transition of China's energy system to a low-carbon and decentralised system is likely to exacerbate these inefficiencies and create new challenges. As the Chinese economy and energy sector decarbonises, it will be increasingly difficult to maintain a high level of grid reliability at an affordable cost. Moreover, decentralisation of electricity resources requires significant investment in smart capabilities and creates challenges for efficient planning and delivery of infrastructure across different networks. ${ }^{21}$

\subsubsection{Differences in the New Round of Electricity System Reform}

When different stakeholders reach a consensus on the problems in the power industry and the necessity of reform, differences arise regarding the reform path to be selected, mainly due to the positioning of grid companies in the power market.

One view is that the new round of power system reform should follow the same path as the last round in 2002 to complete unaccomplished reform tasks. These tasks include separating transmission from distribution, making dispatching organisations and trading institutions independent from grid companies, enabling the market to determine transmission and distribution prices, building regional power markets and creating a power spot market.

People who hold this view generally believe that integrated grid companies that operate transmission, distribution and sales hinder competition due to their control of the grid and large size, making effective regulation impossible. In

\footnotetext{
${ }^{20}$ Vivid Economics, Electricity Grids in Transition, Final Report. Prepared for the DRC-Shell Markets Revolution Work Stream, October 2017.

${ }^{21}$ Ibid.
}

their opinion, the precondition for a competitive power market is to restructure these companies. The basic approaches to restructuring in a Chinese context are:

- separate grid assets from non-grid assets, and transmission assets from distribution assets;

- make dispatching an independent, neutral organisation regulated by government because dispatching is a public service, not a grid company asset;

- build power exchanges involving various stakeholders and explore integrating power dispatching centres with power exchanges;

- create a power market dominated by regional power markets to avoid trans-provincial barriers and provincial oligopolies; and

- build power spot markets as soon as possible, based on the principle of "no spot, no market".

Another view is that the new round of power system reform should develop a practical and effective solution to the problems facing the Chinese power industry. The people holding this view believe that power reform is a long-term and progressive process, and that radical reforms like separation and restructuring will not solve the problems but will impact supply safety and grid stability. They suggest the following reform approaches:

- maintain control of the power grid but deregulate power generation and sales: gradually introduce competition into power generation and sales to develop diversified market participants and create a fair, competitive environment;

- stick to the principle that the power grid is a natural monopoly: maintain integrated management of transmission, distribution, dispatching and trading; strengthen government regulations and provide fair and efficient network services; and

- create a unified, open, competitive and orderly power market in which resource allocation and macro-control are combined organically: forge a sound legal system, 
change government functions, improve the regulatory system and build a scientifically based price mechanism.

The path arrived at in this section of the report is based largely on the second approach but incorporates some of the principles of the first approach.

\subsubsection{Targets and Tasks of the New Round of Power System Reform}

The ZhongFa No. 9 Document of 2015 marks the launch of the new round of power system reform. It defines the targets and tasks of reform in the light of the difficulties faced in building market mechanisms for China's power industry.

According to the document, the targets and tasks of the new round of reform are as follows.

The objective of reform is to make power a commodity by building a power industry market mechanism, developing a rational pricing mechanism, deregulating competitive segments in an orderly manner, diversifying suppliers, controlling energy consumption, enhancing energy efficiency, improving safety and reliability, ensuring fair competition, and protecting the environment.

The main tasks of reform are "three deregulations, one facilitation and three improvements". These are: deregulate (in an orderly manner) pricing in competition-based fields, except transmission and distribution; open distribution and sales to private capital in an orderly manner; lift control over power generation in an orderly manner, except peak-shaving; make power exchanges relatively independent; strengthen government regulations; improve power planning; and make power supply safe, efficient and reliable (Fig. 25).

Generally, the three deregulations, one facilitation and three improvements are all related to building power market mechanisms. The purpose of deregulating price in competition-based fields is to build the market price mechanism. The purpose of lifting control of sales and power generation is to build a market competition mechanism for generation and sales. The purpose of making power exchanges independent is to equip the market with fair and efficient trading

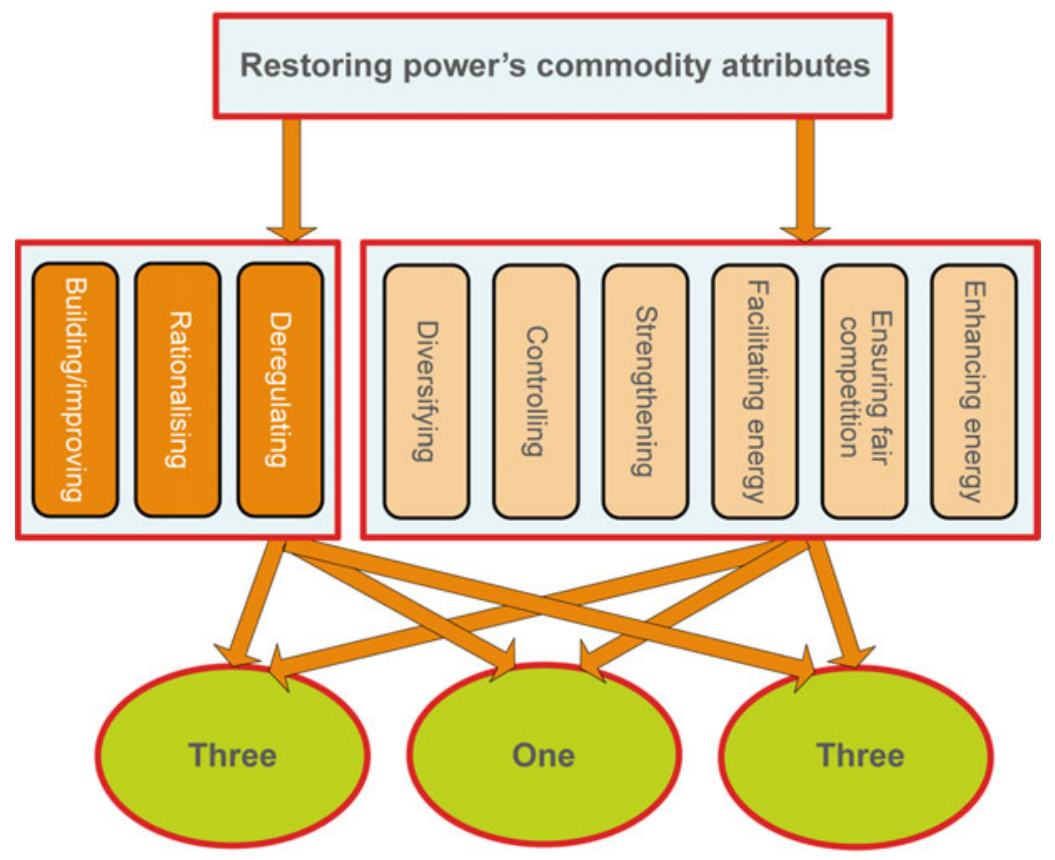

Fig. 25 Targets and tasks of the new round of power system reform 


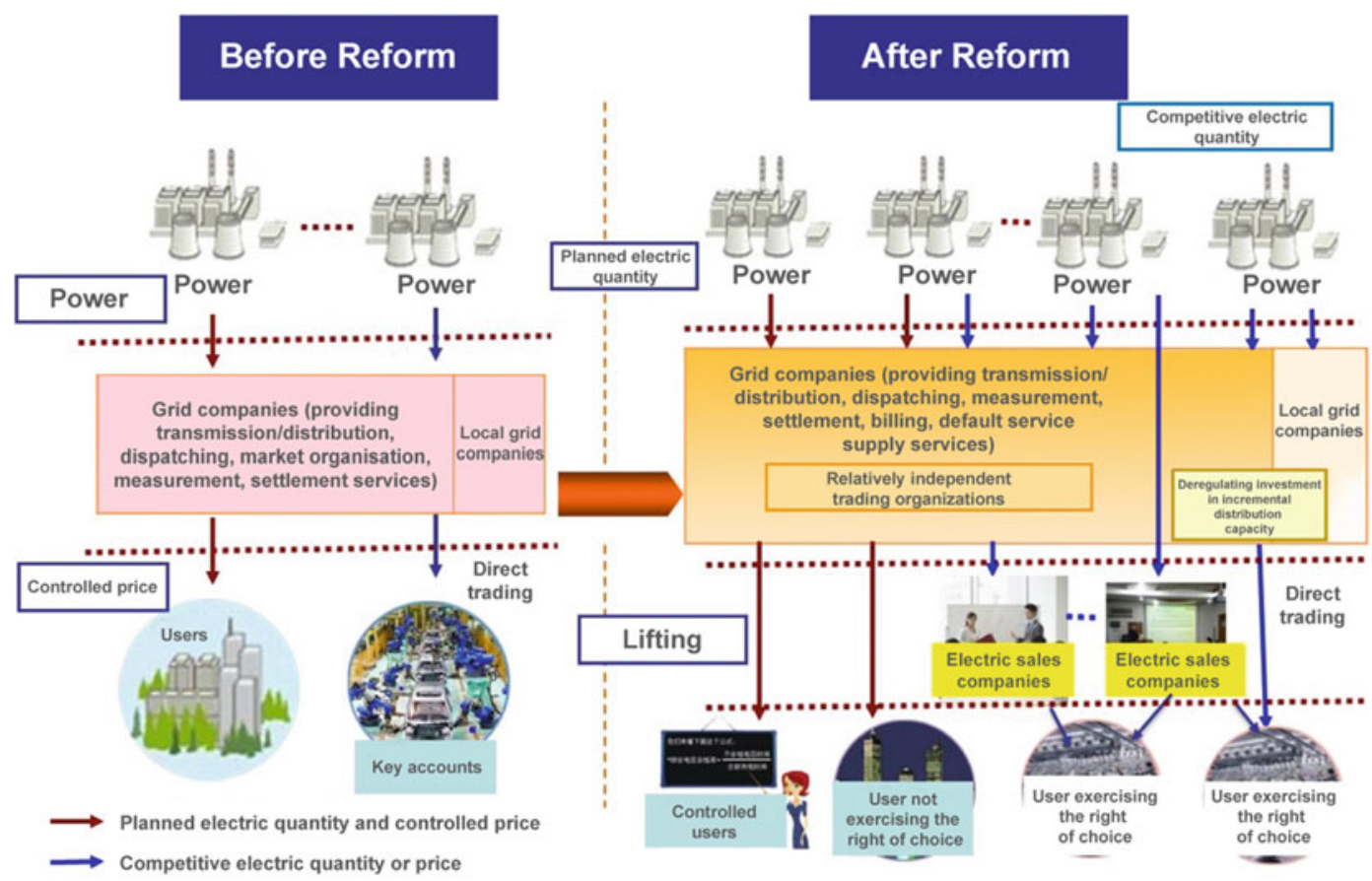

Fig. 26 Competition in the power market before and after reform

services and trading platforms. The purpose of the three improvements is to change government functions and build an effective regulatory system for the power market. The purpose of transmission and distribution price reform and of deregulating investment in distribution is to improve regulation of the power grid-the physical basis of the power market-and facilitate the development of distribution networks (Fig. 26 and Table 7).

Table 7 Measures, objects and purposes of the new round of power system reform

Measure

Deregulate price in competitive fields

Lift control of sales and power generation

Make power exchanges relatively independent

Strengthen government regulation and power planning; make power supply safe, efficient and reliable

Reform transmission and distribution pricing, deregulate investment in power distribution

Object Purpose

Price

Build a market price mechanism

mechanism

Competition

Build market competition mechanisms in mechanism

Trading platforms

Regulation

Physical basis of the power market generation and sales

Equip the market with fair and efficient trading services and trading platforms

Change government functions and build an effective regulatory system for the power market

Strengthen regulation of the power grid - the physical basis of the power market-and facilitate the development of distribution networks 


\subsubsection{Progress in the New Round of Power System Reform}

\section{(1) Reform policies}

The ZhongFa No. 9 Document defines the targets and tasks of China's power system reform. The six main support documents published in November 2015 provide a specific working plan for the reforms. The National Development and Reform Commission and National Energy Administration are formulating detailed rules for their implementation. The Administrative Measures for Access and Withdrawal of Electricity Sale Companies and Administrative Measures for Orderly Deregulation of Power Distribution Networks were released in October 2016.
The Opinions on Promoting Transmission and Distribution Tariff Reform sets three objectives: (i) build a reasonable, scientific, transparent and independent transmission and distribution tariff system that is well regulated with clear rules; (ii) form a transmission and distribution pricing mechanism based on the principle of "allowable cost + reasonable profit"; and (iii) define government funds and cross-subsidies. The main content and requirements are shown in Tables 8 and 9 .

The Opinions on Establishing Power Trading Institutions and Standardising Their Operation defines the objectives of "building a competitive market structure and market system", as required by the ZhongFa No. 9 Document, and of establishing relatively independent and standardised

Table 8 Opinions on promoting transmission and distribution tariff reform

\section{Main content}

Gradually expand the scope of pilot transmission and distribution tariff reform

Carefully calculate the transmission and distribution tariff

Promote cross-subsidy reform by category

Policies on transmission and distribution tariffs for power trading during the transitional period

\section{Main requirements}

Include the regions carrying out pilot power system reform in the scope of pilot transmission and distribution tariff reform Allow regional characteristics to be embodied in transmission and distribution tariff calculation parameters, the price adjustment cycle and total income regulation patterns

For pilot regions, the National Development and Reform Commission performs centralised cost supervision, calculates transmission and distribution tariffs for each voltage class, creates balance accounts for pilot regions, and supervises and regulates income and price levels

For non-pilot regions, research and calculate transmission and distribution tariffs for each voltage class

Gradually reduce cross-subsidies for industrial and commercial users, and correctly manage cross-subsidies for domestic and agricultural users

Grid companies report the amount of tariff cross-subsidies for different types of user during a transitional period, which will be recovered through transmission and distribution tariffs after being reviewed by price authorities After transmission and distribution tariff reform, the transmission and distribution tariff for each voltage class and the cross-subsidies borne by domestic and agricultural users will be calculated

In those regions where transmission and distribution tariffs have been set, power is traded at the approved tariff In those regions where separate transmission and distribution tariffs have not been set, sales-side reform will be promoted 
Table 9 Opinions on advancing the creation of power markets

\begin{tabular}{|c|c|}
\hline Main content & Main requirements \\
\hline $\begin{array}{l}\text { Market } \\
\text { composition }\end{array}$ & $\begin{array}{l}\text { Composed mainly of medium- and long-term markets and spot markets } \\
\text { Medium- and long-term markets cover power trading on a multi-year, yearly, quarterly, monthly and } \\
\text { weekly basis and for interruptible loads, voltage adjustment and other auxiliary services } \\
\text { The spot market mainly covers day-ahead, intra-day, real-time power trading and trading of standby, } \\
\text { frequency modulation and other auxiliary services } \\
\text { After conditions mature, capacity market, power futures and derivatives trading will be explored }\end{array}$ \\
\hline Market mode & $\begin{array}{l}\text { Includes decentralised and centralised markets } \\
\text { Under the decentralised mode based on medium- and long-term physical contracts, power users and } \\
\text { producers themselves determine daily output and load curve during the day-ahead period; the deviation is } \\
\text { adjusted through day-ahead, real-time balance trading } \\
\text { In centralised markets, risk is managed through medium-and long-term contracts for difference, and } \\
\text { centralised price competition is applied with the help of spot trading }\end{array}$ \\
\hline Market system & $\begin{array}{l}\text { Divided into regional and provincial (municipal) power markets, which are not graded } \\
\text { Nationwide optimal allocation of resources is almost achieved, mainly by the Beijing and Guangzhou } \\
\text { power exchanges } \\
\text { Set up spot markets in large and provincial markets that offer optimal allocation of resources }\end{array}$ \\
\hline $\begin{array}{l}\text { Market } \\
\text { participants }\end{array}$ & $\begin{array}{l}\text { Includes power producers, power suppliers (local power grids, bulk sale counties, high-tech industrial } \\
\text { parks and economic and technological development zones), power sales companies and power users. The } \\
\text { users involved in market trading should be those with large capacity and loads whose access voltage } \\
\text { reaches the threshold }\end{array}$ \\
\hline $\begin{array}{l}\text { Market } \\
\text { operation }\end{array}$ & $\begin{array}{l}\text { Detail provisions by trading organisation or implementation, medium- and long-term trade contracts, } \\
\text { day-ahead generation plans, intra-day generation plans, pricing of competitive fields, market settlement, } \\
\text { safety assessment, congestion management, emergency response, market supervision and regulation }\end{array}$ \\
\hline Credit system & $\begin{array}{l}\text { Create a market participant credit rating system, annual information disclosure system, loyalty incentives } \\
\text { and dishonesty penalty mechanisms }\end{array}$ \\
\hline
\end{tabular}

power trading institutions. Its main content and key requirements are shown in Table 10.

The Opinions on Implementing an Orderly Liberalisation of Power Generation and Consumption Planning lists the following objectives: (i) build a power operation mechanism that features orderly competition and is strongly supported, and that shifts the power system gradually from plan-oriented to one in which the market plays a decisive role; (ii) ensure power supply to households and other users who do not have bargaining power by establishing a power generation and purchase priority mechanism, granting preferential grid access for public and peak-shaving purposes. The main content and requirements of the document are shown in Table 11.

The Opinions on Promoting Power Sales Reform has the following objectives: introduce competition into power sales, open power sales to private capital, expand user choice, develop power sellers in different ways, and form a competition-based environment of diversified buyers and sellers. Its main content and requirements are shown in Table 12.

The main objectives of the Guidance on Strengthening and Standardising the Supervision and Management of Privately Owned Coal-Fired Power Plants are: gradually make privately owned power plants equal with state-owned power plants, promote the orderly development of privately owned power plants, increase the absorption of clean energy, improve energy use efficiency, and ensure fair market competition. Its main content and requirements are shown in Table 13.

The Administrative Measures for Access and Withdrawal of Electricity Sales Companies provides clear stipulations on access, exit, classification and scope of business of power sales 
Table 10 Opinions on establishing power trading institutions and standardising their operation

\begin{tabular}{|c|c|}
\hline Main content & Main requirements \\
\hline $\begin{array}{l}\text { Functions and } \\
\text { positioning }\end{array}$ & $\begin{array}{l}\text { Non-profit trading institutions provide market participants with standardised, open and } \\
\text { transparent power trading services under government regulation } \\
\text { Construct, operate and manage market trading platforms, organise market trading, } \\
\text { provide settlement and relevant services, gather bilateral contracts between power users } \\
\text { and producers, register and manage market participants, and disclose and release market } \\
\text { information }\end{array}$ \\
\hline Organisational form & $\begin{array}{l}\text { Separate the trading business of grid companies, establish trading institutions in } \\
\text { accordance with the articles of association and rules approved by government } \\
\text { Trading institutions could be companies partly controlled by grid companies, their } \\
\text { subsidiaries or members of grid companies }\end{array}$ \\
\hline $\begin{array}{l}\text { Market management } \\
\text { committee }\end{array}$ & $\begin{array}{l}\text { Build a market management committee consisting of representatives from grid } \\
\text { companies, power producers, power sales companies and power users. The committee is } \\
\text { responsible for researching and discussing the articles of association of trading } \\
\text { institutions and trading and operational rules, and for coordinating matters related to the } \\
\text { power market } \\
\text { Market management committees adopt a discussion mechanism, such as voting by } \\
\text { category of market participant } \\
\text { Decisions of market management committees are executed after being reviewed. The } \\
\text { National Energy Administration and competent authorities should have the power of } \\
\text { veto }\end{array}$ \\
\hline System and framework & $\begin{array}{l}\text { Set up relatively independent regional and provincial (municipal) trading institutions in } \\
\text { an orderly manner. These include the Beijing and Guangzhou power exchanges and } \\
\text { other trading institutions servicing regional power markets. Encourage trading } \\
\text { institutions to expand the scope of trading services and promote market integration }\end{array}$ \\
\hline $\begin{array}{l}\text { Staffing and sources of } \\
\text { income }\end{array}$ & $\begin{array}{l}\text { Trading institutions could be staffed with existing grid company employees. Senior } \\
\text { managers should be recommended by market management committees and appointed in } \\
\text { accordance with applicable laws and procedures. Trading institutions may charge market } \\
\text { players reasonably for registration fees, annual fees and service charges for trading }\end{array}$ \\
\hline Dispatching & $\begin{array}{l}\text { Trading institutions are responsible for market trading. Dispatching organisations are } \\
\text { responsible for real-time trading, balancing and system security. For day-ahead trading, } \\
\text { functional boundaries should be defined based on circumstances, practical operation and } \\
\text { lessons learned }\end{array}$ \\
\hline
\end{tabular}

companies, and plays an important guiding role in standardising the power sales market. Its main content and requirements are shown in Table 14.

The Administrative Measures for Deregulating Power Distribution Networks in an Orderly Manner deregulate investment in incremental power distribution network capacity. Its main content and requirements are shown in Table 15.

\section{(2) Reform progress}

Power system reform. Up to the end of 2016, the National Development and Reform Commission had designated: Yunnan, Guizhou, Shanxi, Guangxi, Beijing, Hubei, Sichuan, Liaoning, Shaanxi, Shandong, Anhui, Henan, Xinjiang and Ningxia as comprehensive power reform pilot provinces; Guangdong, Chongqing, Xinjiang Production and Construction Corps, Fujian, Heilongjiang and Hebei as power sales deregulation pilot provinces; and Gansu, Hainan and Shanghai as electricity system reform pilot provinces.

Pilot transmission and distribution tariff reform was carried out in six provincial power grids (western Inner Mongolia, Anhui, Hubei, 
Table 11 Opinions on implementing an orderly liberalisation of power generation and consumption planning

Main content
Build a purchase priority system

Build a priority generation system

Ensure electricity balancing

Actively promote direct trading

Lift control of generation planning in an orderly manner

\section{Main requirements}

Priority purchasers: primary industry, domestic users, important utilities supplying the service and public service industries

The measures to protect priority purchase rights: share generating units, improve demand-side management, implement in an orderly manner, and ensure power supply to remote and poor regions

Priority producers: planned renewables, peak-shaving/frequency modulation and cogeneration, hydropower, nuclear power, power generated with waste heat/pressure/gas; power generated in accordance with trans-provincial and interregional national plans, local government agreements or for historical reasons

Measures to protect priority generation: (i) leave space for planning;

(ii) improve power output and absorption; (iii) forecast output in a centralised manner; and (iv) organise and implement replacement power and make priority power tradeable

Manage priority generation: preferentially arrange renewables generation to fill output gaps; arrange peak-shaving and frequency modulation demand as needed; arrange cogeneration using waste heat, pressure or gas; and manage hydropower and nuclear power

Organise direct trading: ensure load characteristics do not deteriorate, avoid an increase in peak-shaving pressure. Direct trading should not affect demand for heating. In regions with a high proportion of hydropower, direct trading should distinguish between the wet and dry seasons

Capacity deduction methods: to motivate power producers, the amount of power traded may be converted into generation capacity based on the users' maximum load utilisation hours, local industrial users' average utilisation hours, or the upper limit

Carry out pilot power market projects in regions with the right conditions. Carry out market-oriented trading in non-pilot regions in accordance with the Opinions on Implementing an Orderly Liberalisation of Power Generation and Consumption Planning. Maintain power load characteristics and avoid irrational competition

Gradually increase the amount of power traded: the market for industrial and commercial users of $110 \mathrm{kV}$ and above could be deregulated, followed by that for industrial and commercial users of $35 \mathrm{kV}$ and above. When the conditions have evolved and matured, the market for all users of $10 \mathrm{kV}$ and above could be deregulated

Establish a power market system: gradually lower trading access requirements for users, power sales companies and power producers to expand the size of the market

Improve the emergency supply mechanism: encourage enterprises and users of priority generation to enter the market voluntarily. Renewable power could take part in market competition with subsidies and be protected by a renewable energy quota system
Ningxia, Yunnan and Guizhou) in 2015. Included in the pilot transmission and distribution tariff reform of April 2016 were the provincial power grids of Beijing, Tianjin, southern Hebei, northern Hebei, Shanxi, Shaanxi, Jiangxi,
Hunan, Sichuan, Chongqing, Guangdong and Guangxi; the provincial power grids covered by the national power system comprehensive reform pilots; and the power grids of north China. In August 2016, the National Development and 
Table 12 Opinions on promoting power sales reform

Main content
Market participants in power sales

Access and exit mechanisms for power sales market participants

Business and trading activities of market participants

Deregulating investment in incremental distribution capacity

Build credit system and risk prevention mechanisms for the power sales market

\section{Main requirements}

Power sales companies fall into three categories: (i) power sales companies that are grid companies; (ii) power sales companies with the right to operate a power distribution network and use private capital to invest in incremental power distribution networks; and (iii) independent power sales companies without the right to operate a power distribution network and that do not provide minimum supply services

Grid companies, eligible power producers, qualified high-tech industrial parks and economic and technological development zones, distributed power and microgrid owners, utilities including water, heat and gas suppliers, energy-saving service providers, private capital and private enterprises may invest in or form power sales companies to carry out power sales activities

Access and exit of market participants, not subject to administrative approval, need to be included in an annual list of provincial government announcements. Such market participants need to make commitments and be registered at trading institutions. Power sales companies need to be independent legal entities registered in accordance with the Company Law of the People's Republic of China

The core business of power sales companies is electricity purchase and sales, which could include energy performance contracting, energy-saving strategies, electricity use consulting and other power-related value-added services

Before selling electricity to users in the quantity and at the price agreed with them, power sales companies may trade with power producers freely or through trading platforms. Distributed power or microgrid users may delegate electricity purchase and sales to power sales companies. The power purchase price for users involved in market trading consists of the market transaction price, the transmission and distribution tariff (including line loss and cross-subsidy) and government funds

Grid companies offering measurement, meter reading, billing, settlement, installation, repair and other power supply services are responsible for settling electricity bills and ensuring safety of the funds. Grid companies ensure minimum power supply in the regions they serve

Encourage the development of the power distribution business through mixed ownership. Deregulate investment in incremental distribution capacity for qualified market players

Private capital investing in and wholly controlling incremental power distribution networks, i.e. with the right to operate the power distribution network, also has the same rights as the grid companies in the same power supply area and should fulfil the same responsibilities and obligations

There could be multiple power sales companies in one power supply area. But only one of them has the right to operate the power distribution network and provide minimum supply services

Establish a market participant credit rating mechanism and blacklist. Government could intervene in the market in the case of serious abnormalities 
Table 13 Guidance on strengthening and standardising the supervision and management of privately owned coal-fired power plants

\begin{tabular}{|c|c|}
\hline Main content & Main requirements \\
\hline $\begin{array}{l}\text { Improve planning guidance and } \\
\text { standardise construction scientifically }\end{array}$ & $\begin{array}{l}\text { The requirements for planning, selection, approval, construction and } \\
\text { grid integration of newly built (or expanded) privately owned } \\
\text { coal-fired power plants (except backpressure and waste } \\
\text { heat/pressure/gas plant units) should in principle be the same as those } \\
\text { for state-owned power plants. State-owned power plants are not } \\
\text { allowed to change into private ownership }\end{array}$ \\
\hline $\begin{array}{l}\text { Improve operational management and } \\
\text { take part in auxiliary services }\end{array}$ & $\begin{array}{l}\text { Grid-connected privately owned power plants should follow } \\
\text { dispatching disciplines, undertake their responsibilities and obligations } \\
\text { to provide safe and stable power supply, and be covered by auxiliary } \\
\text { service assessment or compensation in accordance with the Detailed } \\
\text { Rules for the Administration of Grid-Connected Power Plants and the } \\
\text { Detailed Rules for the Administration of Ancillary Services of } \\
\text { Grid-Connected Power Plants }\end{array}$ \\
\hline $\begin{array}{l}\text { Assume social responsibilities by paying } \\
\text { charges and fees }\end{array}$ & $\begin{array}{l}\text { Electricity generated by privately owned power plants and used by the } \\
\text { owner is subject to government funds and policy-related } \\
\text { cross-subsidies. These monies should not be exempted without } \\
\text { permission or collected selectively by local government at any level. } \\
\text { Enterprises with grid-connected privately owned power plants should } \\
\text { pay a system standby fee to the grid company based on the agreed } \\
\text { standby capacity at the rate set by each province }\end{array}$ \\
\hline Reduce the use of coal combustion & $\begin{array}{l}\text { Replace privately owned coal-fired power plants with renewable } \\
\text { energy generation }\end{array}$ \\
\hline $\begin{array}{l}\text { Define the market participants in market } \\
\text { trading }\end{array}$ & $\begin{array}{l}\text { Enterprises with privately owned power plants that are not able to } \\
\text { meet their own power demand could purchase electricity after paying a } \\
\text { fee set by government. The fee should be in accordance with } \\
\text { applicable laws, regulations and policy-related cross-subsidies }\end{array}$ \\
\hline $\begin{array}{l}\text { Define accountability and improve } \\
\text { supervision and management }\end{array}$ & $\begin{array}{l}\text { Privately owned power plants should name the parties accountable, } \\
\text { improve organisation and coordination, carry out specialised } \\
\text { regulation, improve project management, standardise operation and } \\
\text { modernisation, and strengthen supervision and inspection }\end{array}$ \\
\hline
\end{tabular}

Reform Commission extended the transmission and distribution tariff reform pilot to all provincial power grids except Tibet. Cost supervision and review were completed in January 2017.

Power sales reform. The first power sales company-Shenzhen Shendianneng Electricity Co., Ltd.-was founded in March 2015. After the Administrative Measures for Access and Withdrawal of Electricity Sales Companies was released in October 2016, existing companies could carry out electricity sales activities after applying to expand their business activities and completing the access procedures. The number of power sales companies increased sharply 3.5-fold in three months. The National Enterprise Credit Information Publicity System shows that there were 5,410 power sales companies in China at the end of 2016.

Reform of trading institutions. Up to the end of 2016, two national power trading institutions, the Beijing Power Exchange and the Guangzhou Power Exchange, had been founded, and 32 provincial power exchanges (except Hainan and Tibet) established, covering almost the whole country.

Reform of incremental power distribution. The National Development and Reform Commission (NDRC) and the National Energy 
Table 14 Administrative measures for access and withdrawal of electricity sales companies

\begin{tabular}{|l|l}
\hline Main content & Main requirements \\
\hline Access mechanism & $\begin{array}{l}\text { Define access conditions for power sales companies. Replace administrative licencing } \\
\text { with confirmation of registration. Process of market entry: sign the letter of commitment, } \\
\text { submit registration information online, announce and register at the National } \\
\text { Development and Reform Commission, National Energy Administration and the } \\
\text { third-party credit information service provided by government } \\
\text { Power producers, power-related construction companies, high-tech industrial parks, } \\
\text { economic and technological development zones, water/gas/heat utilities and } \\
\text { energy-saving service providers in an incorporated capacity, and which meet the access } \\
\text { conditions for power sales companies, could carry out power sales activities after } \\
\text { applying to industrial and commercial administrations to expand the scope of their } \\
\text { business and complete the procedures above } \\
\begin{array}{l}\text { Existing qualified high-tech industrial parks, economic and technological development } \\
\text { zones and companies that build or operate power distribution networks could voluntarily } \\
\text { change into power sales companies after completing the procedures above }\end{array} \\
\begin{array}{l}\text { Power sales companies may provide users with other services, including but not limited } \\
\text { to energy performance contracting, comprehensive energy saving, energy use consulting, } \\
\text { electric equipment operation and maintenance, and other value-added services }\end{array} \\
\begin{array}{l}\text { Power sales companies may purchase or sell electricity through the power market, from } \\
\text { or to power producers, or through trading institutions. Power sales companies could }\end{array} \\
\text { select trading institutions for trans-provincial and interregional purchase. There could be } \\
\text { multiple power sales companies in one power distribution area. The same power sales } \\
\text { Establish a credit rating } \\
\text { system }\end{array}$ \\
$\begin{array}{l}\text { Build a power sales company credit rating system. Establish a penalty mechanism for } \\
\text { breaking power industry law and for immoral behaviour }\end{array}$ \\
\hline
\end{tabular}

Administration (NEA) issued an order in August 2016 that requires provinces to start pilot incremental power distribution deregulation programmes and carry out 100 incremental power distribution pilot projects across the country as soon as possible. The order also requires incremental power distribution to be deregulated through mixed ownership. The NDRC and the NEA defined 105 projects, including the Yanqing Smart Power Distribution Network, as the first batch of pilot incremental power distribution reform projects in November 2016.

Market trading. Monthly and annual bidding in Guangdong power markets made great progress. Up to September 2016, 43,960 GWh (RMB $0.033 / \mathrm{kWh}$ cheaper on average) had been traded directly in Guangdong, exceeding the planned annual target of 4,200 billion $\mathrm{kWh}$. A total of $15,980 \mathrm{GWh}$ (RMB $0.073 / \mathrm{kWh}$ cheaper on average) was traded through monthly bidding, exceeding the annual target of 14 billion kWh.

Up to the end of 2016, Guangdong had conducted seven monthly centralised bidding rounds, trading $15,980 \mathrm{GWh}$ in total. The number of power sales companies increased from 13 to 154 . The electricity sold by power sales companies accounted for $70 \%$ of the total. The discount granted by the power producers dropped from a high point of RMB $0.148 / \mathrm{kWh}$ in April to RMB $0.037 / \mathrm{kWh}$ in September (Table 16). 
Table 15 Administrative measures for deregulating power distribution networks in an orderly manner

\begin{tabular}{|c|c|}
\hline Main content & Main requirements \\
\hline Planning guidance & $\begin{array}{l}\text { Include incremental power distribution network projects with the power } \\
\text { distribution network plans developed by local power authorities } \\
\text { Incremental power distribution networks need to be finalised in provincial } \\
\text { plans to ensure that incremental power distribution networks are consistent } \\
\text { with national power development strategies and industrial policies and meet } \\
\text { market participant transmission requirements }\end{array}$ \\
\hline Competition and openness & $\begin{array}{l}\text { Encourage private capital to actively take part in incremental power } \\
\text { distribution. Determine investors through market competition }\end{array}$ \\
\hline Rights and responsibilities & $\begin{array}{l}\text { Private capital investing in an incremental power distribution network is } \\
\text { responsible for its operation and management. Investors should follow national } \\
\text { technical specifications and standards, fulfil their obligations on safe and } \\
\text { reliable electricity supply, minimum supply and social services, while } \\
\text { obtaining a reasonable return on investment }\end{array}$ \\
\hline $\begin{array}{l}\text { Scope of activities in the power } \\
\text { distribution network }\end{array}$ & $\begin{array}{l}\text { Invest in, construct and operate incremental power distribution networks that } \\
\text { meet transmission demand and planning requirements, and expand power } \\
\text { distribution networks through mixed ownership } \\
\text { Companies that control existing assets in power distribution networks, } \\
\text { including high-tech industrial parks, economic and technological development } \\
\text { zones, local power grids and bulk sale counties, could apply to local power } \\
\text { authorities for the right to invest in and operate power distribution networks }\end{array}$ \\
\hline $\begin{array}{l}\text { Operation of power distribution } \\
\text { networks }\end{array}$ & $\begin{array}{l}\text { Private capital that invests in and controls the incremental power distribution } \\
\text { network has the right to operate the network. Those companies that meet the } \\
\text { access conditions for power sales companies may carry out power sales } \\
\text { activities } \\
\text { Those grid companies with an incremental power distribution network have } \\
\text { the right to operate the network. Only power distribution activities can be } \\
\text { carried out in power distribution areas. The grid company's competitive power } \\
\text { sales business should be gradually shifted to an independent power sales } \\
\text { company } \\
\text { Power producers are not allowed to invest in or build dedicated lines through } \\
\text { which power plants supply power directly to users or that connect the plants to } \\
\text { the incremental power distribution network they invest in }\end{array}$ \\
\hline
\end{tabular}

Table 16 Power traded through bidding in Guangdong, up to March 9, 2016

\begin{tabular}{|l|l|l|l|}
\hline & Trading volume $(\mathrm{GWh})$ & $\begin{array}{l}\text { Share of power sold by } \\
\text { power sales companies }(\%)\end{array}$ & $\begin{array}{l}\text { Discount granted by power producers } \\
\text { (li (one thousandth of a yuan)/kWh) }\end{array}$ \\
\hline 1st trade & 1,050 & 64.85 & 125.55 \\
\hline 2nd trade & 1,450 & 68.68 & 147.93 \\
\hline 3rd trade & 1,400 & 82.92 & 133.28 \\
\hline 4th trade & 1,870 & 62.07 & 93.90 \\
\hline 5th trade & 2,660 & 75.50 & 58.87 \\
\hline 6th trade & 3,550 & 75.86 & 43.38 \\
\hline 7th trade & 4,000 & 75.00 & 37.42 \\
\hline
\end{tabular}




\subsection{Principles and Roadmap for Future Reform ${ }^{22}$}

The power market comprises multiple markets and multiple market failures. The primary objective of these markets is to match supply with demand through optimal dispatch and investment. This is delivered through electricity, capacity and balancing markets, which face market failures in the form of the carbon pricing externality, regulation of natural monopolies and the need for policy credibility to underpin long-term and long-lived investment decisions. These market structures and failures will exist in a net zero emissions future, but their relative importance and sophistication will change with greater electricity demand and a greater share of supply from renewables.

While the six characteristics of market efficiency (in terms of price signals) and policy efficiency (in terms of correcting for market failures) described above are essential from the design perspective, their importance will vary based on regional, national and local circumstances. For example, countries with large endowments of non-intermittent, low-carbon generation $^{23}$ will have less need to implement all six elements, although they are still likely to require some evolution of efficient pricing mechanisms and supporting policy frameworks. These countries will have less need for a short-term balancing and ancillary services market and are likely to require less sophisticated

\footnotetext{
${ }^{22}$ Following the publication of the Opinions of the Central Committee of the CPC and the State Council on Further Deepening the Reform of the Electric Power System (Zhongfa No. 9, 2015), which provides a roadmap for power system reform in China over the coming years, the National Development and Reform Commission, the National Energy Administration and other ministries and commissions released specialist action plans. In this section, we include the opinions and suggestions of foreign experts, especially Vivid Economics and Shell International, which help us to analyse the future direction and actions of power reform from the perspective of international experts.

${ }^{23}$ For example, hydropower in Norway, bioenergy in Brazil, nuclear power in France and the abundant fossil fuel and huge carbon capture and sequestration potential of North America and other countries.
}

capacity markets. ${ }^{24}$ However, for most countries relying on variable renewables to decarbonise power, there will be significant pressure for reform of the power sector.

For centrally planned economies like China, the challenge will be to achieve the right balance between market forces and policy interventions. On the one hand, central planning through the Five-Year Plan process provides policy certainty, security of supply and the ability to distribute the burden of costs away from consumers to other parts of the system. On the other hand, market forces, through efficient market design and supporting policy frameworks, are likely to be a less expensive and more adaptive approach, especially in the context of dynamic and changing power demand and technologies. The value of such an adaptive approach is even greater, given the likely scale and pace of change required to achieve net zero emissions in the second half of the century.

Progress towards efficient net zero emissions power markets will not be smooth. It is likely to happen at different speeds in different geographies, with countries experimenting with different approaches; for example, the different approaches taken by the UK and Germany, with the former relying on capacity auctions and the latter on creating strategic reserves to deliver long-term capacity and resilience in the system. ${ }^{25}$ However, the direction of travel is clear, with many countries already making progress towards more efficient power market structures and policies, driven in large part by the efficiency gains they provide. This trend is only likely to intensify with greater electrification of energy use and with the greater imperative to decarbonise power in a way that keeps costs down and delivers a secure supply of electricity.

\footnotetext{
${ }^{24}$ For example, to deal with seasonal intermittency rather than the more frequent intermittency associated with variable renewables like wind and solar.

${ }^{25}$ Strategic reserves provide capacity and flexibility by keeping mothballed or older (usually thermal) generation plants available, whereas capacity auctions provide a fixed revenue for long-term capacity and flexibility in the system.
} 


\subsubsection{Reform Difficulties and Approaches to Resolve Them}

A reforming power market needs to solve six problems urgently.

First, how to allocate power resources optimally; how to design an effective market mechanism to transmit abundant power resources in west China to the load centres in east China; how to make the market set a reasonable price for clean energy; and how to design an effective auxiliary services market mechanism to absorb clean energy across provinces and regions.

Solutions:

- market scope: design a nationwide unified electricity market to allow the free flow of resources across the country;

- roll-out: starting with provincial markets, promote deep integration of provincial markets step by step to eliminate the trade barriers between provinces with a market mechanism;

- increase the types of trading in provinces and regions: gradually introduce trans-provincial and interregional spot trading (starting with medium- and long-term trading), and increase the number of participants by engaging users and power sales companies in trans-provincial and interregional trading; and

- build a market mechanism that promotes the inter-provincial and interregional grid connection of clean energy, and gradually introduce auxiliary service market mechanisms, such as peak shaving, to increase trading volumes of clean power between provinces and regions.

Second, how to launch provincial markets; how to design the power market while taking into consideration the differences between provinces in terms of market concept, environment and maturity; how to coordinate the relationship between planning and the market; how to coordinate the relationship between medium- and long-term trading and spot trading; how to coordinate the relationship between intra-provincial power resources and other provinces' power resources; and when to make the spot market open.

Solutions:

- choose a suitable power market model based on local conditions, the market strength of power plants, power supply and demand, lessons learned from established markets, technical conditions and new energy; and

- increase the types of trading categories and expand power trading step by step, taking medium- and long-term trading first, and then spot trading.

Third, how to solve the problem of dominant companies when establishing a provincial power market. Oligopoly is a serious issue in some provincial markets, such as Zhejiang and Qinghai. In the process of supply-side reform, centrally administered state-owned energy enterprises are very likely to be restructured, intensifying their dominance of provincial power markets.

Solutions:

- expand the scope of the power market, through coupling or fusion, to reduce the concentration of power producers in any one market;

- build a strict regulatory system, setting an upper limit for the market share of power generation companies, forcing those with a large share to disclose information; and

- spin off or sell the assets of those power generation companies with a high market share.

Fourth, how to change a provincial market into a national market, in which each provincial market chooses its path of evolution and support measures based on actual conditions. 
Solutions:

- build the national market by creating provincial markets, then integrate several provincial markets at their transmission endpoints, before finally integrating all provincial markets;

- Integrate provincial markets in order of mutual openness, then relax access conditions for inter-provincial market trading, before unifying market rules; and

- build inter-provincial markets and the national market according to the principle of "medium- and long-term markets first, then the spot market".

Fifth, how to eliminate historical price provincialisation. The tariff in some provinces that are traditionally low-price regions could increase after integration with the national market, which carries the risk of creating social unrest.

Solutions:

- start with provincial markets, expand the scope of the national market and level the electricity tariff in different markets step by step;

- in the early stages of market creation, low-priced power could be partially reserved for industrial users to avoid a drastic impact on their costs after the market is built; and

- set tariff buffers and a protection mechanism for domestic and other public users.

Sixth, how to settle the problem of stranded costs. In the process of creating power markets, some power producers that were previously protected by the planning system may suffer damage to their interests or even go bankrupt, leaving them unable to recover their investment. For example, companies that invested in power plants under the planning system and have outstanding loans might not recover their investment because they are badly positioned for market competition due to their high costs.

Solutions:

- develop a variety of power products, such as contracts for difference and medium- and long-term contracts and futures, to avoid tariff fluctuations and ensure stable revenues for all market participants;

- use short-term planned power allocation to prioritise power plants that are still recovering their investment, or have recovered their investment but are in difficulty, to give them some stability; and

- restructure the assets of power plants and power generation companies separately, in accordance with the principle of sharing reform costs.

\subsubsection{Principles of Reform}

To achieve the economic benefits of liberalised electricity markets, international best practice suggests implementing a set of principles for efficient network provision. ${ }^{26}$

First, proceed towards full liberalisation of the wider power system. Efficient investment in and operation of the overall power system is a necessary precondition for the efficient supply of electricity. This requires liberalisation of sectors suitable for competition (fuel production, generation, retail), use of markets to procure key services (capacity, balancing), and the pricing of externalities (such as air pollution and carbon emissions).

Second, align network-provider incentives with public policy objectives. Make the incentives dependent on the provision of a reliable and affordable supply of electricity by controlling monopoly behaviour and ensuring that prices reflect underlying costs:

- Reform power network institutions. Power networks are natural monopolies. It is therefore critical that their incentives are aligned with public policy objectives. A monopoly is incentivised to underinvest in new infrastructure and to charge prices that are higher than its costs. A state-owned company may be incentivised to prioritise short-term political objectives, rather than longer-term public

\footnotetext{
${ }^{26}$ This part is provided by Vivid Economics. See Vivid Economics, Low Carbon Power Markets: Lessons from International Experience for the DRC-Shell Markets Work Stream, 2017.
} 
policy objectives. These incentives can be mitigated through institutional reform of the power network. One option is to reform the network company's incentives through performance-based regulation enforced by an independent regulator. Another is to separate network operation and ownership through the creation of an independent system operator (ISO). The UK and most European countries currently use performance-based regulation, while the USA uses the ISO model across its transmission systems, for example in PJM (the transmission system in the north-eastern states), California and New York.

- Consider the use of locational pricing. Efficient network investment and operation make use of information on network congestion. If implemented, locational (nodal or zonal) pricing can help reveal the cost of network congestion. Nodal pricing is used in several US states, Argentina, Chile, Ireland, New Zealand, Russia and Singapore, while zonal pricing has been adopted by most European countries and Australia. However, locational pricing has disadvantages as well as advantages. Importantly, locational pricing is most effective once time-of-use pricing is fully implemented across network users.

Third, take action to meet the challenges of a decarbonised system. Rising electrification and improvements in the efficiency of electrical appliances will increase the uncertainty over the future volume and location of demand for transmission capacity. Flexible resources such as electricity storage and demand response can substitute for new network investment, so long as sufficient investment incentives are present.

- Designate strategic zones for transmissionscale renewable generation to reduce planning and investment uncertainty. Renewable energy resources may be located far from demand centres and thus require large-scale transmission investment. Uncertainty over the volume and location of generation can be mitigated through zoning.

- Ensure there is money available to encourage flexible resources to offer a full range of system services. The flexible resources needed for decarbonisation provide several system services, such as balancing and frequency response, but there may be underinvestment if the markets do not exist for these services. Several electricity markets in the West run demand curtailment markets, allowing flexible resources to generate revenues.

Fourth, prepare for the development of a decentralised power system and its associated digitalisation by coordinating investment in decentralised resources, their control, balancing, security and data flows.

- Coordinate investment in decentralised resources. A coordination problem arises when independent developers that lack information about the plans of other developers make similar investments, creating overinvestment or, if the developers are risk-averse, underinvestment. Either way, the result can be inefficient. Solutions include formal processes for multilateral resource planning and the publication of current and consented resources, as used by the transmission and distribution system operators of Spain and Ireland.

- Determine how decentralised resources will be controlled. While distribution networks today are largely passive, an active distribution network is capable of accommodating distributed resources. As the electricity system becomes more active and complex, a single system operator may start to rely on intermediaries, such as virtual power plants and partners such as distribution system operators, to assist with system balance. New systems of control, with new computational requirements, administrative rules and institutional characteristics, may then be employed, reflecting new operational vulnerabilities. 
- Balance data transparency with security. As information and communications technology infrastructure expands, the amount of data from the electricity system grows. The data systems need their own infrastructure, with public access to facilitate competition and optimise operations. Meanwhile, the distribution of data across resources creates new risks of cyberattack and privacy loss, solved through adequate protocols.

\subsubsection{Reform Roadmap}

Vivid Economics and Shell's international experts proposed a roadmap for the development of future network arrangements in China. The roadmap is based on the following guiding principles:

- Strong markets need strong government. Market-based solutions have the potential to identify and deliver cost-effective investment and operation of electricity systems. However, both markets and natural monopoly networks benefit from a strong government to take an active role in ensuring that institutional incentives are aligned with public policy objectives. Network incentives can be aligned through separation of roles (unbundling) or strong regulation.

- The institutional framework can be developed progressively. Wholesale institutional reform is challenging and disruptive. At the outset, small changes in current practice and small-scale pilots may provide proof-ofconcept sufficient to build consensus for larger-scale reforms.

The main points of the proposed roadmap are as follows:

\section{(1) Immediate actions}

- Continue the market liberalisation programme. Phase 1 of the DRC-Shell cooperation proposed a programme of power market liberalisation; consistent with this, China's 13th Five-Year Plan (2016-20) aims to improve the systems by which markets play the decisive role in resource allocation. It will be important to continue with the market liberalisation programme to deliver a more advanced and efficient power system.

- Rationalise investment planning. Clearly defined metrics for reliability and economic efficiency help network planners to identify efficient investments. Meanwhile, the application of the beneficiary pays principle encourages investment that increases productivity and avoids diverting national resources to stimulate regional output. Together, these approaches, when applied at national and regional level, facilitate greater interconnection and sharing of generation services.

- Implement a coordinated approach to investment. The use of a common investment framework enables generation and network investment planning to be coordinated, harnessing strategic decisions and market enterprise. For example, the framework might set out the role of generation zones for large-scale renewables alongside alternatives such as small-scale distributed generation.

- Implement smart system architecture. Smart, distributed resources are crucial to affordable decarbonisation. Before building the distributed resources, the system architecture to manage it should be determined. At a minimum, this includes deploying smart meters to introduce time-of-use pricing to consumers on the distribution network; creating upstream information and communications architecture; and carrying out $\mathrm{R} \& \mathrm{D}$ to develop technical solutions for the smart grid.

(2) Move towards an efficient pricing mechanism

- Deregulate prices. Cost-reflective pricing can signal efficient investments and operations to decision makers. The deregulation of prices can proceed sequentially, with further price reform contingent on the success of previous reforms. Price reform could commence 
upstream and progress downstream, beginning with input fuels and progressing through generation, network access and ending with retail, with provision to protect retailers if wholesale prices rise above retail prices before deregulation is complete.

- Create harmonised trading arrangements between transmission systems. Use prices to determine interconnector flows between provincial and regional transmission systems, signalling which provinces or regions could benefit from new investment. The prices would stimulate lower-cost generators to respond to demand.

- Implement time-of-use pricing. Time-of-use pricing allows consumers and flexible resources to respond to variation in generation costs and demand. Again, it can proceed sequentially, starting with larger consumers, such as industrial facilities with flexible production schedules, and ending with smart household appliances.

- Consider locational pricing. Similarly, locational pricing can signal efficient investments and operations, but it brings disadvantages as well as advantages. China may consider locational pricing, following the implementation of time-of-use pricing. That is, signal geographical network constraints once demand peaks have been shaved. Zonal pricing is a potential intermediate step between uniform and full nodal pricing.

- Protect end users. The deregulation of retail electricity may result in rent-seeking by retailers, raising consumer prices. This can happen if consumers do not switch suppliers readily or if for other reasons competition is not effective. Policies to protect consumers could be developed alongside any deregulation of retail electricity prices.

\section{(3) Begin market trials}

- Create small-scale trials. Create small-scale trials to procure competitively new transmission investments, non-network alternatives to new transmission assets, ancillary services and so on. Use competitive tenders or auctions for the trials. These may provide proof-of-concept and experience with innovative, cost-effective solutions. To be successful, procurement must be open-access and transparent.

- Progressively introduce market procurement. If the competitive procurement trials are successful, they can be scaled up and wider market procurement progressively introduced, where appropriate, across each transmission system. Market procurement can help to reveal information about the relative costs and benefits of a range of generation technologies.

\section{(4) Make institutional choices}

- Develop transmission network institutions. Options include the status quo, an enhanced role for market procurement and a regulated transmission system operator (TSO) or independent system operator (ISO). International experience of the regulated TSO or ISO model is yet to reveal the best performer of the two, so it matters more to adopt a good-quality institutional model early than to choose between the options.

- Select a model of control for decentralised resources. Initially, when the number of resources is small, the transmission system operator may be able to control them directly. However, as the number of resources increases, and as temporal and locational pricing become more sophisticated, the computational, commercial and contractual capacity of a single operator model may be exceeded, and new models of control may be needed.

\section{Build a Unified and Dynamic National Carbon Market}

To control total carbon and carbon intensity, China plans to launch a national unified carbon market by 2018, which will cover key industries 
such as steel, power, chemicals, construction materials, papermaking and nonferrous metals. After national carbon exchanges are created, China will become an integral part of the international carbon trading market. The pressure on China to reduce carbon emissions will be largely alleviated by means of the market. Launch of China's carbon exchanges will drive the transformation and modernisation of traditional industries and sharpen the international competitive edge of China's low-carbon sectors. ${ }^{27}$

The Notice on Carrying out Pilot Carbon Emissions Permit Trading issued by the National Development and Reform Commission (NDRC) in October 2011 approved the launch of pilot carbon emissions permit trading in Beijing, Tianjin, Shanghai, Chongqing, Hubei, Guangdong and Shenzhen. The pilot carbon exchanges in the seven provinces and municipalities were opened between June 2013 and June 2014. The NDRC released the Notice on Key Points for the Launch of a National Carbon Trading Market in January 2016, according to which Phase 1 of the national carbon market should cover petrochemicals, chemicals, construction materials, steel, nonferrous metals, papermaking, power, aviation and other high-emitting industries. However, China's carbon market uses a baseline method to set the carbon quota, which is stricter than the historical method and more demanding in terms of technologies and data.

Given the progress of current pilot carbon markets, when building the carbon market, China should: improve the system of laws and regulations; coordinate allowance allocation; establish a unified trading platform and pricing mechanism; and optimise the design of the national carbon market to include guidance and benchmarks for its creation and improvement.

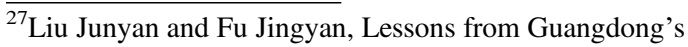
Carbon Market Practice for Building a National Unified Carbon Market, in Science and Technology Management Research, 2016, 36 (13): pp. 237-242 and 254; Xue Rui, China's Carbon Market Response in the Context of the Paris Agreement, in Ecological Economy, 2017, 33(02): pp. 45-48 and 128; Peng Sizhen, Chang Ying and Zhang Jiutian, Reflections on Major Problems in the Development of China's Carbon Market, in China Population, Resources and Environment, 2014, 24(09): pp. 1-5.
}

\subsection{Summary}

Carbon markets are a key instrument for delivering cost-effective mitigation. Mitigation of carbon emissions is in the best interest of all nations, because the cost is less than that of unconstrained climate change. The cost of mitigation can be minimised via carbon markets, especially if carbon markets are the primary driver of mitigation in an economy, if the carbon price is robust to shocks, and if the price provides incentives for long-term investment.

However, competing objectives often require trade-offs that are reflected in carbon policy. Carbon markets, such as an emissions trading system (ETS), can help deliver benefits that are in line with other policy goals, for example improved air quality or resource efficiency. However, carbon markets can also adversely affect some policy goals, like industrial competitiveness, or be undermined by shocks, such as when a recession leads to an oversupply of permits that undermines the ability of the carbon price to incentivise long-term investment. These competing objectives are often legitimate, and shocks should be expected. The challenge to policymakers is, therefore, how to take these into account when designing carbon markets, without reducing the cost-effectiveness of mitigation.

We call carbon markets that accommodate competing objectives and shocks while maintaining cost-effectiveness robust markets, while those that fail to do so are fragile. Unfortunately, most carbon markets in international experience are fragile, having become stuck in a transition trap of managing competing objectives and shocks via countervailing policies that further undermine the markets. As China's ETS will double the quantity of emissions covered by a carbon price globally, when it is fully implemented, it is imperative that it is robust, or else carbon markets may lose support, which would seriously undermine decarbonisation efforts.

International experience suggests that carbon markets can be robust if certain design features are incorporated. Carbon markets have four sets of design options. These are options around: (i) the creation of carbon units, such as targets 
and cap setting; (ii) the distribution of allowances; (iii) governance of the market, such as coverage, banking, offsets, price controls and trading arrangements; and (iv) policy interactions with other decarbonisation policies. We analysed the experience of the European Union ETS, the Regional Greenhouse Gas Initiative in the USA, the New Zealand ETS and the California ETS, for lessons on which choices in each of these sets of design options lead to a robust carbon market.

China looks likely to use a slow start to emissions trading. As such it should consider adopting price controls and a clear reform path to reduce the risk of becoming stuck in the transition trap. Design trade-offs in the early stages of carbon pricing are common and can result in fragility. This means that an active approach to price management, such as a tight price corridor, can be used to ensure that incentives are maintained while the market develops. This can be supported by signalling the direction of climate policy. For instance, committing to specific changes through legislation can provide clear guidance on the direction of policy. This can help maintain prices and public support for carbon markets in the event of a shock.

While the next stage of China's ETS is being planned, policymakers should consider whether China should adopt an evolutionary or a revolutionary approach to carbon markets. Climate change has aspects that suggest a balance between evolutionary and revolutionary change. The rate and level of the required emissions reduction suggests the need for revolutionary change. However, the difficult politics of such a change, and limitations in institutional capacity, suggest that an evolutionary approach may be more feasible. The choice of approach is for Chinese policymakers to make. We provide a detailed roadmap for both options, across the four sets of design choices, so that the required actions and pace of reform are clear, whether an evolutionary or revolutionary approach is taken. These roadmaps, presented in Sect. 8.4, reflect best practice from international experience, drawn from the examples provided in Sect. 8.3.

Table 17 illustrates what an evolutionary versus revolutionary approach may look like in China. An evolutionary approach would start slow, providing assistance to companies and a low, but stable price; while a revolutionary approach would rapidly make the ETS a central force in economic decisions through strong price support and low levels of assistance.

Regardless of whether China takes an evolutionary or revolutionary approach to carbon markets, international experience suggests some general lessons for China:

Table 17 Evolutionary and revolutionary change can differ in all aspects of scheme design

\begin{tabular}{|c|c|c|}
\hline & Evolutionary & Revolutionary \\
\hline Creation & $\begin{array}{l}\text { - Target setting based on national circumstance, } \\
\text { gradually transitioned to global carbon goal by } 2030 \\
\text { - Bottom-up cap setting to } 2020 \\
\text { - Net carbon neutrality after } 2050\end{array}$ & $\begin{array}{l}\text { - Move to binding, absolute targets and top-down cap } \\
\text { selting by } 2020 \\
\text { - Targets aligned with goal of achieving global net carbon } \\
\text { neutrality before } 2050\end{array}$ \\
\hline Distribution & $\begin{array}{l}\text { - Move from grandfathering to production-based } \\
\text { allocations by } 2020 \\
\text { - Assistance to emissions intensive industries only with } \\
\text { high assistance rates, declining gradually over time } \\
\text { - Auctioning of remaining units }\end{array}$ & $\begin{array}{l}\text { - End grandfathering as soon as possible, immediate } \\
\text { development of process level baselines } \\
\text { - Assistance limited to emissions-intensive, trade-exposed } \\
\text { industries, and quickly declines } \\
\text { - } 100 \% \text { auctions by } 2030\end{array}$ \\
\hline Governance & $\begin{array}{l}\text { - Start with low }(\mathbf{\$ 1 0 - 2 0 )} \text { price floor or MSR, may } \\
\text { also include price ceiling, both growing slowly } \\
\text { - Phase in coverage starting with electricity generators } \\
\text { and major industrial energy users } \\
\text { - Slow movement to linking with international partners }\end{array}$ & $\begin{array}{l}\text { - High (>\$40) price floor that increases rapidly } \\
\text { - Immediate coverage of all energy, transport and } \\
\text { industrial emissions, with full banking } \\
\text { - Agriculture and land sectors covered by } 2025 \\
\text { - Near-term linking with willing international partners }\end{array}$ \\
\hline $\begin{array}{l}\text { Policy } \\
\text { interactions }\end{array}$ & $\begin{array}{l}\text { - ETS operates as part of a broad policy mix, with } \\
\text { other policies playing dominant role before } 2030 \\
\text { - Carbon market gradually becomes more influential in } \\
\text { economic decisions }\end{array}$ & $\begin{array}{l}\text { - ETS plays immediate major role in investment decision- } \\
\text { making, becomes the major driver of decarbonisation } \\
\text { investment by } 2025 \\
\text {. Other policies aligned with decarbonisation objective }\end{array}$ \\
\hline
\end{tabular}

Note $\mathrm{MSR}=$ market stability reserve

Source Vivid Economics 
- developing an ETS requires consideration of three key questions: how many units to create, how to distribute them, and how to govern their trade;

- the supply of emission units should reflect the nature of the climate policy problem in the longer term. This requires movement to caps and targets that reflect the absolute global emission reductions required;

- some auctioning is important for price formation early on, but movement to full auctioning may be gradual;

- allocating free permits may be necessary, but costs can be reduced through benchmarking and limiting allocations to cost pass-through in constrained industries; this requires addressing data constraints as a priority;

- the early learning phase of an ETS brings a risk of price shocks, so that price controls may be needed;

- broad coverage increases market efficiency and stability, and should be sought as rapidly as politically feasible;

- full banking is preferable to support investment from the outset, so long as caps do not create hot air;

- designing an ETS that is robust to shocks is essential for success. ETSs to date have suffered from fragility, with poor design interacting with cyclical, technological and/or supply shocks to undermine their effectiveness; and

- investing in early data collection can help improve policy outcomes and better ETS design.

Overall, China has an important opportunity to learn from international experience and deliver a robust carbon market. While the design of China's forthcoming ETS is largely finalised, revisions are expected by 2020 . Therefore the next few years provide an important opportunity to learn from the initial stage of China's ETS and determine which path, evolutionary or revolutionary, China should take in the next phase of its ETS, drawing on the best practice of international experience to ensure a robust design and taking into account the competing objectives and shocks the ETS is likely to face.

\subsection{Introduction}

\subsubsection{Policy Objectives, Market Failures and Trade-Offs}

Responding to climate change requires a transformation of energy systems. The world's fossil-fuel-dependent energy mix is not consistent with the Paris Agreement objective to limit global temperature rise to well below $2^{\circ} \mathrm{C}$ above pre-industrial levels. If this objective is to be achieved, it means that all countries must take action to ensure that their future energy needs are provided by low-emission energy sources.

This transformation requires significant investment in the development and deployment of low-emission technologies and practices. The energy sector is capital-intensive, relying heavily on long-lived assets with high upfront costs. Further, there are multiple technologies that can deliver low-carbon energy. These include mature technologies like nuclear and hydropower, and rapidly developing technologies such as solar, wind and battery storage. This means that policies seeking to drive an energy transformation must both mobilise finance to fund investments and provide a mechanism to choose between competing technologies and providers.

The range of options for low-carbon energy can come with widely varying costs. These costs will be determined by a range of different factors, including, for instance, the development of technology, the geographic location of different energy technologies, and network and learning effects associated with the roll-out of these technologies. This means that while there are many different ways in which an energy transformation can be pursued, these options may come with very different costs.

Achieving climate change mitigation cost-effectively frees resources for alternative uses and enables society to pursue a broader range of opportunities to increase well-being. Climate change mitigation is only one of many outcomes that society seeks to achieve; other outcomes include greater material well-being, higher rates of employment and an engaged and content population. However, these outcomes all have some degree of cost associated with them. 


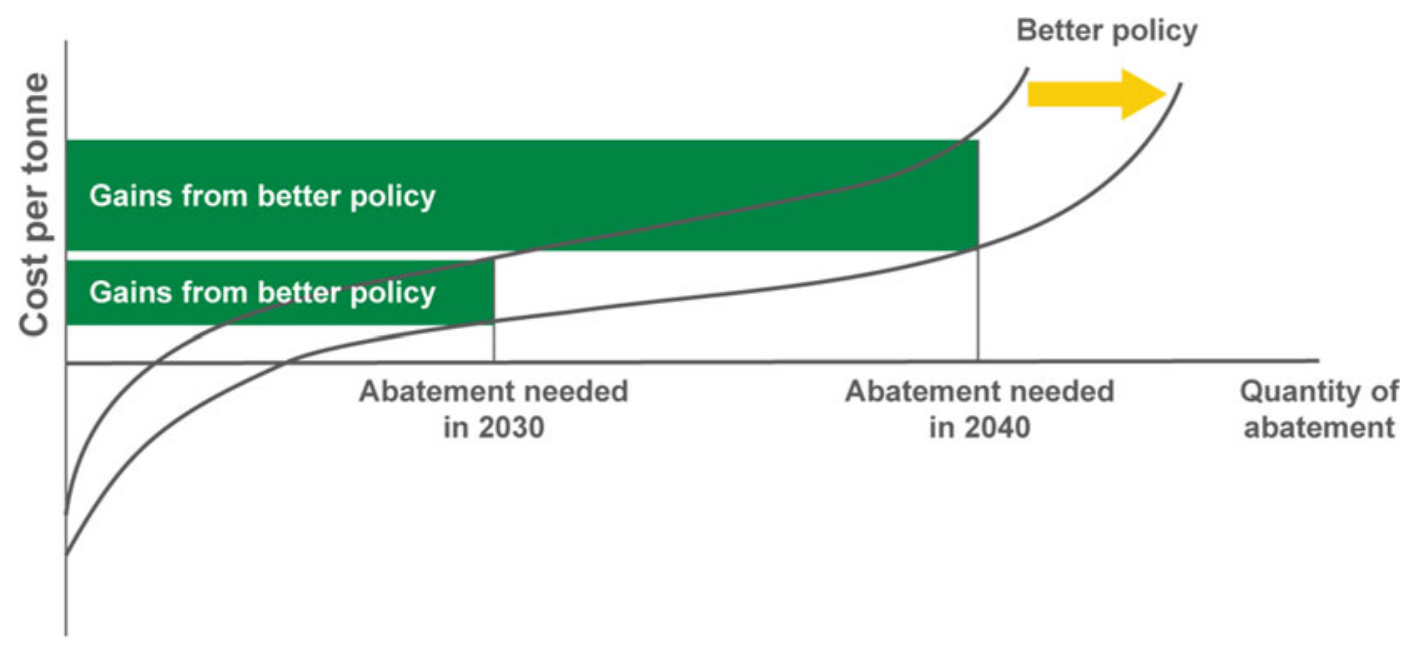

Fig. 27 The gains from better climate policy will grow over time, as low-cost mitigation is exhausted and more mitigation is required. Source Vivid Economics

By reducing the costs of achieving climate mitigation, more of a society's resources can be devoted to achieving other objectives.

As the level of climate change mitigation required is likely to increase over time, the cost-effectiveness of a given policy mix becomes increasingly important. If dangerous climate change is to be avoided, then over the next 30 years action on climate change must accelerate to achieve the required balance between sources and sinks of greenhouse gases. This implies a rapid progression in the level of mitigation and the movement to higher-cost forms of mitigation. This means that the difference between an expensive policy mix and a cost-effective policy mix will become greater in absolute terms as time progresses. In order to limit the impact of climate change mitigation on achieving other policy objectives, the focus on cost-effectiveness should increase over time.

The need for a cost-effective mechanism to identify and allocate competing mitigation options has led many jurisdictions to turn to markets. In doing so, individual incentives can be used to identify mitigation options that are suitable to a specific context. Markets enable decision-making processes to be aggregated across individuals, in turn ensuring that the broadest possible set of information and mitigation options is being considered. This can reduce the incremental and overall cost of moving towards a low-carbon energy mix.

Policy objectives do not exist in isolation, and progress in achieving one objective may have an impact on society's ability to achieve others. This is true for climate change mitigation, where achieving lower emissions cost-effectively can make some policy objectives easier, while making others more difficult. For instance, achieving cost-effective climate mitigation may improve local air pollution by simultaneously reducing emissions of particulate matter. However, it may also make other objectives more difficult; for example, maintaining industrial competitiveness may be harder if a carbon price is applied in one jurisdiction but not another (Fig. 27).

Achieving effective climate policy is made more difficult by the existence of multiple market failures and the interaction of different policies. Carbon pricing is an example of a policy that targets a market failure by seeking to internalise the externality of unpriced climate change. However, other externalities are also relevant to climate policy, such as:

- coordination failures, which may result in inadequate investment in the research, 
Fig. 28 Achieving cost-effective abatement makes some policy objectives easier, but may require trade-offs with others. Source Vivid Economics

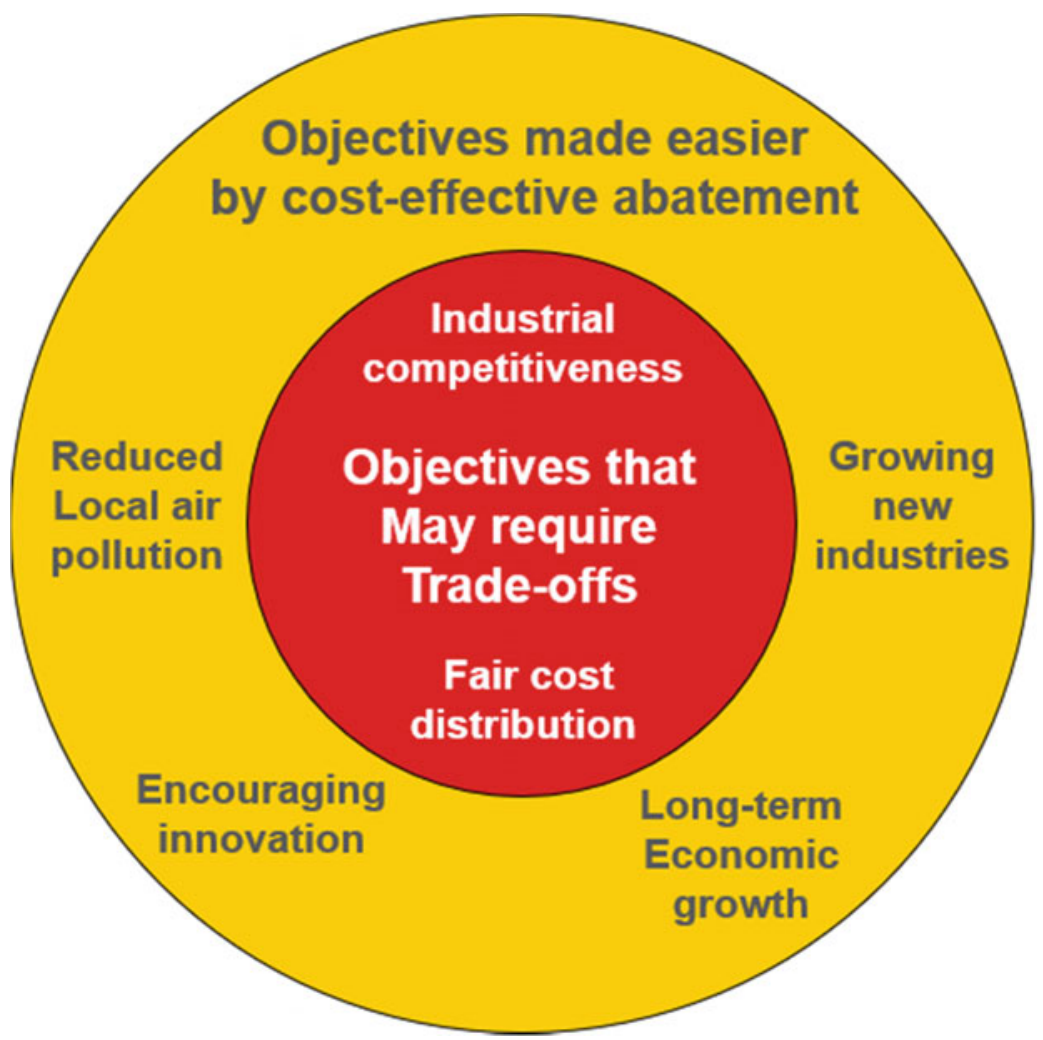

development and commercialisation of low-emission energy technologies;

- network effects, which may create barriers to the expansion of low-emission transport; and - asymmetric information, which means that opportunities to improve energy efficiency are left untapped.

Different market failures may require different policy interventions, not all of which are compatible. For instance, encouraging investment in low-emission technologies through a feed-in tariff may result in lower emissions from the energy sector and a lower carbon price. This means that there are trade-offs made between objectives, and within the policy mixes that are used to achieve them (Fig. 28).

Balancing and achieving competing societal objectives subject to constraints is a central role of government. There is a range of legitimate objectives that government seeks to achieve at the same time, using imperfect policy mechanisms. Policy objectives that are commonly affected by climate policy include:

- economic objectives: for instance, ensuring that increased energy costs do not reduce competitiveness in a perverse manner by avoiding carbon leakage;

- social objectives: for instance, ensuring that the costs of transition are fairly distributed;

- environmental objectives: for instance, the specific mitigation options that are taken up will determine the pollution co-benefits that occur at the local level; and

- political objectives: for instance, as different segments of society will be affected in different ways, climate policy choices may have an impact on a government's political support.

The existence of potentially competing objectives means that trade-offs may be necessary, with social preferences determining the relative valuation of different objectives, and the 
Fig. 29 The social objectives frontier represents all potentially optimal outcomes based on societies' preferences regarding two objectives. Source Vivid Economics

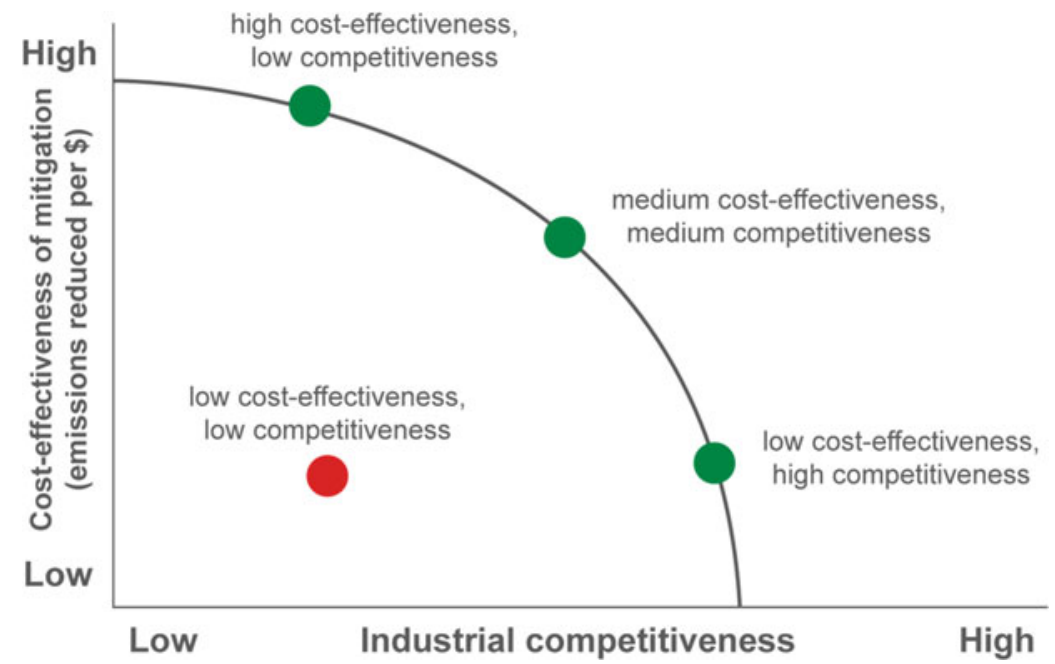

preferred quantity of these objectives that would be obtained with a given constraint.

The necessary trade-offs between two competing objectives can be represented as a frontier. This frontier shows the maximum extent to which different combinations of two competing objectives can be achieved. Any point on this frontier represents a potentially optimal social outcome given a specific set of societal preferences. This in turn will be reflected in different policy designs which may be capable of achieving these objectives to a greater or lesser extent.

Achieving social objectives requires trade-offs. However, poor management of these trade-offs often leads to suboptimal outcomes. When policy results in an outcome inside the social objectives frontier, each objective is achieved to a lesser extent than is possible. For instance, the red dot in Fig. 29 shows low cost-effectiveness and low competitiveness outcomes, where both outcomes can be improved on by moving closer to the frontier.

\subsubsection{Fragile Carbon Markets and the Transition Trap}

Carbon markets to date have not delivered on the objectives for which they were developed. Across several carbon markets, persistently low prices have undermined incentives to invest in new, low-emission technologies, and have caused policymakers to turn to overlapping policy instruments.

Poor policymaking has resulted in fragile carbon markets incapable of recovering from economic shocks. A carbon price should seek to deliver a price signal that is both efficient and robust. An efficient carbon price is one that is sufficient to deliver the changed production and consumption patterns that are required at least cost. A robust carbon market will also ensure that this price signal is stable and predictable in the long run. This is necessary to reflect the long-run scarcity value of greenhouse gas emissions, and to drive investment in new technologies and capital so that costs may fall in the future. In contrast, a fragile carbon market will fail to deliver the incentives needed to drive the long-term emission reductions required, at the lowest cost possible over time. The fragility of a carbon market may not be obvious until it is hit by a shock. To date, however, almost all carbon markets have been hit by some form of shock that has contributed to their ineffectiveness.

There is a range of shocks that can negatively impact a carbon market. These include:

- demand shocks: for instance, the EU recession reduced industrial demand, production and emissions;

- supply shocks: such as the oversupply of credits in the form of certified emission 


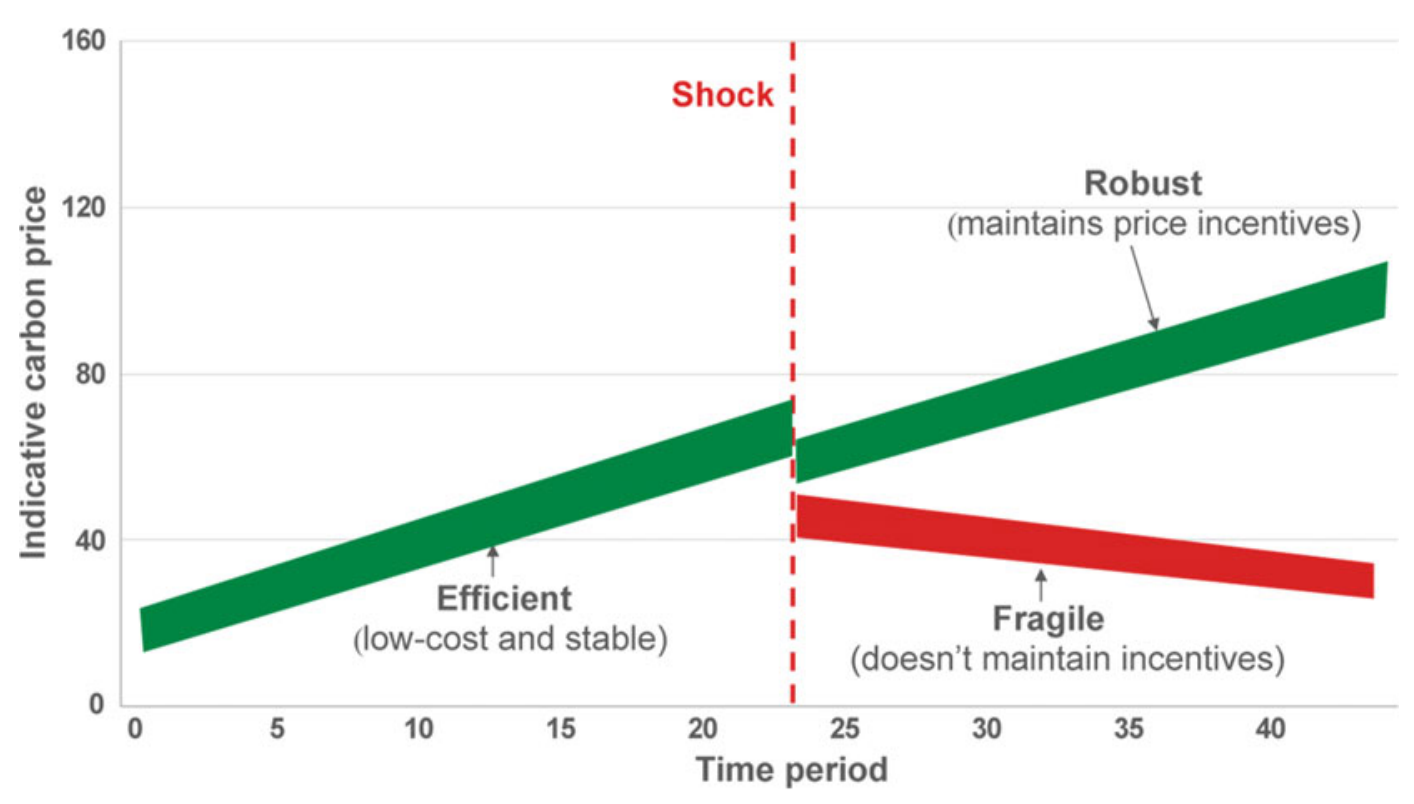

Fig. 30 An effective carbon price will be both efficient and robust. Source Vivid Economics

reductions and emission reduction units, which depressed prices in the EU ETS; and

- technology shocks: such as the shale gas revolution that changed the structure of the east-coast US energy industry and depressed prices in the Regional Greenhouse Gas Initiative.

Often policymakers will seek to limit opposition to a new policy through a slow start. A slow start may have different elements in different contexts. However, most are characterised by seeking to limit the reallocation of resources between groups in the economy. For instance, a slow start may see the grandparenting of free allocations to existing firms, the limitation of coverage to only a small set of emission sources, or significant access to low-cost emission reductions through the use of international units or offsets (Fig. 30).

A slow start occurs when other objectives are prioritised above the cost-effectiveness of the carbon market in the short term. This may focus particularly on increasing political support for the carbon market, given the political challenges that can occur in establishing a new tax and changing the competitiveness of industries. This limits the impact of carbon pricing on the attainment of other policy objectives in the short term. However, policymakers may intend to strengthen it in the future as the carbon markets gain acceptability and political support. However, these policies may also result in systematic fragility, which means that when a shock occurs it can result in persistently low prices.

A slow start can make new carbon markets susceptible to the transition trap. The transition trap occurs when policymakers decide to take a slow start to carbon markets, but an economic or technology shock interrupts the reform process, shifting the market to a suboptimal equilibrium before it can be strengthened. When this occurs, it can reduce the credibility of carbon markets and create support for the introduction of overlapping measures, such as feed-in tariffs to support renewable energy investment. The proliferation of these overlapping measures further reduces prices in the carbon market, driving a self-enforcing cycle that keeps carbon prices low. This is shown in Fig. 31.

The transition trap helps to explain the persistently low prices in carbon markets to date. Carbon prices have proved insufficient to drive investment in new low-carbon technologies and 


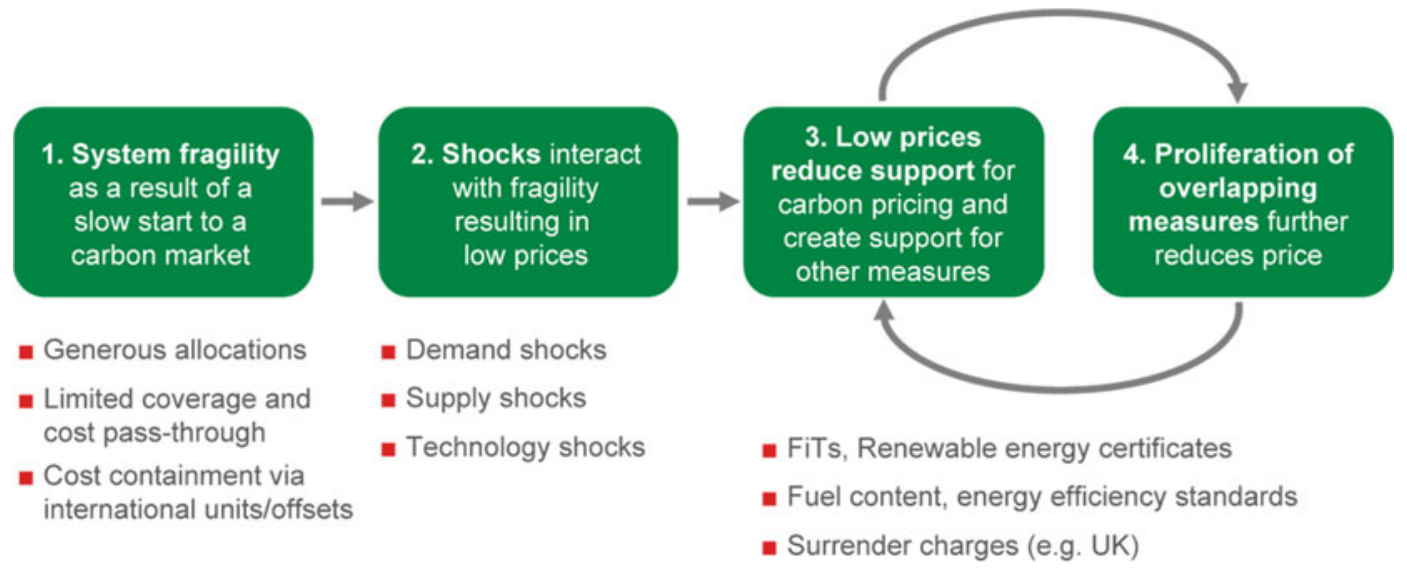

Fig. 31 The transition trap explains how a carbon market may become stuck in an ineffective equilibrium. Source Vivid Economics

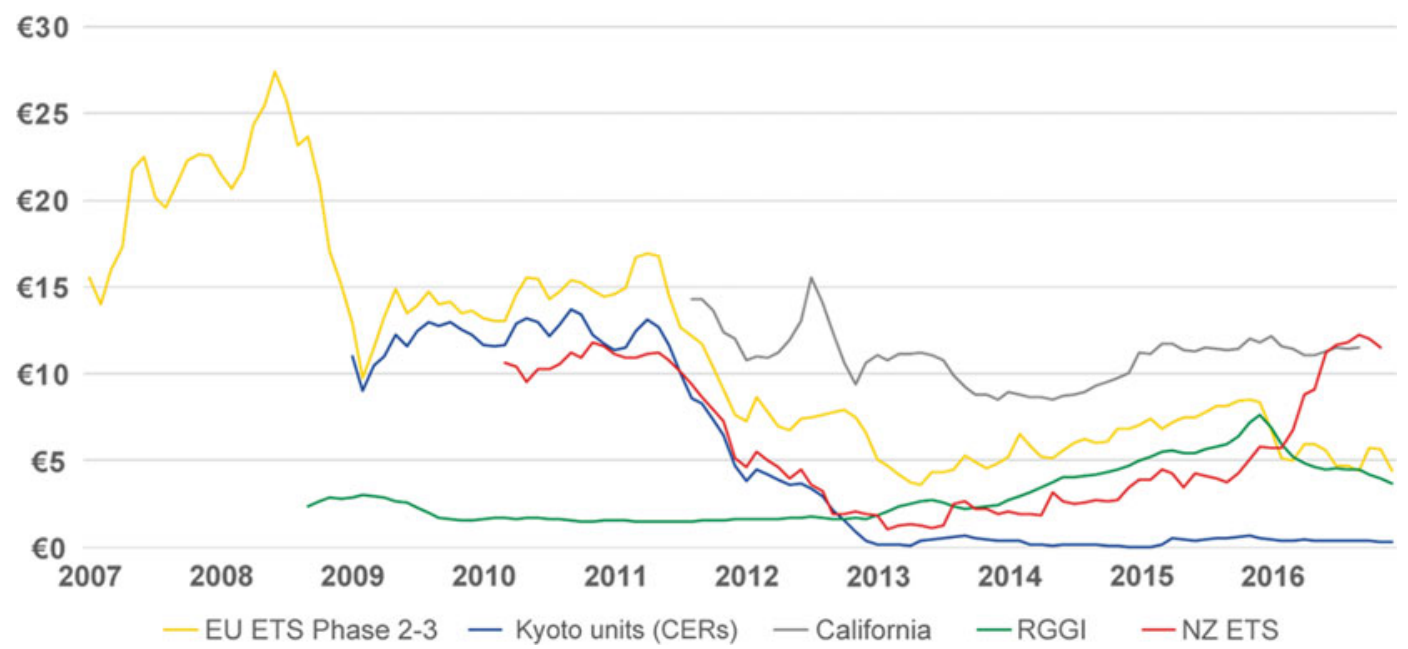

Fig. 32 Carbon markets have experienced persistently low prices. Note EU ETS Phase 2 and 3 prices refer to December settlement futures contracts, the most commonly used contract type; RGGI prices are taken from quarterly auction results; and NZ ETS prices were graphically digitalised and are indicative only. RGGI auction prices have been converted to tonnes. All prices

assets, which have instead largely been incentivised through overlapping policy, such as minimum renewable energy generation requirements, energy efficiency standards and feed-in tariffs.

China can draw on the lessons from international experience to avoid the transition trap and develop a robust carbon market. If well designed, have been converted to euro using monthly average exchange rates. CER = certified emission reductions. Source Intercontinental Exchange and Quandl (2016), Intercontinental Exchange (2016), Climate Policy Initiative (2016) RGGI (2016) and International Carbon Action Partnership (2016). Exchange rates from OECD (2016)

carbon markets can be a cost-effective mechanism for achieving emission reductions alongside attaining other objectives. International experience provides a range of lessons applicable to China as it considers the role of carbon markets, and how it can improve market design and functioning in the future (Fig. 32). 


\subsection{International Experience}

Creating a carbon market is a process of setting rules for the creation of carbon units, deciding how they should be distributed, establishing rules for market governance and trade, and managing interactions between the carbon market and other policies:

- creating carbon units is the process of determining targets and caps;

- distributing carbon units involves deciding on the level and manner of distribution of free carbon units, and the use of revenue-raising distribution mechanisms, such as auctions;

- governance includes rules regarding coverage and cost pass-through, the banking of units, the use of domestic and international offsets, linking with other emissions trading systems, the use of price controls and the impact of design on the development of the secondary market; and

- managing policy interactions involves considering the appropriate role of carbon price and complementary, overlapping and countervailing policies.

\subsubsection{Creating Carbon Units}

Targets and coverage decisions will largely determine an ETS's cap - the number of carbon units that can be created. Targets determine the long-term trajectory of emissions in a jurisdiction, and therefore the long-term supply of units in the carbon markets. Caps give the number of emission units that are added to a carbon market in each compliance period. They are generally calculated as the target level of emissions less the expected emissions from sectors that are not covered by the ETS, known as uncovered sectors, as illustrated in Fig. 33.

To ensure that emissions do not exceed a jurisdiction's target, emissions from uncovered sectors must be considered when establishing a cap. This involves estimating the likely trajectory of these emissions based on an assessment of economic conditions and the impact of mitigation policies on uncovered sectors. In the EU, emissions from uncovered sectors are also subject to a target through the effort-sharing decision, providing further guidance on the likely emissions trajectory.

Jurisdictions often overestimate the trajectory of future emissions, as a preference for

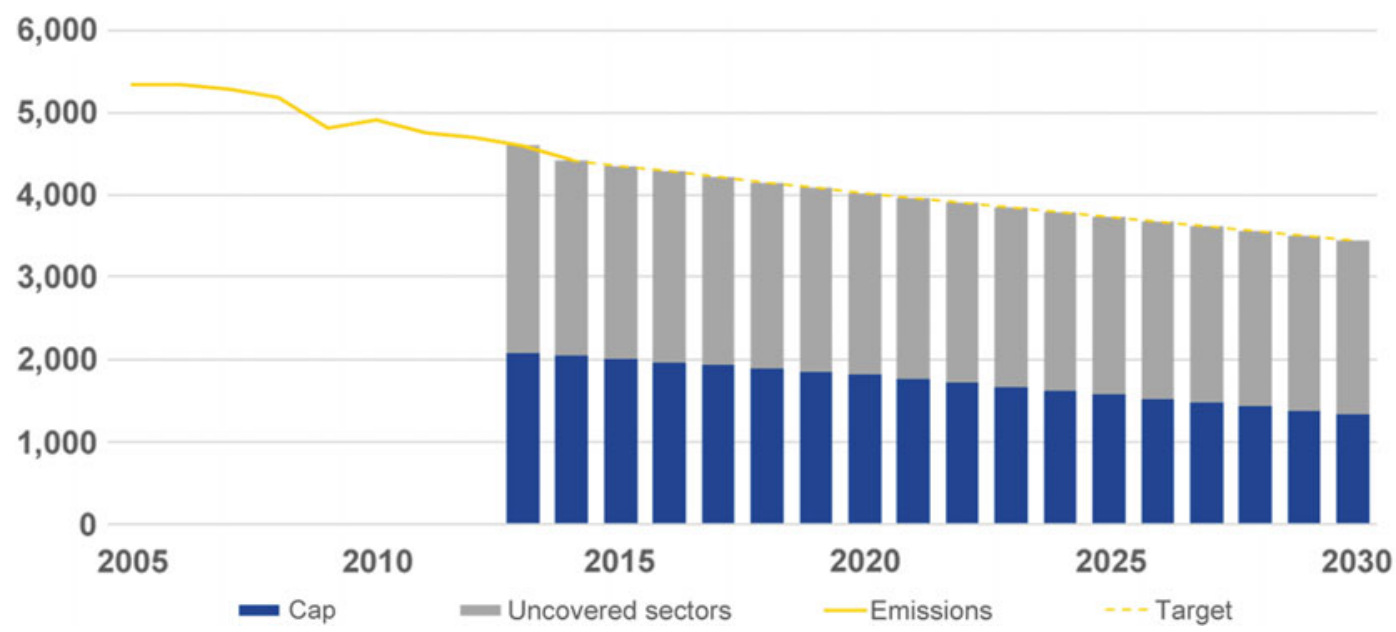

Fig. 33 Targets and coverage decisions largely determine ETS caps. Source Emissions from 2005 to 2014 sourced from Eurostat (2016); 2014 emissions cap and linear reduction factor from the European Commission's Directorate-General for Climate Action (2016); other calculations by Vivid Economics 


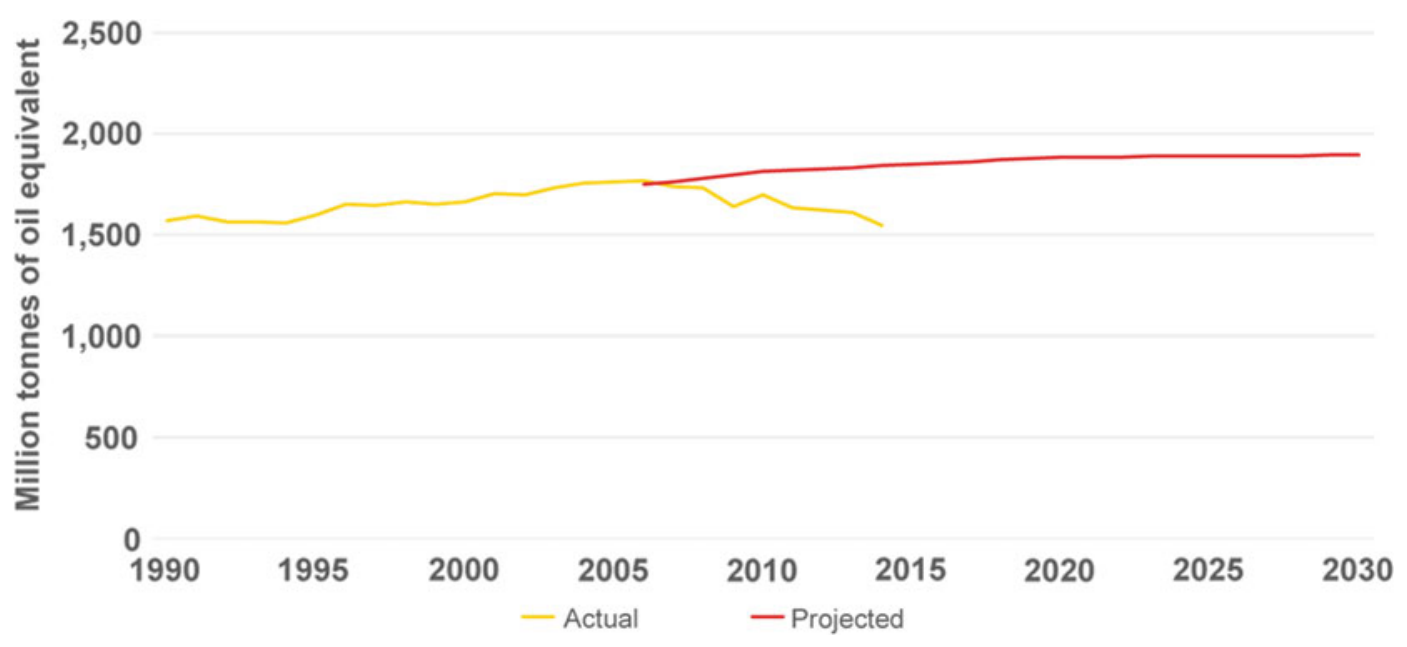

Fig. 34 Projections of continued growth in energy use may have resulted in the adoption of a weaker target in the EU. Source European Commission (2006) and Eurostat (2016)

conservative assumptions creates a projection bias towards the continuation of current trends. This can have real effects on the functioning of a carbon market. For instance, in 2006, EU projections suggested continued growth in energy use. However, the recession that followed resulted in a rapid decline in energy use and emissions, as shown in Fig. 34. An assumption of continued energy sector growth would mean that the EU's 2020 emissions target was less ambitious (in terms of deviation from business as usual) than was originally intended. The impact of unexpected outcomes (shocks) can be mitigated by adjusting supply or demand for permits to maintain a relatively stable price trajectory.

The response to short-term market shocks is best dealt with by adjusting caps, while structural oversupply should be rectified by adjusting targets. Cap and target-setting arrangements should provide the market with a clear direction regarding the trajectory of future caps, while maintaining the flexibility to respond to changed conditions. Rule-based supply mechanisms like market stability reserves and contingency reserves are considered in the discussion on price controls below.

Cap-setting mechanisms should provide the market with a clear direction regarding the trajectory of future caps, while maintaining flexibility to respond when conditions change. Flexible target and cap-setting arrangements can include the use of conditional targets, establishment of institutional review mechanisms and the use of active cap management approaches:

- conditional targets enable governments to respond to changed circumstances. A pricecontingent target would increase targets when prices are low;

- institutional mechanisms can be used to review caps and targets, for instance Australia's Climate Change Authority provided the government with advice on the appropriate range of emissions targets; and

- cap management mechanisms could be established within an independent body, such as a carbon central bank, to alter mediumterm supply to manage prices.

\subsubsection{Distributing Carbon Units}

Allocations determine who gets carbon units and what price, if any, they pay for them. Auctions remain the best way to establish the value of units on the primary market. However, in many cases, a jurisdiction will allocate units to businesses with liabilities under the carbon price, free 
of charge, to offset potential impacts on competitiveness and avoid carbon leakage. Carbon leakage may occur when domestic companies are unable to pass on their cost increases because of competition from companies overseas that are not subject to an equivalent carbon price. This can mean that emission reductions that occur domestically are offset by emission increases overseas, as production can transfer to jurisdictions with a lower-or no-carbon price.

When allocations are done poorly, they can contribute to overallocation, which can increase the fragility of the carbon pricing system. There are two main approaches to free allocations:

- grandparenting, where assistance is tied to historical emissions; and

- production-based benchmarking, where assistance is tied to the level of actual production.

Grandparenting on its own does not cause overallocation. However, it is often part of a broader set of arrangements that cause overallocation and drive low prices. Grandparenting does not of itself prevent carbon leakage, as the provision of free units occurs regardless of the level of production. Grandparenting can be used as a transitional measure while benchmarks are being developed for other allocation methods (Fig. 35).

The design of a benchmark determines the mitigation options that are used:

- process benchmarks: allocation is based on the emissions intensity of a process used to produce a specific good, which incentivises process efficiency;

- product benchmarks: allocation is based on the average emissions intensity of the production of a particular product, which incentivises technology substitution; and

- sectoral benchmarks: allocation is based on the emissions intensity of a particular industry or product category, which encourages substitution between similar products. However, this would be very difficult to implement.

Having no free allocations also incentivises end-use substitution, the choice to consume different products when relative prices change. Overall, this means that the gradual movement away from free allocations to full auctioning will incentivise a greater array of domestic mitigation options.

The auctioning of units also provides revenues that can be put to other uses. Revenues may be used to reduce other taxes, to increase

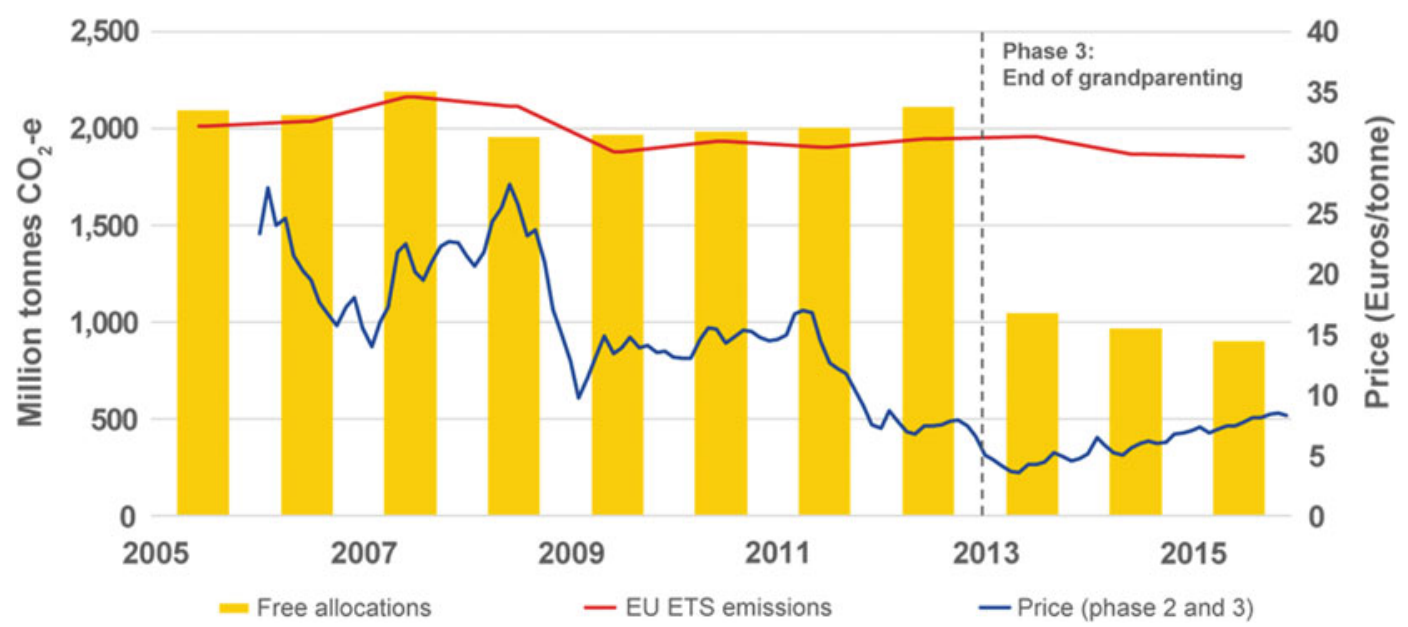

Fig. 35 EU ETS grandparenting contributed to overallocation, which lowered prices. Note EU ETS Phase 2 and 3 prices refer to December settlement futures contracts.
Source Prices sourced from Intercontinental Exchange and Quandl (2016); emissions and allocations from the European Environment Agency (2016) 
general government revenues, or be directly tied to other spending programmes. For instance, in the EU at least half of all auction revenues must be used for climate- or energy-related purposes (Fig. 36).

There are several design features that may be used to limit the amount of free allocations and increase the number of units available for auction. These include:

- limiting allocations to certain industries, in particular those industries that present a carbon leakage risk. These are usually industries that are trade-exposed, which means that they are less likely to be able to pass on costs due to overseas competition, and emissions-intensive, which means that a carbon price could have a potentially large impact on their relative competitiveness;

- differentiated assistance rates seek to reflect different levels of exposure to carbon leakage. A jurisdiction may therefore decide to provide different rates of assistance to jurisdictions that are judged to have different rates of exposure to carbon leakage risk; for instance, Australia's ETS differentiated allocation rates are based on the emissions intensity of the industry;

- envelopes cap free allocations by limiting them to a certain proportion of total units. For instance, for Phase 3 of the EU ETS, free allocations are limited to $43 \%$ of the total cap;

- automatic cuts to assistance: for instance, Australia's ETS included a carbon productivity dividend to account for potential natural carbon efficiency improvements over time, and this reduced the rate of assistance by $1.3 \%$ per year; and

- reviews can independently assess evidence of an industry's ability to pass through costs, and therefore their exposure to carbon leakage. These reviews can be a formal mechanism with outcomes that are directly tied to rates of assistance, or they can simply provide a source of information that enables government to make informed decisions. For instance, Australia's Productivity Commission was responsible for assessing cost pass-through and leakage risks.

Figure 37 shows the rates of assistance for moderately emissions-intensive and highly emissions-intensive industries in the Australian ETS. Assistance to highly emissions-intensive industries started at $94.5 \%$ of the benchmark level, while assistance for moderately emissionsintensive industries started at $66 \%$. Both assistance rates were subject to the carbon productivity dividend, and assistance rates then declined by $1.3 \%$ each year.
Allocation methodology Processes, technologies, products and end uses

\begin{tabular}{|c|}
\hline $\begin{array}{c}\text { Process } \\
\text { benchmark }\end{array}$ \\
\hline $\begin{array}{c}\text { Product } \\
\text { benchmark }\end{array}$ \\
\hline $\begin{array}{c}\text { Sectoral } \\
\text { benchmark }\end{array}$ \\
\hline No allocations \\
\hline
\end{tabular}

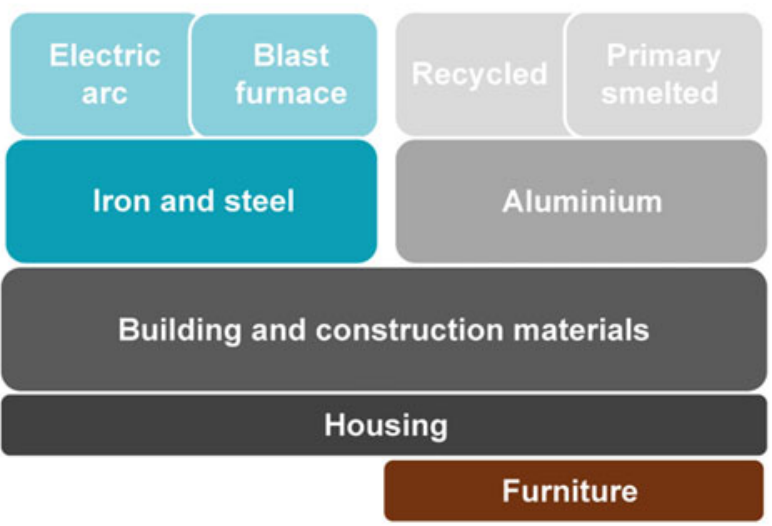

Mitigation possibilities

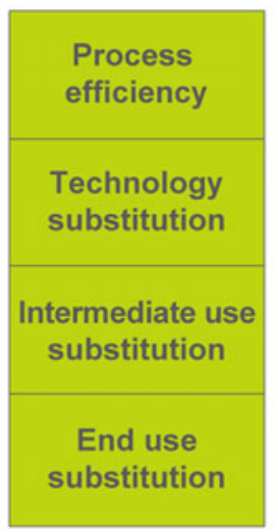

Fig. 36 The manner of assistance provided to companies determines the mitigation possibilities available. Source Vivid Economics 


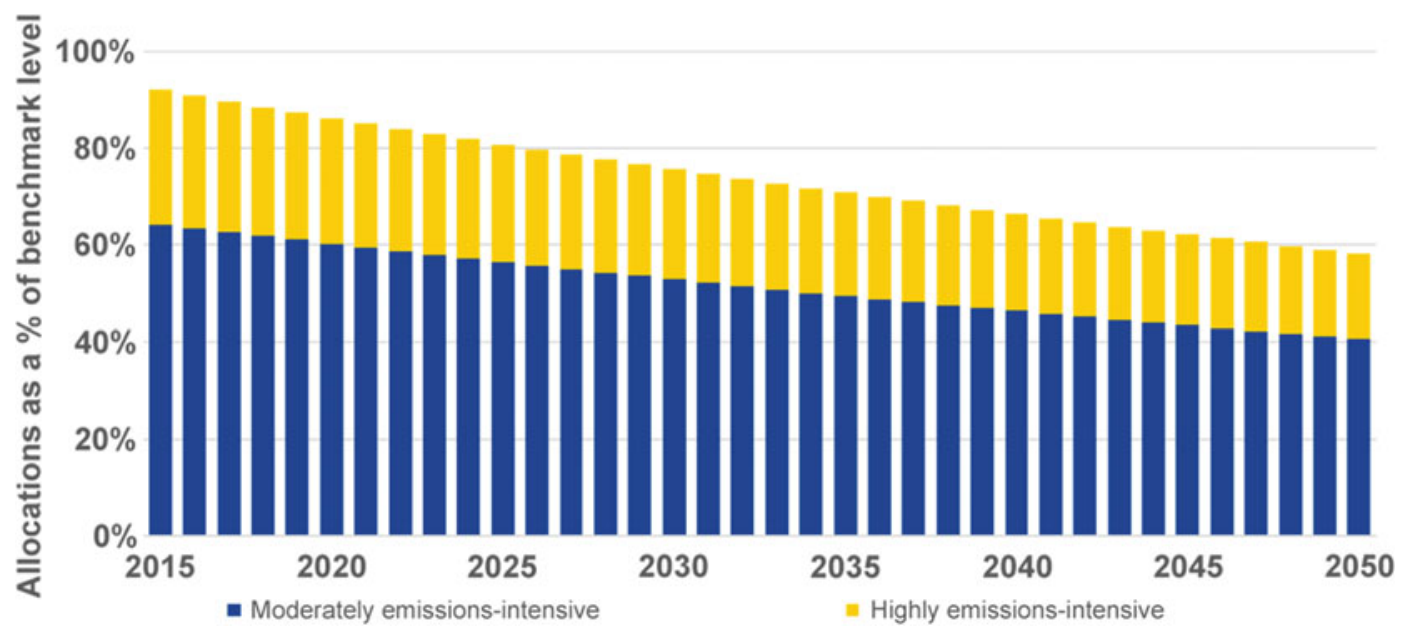

Fig. 37 Differentiated and declining assistance in the Australian ETS signalled transition to auctions. Source Vivid Economics

\subsubsection{Governing Carbon Markets}

The rules for governing a carbon market are essential to its efficient and robust functioning. The governance of a carbon market can include a wide variety of different decisions and design options. However, several design considerations common to all carbon markets are particularly important. These include decisions regarding:

- coverage of emissions;

- banking of emissions units;

- international linking and the use of offsets;
- the use of price stabilisers; and

- provisions for secondary market development.

\section{(1) Coverage}

Broad coverage and market design that encourages cost pass-through and increases the efficiency of an ETS can improve its robustness. Coverage rules determine which sectors and greenhouse gases incur a carbon price liability; cost

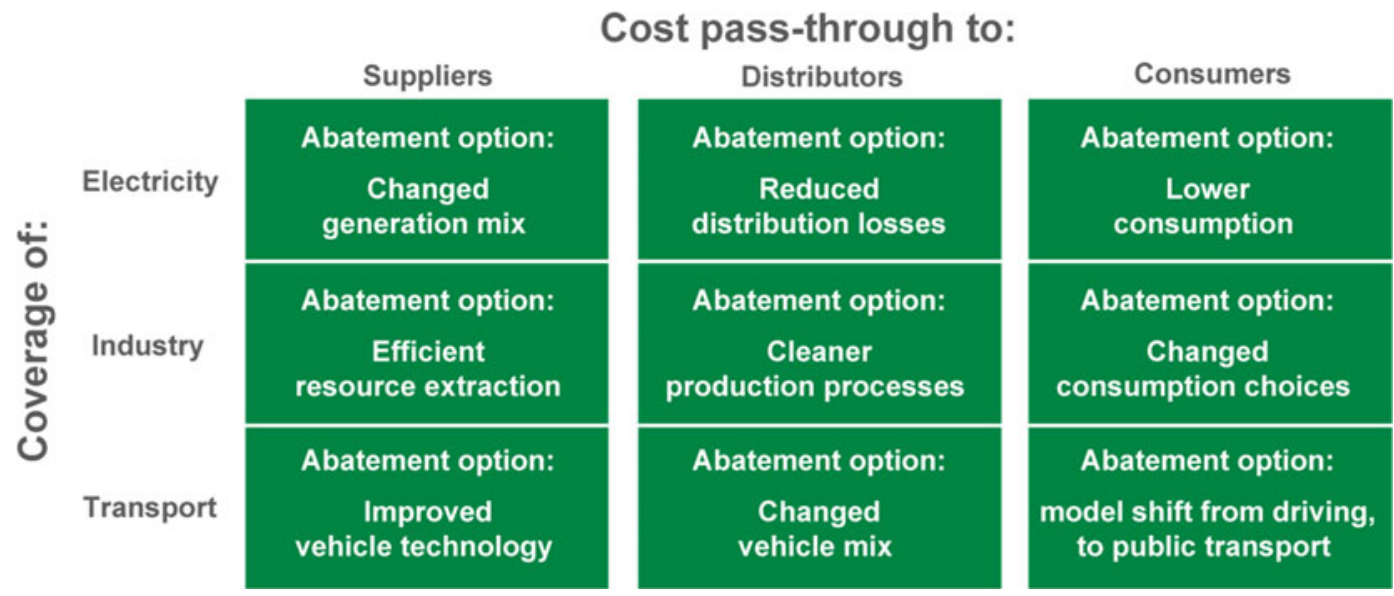

Fig. 38 Coverage decisions and the level of cost pass-through determine the mitigation options available. Source Vivid Economics 
pass-through is determined by the broader set of rules that determine which users will face the costs and incentives following from a carbon price.

Broad coverage and cost pass-through increase market efficiency by incentivising more abatement options. Examples of the abatement options that might be incentivised through different coverage and cost pass-through arrangements are outlined in Fig. 38. When coverage is limited or cost pass-through does not occur, these options are not considered, which means that mitigation becomes more expensive.
The potential emission reductions from any given mitigation option increase with the carbon price. This means that as carbon prices rise more and more, potential mitigation options will be missed if a specific source of mitigation is not incentivised. In turn, this means that when coverage is limited, or cost pass-through is constrained, more costly abatement will be required and less abatement will be achieved at any given carbon price. This is illustrated in Fig. 39.

Narrow coverage reduces robustness by increasing the carbon market's exposure to

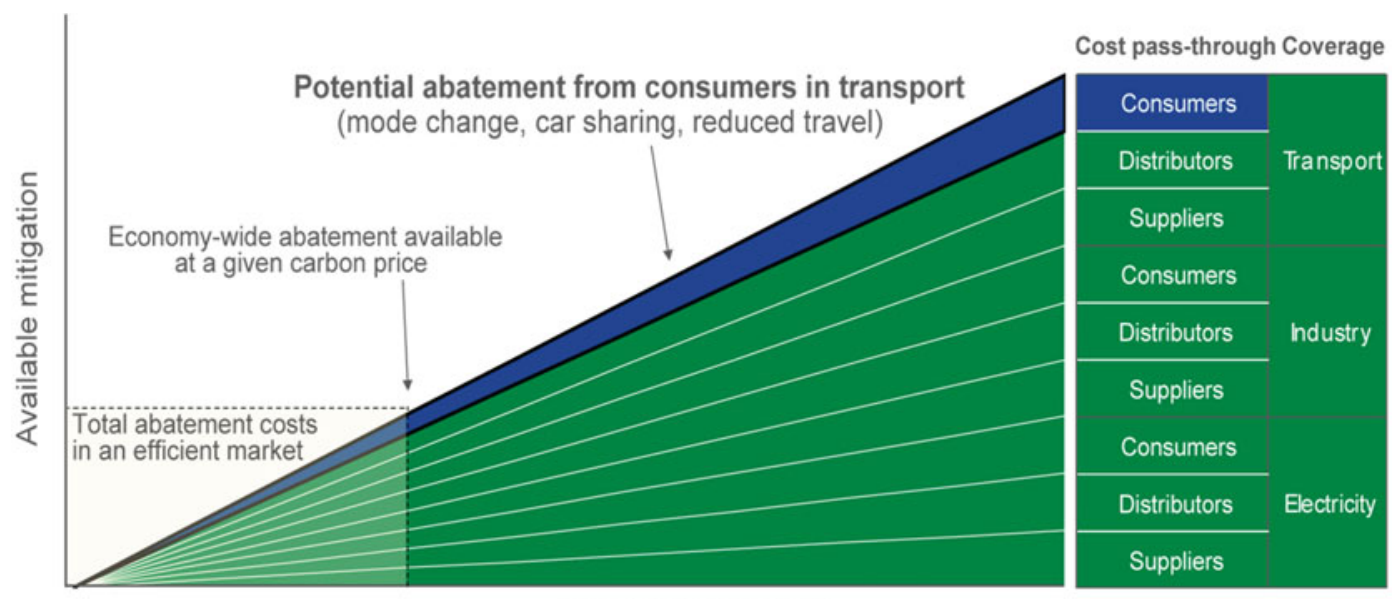

Required carbon price
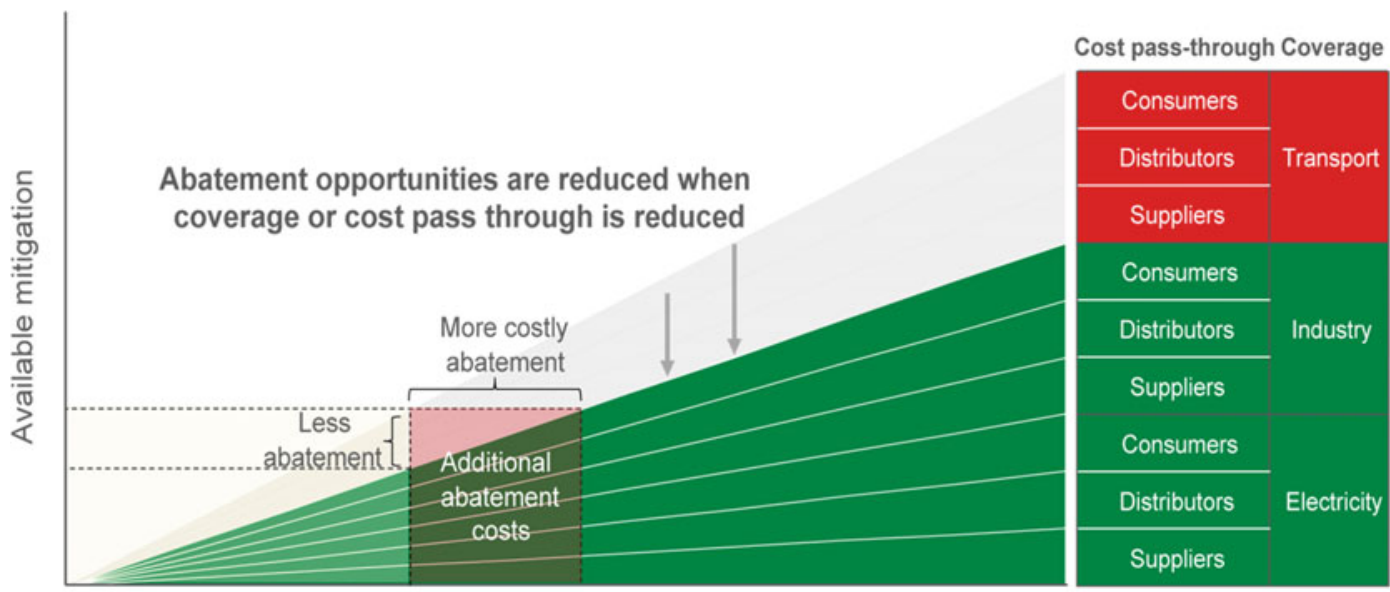

Required carbon price

Fig. 39 When coverage or cost pass-through is limited, any given target will require more costly abatement. Source Vivid Economics 

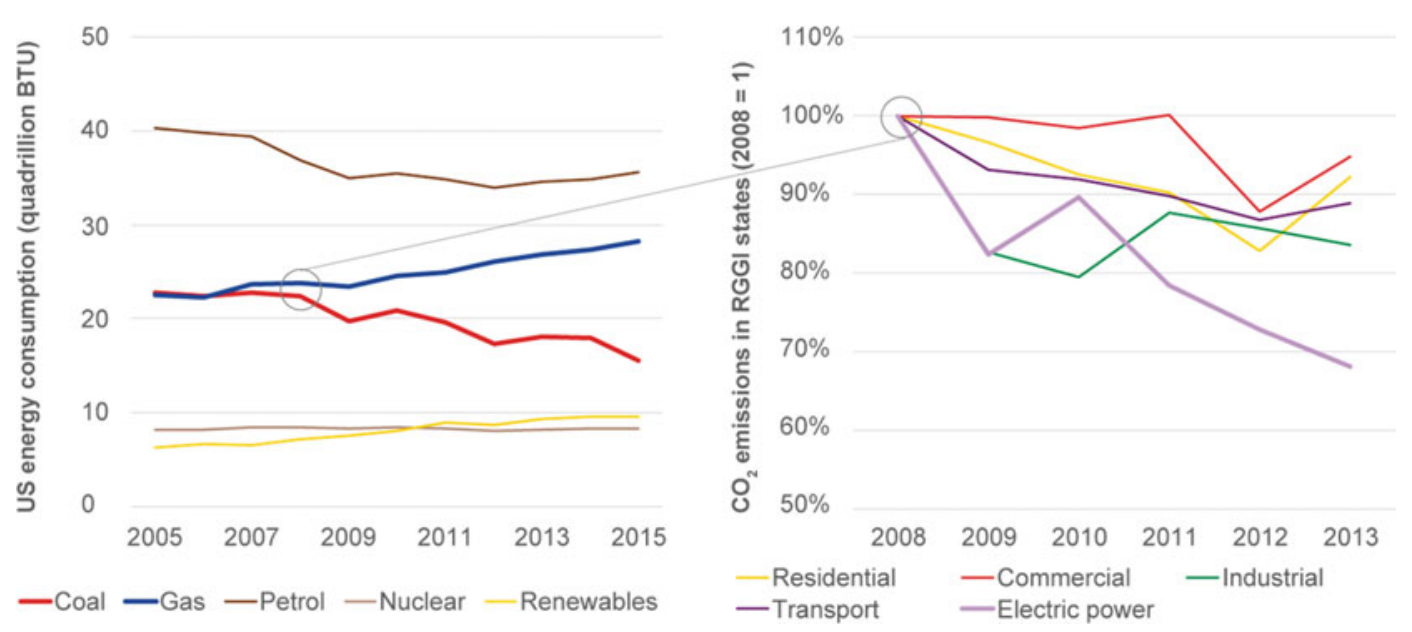

Fig. 40 The decision of RGGI member states to limit coverage to the power sector exaggerated the impacts of the unconventional gas technology shock. Source Calculated from U.S. Energy Information Administration (2016) data

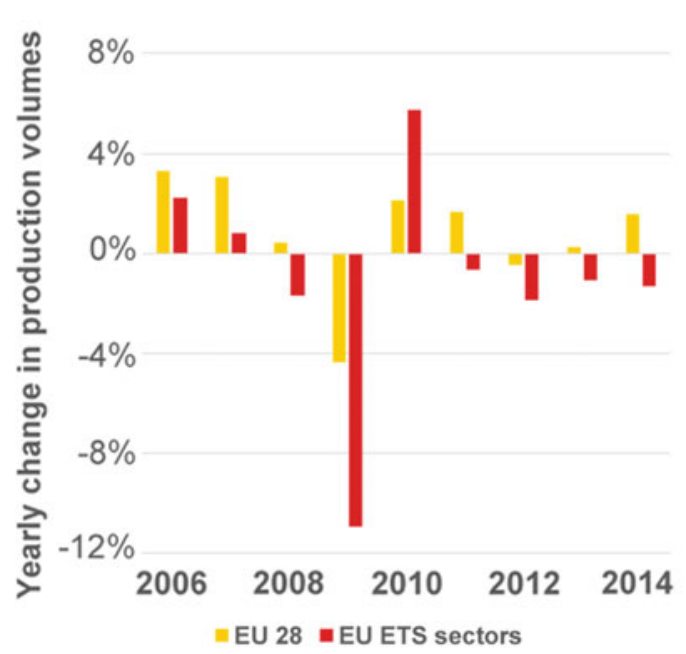

Fig. 41 Production shock concentrated in EU ETS sectors exaggerated the impact of the EU recession on demand for emission units. Note Production levels in EU ETS sectors are proxied by the weighted production value of NACE codes 17, 19, 20, 23, 24 and 35 using constant 2010 prices disaggregated by industry sector. This includes industries responsible for the vast majority

sector-specific shocks. Shocks will often affect different parts of the economy in different ways.

Technology shocks will often drive major change in the emissions profile of a single sector, while leaving others largely unaffected. For instance, the expansion of unconventional gas extraction in the USA had a major impact on power sector emissions. This in turn was

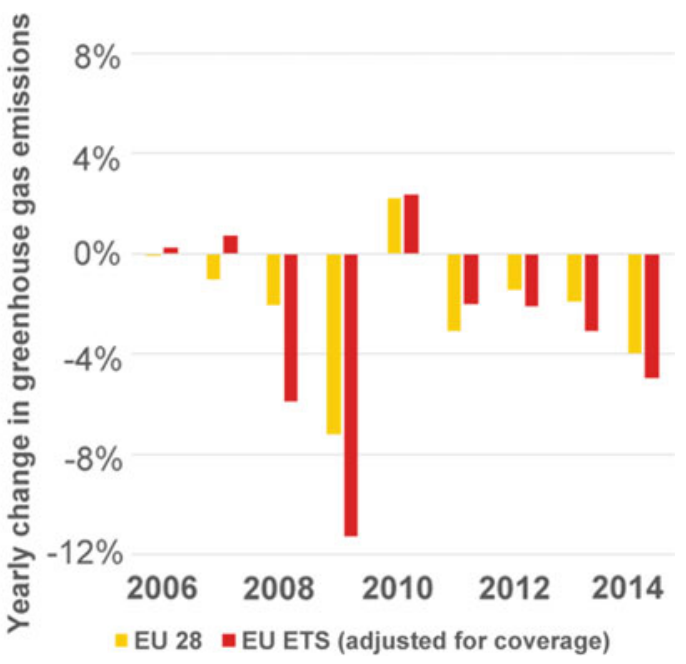

of EU ETS emissions covered, including the manufacture of paper, coke, refined petroleum, chemicals, base metals, other mineral products and electricity and gas supply. Emissions have been adjusted to account for geographic expansion and changed coverage arrangements to ensure inter-annual consistency. Source OECD (2016) and Eurostat (2016)

reflected in demand for units in the Regional Greenhouse Gas Initiative (RGGI), which only covered the electricity sector. In RGGI member states, emissions from electricity generation declined by more than $30 \%$ between 2008 and 2013, while emissions from other sectors declined at a far slower rate. This is shown in Fig. 40. 
Economic shocks can also be concentrated in specific sectors. For instance, the EU ETS primarily covers emissions from the industrial and energy sectors. These sectors were particularly affected by the recession in 2007-08, where production levels in those sectors covered fluctuated far more than in the EU as a whole. This was reflected in emission outcomes, and therefore demand for European emission allowances. This sharp fall in demand was largely responsible for the fall in prices that occurred in 2008. This is shown in Fig. 41.

\section{(2) Banking}

The banking of carbon units can both increase the cost-effectiveness of an ETS by enabling substitution of abatement across time and improve the robustness of the market. Banking lets firms stockpile carbon units for later use. This makes caps across compliance periods function as a budget rather than a target. This in turn means that when emissions in a compliance year are lower than expected, carbon units of that vintage retain their value, as they can still be used to discharge liabilities. Banking increases efficiency as it enables emissions to be reduced at the time when mitigation is at its lowest cost; it also increases robustness by ensuring that carbon units retain a positive value even after a shock. However, this also means that when a shock is large, banking can lead to a persistent oversupply that can continue to depress prices for many years.

The importance of banking is demonstrated by the experience of the EU ETS. Banking of units was not allowed from phase 1 to phase 2 of the ETS, which led prices to fall towards zero as the level of oversupply was revealed. Subsequently, the European recession in phase 2 of the ETS, led to large falls in industrial production, which resulted in an oversupply more than 10 times larger than in phase 1 . The ability to bank units meant that prices remained low, but greater than zero. However, this has also contributed to the prolonged depression in prices in phase 3 of the ETS, as shown in Fig. 42.

\section{(3) Linking and offsets}

Linking with other emission trading systems, or with credible offset mechanisms, will increase the efficiency of carbon markets, and may strengthen its robustness. Linking to other ETSs generally stabilises demand across markets, because overall emissions become less dependent

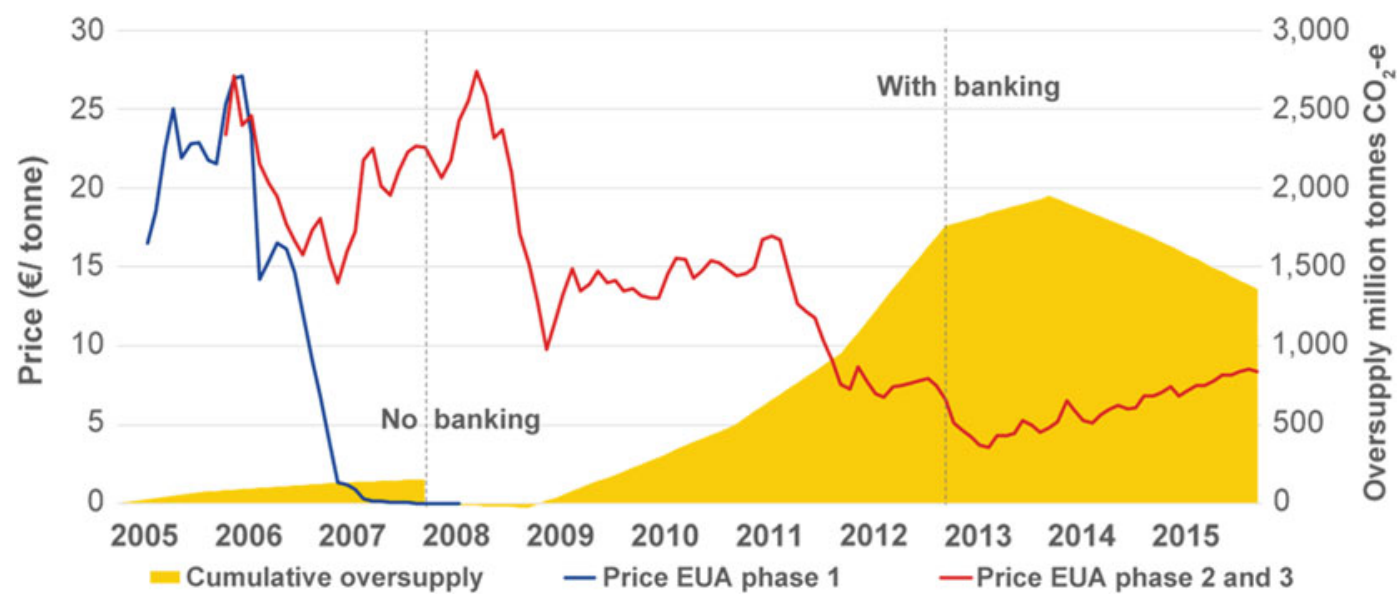

Fig. 42 Banking ensured prices remained positive despite oversupply in the EU ETS. Note European emission allowances (EUA) prices based on December delivery futures prices. Cumulative oversupply is calculated as total EUAs allocated (both free and auctioned) plus the number of Kyoto units surrendered, minus verified emissions. Source European Environment Agency (2016), Intercontinental Exchange and Quandl (2016) 


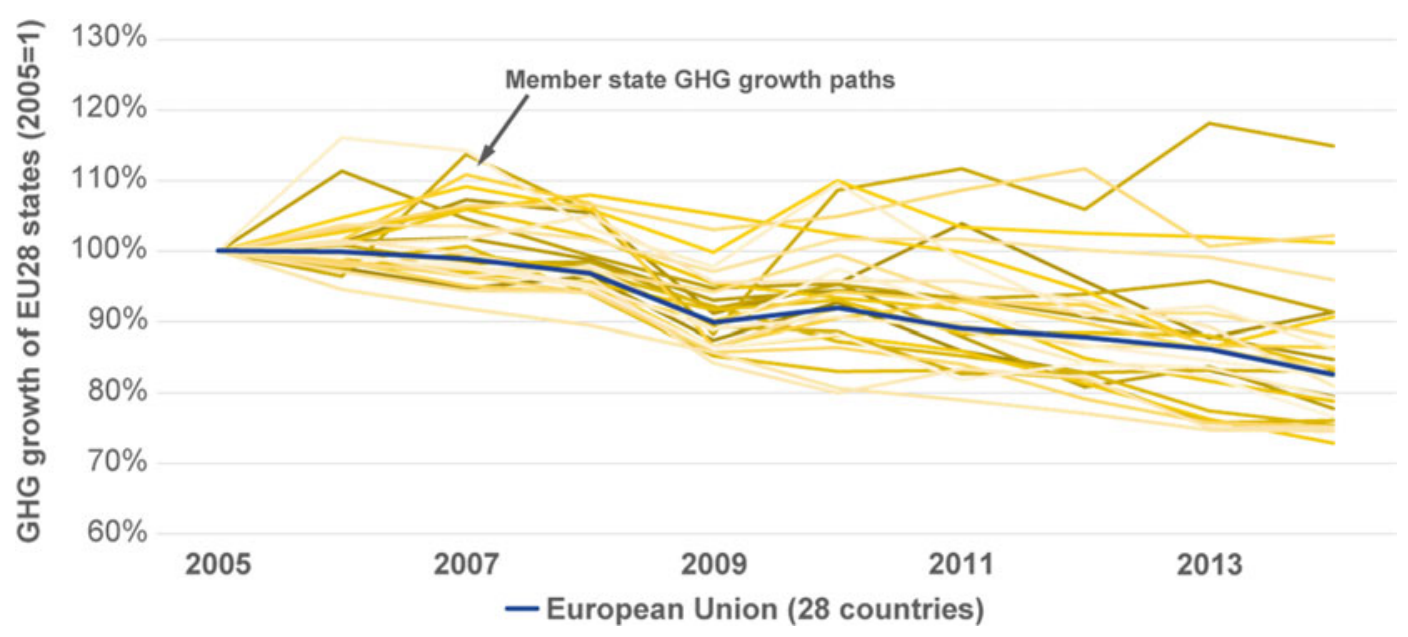

Fig. 43 Volatility in country emissions can be stabilised by linking markets. Note GHG = greenhouse gas emissions. Source Eurostat (2016)

on economic circumstances in any one market. For instance, emissions in the EU as a whole exhibit much more stability than emissions in an average EU member state, as is shown in Fig. 43. A link can affect:

- supply only, such as the use of Kyoto offsets in the EU ETS and New Zealand ETS;

- demand only, such as the proposed one-way link between the Australian ETS and the EU ETS; and

- supply and demand, such as the link between RGGI member states and California and Quebec.

A supply-only link can reduce prices within an ETS but may also be a mechanism for transmitting supply shocks through low prices. A demand-only link can increase the cost of mitigation but can also stabilise prices in the event of a demand or technology shock. Supply and demand links mean that shocks are transmitted between markets, but their effects are usually tempered. When a small market links with a larger market, however, economic circumstances in the larger market can dominate circumstances in the smaller market.

International offsets can provide substantial abatement at low cost and support the expansion of carbon markets. However, offsets often suffer from quality concerns, because determining the actual level of emission reductions from project or sectoral crediting mechanisms remains difficult. As such, offsets are often subject to a set of limits that seek to constrain their impact on the broader functioning of markets. These limits come in two main forms:

- qualitative limits allow only certain types of units to be used in an ETS (for instance, restrictions on the source country of Kyoto units in the EU ETS); and

- quantitative limits restrict the number of a certain unit class that can be used. When a limit is binding (or expected to bind), a quantitative limit will force prices to diverge.

The propensity for prices to diverge when a qualitative limit is applied or when a quantitative limit binds means that there can be a direct trade-off between efficiency and robustness. For instance, prices of New Zealand emission units closely tracked the Kyoto unit price from 2010 to 2013. However, the prospect of a ban on Kyoto units and its subsequent introduction led prices to diverge after this period. In introducing this ban, New Zealand made a trade-off between efficiency and robustness, forgoing a low-cost source of 


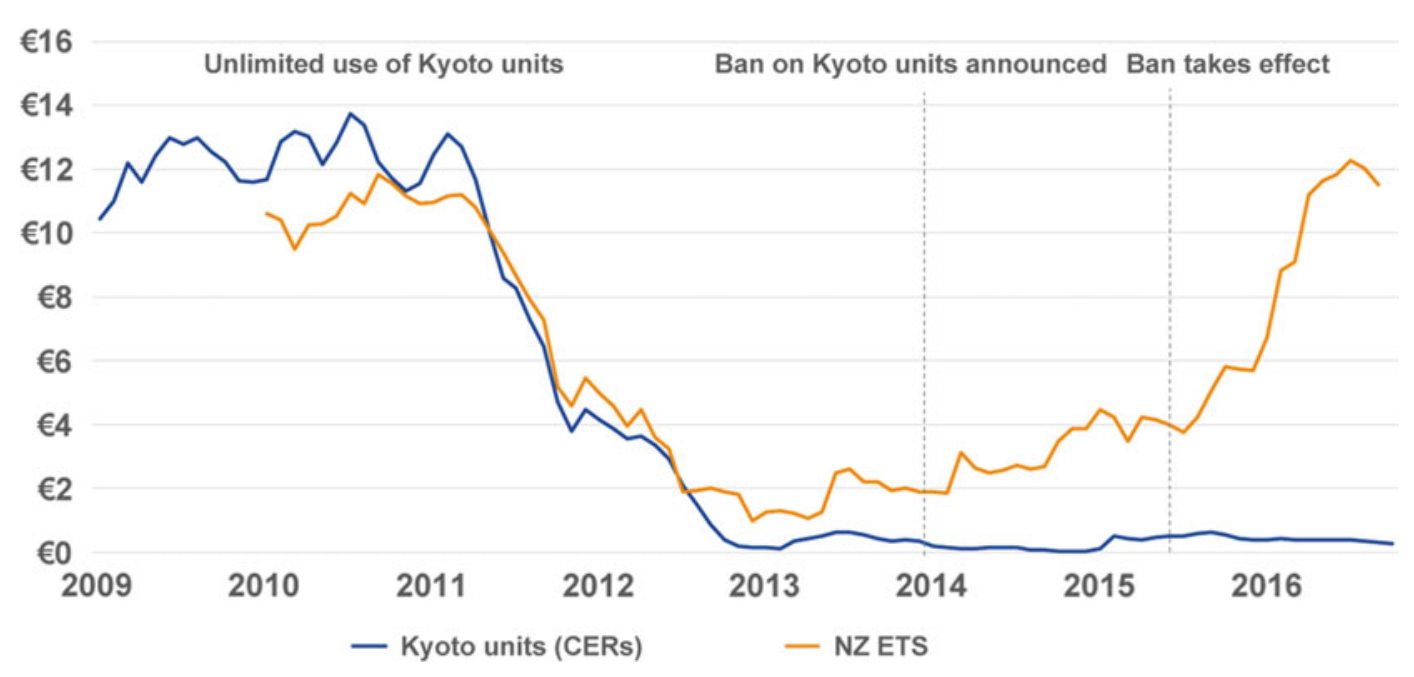

Fig. 44 Compliance rules determine relative prices. Note CER = certified emission reductions. Source Intercontinental Exchange (2016) and International Carbon Action Partnership (2016). Exchange rates from OECD (2016)

mitigation to achieve a carbon price more consistent with the long-term need to reduce emissions. This is shown in Fig. 44.

\section{(4) Price stabilisers}

Price stabilisers can be a useful tool to maintain a robust carbon price signal, especially in new markets. The policy compromises that are made when establishing a carbon market mean that carbon markets may be particularly fragile to economic shocks. There are two main types of price stabiliser that can be used: price-contingent stabilisers and quantity-contingent stabilisers.

Price-contingent stabilisers intervene in the market when one or more price criteria are met. These stabilisers include:

- price floors, auction reserve prices and surrender charges, which seek to maintain a minimum price or the equivalent price incentive;

- price ceilings and contingency reserves, which seek to maintain a maximum price; and

- price corridors, which seek to ensure that the price remains within a given range.

Most stabilisers target a price level by adjusting the level of supply or demand in the market. In its purest form a price floor will provide unlimited demand, and a price ceiling will provide unlimited supply, when prices hit certain predetermined levels. More common is the use of soft-price controls like auction reserve prices, which limit supply by setting a minimum price at auction, and contingency reserves, which increase unit supply when a specific price level is reached. A price corridor refers to stabilisers that seek to maintain both a minimum and a maximum carbon price. Price corridors, in the form of auction reserve prices and contingency reserves, are used in both the Californian ETS and RGGI. The effect of these policies on prices in these markets is shown in Figs. 45 and 46.

Surrender charges do not seek to maintain a specific price but try to maintain a minimum price incentive by charging a top-up fee for each unit that is surrendered for compliance. A surrender charge is currently used in the UK to encourage greater levels of mitigation than those driven by the current low carbon price.

Quantity-contingent stabilisers are less common, the main example being the EU's market stability reserve (MSR). The MSR seeks to correct imbalances in the carbon market by adjusting supply based on the number of excess units currently in the secondary market. When the quantity of units in the secondary market is 


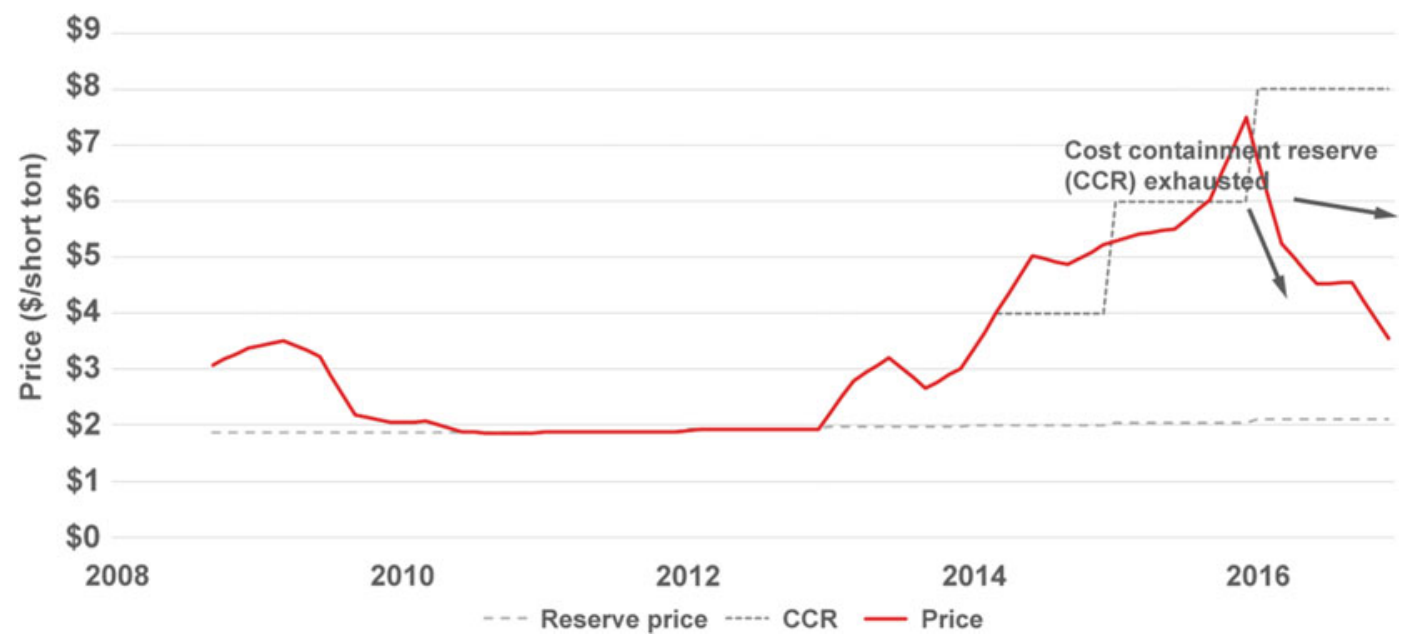

Fig. 45 Soft price floors and ceilings may result in prices deviating outside their target range. Source Regional Greenhouse Gas Initiative (2016)

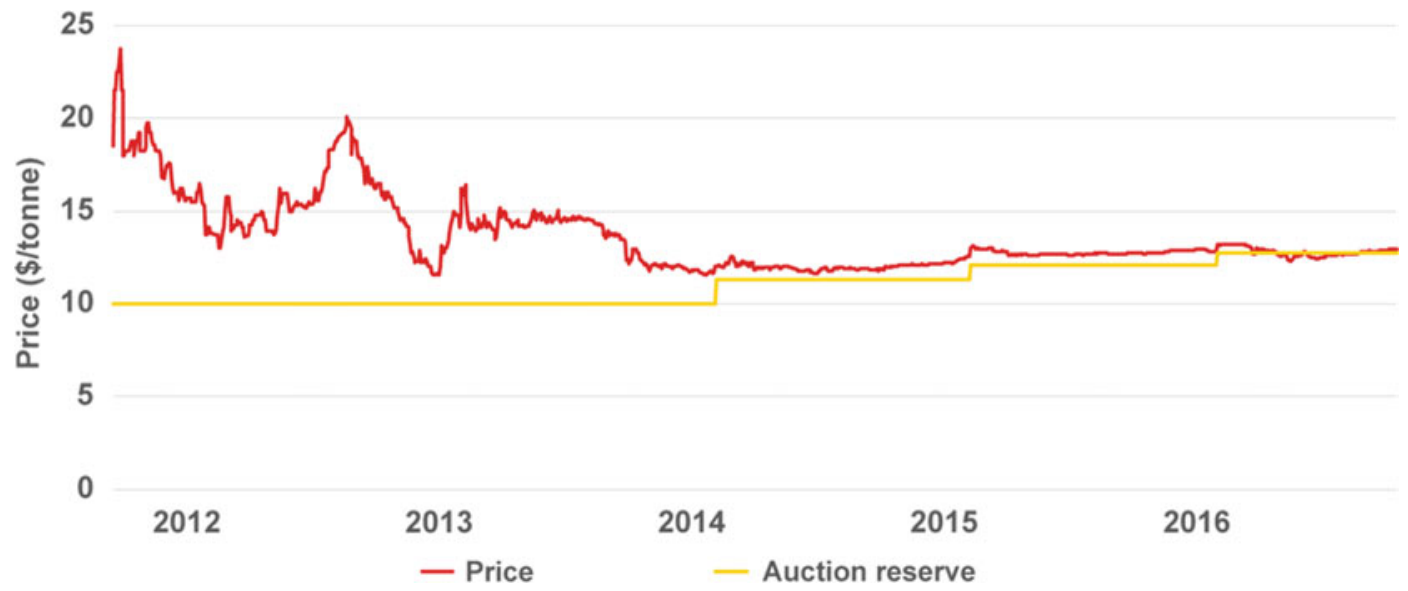

Fig. 46 California's auction reserve price has limited falls in the carbon price, but also reduced revenues. Source Climate Policy Initiative (2016)

above a certain level, units that were to be auctioned are instead placed in the MSR. When the quantity of units in the market is below a predetermined level, it reintroduces some of the previously withheld supply. As the MSR withdraws supply gradually, it may be better suited to addressing temporary imbalances rather than structural oversupply. Figure 47 demonstrates the way in which the MSR would alter supply given an illustrative emissions trajectory.

Price controls can be difficult to integrate with other policy mechanisms and may create difficulties in linking with other markets. By making supply responsive to prices, the use of price controls may undermine the environmental integrity of a link. It is possible that if a price floor is triggered in one jurisdiction, it can increase supply to such an extent that net emissions in that jurisdiction exceed the emissions that would have occurred under business as usual. Price controls can also have difficult distributional consequences; if triggered, they may result in a net transfer of resources from one jurisdiction to another. Harmonising price 


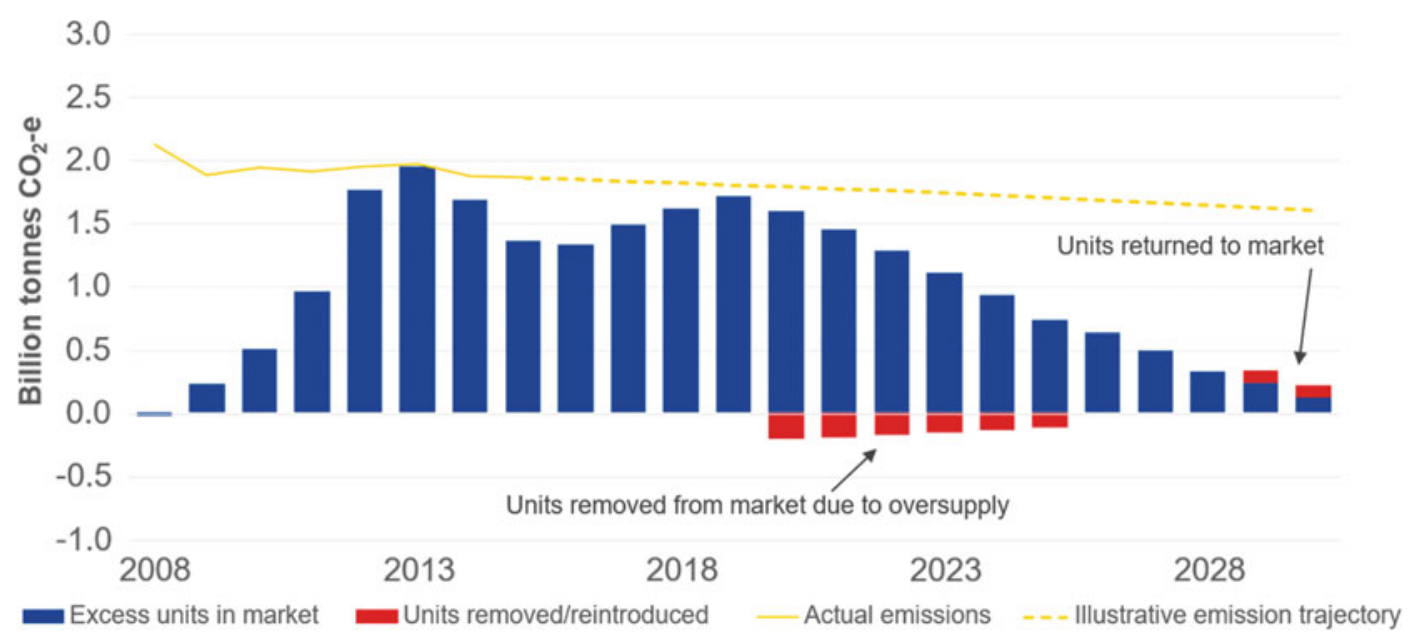

Fig. 47 The EU's market stability reserve adjusts the quantity of units in the market in response to over- or undersupply. Note Illustrative emissions trajectory developed for illustrative purposes only. Cumulative

controls may deal with these issues to some extent. However, this entails other complications; for instance, it may require the development of common auctioning platforms or agreeing to methods to correct for exchange rate fluctuations.

\section{(5) Secondary market development}

Policy design can support the development of a liquid and transparent secondary market, which increases efficiency and improves price discovery. In particular, market design should seek to support the development of institutions that lower transaction costs and reduce the counterparty risks borne by participants engaging in the market.

The market relies on central counterparties to reduce delivery risks on contracts. Active trading of emission units requires that market participants are confident that their counterparty will deliver either units or payment, as agreed. In a large market with many buyers and sellers, assessing the financial risks associated with each counterparty can be arduous. As such, markets often rely on trusted central counterparties to reduce these risks and facilitate trade. These central counterparties ensure that all parties meet minimum standards and will guarantee delivery oversupply is calculated as the total EU emission allowances allocated (free and auctioned) plus the number of Kyoto units surrendered, minus verified emissions. Source European Environment Agency (2016)

in the event of a default from either party. They often support both over-the-counter (OTC) trading and exchange trading platforms.

Cost reductions are sought through movement from trading in OTC markets to exchange-based trading of standardised contracts. Exchangebased trading generally develops in markets with large numbers of buyers and sellers, as the aggregation of trades provides greater liquidity. Over the course of phases 1 and 2 of the EU ETS, the market gradually moved from OTC trading to exchange-based trades. Exchangebased trading has several advantages, including providing transparent signals on pricing and reducing costs. The shift to exchange-based trading in the EU ETS is illustrated in Fig. 48.

The growth of futures markets reflects the desire to hedge risks and develop a longer-term price signal for long-lived assets. Over phases 2 and 3 of the EU ETS, futures markets expanded and have since consolidated, with liquid futures markets operating several years in advance - this is shown in Fig. 49. Nearly all trades in the EU ETS secondary market are now futures contracts. The most commonly traded contracts are within-year and December delivery futures, while large markets also exist for December delivery futures contracts running up to 2020 . 


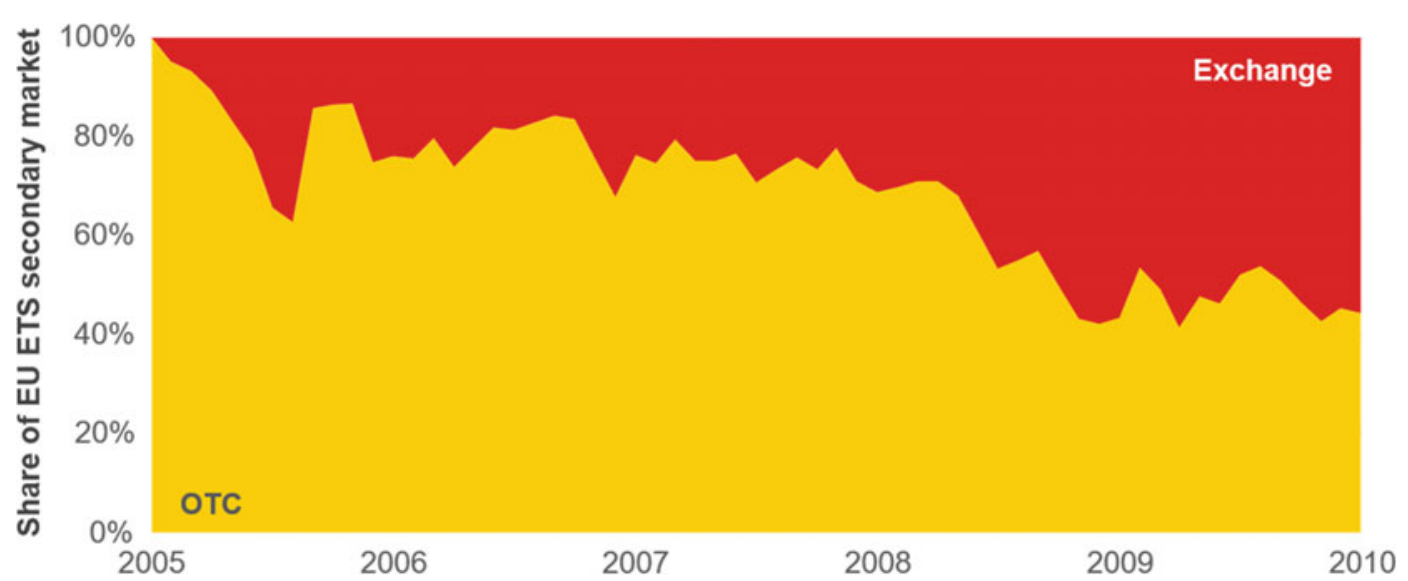

Fig. 48 As markets mature and participation increases, trading tends to move to secondary exchanges. Note As source data were not available, the figure was created by digitalisation; as such it is indicative only
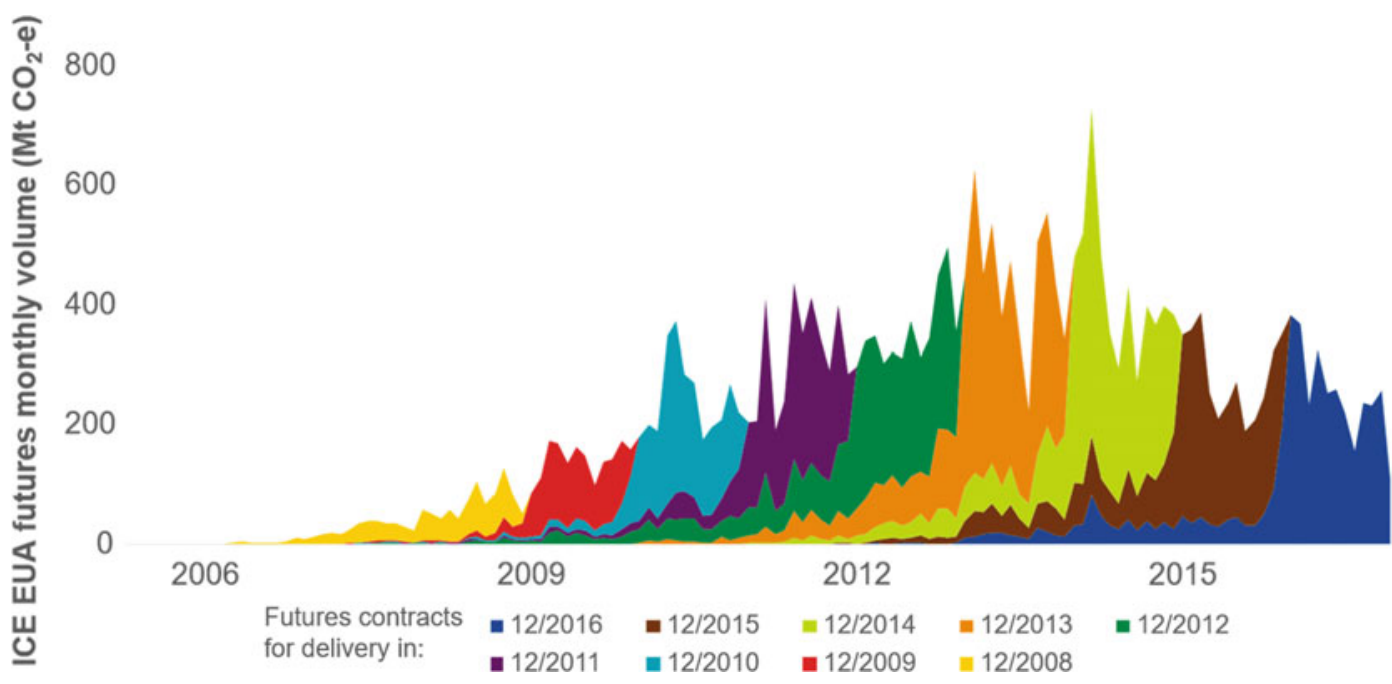

Fig. 49 The growth of futures markets provides new opportunities for risk management and improves price discovery. Note Volumes for December delivery futures

The EU's changing institutions and regulations have supported these market developments. In phases 1 and 2 of the EU ETS, registries were managed by member states, creating significant duplication across jurisdictions. However, trade in units was concentrated in just a few of these registries, which were linked with active exchange platforms - in particular, France, which hosted the BlueNext exchange. Trading was facilitated through open market access, only. ICE EUA = Intercontinental Exchange EU (emission) allowances. Source Intercontinental Exchange and Quandl (2016)

which enabled liable entities, financial institutions and other individuals and businesses to hold emission units. Instances of fraud in spot markets in 2008 and 2009 led to more stringent regulation, with spot markets regulated as financial products, whereas they were initially regulated as commodities. These problems on the spot market also accelerated the shift toward futures contracts, which were regulated as financial products from the outset. 


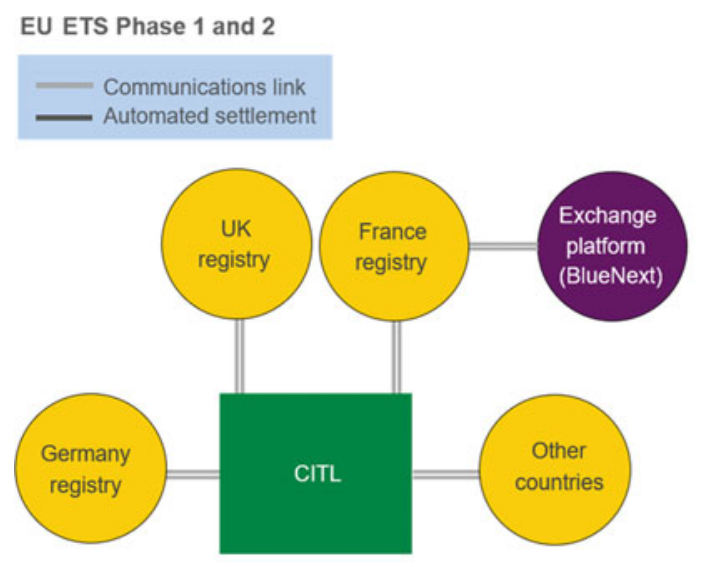

Fig. 50 The design of the EU registry system has become more centralised, and has developed to facilitate the development of exchange trading platforms. Note

In phase 3 of the EU ETS, national registry systems were consolidated into a single EU registry, which supported the development of a more efficient and mature market. The move to a centralised market increased the ease of trade across the EU by requiring a common set of processes and approaches for accessing the registry. The move to centralised reporting increased the transparency of market information, which enabled better decision-making by market participants. The EU registry also included a new type of account for exchange platforms. This simplified the process of engaging in exchange-based trading, while ensuring that security standards were maintained. The single registry also facilitates linking with other carbon markets in the future, by enabling registry links to occur under specified circumstances. These changes in registry design are illustrated in Fig. 50.

\subsubsection{Managing Policy Interactions}

Carbon pricing operates within a broader policy mix. Many of these other policies will influence how a carbon market functions and its ability to reduce emissions efficiently. Policies that impact the operation of the carbon market can include those that directly target climate change mitigation, as well as those that target other policy objectives. They can be grouped into three broad categories:
EU ETS Phase 3 and beyond

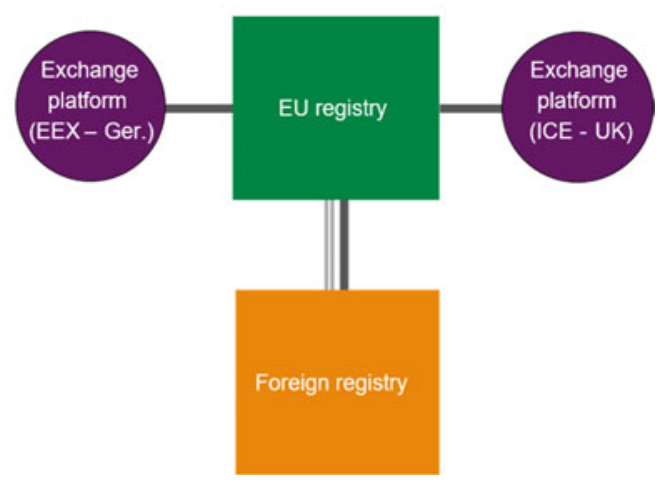

CITL = community independent transaction log; EEX = European Energy Exchange; ICE = Intercontinental Exchange. Source Vivid Economics

- complementary policies improve the functioning of carbon markets and increase efficiency; this in turn reduces costs and the likely carbon price;

- overlapping policies duplicate some of the incentives provided by carbon markets. These may increase or decrease the overall efficiency of climate policy depending on policy design, but all overlapping policies tend to reduce the equilibrium carbon price; and

- countervailing policies provide incentives that oppose those provided by the carbon market. These will reduce the efficiency of climate policy and increase prices.

These policy groupings are outlined in Fig. 51.

\section{(1) Complementary policies}

Complementary policies are those that improve the functioning of an ETS by addressing market or regulatory failures that can impede the efficient operation of the carbon market. There is a wide variety of complementary policies that can improve market functioning in several ways. Some examples include:

- mandatory energy efficiency labelling, which reduces search costs and allows people to 


\section{Examples}

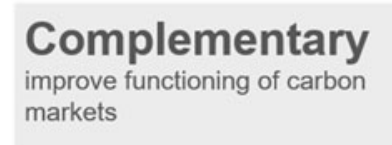

Overlapping

duplicate incentives in carbon markets
- energy market reform (facilitating cost pass-through)

- transmission infrastructure

- energy efficiency labelling

- pollution/emissions measurement
Efficiency of Likely impact on climate policy carbon price

\section{Countervailing}

oppose incentives in carbon markets
- renewable energy directive

- energy efficiency directive

- vehicle fuel efficiency standards

- feed-in-tariffs
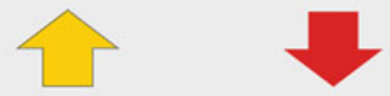
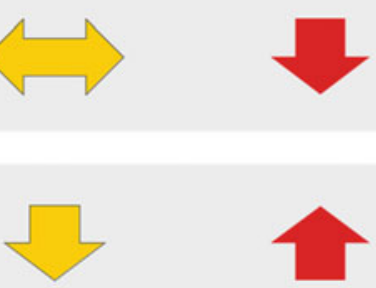

Fig. 51 The efficiency of climate policy is affected by the interaction of carbon pricing with complementary, overlapping and countervailing policies. Source Vivid Economics

make better decisions regarding appliance purchases. Figure 52 shows how the demand for new refrigerators shifted towards more efficient models following the introduction of energy use labels and minimum performance standards; and

- direct measurement of methane in underground coal mines for safety purposes, which allows those emissions to be priced more accurately than using a standard regional factor.

In many cases, carbon pricing can work alongside complementary policies to support policy objectives other than emission reductions. This provides the opportunity to implement a broader package of reforms that enhance the performance of each policy and support sustainable growth.

\section{(2) Overlapping policies}

Overlapping policies can have a positive or negative impact on the efficiency of climate policy. Some will increase efficiency, especially when they are addressing a genuine market failure. For instance, without guidance, consumers

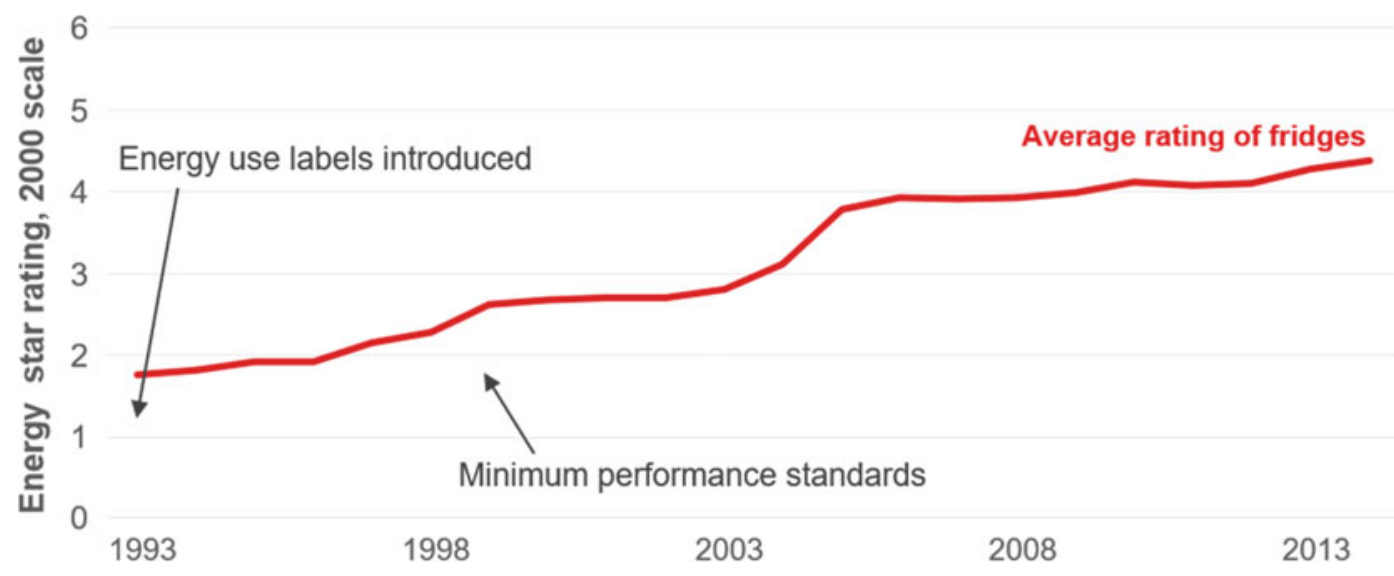

Fig. 52 Labels may have helped improve consumer choice of refrigerators in Australia. Source Energy Efficiency Strategies (2016) 


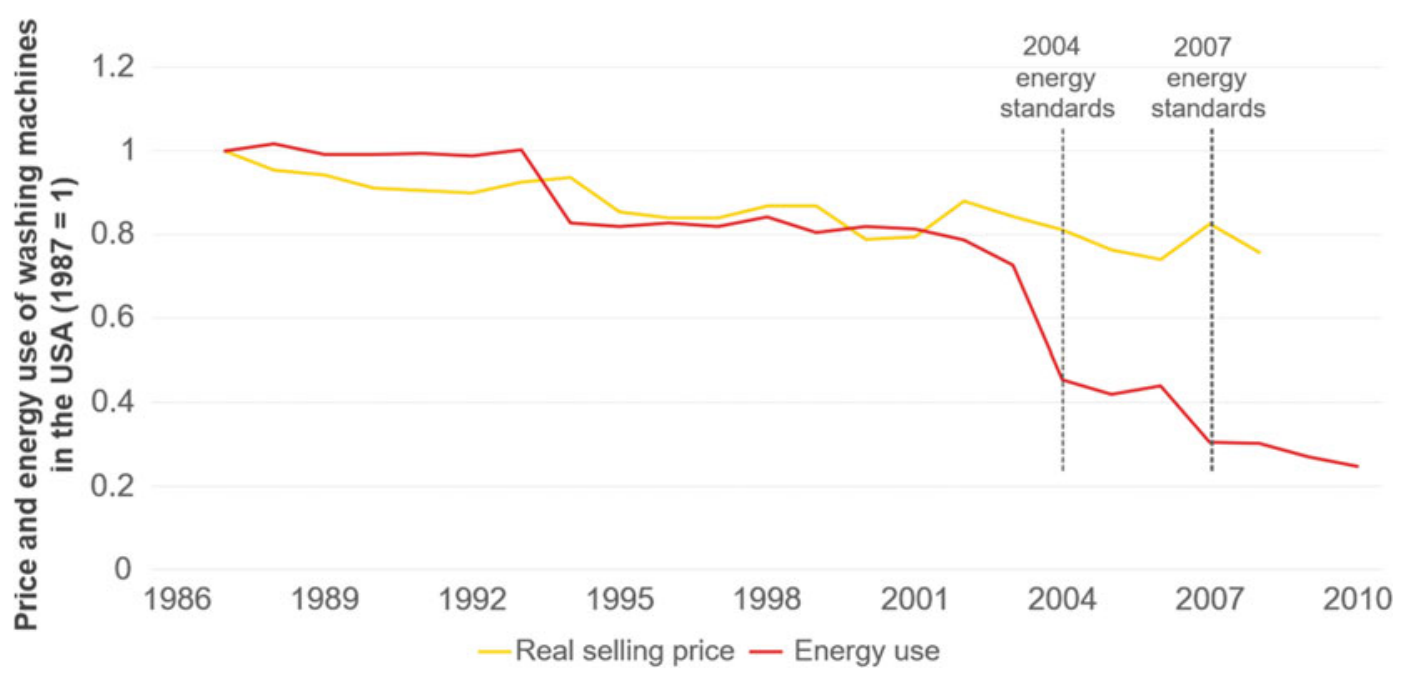

Fig. 53 Energy efficiency standards in the USA have reduced energy use at a low cost. Source International Energy Agency (2015)

will often purchase appliances that are inefficient and high cost to operate. This can occur for a variety of reasons. For instance, consumers may seek to reduce the time costs associated with researching the relative performance of different appliances and not consider the environmental or energy impacts of their choices. Alternatively, landlords may purchase cheap but inefficient appliances, which are higher cost because their tenants pay for high rates of energy use. Because of these and other market failures, the introduction of energy efficiency standards has reduced emissions cost-effectively in many countries. These standards improve the quality of the stock of appliances sold, while in many cases having very little impact on prices. Figure 53 shows the impact of the introduction of energy efficiency standards for washing machines in the USA, which resulted in substantial reductions in energy use while having no noticeable impact on prices.

In other cases, overlapping policies will reduce the efficiency of a carbon-pricing system, particularly when multiple policy instruments seek to address the same market failure. An example of this is the use of feed-in tariffs in Germany, where generous subsidies for the generation of solar power led to significant growth of the industry. However, this mitigation occurred at a very high cost and placed downward pressure on prices in the ETS.

California's low-carbon fuel standard is an example of an overlapping policy that probably reduces the effectiveness of the carbon price. The fuel standard is enforced through the creation and trade of certificates, expressed in tonnes per $\mathrm{CO}_{2}$ equivalent. As such, it duplicates the incentives of the California ETS, which also requires carbon units to be surrendered for emissions from the combustion of transport fuels. This reduces the efficiency of climate policy as it means that the transport sector faces a higher effective carbon price than other sectors of the economy. This larger incentive to reduce emissions in the transport sector also puts downward pressure on the carbon price. The disparity between the effective carbon price faced by transport and other covered sectors is illustrated in Fig. 54.

\section{(3) Countervailing policies}

Countervailing policies are those that act in opposition to the incentives created by a carbon market. The most obvious example of a countervailing policy is fossil fuel subsidies. These subsidies are often large and remain in place in many jurisdictions that are also subject to an 


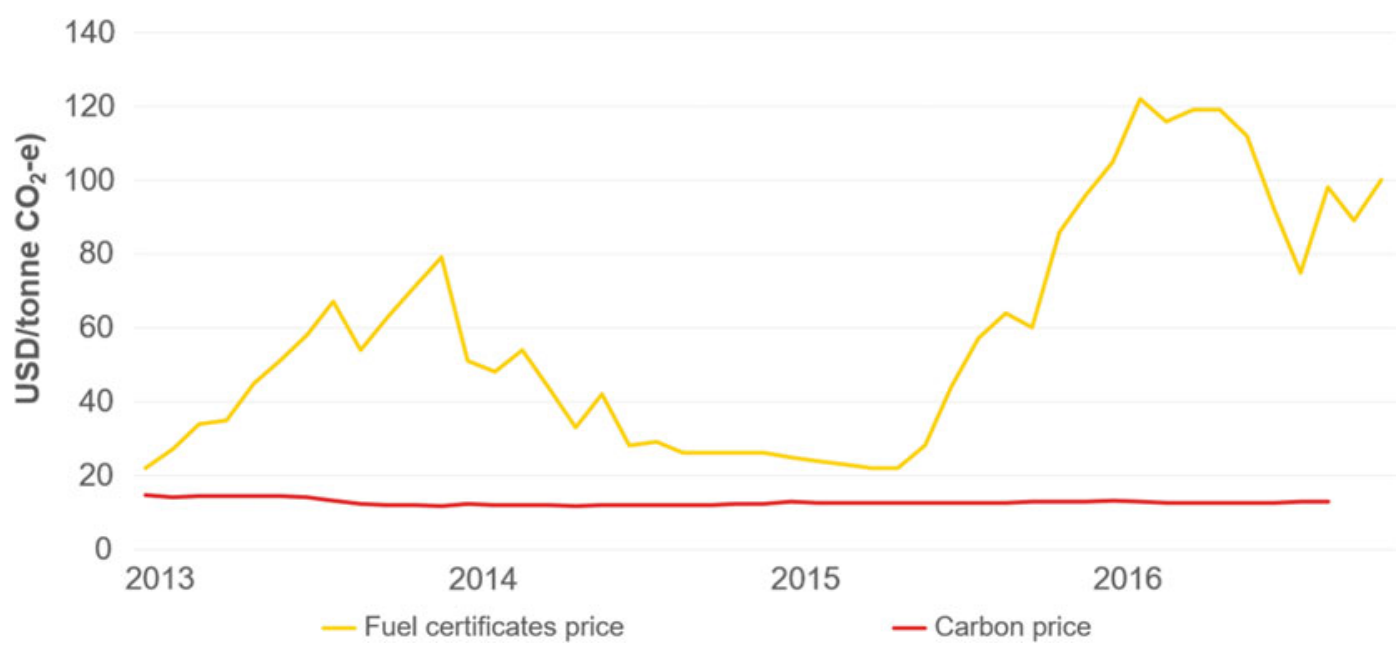

Fig. 54 California's low-carbon fuel certificates duplicate carbon price incentives, with their high price reducing both demand and price in the carbon market.

Source California Air Resources Board (2016) and Climate Policy Initiative (2016)

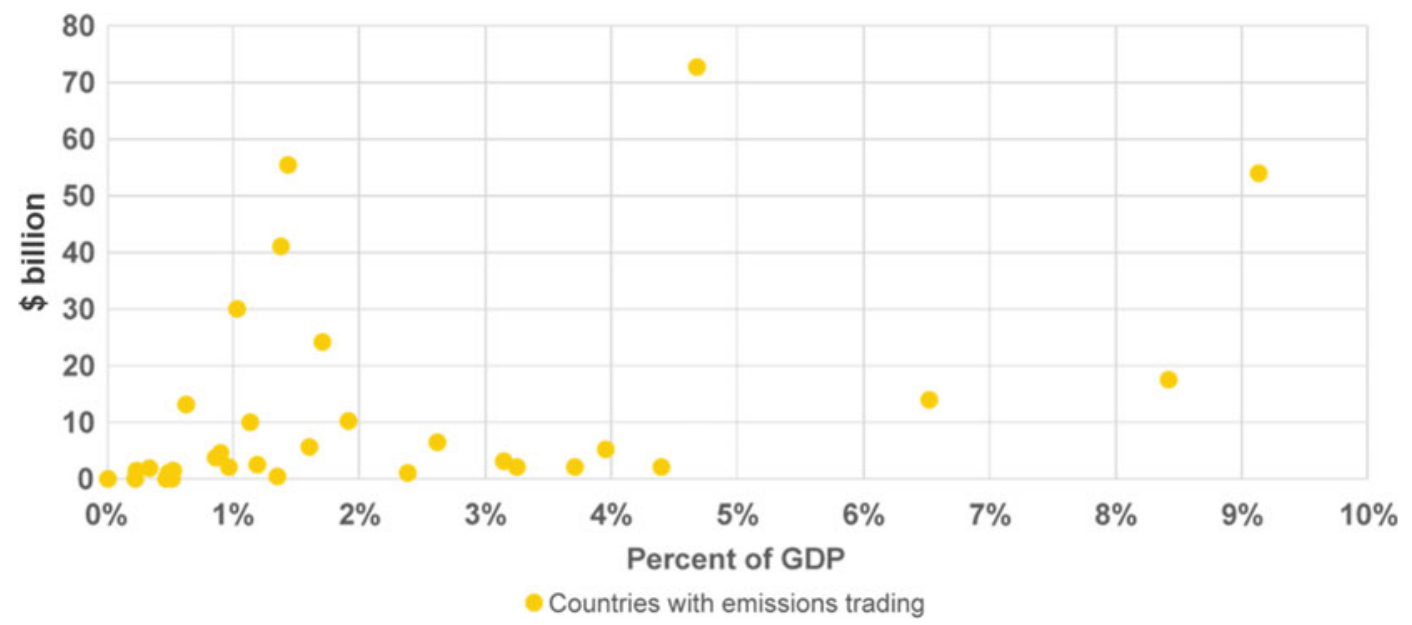

Fig. 55 Many countries retain expensive fossil fuel subsidies that counteract the goals of their carbon markets. Source International Monetary Fund (2015)

ETS, as shown in Fig. 55. Other countervailing policies may be less obvious. For instance, urban mobility policies counteract the impact of the carbon price, even though this was not their original intent.

In some cases, a jurisdiction may decide to retain a countervailing policy despite its impact on the functioning of the carbon market. This may occur when the jurisdiction judges that the negative impact of the policy on the efficiency of climate policy is more than outweighed by its benefits, and that alternative policies are unable to deliver the desired policy outcomes. 


\subsection{Evolutionary and Revolutionary Change in Carbon Markets}

Changes in carbon markets can be evolutionary or revolutionary. China will shortly establish a carbon market. On December 19, 2017, the National Development and Reform Commission (NDRC) announced the official launch of China's carbon emissions trading system, starting with the power generation sector. Previously, the NDRC had issued the Plan for Building a National Carbon Emissions Permit Trading Market (for the Power Generation Sector), which outlined the design of China's carbon emissions trading system. However, the design is likely to change over time in response to shocks and changing policy priorities. Identifying the changes necessary and what they entail can help guide the future policy direction for China's carbon market. Our research shows that the cost-effectiveness of climate change mitigation will become more important over time as greater levels of higher-cost mitigation are required. This means that policymakers may wish to move from a carbon-pricing system that is less weighted towards cost-effectiveness to one where the cost-effectiveness of the policy is a more important consideration. The nature of the policy change required to give this effect depends on the nature of the problem and China's specific circumstances.

Evolutionary and revolutionary change differ in their speed, level and type of impact. In general, a change will be more revolutionary if it occurs rapidly, has a large impact and changes the nature of the system, rather than just adjusting its efficiency or the distribution of costs. For instance, policy change that results in net zero emissions before 2050 through a fundamental change in the energy system and in industrial composition would be a revolutionary change (Fig. 56).

The decision to pursue evolutionary or revolutionary change depends on the rate and level of change required, the certainty of impacts, and the political and institutional feasibility of delivery. A more revolutionary approach will be required when a faster transition or a larger change is required. Consideration must also be given to the uncertainty of impacts, with risk-averse decision makers likely to prefer evolutionary change when the level of uncertainty regarding a policy's impact is lower. The political feasibility of a change is also important. For example, evolutionary change may be more appropriate when the trade-offs required by a change are large, or where the need for change is contested. The level of institutional capacity also plays a role: if institutions are more capable, they will be more able to manage change effectively and respond to changing circumstances as they occur (Fig. 57).

Climate change has aspects that suggest a balance between evolutionary and revolutionary change. The rate and level of required emission reductions suggest the need for revolutionary change. However, the difficult politics of such a

\begin{tabular}{|l|l|l|}
\hline \multicolumn{1}{|c|}{ Indicator } & \multicolumn{1}{|c}{ Revolutionary } & \multicolumn{1}{c}{ Evolutionary } \\
\hline Rate & $\begin{array}{l}\text { Rapid change } \\
\text { (e.g.net zero emissions before 2050) }\end{array}$ & $\begin{array}{l}\text { Gradual change } \\
\text { (e.g. net zero emissions after 2050) }\end{array}$ \\
\hline Level & $\begin{array}{l}\text { Large impact } \\
\text { (e.g. high carbon prices, radical } \\
\text { change to industry composition) }\end{array}$ & $\begin{array}{l}\text { Small impact } \\
\text { (e.g. low carbon prices, changes } \\
\text { competitiveness within industries) }\end{array}$ \\
\hline Type & $\begin{array}{l}\text { Changes the functioning of a system } \\
\text { (e.g. liberalising energy markets) }\end{array}$ & $\begin{array}{l}\text { Change to efficiency or cost burden } \\
\text { (e.g. shift from free allocations to auctions) }\end{array}$ \\
& & \\
\hline
\end{tabular}

Fig. 56 Evolutionary and revolutionary change differ in their rate, level and type of impact. Source Vivid Economics 


\begin{tabular}{l|l|l}
\multicolumn{1}{c|}{ Indicator } & \multicolumn{1}{c}{ Revolutionary } & \multicolumn{1}{c}{ Evolutionary } \\
\hline Rate & Faster transition required & Slower transition acceptable \\
Level & Large change is required & Change has a smaller impact \\
\hline $\begin{array}{l}\text { Certainty } \\
\text { Political } \\
\text { feasibility }\end{array}$ & $\begin{array}{l}\text { No regrets or small trade-offs with } \\
\text { broad support }\end{array}$ & $\begin{array}{l}\text { Requires significant trade-offs, widely } \\
\text { contested }\end{array}$ \\
$\begin{array}{l}\text { Institutional } \\
\text { capacity }\end{array}$ & $\begin{array}{l}\text { Systems and processes are sufficient to } \\
\text { handle change }\end{array}$ & Capacity constraints make change difficult \\
\hline
\end{tabular}

Fig. 57 The appropriate approach to policy change should be based on the rate and level of change required, the certainty of impacts, and the political and institutional feasibility of the change. Source Vivid Economics

change, and limitations in institutional capacity, suggest that a rapid evolution may be more appropriate (Fig. 58).

Achieving the desired result requires careful consideration of how to sequence change, with a jurisdiction's choices heavily dependent on its specific circumstances. Some elements of climate policy may be more conducive to revolutionary change than others. The interaction of these elements is therefore a key determinant of the sequencing of policy change.

China looks likely to use a slow start to emissions trading; if it does, it should consider adopting price controls and a clear reform path to reduce the risk of becoming stuck in the transition trap. Design trade-offs in the early stages of carbon pricing are common and can result in fragility. This means that an active approach to price management, such as a tight price corridor, can be used to ensure incentives are maintained while the market develops. This can be supported by signalling the direction of climate policy. For instance, committing to specific changes through legislation can provide clear guidance on the direction of policy to help maintain prices and public support for carbon markets in the event of a shock.

In the longer term, climate policy should develop in a manner that delivers:

- increased clarity of price signals, with the ETS playing an increasingly large role in
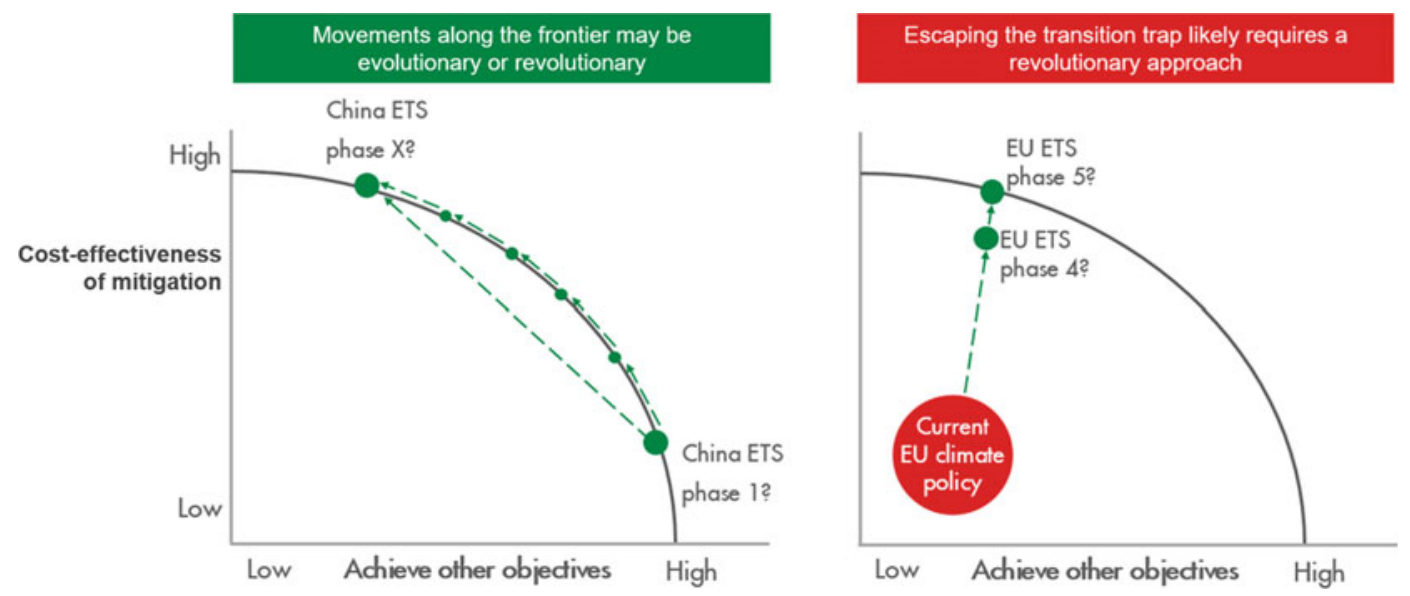

Fig. 58 The choice between evolutionary and revolutionary change is context-dependent. Source Vivid Economics 


\begin{tabular}{|c|c|c|}
\hline & Evolutionary & Revolutionary \\
\hline Creation & $\begin{array}{l}\text { - Target setting based on national circumstance, } \\
\text { gradually transitioned to global carbon goal by } 2030 \\
\text { - Bottom-up cap setting to } 2020 \\
\text { - Net carbon neutrality after } 2050\end{array}$ & $\begin{array}{l}\text { - Move to binding, absolute targets and top-down cap } \\
\text { setting by } 2020 \\
\text { - Targets aligned with goal of achieving global net carbon } \\
\text { neutrality before } 2050\end{array}$ \\
\hline Distribution & $\begin{array}{l}\text { - Move from grandfathering to production-based } \\
\text { allocations by } 2020 \\
\text { - Assistance to emissions intensive industries only with } \\
\text { high assistance rates, declining gradually over time } \\
\text { - Auctioning of remaining units }\end{array}$ & $\begin{array}{l}\text { - End grandfathering as soon as possible, immediate } \\
\text { development of process level baselines } \\
\text { - Assistance limited to emissions-intensive, trade-exposed } \\
\text { industries, and quickly declines } \\
\text { - } 100 \% \text { auctions by } 2030\end{array}$ \\
\hline Governance & $\begin{array}{l}\text { - Start with low }(\$ 10-20) \text { price floor or MSR, may } \\
\text { also include price ceiling, both growing slowly } \\
\text { - Phase in coverage starting with electricity generators } \\
\text { and major industrial energy users } \\
\text { - Slow movement to linking with international partners }\end{array}$ & $\begin{array}{l}\text { - High }(>\$ 40) \text { price floor that increases rapidly } \\
\text { - Immediate coverage of all energy, transport and } \\
\text { industrial emissions, with full banking } \\
\text { - Agriculture and land sectors covered by } 2025 \\
\text { - Near-term linking with willing international partners }\end{array}$ \\
\hline $\begin{array}{l}\text { Policy } \\
\text { interactions }\end{array}$ & $\begin{array}{l}\text { - ETS operates as part of a broad policy mix, with } \\
\text { other policies playing dominant role before } 2030 \\
\text { - Carbon market gradually becomes more influential in } \\
\text { economic decisions }\end{array}$ & $\begin{array}{l}\text { - ETS plays immediate major role in investment decision- } \\
\text { making, becomes the major driver of decarbonisation } \\
\text { investment by } 2025 \\
\text { a Other policies aligned with decarbonisation objective }\end{array}$ \\
\hline
\end{tabular}

Fig. 59 Evolutionary and revolutionary change can differ with regard to all aspects of scheme design. Note MSR = market stability reserve. Source Vivid Economics

economic activity and in different sectors and sources of emissions facing equivalent price signals; and

- a greater international focus, with domestic circumstances playing a progressively smaller role in determining policy relative to the broader global need to reduce greenhouse gas emissions.

Figure 59 outlines what evolutionary and revolutionary change could involve for China's climate policy. The major difference is the rate of change, with the revolutionary approach adopting more cost-effective policy approaches sooner and achieving net zero emissions earlier. In the revolutionary case, carbon pricing becomes the major driver of new energy investment in the short term, supported by a robust price corridor, broad coverage and near-term linking with international partners.

The following sections provide more detail on the differences between an evolutionary or revolutionary change in the aspects of carbon market design.

\subsubsection{Creation of Carbon Units}

Targets and cap setting are closely related, with changes in targets often automatically reflected in caps. Figure 60 outlines the interrelationships and potential sequencing of policies regarding the creation of carbon units. It demonstrates the relationship between targets, caps and enabling factors, to demonstrate two potential pathways for reform.

In these scenarios targets shift over time from being heavily dependent on national circumstances to an assessment of the emission reductions required to stabilise the global climate system. Over time, emission targets move from quantified actions or targets based on emissions intensity, to targets based on absolute emissions. The shift to absolute targets is only likely to occur after robust projections of emission levels have been completed, to allow future targets to be calibrated against expected emission outcomes. Once absolute targets are established, China may choose to move from aspirational targets to binding commitments. This could include a commitment to make good any failure to achieve a targeted emissions level in a given year. At this time, China may work with international partners to establish principles for setting national targets to achieve the required global emission reductions. These principles can facilitate a shift in the factors that determine the emissions target, from a focus on national political and economic circumstances to principlesbased global mitigation shares. 


\section{An evolutionary approach to creation}

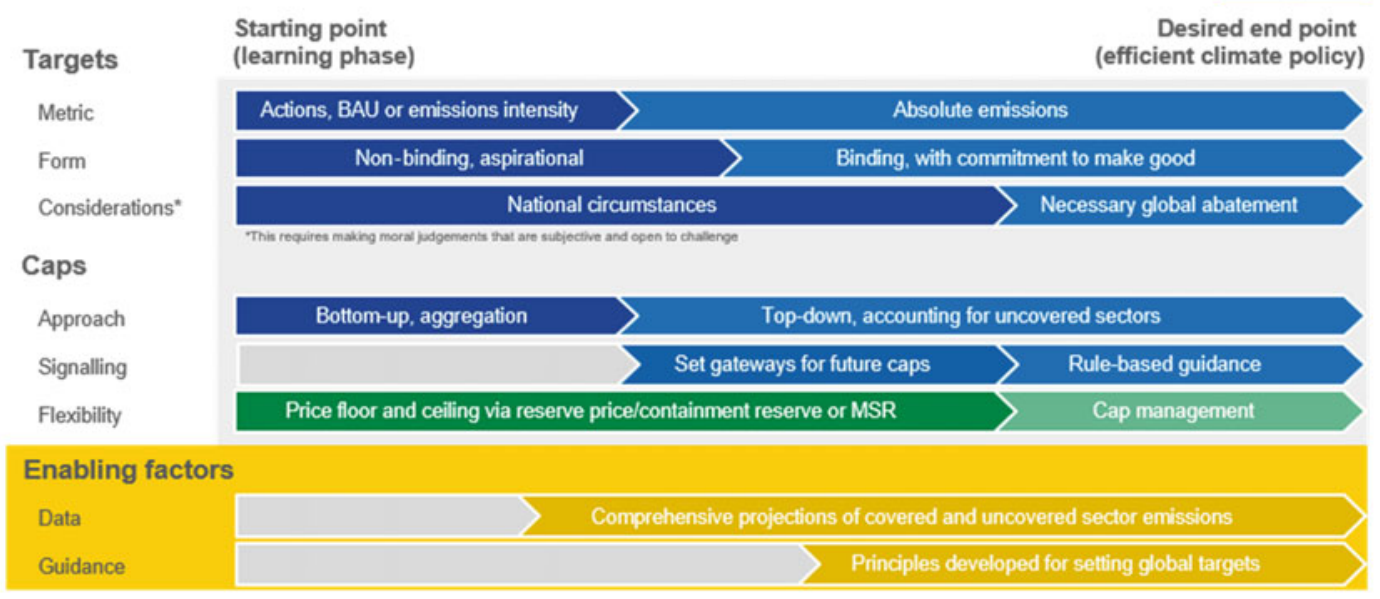

\section{A revolutionary approach to creation}

\begin{tabular}{|c|c|}
\hline Targets & $\begin{array}{l}\text { Desired end point } \\
\text { (efficient climate policy) }\end{array}$ \\
\hline Metric & Absolute emissions \\
\hline Form & Binding, with commitment to make good \\
\hline Considerations* & Necessary global abatement \\
\hline \multicolumn{2}{|l|}{ Caps } \\
\hline Approach & Top down, accounting for uncovered sectors when data enables \\
\hline Signalling & Set gateways for future caps \\
\hline Flexibility & A high price floor via reserve price or MSR \\
\hline \multicolumn{2}{|c|}{ Enabling factors } \\
\hline Data & Comprehensive projections of covered and uncovered sector emissions \\
\hline Guidance & Principles developed for setting global targets \\
\hline
\end{tabular}

Fig. 60 Sequencing of evolutionary and revolutionary approaches to creating carbon units. Note BAU = business as usual. Source Vivid Economics

ETS caps follow a similar progression, moving from the bottom-up estimation of emissions from covered sectors to a calculation based on the required emission reductions. In the learning phase of an ETS, a jurisdiction may have insufficient information to establish a credible cap and may instead allow caps to vary, for instance, based on the level of free allocations in a given year. However, over time, the ETS cap should take on a larger role in ensuring that national targets are achieved, which would require a top-down calculation of the required cap, given targets and expected emissions in uncovered sectors. To provide guidance to markets, China may choose to establish gateways that indicate the range of future caps in the medium term. Eventually China may adopt a set of rules aligned across jurisdictions that outlines the processes for calculating caps.

The number of units released into the secondary market may be altered through the use of price flexibility mechanisms. In the early years of 
operation, this could include price floors, contingency reserves or market stability reserves. In the longer term, price management may be provided through flexible cap management, either independently or in concert with other jurisdictions.

A more revolutionary approach to the creation of units would see an immediate move to more stringent target conditions and a more rapid evolution of caps. China could choose to adopt absolute targets immediately and to make good any discrepancy that may be caused through uncertain uncovered sector emissions and covered sector response. Targets would be more stringent as they transition to reflect required global mitigation at an earlier stage, while changes to cap setting and price controls would also accelerate.

\section{An evolutionary approach to distribution}

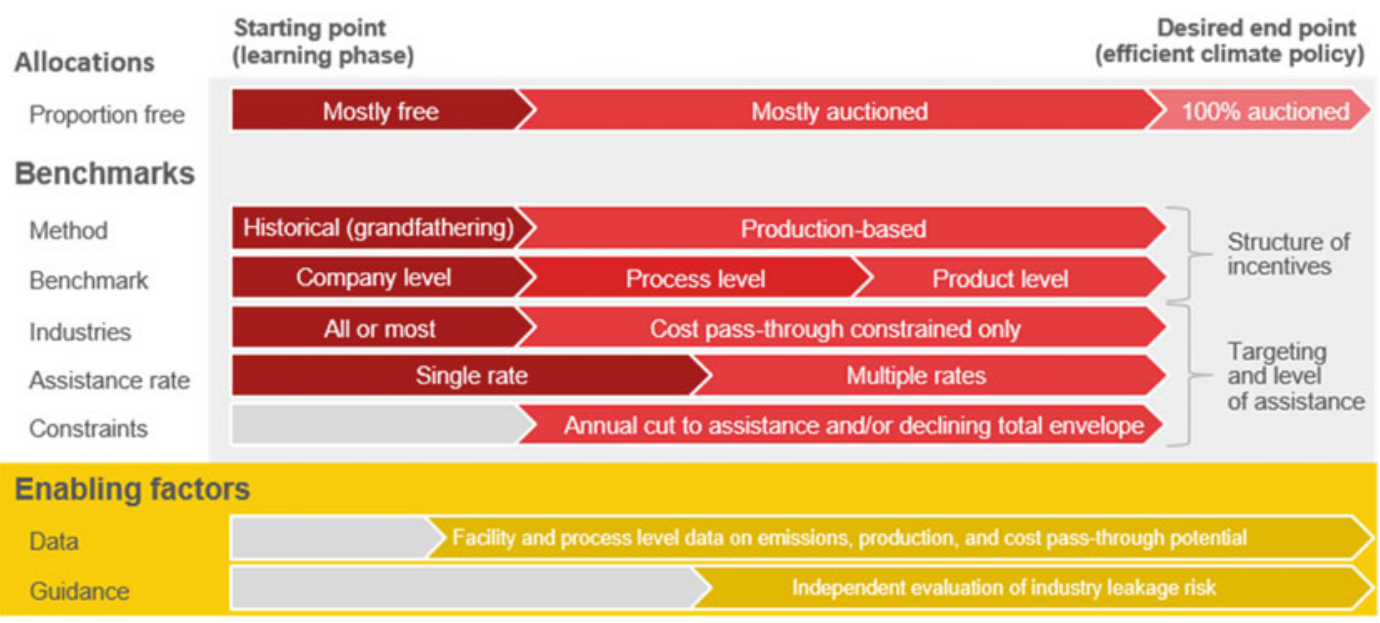

\section{A revolutionary approach to distribution}

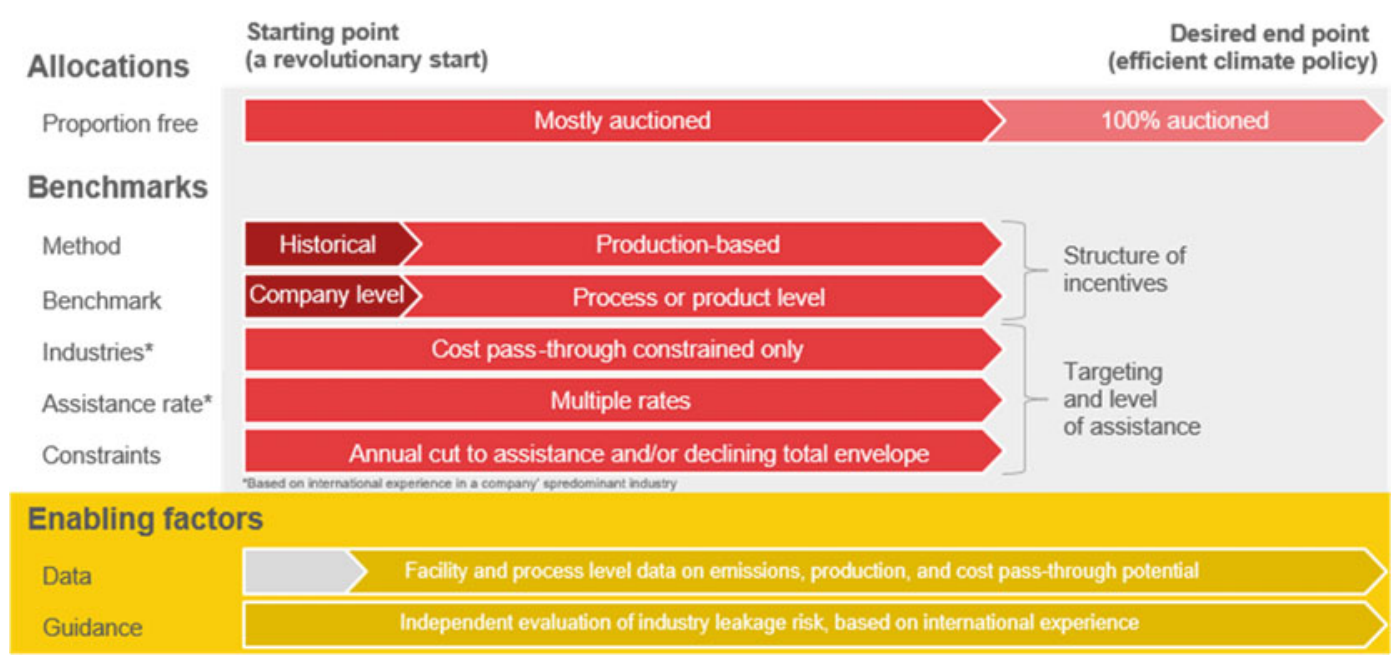

Fig. 61 Sequencing of evolutionary and revolutionary approaches to distribution. Source Vivid Economics 


\subsubsection{Distribution of Carbon Units}

With the supply of carbon units determined, the next step is to decide how, and how many units should be auctioned and freely allocated. In the learning phase of the ETS, China may choose to allocate most units free of charge, as it seeks to introduce liable polluters to their obligations under the ETS and reduce the risk of carbon leakage. In this case, the method of freely allocating permits will determine which mitigation opportunities will be used. Figure 61 outlines in more detail the potential sequencing of distribution methods.

Data limitations may mean that initially units may be grandfathered or allocated according to a company's historical emissions. A quick movement away from grandfathered allocations will free up a greater proportion of units to be auctioned and reduce the risk that allocations are simply sold for profit.

Limiting allocations to those industries that are constrained by cost pass-through can be an effective means of avoiding carbon leakage while reducing costs. Determining whether an industry is constrained by cost pass-through requires facility- and process-level data to be collected to enable the assessment of emissions intensity and trade exposure. These data may also be used for benchmarking, which facilitates the movement away from grandfathered allocations. Over time, regular independent evaluations of cost pass-through can be used to more closely target assistance to those industries most at risk of carbon leakage.

The level of assistance to industries should be reduced over time to encourage greater efficiency and product substitution. This can be achieved by differentiating assistance rates by emissions intensity and/or instituting rules-based mechanisms to reduce allocations over time. In the long term, the market should move to $100 \%$ auctioning of units as the expansion and linking of carbon markets negates the risk of carbon leakage.

A revolutionary approach to allocations would prioritise the collection of data needed to assess cost pass-through and develop benchmarks. It would rapidly move to more cost-effective benchmarking methodologies and shift to the full auctioning of units at an earlier point in time.

\subsubsection{Governance of Carbon Units}

The rules that govern the carbon market will determine its cost-effectiveness and its robustness. As higher levels of mitigation are required, movement towards more efficient governance designs will help limit the costs associated with China's energy transition. Figure 62 provides further detail on the potential scheduling of reforms and their relationship with the allocation and distribution of carbon units.

Over time the role of an ETS can change, from first being a learning mechanism, to then being one that plays a major role within a broader policy mix, to eventually becoming the key driver of decarbonisation in an economy. This change is facilitated through changed market rules that act to broaden and deepen the impact of the carbon market on decision-making throughout the economy.

There are some design decisions, like banking, where China may choose to move to the optimal policy setting immediately or after a very brief period. This is because there are limited negative consequences of adopting banking early on, and banking can significantly improve the robustness of a carbon market.

Other decisions, like coverage, are subject to more complex trade-offs and capability constraints. For simplicity, an ETS may first cover a small number of high-emitting facilities in order to incentivise those mitigation options that have the potential to make the biggest impact. Over time this can be expanded to include all sectors of the economy with accurate measurement, reporting and verification (MRV) and, as MRV improves, can extend to all sectors.

Domestic offsets may be used in sectors that have insufficiently robust MRV to be subject to liabilities under an ETS, but where the mitigation outcomes of specific projects are well known. With a slow start to emissions trading, it may be 
An evolutionary approach to governance

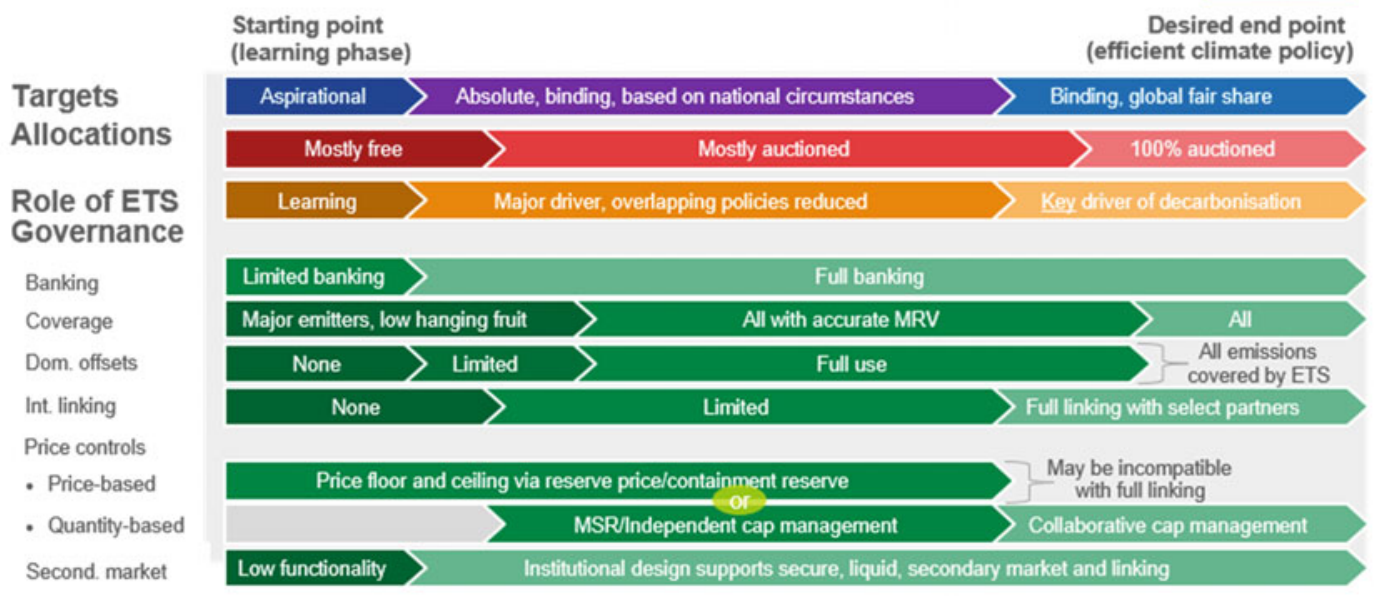

\section{A revolutionary approach to governance}

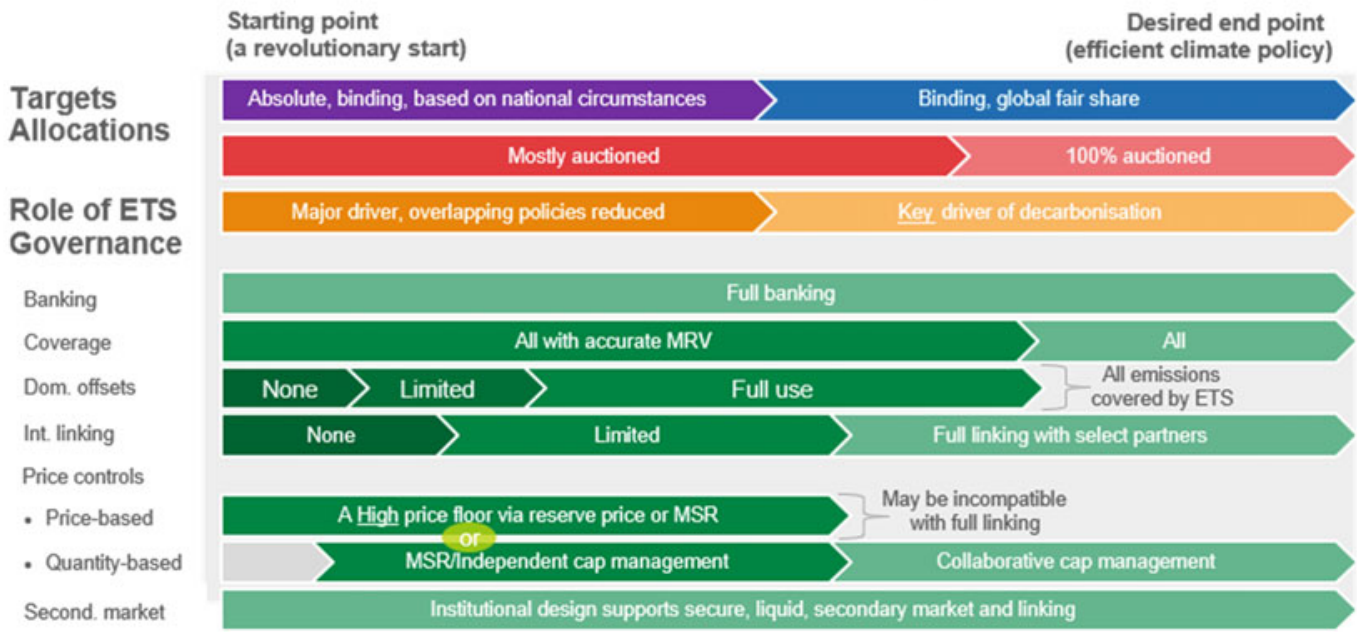

Fig. 62 Sequencing evolutionary and revolutionary approaches to governance. Source Vivid Economics

appropriate to apply quantitative limits to the use of domestic offset units to limit their potential impact on these potentially fragile markets. As the market matures, these limits may be removed, ensuring that domestic offsets trade at the same price as other carbon units. As MRV processes improve and more sectors are covered, the domestic offset market will gradually disappear.

Similarly, the use of international units may not be allowed in the early years of the carbon market given its fragility, but over time movement to a fully linked global carbon market will reduce costs and increase the robustness of interlinked ETSs. Given the current state of the global carbon market, full linking may take several years to progress. In the interim, limited linking can be used, with quantitative limits used to quarantine the potential impacts of these units on markets. The choice to move to full linking will have implications across a range of policy areas. For instance, traditional price controls may be inconsistent with full linking as the 
divergence in prices between markets can lead to perverse effects. Fully linked jurisdictions will also need to agree to principles and rules for determining the minimum ambition of targets appropriate for each jurisdiction.

Price controls should apply from the outset to ensure that credible prices are maintained while the market is fragile. As the market develops, the price should be allowed to vary more freely, as market forces will be better able to identify the appropriate price. Direct price controls may need to be removed when jurisdictions fully link their carbon markets. At this point, linking partners may choose to empower an independent institution, like a carbon central bank, to manage caps in a manner that achieves targets while maintaining a credible price trajectory.

The development of the secondary market should proceed rapidly to increase costeffectiveness and enable liable entities to hedge their risks. In the learning phase of an ETS, some market institutions, like the system of registry units, may not have the degree of functionality they would require as the ETS expands. Price discovery in the secondary market may be less important at this stage if a tight price corridor is in place. However, as the market expands and prices float more freely, providing the necessary institutions and market rules to support the secondary market becomes of vital importance.

A revolutionary approach to the governance of carbon markets would rapidly move to more advanced market designs and target higher prices through price controls and caps. Such an approach would have no learning phase but would instead start with robust design and rules. Banking would be allowed from the outset and coverage would be maximised. There would be more rapid movement to trade in domestic offsets and international units, with full linking occurring in the medium term. A rapid transition to a low-carbon economy would be supported initially by a high price floor or similarly robust quantity-based instrument, and by rapidly declining emission caps. The design of institutions and market rules would ensure efficient secondary market functioning, supported by exchange-based trading and liquid futures markets.

\subsection{Challenges in Establishing a National Carbon Market}

Establishing a carbon market is a complex and systematic task, especially the unification of China's carbon markets. Impeccable systems and institutions are needed, including determining the scope of the market, allocating allowances, choosing the allowance allocation method, building sophisticated monitoring, report and supervisory systems, and establishing a market control mechanism. ${ }^{28}$ The design and implementation of each element has an impact on the emissions reduction outcome of the carbon market, and will have a wide and profound influence on the regional economy's development and the evolution of industry. ${ }^{29}$

However, due to insufficient time to prepare and gain experience, the creation of China's carbon markets is faced with some challenges: regulated tariffs, poor regulatory ability, a defective trading mechanism and poor market fluidity. Most regions are constructing carbon exchanges in accordance with administrative regulations. Total allowances in pilot regions are high, which decrease the allowance price significantly. The markets are not active enough, leading to limited trading volumes. The market supervisory and regulatory system needs further improvement. The awareness and skills of market participants need to be strengthened. ${ }^{30}$

Pilot regions face more difficulties than non-pilot regions as they are integrated into the national carbon market. The pilot regions have gained a lot of experience, but their existing trading systems need to be aligned with the national carbon market. They also face transitional obstacles related to the enterprises controlled, the allowance allocation methods used

\footnotetext{
${ }^{28}$ Zhang Xin, Challenges in Integrating Local Carbon Markets into the National Carbon Market, in China Economic \& Trade Herald, 2015, (16), pp. 74-76.

${ }^{29}$ Zhang Xin, Sun Zheng, Meng Tianyu and Wang Ying, Reflections on and Suggestions for Regional Disparity in the Construction of a National Carbon Market, in China Economic \& Trade Herald, 2017, (20), pp. 30-31.

${ }^{30}$ Zou Chunlei, The National Carbon Market is Emerging, in China Electric Power News, 2016.
} 
and the greenhouse gas emission monitoring, report and verification system. ${ }^{31}$

\subsubsection{The Failure to Achieve Market-Based Electricity Pricing Prevents the Carbon Market from Working Effectively}

China's power industry has been dominated by coal-fired power plants for a long time. The power industry is not only a major primary energy consumer, but also a major carbon dioxide emitter. Its carbon dioxide emissions account for around $40 \%$ of the total emissions from China's fossil energy consumption. The power industry has inevitably become a major target for control, and it plays an important role in shaping the national carbon market. ${ }^{32}$

The Dian Gai No. 9 Order, issued by the central government in March 2015, opened a new phase in power system reform. In the previous 18 months, six key policies, including accelerating transmission and distribution tariff reform, were introduced. The pilot projects for transmission and distribution tariff deregulation were expanded to 20 regions (Shenzhen, western Inner Mongolia and 18 provinces). In addition, there are four pilot regions for comprehensive reform and two pilot regions for power sales reform. A new mechanism where "the electricity price is determined mainly by the market" will eventually be built and will be extremely beneficial to China's energy saving and emission reductions.

Overall, the 13th Five-Year Plan (2016-20) is a critical period for power reform and an initial stage for the carbon market. The challenge of how to dynamically align carbon market rules to power system reform needs to be overcome urgently. ${ }^{33}$ According to Li Jifeng, given that China is vigorously promoting tariff deregulation, the carbon emitted in power generation should be attributed to the power producers, and the rules of the carbon market should be designed on that basis.

Electricity tariff deregulation could improve the effectiveness of carbon markets and reduce emissions in three ways. It could facilitate technical progress in power producers and optimise the power mix; and it could encourage electricity users - both those covered and those not covered by the carbon market - to save energy. Optimisation of the power mix depends largely on energy authorities planning for power generation with renewables. The role of the carbon market should, therefore, be to reduce emissions by encouraging downstream users to save electricity. $^{34}$

Prices in the carbon market, an important indicator of the effectiveness of the market's rules, reflect the marginal cost for market participants to achieve emissions reduction objectives. The lower the carbon price, the more effective the rules, and vice versa. Take China's carbon markets launched after 2017: calculations using a computable general equilibrium model show that the carbon cost for achieving the same emissions reduction if the power tariff is controlled is $18-32 \%$ higher than if the power tariff is deregulated. This is because electricity price control prevents the power sector from tapping the potential for low-cost emissions reduction, which intensifies the pressure on other sectors and increases the overall cost of emissions reduction. In other words, promoting the deregulation of the power tariff may not only reduce carbon emissions by the power industry, but significantly reduce emissions reduction pressure

\footnotetext{
${ }^{31} \mathrm{Li}$ Zhuo, Obstacles to Integrate Pilot Regional Markets into National Carbon Market, in Invest Beijing 2016, (04), pp. 39-41.

${ }^{32}$ Zhang Lixing, Comparative Study on and Suggestions for Participation by Power Companies in Pilot Regions in Carbon Trading, in Resources Economization \& Environment Protection, 2016, (12), pp. 16-17.
}

\footnotetext{
${ }^{33}$ Li Jifeng, The Design of Carbon Market's Rules should be Aligned to Price Deregulation, in China Energy News, 2016-09-12.

${ }^{34}$ Li Jifeng, The Design of Carbon Market Rules Should Be Aligned with Tariff Deregulation, in China Energy News, 2016-09-12.
} 
on companies from other sectors in carbon markets. ${ }^{35}$

\subsubsection{Carbon Emission Regulations Barely Support the Carbon Market}

China has not imposed a compulsory carbon emissions permit trading system. Carbon trading in China is now mainly on a voluntary basis, i.e. businesses or individuals can voluntarily purchase carbon emission reductions. Although some provinces and municipalities, including Hubei and Jiangsu, introduced some local regulations on carbon emissions permit trading, laws have not been passed at the state level. There are no uniform settlement standards yet, nor effective supervision. In addition, it is difficult to give purchasers long-term economic incentives with voluntary emissions reduction trading. ${ }^{36}$

Once the basic framework of the national carbon market has been built and the market is running, each module should be managed by professional organisations. For instance, the China Securities Regulatory Commission could manage carbon trading, and the Certification and Accreditation Administration of the People's Republic of China could review and approve third parties. Establishing the carbon market will involve many departments, but China still needs one department to coordinate all other departments and mobilise forces across the country to complete the work. While China's carbon market is being established, the National Development and Reform Commission could be responsible for overall planning and coordination. The most scientific approach would be dual-level management, with the central government designing the main rules for market unification and local government enforcing them.

\footnotetext{
${ }^{35}$ Lu Zhengwei and Tang Weiqi, Operation Experience from Domestic Pilot Carbon Markets and the Construction of a National Market, in Fiscal Science, 2016, pp. 81-94.

${ }^{36}$ Wang Chaoying and Gan Aiping, Problems in the Unification of China's Carbon Markets and Countermeasures, in Foreign Economic Relations and Trade, 2015, pp. 100-103 and 145 .
}

\subsubsection{The Carbon Trading Mechanism Is not yet Mature}

Compared with international carbon markets, China's trading mechanism for carbon products is not sound. Currently, there are many kinds of carbon trading market in the world, including curb exchanges, markets regulated by government, and markets that function on a voluntary basis. They differ in their method of allocating allowances and in their regulations and emissions reduction verification mechanisms. Direct trading between different markets is impossible. The international carbon finance market is highly fragmented. Although China is a developing country, any clean development mechanism projects it participates in can only be traded in as a primary market, through the International Carbon Fund. Trading and circulation between domestic sub-accounts are not allowed. Domestic products are isolated from the international carbon trading market, making China's carbon emission resources uninfluential. China is at the end of capital and resource chains. Due to the separation between China and the UN's registration mechanisms, the clean development mechanism cannot properly register carbon emission reductions. $^{37}$

In addition, there is still a dispute over whether China's future national carbon market should choose centralised trading at a single exchange or decentralised trading at several exchanges under common rules.

The advantages of centralised trading are unified standards and centralised management, which is conducive to price discovery. It also matches China's "from top to bottom" approach to energy saving and emissions reduction. The competent authorities in central government could make flexible adjustments, creating a synergy between the carbon trading mechanism and other energy and climate policies. The planned national carbon market is expected to cover 4 billion tonnes of carbon allowances, the largest in the world. The huge size imposes very

\footnotetext{
${ }^{37}$ Feng Weiwei, China will Launch a Carbon Emissions Permit Trading Mechanism in 2017, in Energy Conservation and Environmental Protection, 2017, pp. 34-35.
} 
strict requirements on the design and improvement of trading platforms and rules. If the trading rules of a single trading platform are not perfect at the moment the market is launched, there will be a strong impact, and the competition mechanism will not be in place and functioning correctly, which runs counter to the goal of optimising rule-related services. ${ }^{38}$

Decentralised trading means that trading is conducted simultaneously on many trading platforms under strictly unified calculation criteria and trading rules. Market systems are improved through free competition and the survival of the fittest. Decentralised trading is common in carbon exchanges in Europe and North America. First, unified, clear and transparent carbon emission calculation criteria should be set up to ensure that the objects traded in different markets are homogeneous and to avoid cross-market arbitrage. Second, unified registration systems should be set up to ensure the reliability of cross-market trading information. Once these conditions are met, exchanges should be allowed to carry out carbon trading at the same time. This will introduce competition among trading platforms, forcing them to improve services and motivating them to innovate, thus driving China's carbon market towards maturity and perfection. $^{39}$

In decentralised trading, local exchanges could attempt to form a trading alliance or use other cooperative mechanisms to facilitate mutual recognition of their members. They could also work towards integration by engaging financial institutions to open accounts on behalf of clients. This would optimise the process of opening, registering and managing accounts and facilitate cross-market trading.

\footnotetext{
${ }^{38}$ Wang Junchun, A National Carbon Market is a High-Speed Train for China's Green Low-Carbon System, in Strategic and Emerging Industries of China, 2017, pp. 48-49.

${ }^{39}$ Chen Xiangguo and Ma Aimin, Construction of the National Carbon Market is Faced with New Challenges, in Energy Conservation and Environmental Protection 2016, pp. 24-25.
}

\subsubsection{Fluidity Needs to Improve}

China's pilot carbon markets have a common problem of poor liquidity, low volumes and low turnover. Currently, the daily trading volume of most pilot carbon markets is small. Although the phenomenon of zero deals on trading days during the non-performance period is becoming less and less frequent, a daily trading volume of only hundreds or dozens of tonnes is not uncommon. ${ }^{40}$ Due to such low fluidity, it is difficult to attract financial and investment institutions to carry out stable and active carbon trading activities, which increases the likelihood that the market will be controlled by a few oligarchs.

The seven pilot carbon markets are dominated by trading through performance agreements. It is common for trading volume and value to be high when a performance period is near at hand, and low after it has ended. During the three performance years of 2013-15, the total trading volume of the seven pilot carbon markets was slightly above RMB 2 billion. This is not enough for a country like China with a huge carbon emissions reduction potential. The size of the global carbon market in 2011 was $\$ 176$ billion (the EU Emissions Trading System accounted for more than 90\%). Unlike the EU carbon market, which has various carbon financial products (futures, options, spot, forwards), China only has the spot carbon product, and no price discovery or risk hedging tools. China's carbon exchanges are far from mature. ${ }^{41}$

Moderate fluidity is the key to achieving reasonable prices and guiding companies to reduce emissions cost-effectively. Without fluidity, those companies planning to purchase allowances would not be able to buy them, and those planning to sell would not sell them. Nor would companies be able to compare the price with their own emission reduction costs and make cost-minimising emission reduction decisions. To improve fluidity, allowances must be

\footnotetext{
${ }^{40} \mathrm{Lu}$ Zhengwei and Tang Weiqi, Operation Experience from Domestic Pilot Carbon Markets and Construction of the National Market, in Fiscal Science, 2016, pp. 81-94.

${ }^{41}$ Jiang Rui, Carbon Trading and Outlook on China's Carbon Market, in China Policy Review, 2017, pp. 5256.
} 
tight. Market players and traded products need to be diversified into futures, options and other allowance derivatives. The starting price should not be high. The policies should be progressive, which may strengthen investors' trust in the market and emissions reduction policies. More carbon asset management training should be made available for the companies controlled. Violations of regulations should be penalised. ${ }^{42}$

Carbon allowances should be traded in a fair environment with fluidity. To this end, risk control during trading, and supervision and management of market participants and staff, should be improved. Carbon exchanges play a unique role in building the national carbon market. Every pilot province and municipality should set up its own exchange. We know that other regions have expressed interest in building exchanges. Maintaining more than one exchange in an existing market encourages fair competition and improves services. But too many exchanges will reduce average profitability, which might lead to cut-throat competition and fragmentation of the national carbon market, resulting in local protectionism. We should pay attention to these problems when building the national carbon market. $^{43}$

\section{Strategic Transition and Structural Reform of Energy Companies}

In the context of the global energy transition, international energy companies and China's state-owned companies are undergoing a series of significant strategic transitions that affect their decision-making, organisational structure, priorities, global planning, business models, finance and asset strategies, and digital platforms. In previous sections of Special report 4 we said that international oil and gas companies like BP,

\footnotetext{
${ }^{42}$ Fai Li, Clear Our Mind: Make Full Preparation for the National Carbon Market, in Energy Conservation and Environmental Protection, 2014, pp. 32-33.

${ }^{43}$ Zhang Xin, Promoting the National Carbon Market through Effective Policies and Useful Actions, in Zhejiang Economy, 2016, pp. 24-26.
}

Shell and Total have adapted their strategies to changing market conditions. However, international energy companies are not the only ones doing this: global electric utilities, especially grid companies, are also changing their strategies.

This section begins with the findings of research on power grids in transition by Vivid Economics, a UK-based consultancy. The section will then discuss the reform of China's state-owned energy enterprises (SOEs), since they are a key part of China's energy administration system reform. In the context of China's slowing economic growth, severe overcapacity, mounting environmental pressures, and adjustment of the energy mix, the reform of China's SOEs is an important element in the larger reform of state-owned assets. SOE reform focuses on optimisation, improving efficiency and unlocking dynamism. Both central energy enterprises and local state-owned energy companies have begun their reforms. Given its initial difficulties, the reform programme needs to be pushed continuously.

\subsection{Structural Reform of Global Energy Companies- Electricity Grids in Transition ${ }^{44}$}

Decarbonisation, decentralisation and intelligent technologies pose challenges to the global energy transition. As a result, structural reforms must be accelerated to ensure energy resources are allocated in a more efficient, safer and more sustainable way, especially renewables like wind and solar power, thus delivering the strategic goal of low-carbon energy. The structural reforms and institutional changes designed to address the challenges have significant implications for the market-oriented low-carbon reform of China's power network.

\footnotetext{
${ }^{44}$ The main ideas and content in this section are taken from Electricity Grids in Transition, a research report prepared for the DRC-Shell Markets Revolution Work Stream by UK-based Vivid Economics, October 2017.
} 


\subsubsection{Key Principles of Efficient Network Provision}

In order to realise the economic benefits of liberalised electricity markets, international best practice suggests a set of principles for efficient network provision:

\section{(1) Proceed towards full liberalisation of the wider electricity system}

Effective investment in and operation of the wider electricity system is a necessary condition for electricity network efficiency. This requires liberalising sectors suitable for competition (such as fuel production, generation and retail), use of markets to procure key services (capacity, balancing) and the pricing of externalities, such as air pollution and carbon emissions.

\section{(2) Align incentives with public policy objectives}

Make incentives for network operators consistent with their providing a reliable and affordable supply of electricity by controlling monopolistic behaviour and ensuring prices reflect underlying costs:

- Reform electricity network institutions. Electricity networks are natural monopolies, with little scope for competitive markets. It is therefore critical that their incentives are aligned with public policy objectives. A monopoly faces incentives to underinvest in new infrastructure and to charge prices that are higher than its costs. A state-owned company may face incentives to prioritise short-term political objectives, rather than longer-term public policy objectives. These incentives can be mitigated through institutional reform of the electricity network. One option is to reform the network company's incentives through performance-based regulation enforced by an independent regulator. Another is to separate network operation and ownership through the creation of an independent system operator (ISO). The UK and most European countries currently use performance-based regulation, while the USA uses the ISO model across its transmission systems, for example in Pennsylvania-New Jersey-Maryland (PJM, the transmission system in north-eastern USA), California and New York.

- Consider the use of locational pricing. Efficient network investment and operation make use of information on network congestion. If implemented, locational (nodal or zonal) pricing can help reveal the costs of network congestion. Nodal pricing is used in several US states, Argentina, Chile, Ireland, New Zealand, Russia and Singapore, while zonal pricing has been adopted by most European countries and Australia. However, locational pricing has disadvantages as well as advantages. Importantly, locational pricing is most effective once time-of-use pricing is fully implemented across network users.

\section{(3) Take further action to meet the challenges of a decarbonised system}

The electrification of energy demand and improvements in the efficiency of electrical appliances will exacerbate the uncertainty over the future volume and location of demand for transmission capacity. Flexible resources such as electricity storage and demand response can substitute for new network investment, so long as sufficient investment incentives are present:

- Designate strategic zones for transmissionscale renewable generation to reduce planning and investment uncertainty. Renewable energy resources may be located far from demand centres and thus require large-scale transmission investment. Uncertainty over the volume and location of generation can be mitigated through zoning. 
- Ensure there are revenues available to encourage flexible resources to offer a full range of system services. The flexible resources needed for decarbonisation contribute several system services, such as balancing and frequency response, but there may be underinvestment if markets do not exist for these services. Several electricity markets in the West run demand curtailment markets, allowing flexible resources to generate revenues.

(4) Prepare for the development of a decentralised electricity system and its associated digitalisation by investing in the coordination of decentralised resourcestheir control, balancing, security and data flows

- Coordinate investment in decentralised resources. A coordination problem arises where independent developers that lack information about the plans of other developers may make similar investments, creating overinvestment or, if the developers are risk-averse, underinvestment. Either way, the result can be inefficient. Solutions include formal processes for multilateral resource planning and the publication of current and consented resources, as used by the transmission and distribution system operators of Spain and Ireland.

- Determine how decentralised resources will be controlled. While distribution networks today are largely passive, an active network is capable of accommodating distributed resources. As the electricity system becomes more active and complex, a single system operator may start to rely on intermediaries, such as virtual power plants and partners such as distribution system operators, to assist with system balance. New systems of control, with new computational requirements, administrative rules and institutional characteristics, may then be employed, reflecting new operational vulnerabilities.

- Balance data transparency with security. As information communications technology (ICT) infrastructure expands, the amount of data from the electricity system grows. The data systems need their own infrastructure, with public access to facilitate competition and optimise operations. Meanwhile, the distribution of data across resources creates new risks of cyberattack and privacy loss, solved through adequate protocols.

\subsubsection{Roadmap for Efficient Network Arrangements}

This section suggests a roadmap for the development of network arrangements in China, as the country simultaneously carries out large-scale investment, market reforms and decarbonisation of its electricity system. These options are based on international best practice and leading thinking on future arrangements.

The roadmap is based on the following guiding principles:

- Strong markets need strong government. Market-based solutions have the potential to identify and deliver cost-effective investment and operation of electricity systems. However, both markets and natural monopoly networks benefit from a strong government to take an active role in ensuring institutional incentives are aligned with public policy objectives. Network incentives can be aligned through separation of roles (unbundling) or strong regulation.

- The institutional framework can be developed progressively. Wholesale institutional reform is challenging and disruptive. At the outset, small changes in current practice and small-scale pilots may provide proof-ofconcept sufficient to build consensus for larger-scale reforms.

The roadmap suggests the following:

\section{(1) Immediate actions}

- Continue the market liberalisation programme. Phase 1 of the DRC-Shell cooperation suggested a programme of electricity market liberalisation consistent with this. China's 13th Five-Year Plan (2016-20) aims 
to improve the systems by which markets play the decisive role in resource allocation. It will be important to continue with the market liberalisation programme to deliver a more advanced and efficient electricity system.

- Rationalise investment planning. Clearly defined metrics for reliability and economic efficiency help network planners to identify efficient investments. Meanwhile, the application of the beneficiary pays principle encourages investment that increases productivity, avoiding diverting national resources to stimulate regional output. Together, these approaches, when applied at national and regional level, facilitate greater interconnection and sharing of generation services.

- Implement a coordinated approach to investment. The use of a common investment framework enables coordinated planning of generation and network investment, harnessing both strategic decisions and market enterprise. For example, the framework might set out the role of generation zones for large-scale renewables alongside alternatives such as small-scale distributed generation.

Implement smart system architecture. Smart, distributed resources are crucial to affordable decarbonisation. Before building the distributed resources, the system architecture to manage it can be laid down. At a minimum, this includes: deployment of smart meters to introduce time-of-use pricing to consumers on the distribution network; upstream information and communications architecture; and R\&D to develop technical solutions for the smart grid.

\section{(2) Move towards efficient pricing}

- Deregulate prices. Cost-reflective pricing can signal efficient investments and operations to decision-makers. The deregulation of prices can proceed sequentially, with further price reform contingent on the success of previous reforms. Price reform could commence upstream and progress downstream, beginning with input fuels, followed by generation and network access, and ending with retail, with provision to protect retailers if wholesale prices rise above retail prices before deregulation is complete.

- Create harmonised trading arrangements between transmission systems. Use prices to determine interconnector flows between provincial and regional transmission systems, signalling which provinces or regions could benefit from new investment. The prices would stimulate lower-cost generators to respond to demand.

- Implement time-of-use pricing. Time-of-use pricing allows consumers and flexible resources to respond to variation in generation costs and demand. Again, it can proceed sequentially, starting with larger consumers, such as industrial facilities with flexible production schedules, and ending with smart household appliances.

- Consider locational pricing. Similarly, locational pricing can signal efficient investments and operations, but it brings disadvantages as well as advantages. China may consider locational pricing, following the implementation of time-of-use pricing, that is, signal geographical network constraints once demand peaks have been shaved. Zonal pricing is a potential intermediate step between uniform and full nodal pricing.

- Protect end users. The deregulation of retail electricity may result in rent-seeking by retailers, raising consumer prices. This can happen if consumers do not switch suppliers readily or for other reasons competition is not effective. Policies to protect consumers could be developed alongside any deregulation of retail electricity prices.

\section{(3) Begin market trials}

- Create small-scale trials. Create small-scale trials to competitively procure new transmission investments, non-network alternatives to new transmission assets, ancillary services 
and so on. Use competitive tenders or auctions for the trials. These may provide proof-of-concept and experience with innovative, cost-effective solutions. To be successful, procurement has to be open-access and transparent.

- Progressively introduce market procurement. If the competitive procurement trials are successful, they can be scaled up and wider market procurement progressively introduced, where appropriate, across each transmission system. Market procurement can help to reveal information about the relative costs and benefits of a range of technologies.

\section{(4) Make institutional choices}

- Develop the transmission network institutions. Options include the status quo, an enhanced role for market procurement and a regulated transmission system operator (TSO) or independent system operator (ISO). International experience of the regulated TSO and ISO models is yet to reveal the best performer of the two, so it matters more to adopt a good-quality institutional model early than to choose between the options.

- Select a model of control for decentralised resources. Initially, when the number of resources is small, the TSO may be able to control them directly. However, as the number of resources increases, and as temporal and locational pricing become more sophisticated, the computational, commercial and contractual capacity of a single operator model may be exceeded, and new models of control may be needed.

\section{Box 1: Balancing the electricity system}

A simple example of balancing an electricity system under network constraints is shown in Fig. 63. In this example, a system operator balances a system of two cities interconnected with a capacity-constrained transmission line. The numbers in green, blue and purple are the inputs for the system operator's balancing problem. The numbers in red are the outputs.

In City A, generators can produce up to $150 \mathrm{MW}$. Generation costs \$10/MWh. Consumers demand $50 \mathrm{MW}$. In City B, generators have $50 \mathrm{MW}$ capacity. Generation costs \$20/MWh. Consumers demand $90 \mathrm{MW}$, exceeding the local generation capacity. Consumer demand in both cities is constant and does not change with price. The interconnection between City A and City B can carry up to $80 \mathrm{MW}$.

To minimise the total cost of the system, the system operator first uses the cheap generation in City A. Generators in City A serve the local demand (50 MW) and

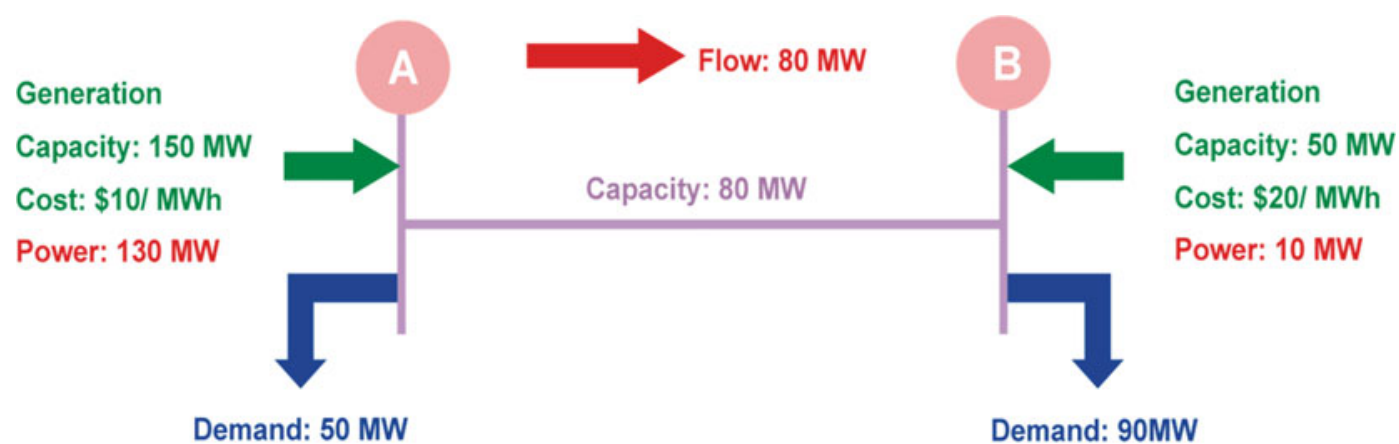

System price: $\$ 20 / \mathrm{MWh}$
Total cost: $\$ 2800$

Fig. 63 Example of system balancing with network constraints. Source Vivid Economics 
export $80 \mathrm{MW}$ to City $\mathrm{B}$ (in total $130 \mathrm{MW})$. Because the capacity of the interconnection is fully utilised, expensive generators in City B serve the rest of the local demand (10 MW). As a result, the system price equals the cost of the generators in City B (\$20/MWh), and the total cost is $\$ 2,800$ (140 MW $\times$ \$20/MWh).

\subsubsection{Challenges in Network Provision}

As electricity systems decarbonise and decentralise, the challenges of planning, delivery, operation and cost recovery are changing for network service providers.

\section{(1) The challenges of network provision}

The challenge of efficient provision encompasses planning, delivery, operation and cost recovery. Challenges in planning and delivery of electricity networks arise due to uncertainty over future electricity demand and the difficulty of coordinating network investment with independent generators. Challenges in operation arise from the capacity constraints of the network, the complexity of the system and the unpredictability of flows of electricity. Challenges in cost recovery arise due to the natural monopoly characteristics of electricity networks and the difficulties of mitigating monopoly behaviour with conventional regulation:

- Planning and delivery. The planning and delivery of electricity networks faces uncertainty over future electricity demand and difficulties in coordinating network investment with independent generators. First, the volume and location of future demand is uncertain and depends on population growth, changes in settlement patterns, changes in industrial structure, technology and economic growth. Network planners judge where network assets will be required. Second, while vertically integrated utilities plan generation and network investment simultaneously, in a liberalised electricity system, generation and network investment are carried out by separate organisations. Without coordination, generators face the risk that their revenues may be curtailed by network congestion and networks face the risk that generators will underutilise their assets.

- Operation. Balancing the electricity system is challenging due to system complexity and the unpredictability of electricity flows. With many sources of generation and consumption, as well as network constraints, the optimal level of production and consumption for each source is a complex calculation. Furthermore, due to the physical laws governing electricity networks, the precise flows of electricity through the network depend on the volumes of consumption and production of each generator and user and cannot be predicted in advance.

- Cost recovery. Electricity networks are natural monopolies. One of the roles of the system operator is to levy charges to pay the network owner. This is achieved through designing tariffs which recoup capital, operation and maintenance costs for the network owner, and passing these costs through to network users. In the case where the network operator is also the network owner, it operates as a monopoly, and faces incentives to underinvest in network infrastructure while charging high prices to consumers.

Innovative arrangements are needed to mitigate monopoly behaviour effectively. Electricity networks are characterised by high capital costs and economies of scale. For these reasons, electricity networks are natural monopolies, with a single network serving a given area. The conventional approach to mitigating monopolistic behaviour in a natural monopoly is regulation. However, regulators have imperfect information on current network costs and how these costs can be reduced over time as productivity improves. Depending on the type of regulation, network companies may face incentives to overstate their costs or to overinvest. 
(2) Future changes: decarbonisation and decentralisation

Electricity systems are decarbonising and decentralising, and efficient network provision takes these changes into account. Potential changes in key characteristics of the electricity system are encompassed within two broader trends: decarbonisation of electricity and the wider energy system; and decentralisation of system resources, as summarised in Fig. 64. These changes, and their implications for the challenges of efficient network provision, are described in turn.

\section{(1) Decarbonisation}

Decarbonising an electricity system and related changes in the wider energy system involve changes to generation technologies and far-reaching changes to patterns of electricity demand. Generation technologies will shift from fossil generation to low-carbon generation, that is, a mix of carbon capture and storage, nuclear, biomass and renewables. Electricity demand will be affected by increases in demand from electrification of end-use sectors, particularly heat and transport, as well as decreases in demand from greater efficiency of electrical appliances. There will also be a shift in the profile of demand as low-carbon flexible resources (electricity storage and demand-side response) emerge to balance the relatively inflexible generation profile of nuclear and renewables.

These changes are likely to exacerbate the challenge of planning and delivery of network infrastructure. Future volumes of demand will be more difficult to forecast due to uncertainty over the level of electrification of end-use sectors and improvements in the efficiency of electrical appliances. Another element of uncertainty is the degree to which low-carbon flexible resources will reduce peak demand, and therefore the appropriate level of network capacity.

Low-carbon flexible resources can substitute for new network investments and can reduce total network costs. However, as these resources provide different system services (balancing, frequency response, network congestion mitigation) there may be underinvestment in flexible resources if markets do not exist for all the services that these resources provide.

\section{(2) Decentralisation}

Decentralisation involves a shift in electricity resources from the transmission system to the distribution system. Decentralised electricity resources comprise generation, demand response and storage. Decentralised generation includes
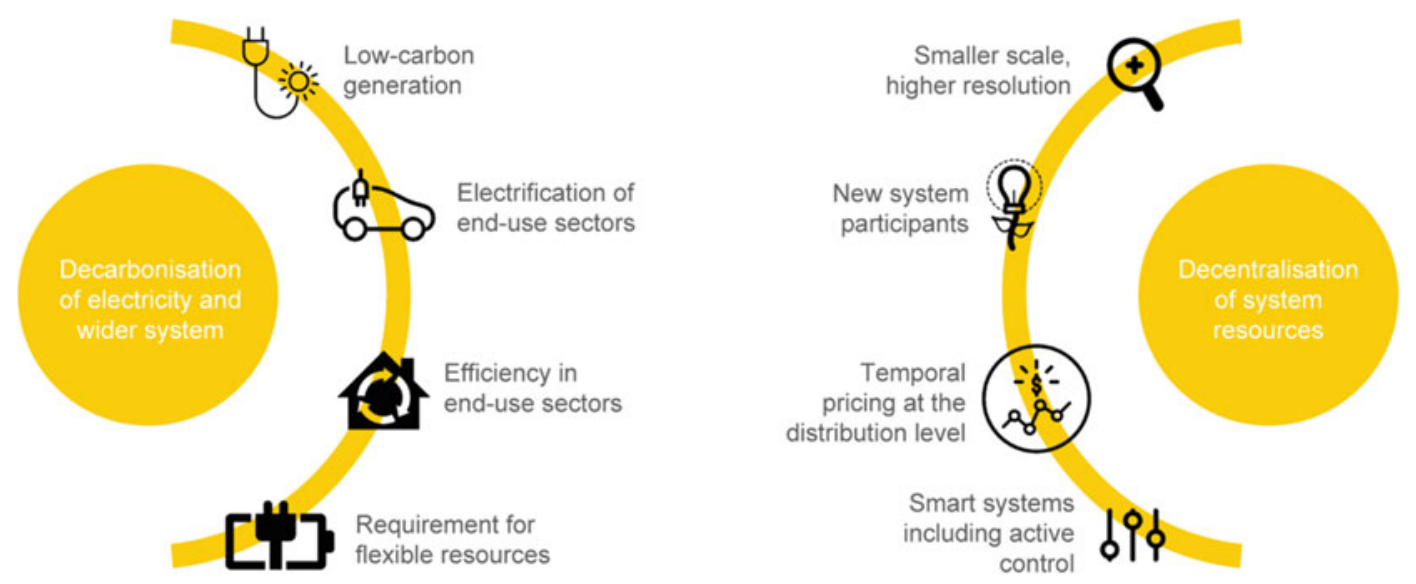

Fig. 64 Future electricity grids will be shaped by two broad trends: decarbonisation and decentralisation. Source Vivid Economics 
wind and solar, which are increasingly connected to the distribution network, including at the household level. Demand response is the flexible operation of electrical equipment in response to system conditions; electric vehicles are expected to significantly increase this potential as they may be able to charge at times of high electricity generation and low demand. Decentralised storage may also increase, potentially even at the household level.

To unlock decentralised electricity resources requires a shift to a smart grid. A smart grid is characterised by dominance of controllable electricity resources (generators, storage, appliances) throughout the electricity system, the ability of users to express preferences for use of their devices, the development of operating standards to allow resources to be operated in a coordinated way, sufficient development of information and communications technology (specifically, communications bandwidth, data storage and computing power), and adequate data security and privacy protocols.

Decentralisation exacerbates both the planning and delivery, and operation challenges:

- A coordination problem may arise between the transmission system and the various distribution systems. In current electricity systems, the bulk of new investment occurs in the transmission system, where adequate information is available on current and planned resources to inform new investment decisions. A shift in resources to the distribution network, where adequate information is not typically available, will create a coordination problem, where investors will not have a clear understanding of system needs, nor consequently of potential returns on investment. This could result in overinvestment, underinvestment, a poor technology mix or a poor spatial distribution of resources.

- The computational requirements of balancing a decentralised system will increase significantly. Optimising the operation of the entire system requires determining the optimal volume of output and consumption of every resource in the system. As the number of controllable resources increases from the limited set of large resources in a transmission system to the total set of resources across all distribution systems, the computational demands of this optimisation calculation also increase. If computing technology is not able to meet these computational demands, then intermediate levels of control are required, and only partial optimisation is possible.

Finally, decentralisation will require risks of data privacy and cybersecurity to be effectively managed. Decentralisation will be accompanied by a very significant extension of information and communications technology across all distributed resources and will create risks of data privacy and cybersecurity. Protocols to manage data use and control these risks can be developed and implemented.

\subsubsection{Network Arrangements to Address Current Challenges}

To address the challenges arising from decarbonisation and decentralisation, grid companies need to take effective measures to ensure efficient network arrangement. The international experience in previous electricity market reform provides some best practice arrangements that China can draw from:

- an institutional model to align incentives with public policy objectives: an institutional model is needed that mitigates monopolistic behaviour and provides networks with incentives to invest in appropriate network infrastructure and to operate infrastructure efficiently;

- strategic transmission planning: determining the appropriate profile of new transmission investment is a complex process and requires strategic planning;

- the appropriate level of locational pricing: investing in and operating networks efficiently requires an understanding of current network congestion; and

- a regime for merchant investments: entry of merchant investors has the potential to deliver 


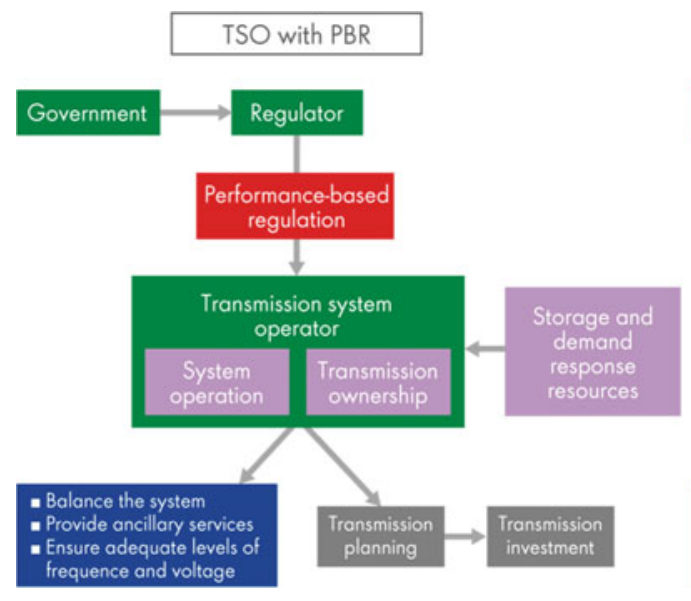

Fig. 65 The transmission system operator (TSO) and independent system operator (ISO) are the two main alternative institutional models for system ownership and

greater adequacy of investment than a single-owner network.

\section{(1) An institutional model to align incentives with public policy objectives}

An institutional model is needed that mitigates monopolistic behaviour and provides networks with incentives to invest in appropriate network infrastructure and to operate infrastructure efficiently. Two institutional models that can create an efficient regime are the TSO model, with performance-based regulation, and the ISO model. Figure 65 highlights the key difference between these two models: a TSO both owns and operates the transmission system, requiring strong regulation, while an ISO is a system operator that is fully separated from ownership of all network resources. A number of intermediate models also exist, for example where the system operator and transmission owner are legally separate companies but owned by the same parent company.

As shown in Fig. 64, most electricity systems have moved from vertically integrated monopoly utilities before liberalisation to one of these institutional models today. In 1985, Chile was

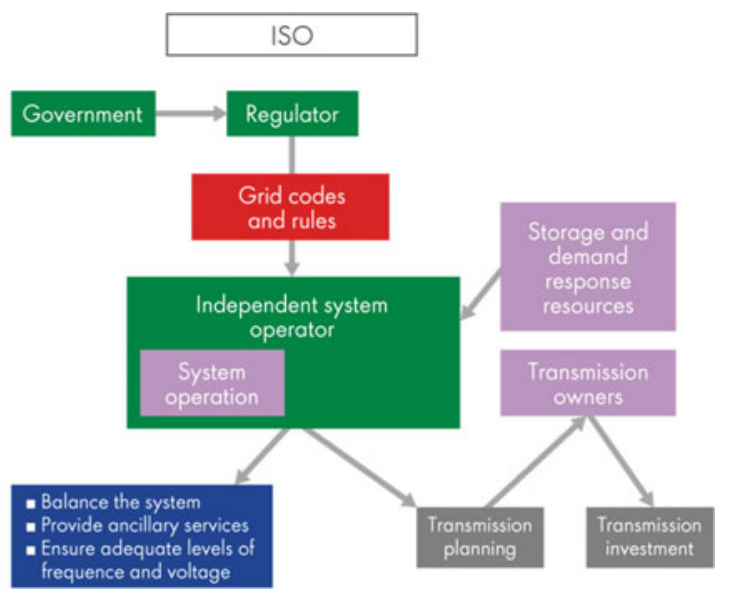

operation. Note $\mathrm{PBR}=$ performance-based regulation. Source Vivid Economics

the first country to adopt the ISO model. The UK shifted from vertical integration to a TSO with performance-based regulation structure in 1990, with Germany following suit in 1998. Following the orders of the Federal Energy Regulatory Commission (FERC) (the US electricity regulator), the US regions of Pennsylvania-New Jersey-Maryland (PJM), and California (CAISO) transitioned from a vertically integrated structure to the ISO model in the late 1990s (Fig. 66).

\section{(1) TSO with performance-based regulation}

A transmission system operator (TSO) is an entity that both owns and operates the transmission system; it therefore has incentives for monopoly behaviour. The TSO owns all the network assets and is also responsible for planning, deployment and operation of the system. The TSO model is prevalent in most European countries.

Performance-based regulation is needed to align a TSO's incentives with public policy objectives. A TSO is difficult to regulate as it has better information than the regulator on the costs it faces. This gives rise to one of two problems. If 


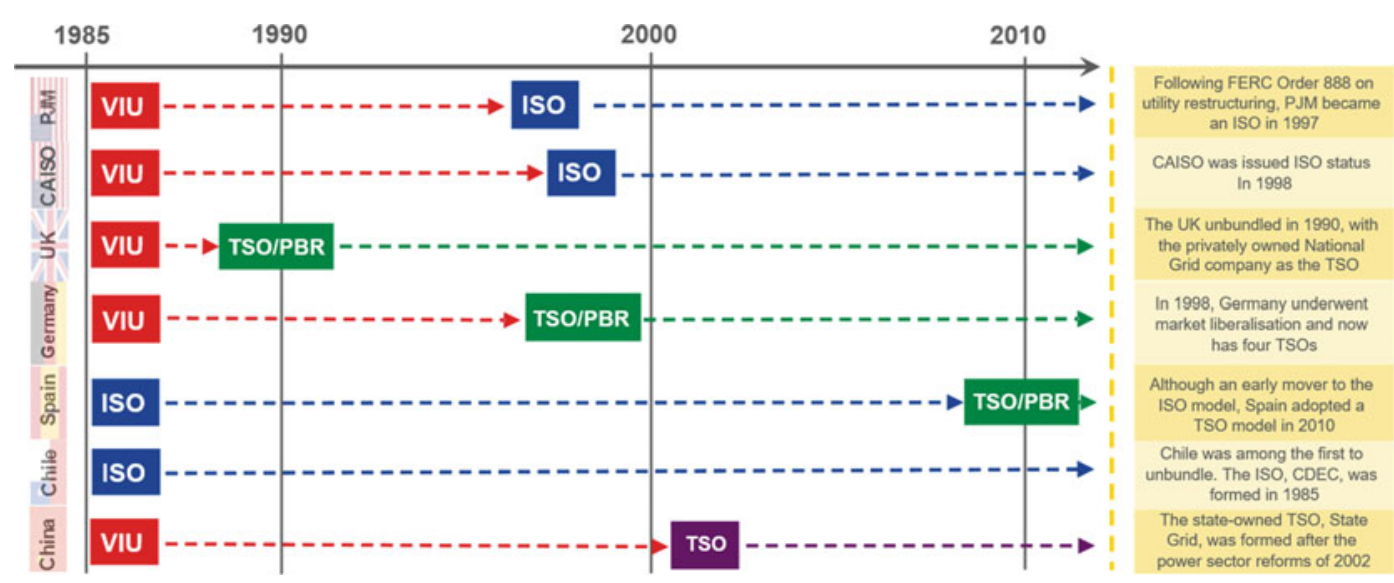

Fig. 66 Several countries shifted to the TSO and ISO models as they liberalised their electricity markets. Note VIU = vertically integrated utility; TSO/PBR = transmission system operator with performance-based regulation;

the regulator tries to prevent monopoly behaviour by imposing a cap on prices, known as price regulation, it estimates the price level required for the TSO to recover its costs. The TSO then has incentives to exaggerate the costs it faces, and secure price caps greater than its actual costs, a problem known as adverse selection. In this case, the TSO can underinvest and continue to set high prices. If instead the regulator tries to prevent monopoly behaviour by paying the TSO for its costs plus a regulated return (cost-of-service regulation), the TSO does not have any incentive to take necessary measures to decrease its costs, a problem known as moral hazard. In contrast to these approaches, performance-based regulation seeks simultaneously to address both monopoly profits and underinvestment. An example of performancebased regulation is the imposition of a price (or revenue) cap, which is adjusted every year by the rate of inflation and target rate of productivity growth. The TSO is constrained in exaggerating its costs by the regulator conducting benchmark analysis and detailed studies of the TSO's historical accounts. The TSO has some incentive to lower its costs because it can retain the difference
$\mathrm{PJM}=$ the regional transmission organisation for the north-eastern USA; CAISO = California Independent System Operator

between the price cap and its actual costs as profits.

Performance-based regulation is still evolving and there is no consensus on the optimal mechanism. Several forms of performance-based regulation have been adopted and these continue to evolve. An example of their evolution is the introduction in the $\mathrm{UK}$ of the retail price inflation minus X (RPI-X) mechanism in 1992, and its eventual replacement by the revenue $=$ incentives + innovation + outputs (RIIO) mechanism in 2013, which is described in Box 2. A key challenge in performance-based regulation is its high information burden. The regulator has to review the TSO's accounts and business plans and undertake benchmark analysis.

\section{Box 2: Performance-based regulation in the UK}

The UK introduced performance-based regulation in electricity networks in 1992 with the RPI-X mechanism, eventually replacing this in 2013 with the more sophisticated RIIO mechanism: 
- RPI-X mechanism. Ofgem and its predecessors, the electricity market regulator in the UK, used the RPI-X mechanism until 2013. Under this mechanism, Ofgem carried out cost forecasts to determine the base revenue required by the TSO to recover its costs. Based on this base revenue Ofgem set a price cap and adjusted it each year for retail price inflation (RPI) and an assumed target rate of productivity growth calculated by statistical benchmark analysis. Ofgem reset the price cap at the end of the five-year price control period to ensure that the TSO's cost savings are passed on to end consumers. Under the RPI-X mechanism, the TSO had incentives to reduce its costs because it was able to retain the margin between the price cap and its own actual costs as profit, as shown in Fig. 67. However, the RPI-X mechanism did not adequately incentivise service quality or innovation. It allowed cost savings to be achieved through decline in quality of service, and the five-year price control periods did not provide sufficient incentives to develop new technologies (such as smart meters) with longer investment cycles and the potential to provide cost savings over the longer term.

- RIIO mechanism. In 2013, Ofgem introduced the revenue $=$ incentives + innovation + outputs (RIIO) mechanism to address the concerns with the RPI-X mechanism. The RIIO mechanism takes the elements of the RPI-X mechanism that work well, such as the determination of the base revenue, and adds extensive innovation and output targets to them. The RIIO mechanism determines the base revenue from output-led business plans with greater use of option analysis and scenario planning. In their business plans, companies compare the costs and benefits of options for delivering long-term outputs under various scenarios and assess the value of keeping these options open. Moreover, financial and reputational incentives strengthen the incentive structure. Ofgem rewards or penalises companies when they achieve or miss their output targets respectively. Reputational incentives do not have a financial element, but they affect Ofgem's evaluation of base revenue in the next review periods. A longer control period, of eight years, encourages

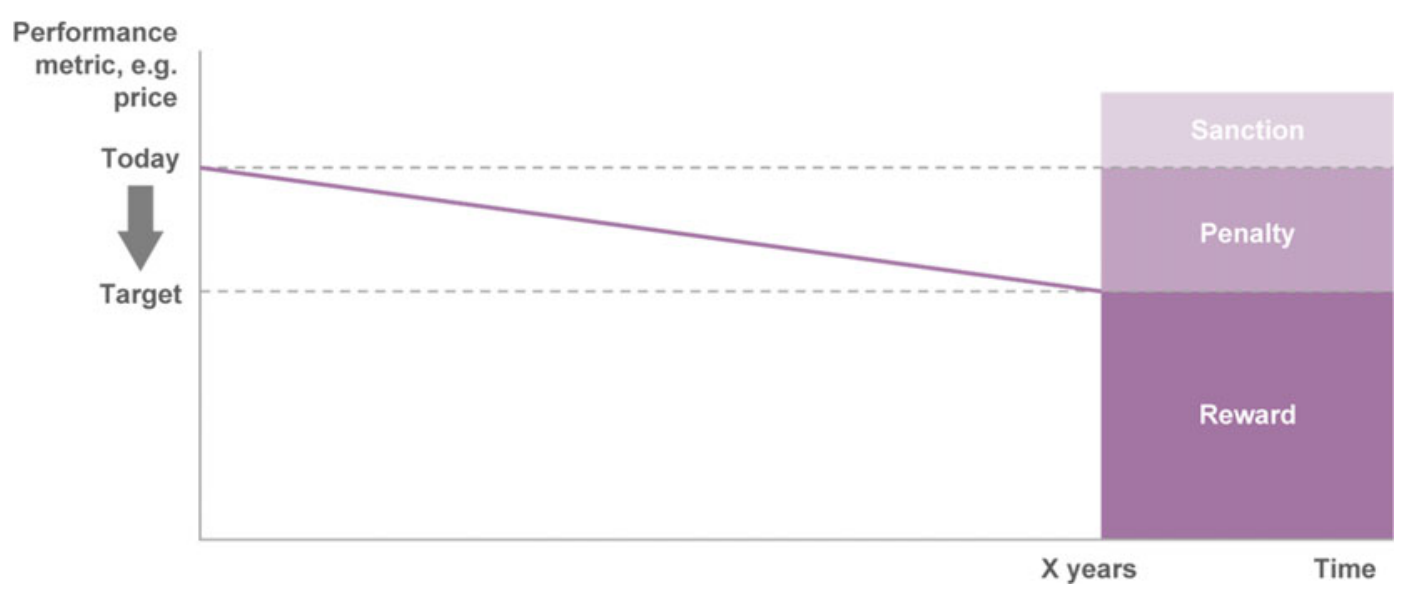

Fig. 67 Under the RPI-X mechanism, the TSO takes measures to decrease its costs because it retains revenues from cost savings. Source Vivid Economics 
the TSO to focus on longer-term investments, such as smart meters. RIIO provides a wider set of performance incentives than did RPI-X, but at a cost of greater complexity and reduced transparency.

\section{(2) Independent system operator}

An independent system operator (ISO) is a system operator that is fully separated from ownership of all network resources. The ISO performs all system operation functions, including allocating network capacity among generators and consumers to respect the physical characteristics of the network, carrying out residual balancing to ensure electricity is delivered to where it is most valued, and maintaining the stability of the electricity system. In an ISO model, the transmission network resources are owned by one or more transmission owners (TOs). The ISO levies charges from generators and/or consumers for use of the transmission system and pays these charges to the TOs. Typically, an ISO is also responsible for planning new transmission investments, either mandating TOs to carry out these investments or organising competitive tenders to facilitate delivery of investment. An ISO is usually a non-profit entity.

Separation of operation from ownership removes the system operator's incentives to charge monopoly prices. An ISO may be a non-profit organisation or may earn profits on revenues for system operation. As an ISO does not earn profits determined by revenues from use of the transmission system or by the costs of transmission investments, it has no incentive to charge tariffs that are higher than needed to recover the investment costs of the transmission network, or underinvest in transmission assets. Unlike a TSO, therefore, an ISO does not need performance-based regulation.

The ISO's functions can be specified by its mandate and its behaviour can be governed by a set of rules. The mandate could be to minimise the total cost of meeting a given reliability standard. Rules could govern processes for transmission planning and investment; providing grid connections to new system resources; administering competitive tenders for new network assets; levying charges for network use; and monitoring market power in the electricity system.

Nevertheless, it is desirable to have in place a mechanism to incentivise the ISO. It is unlikely to be possible to specify a set of rules that perfectly incentivise the management to meet the ISO's mandate. That is, to encourage the ISO to carry out the planning, investment and operation of the transmission system to strike the best possible balance between reliability of electricity supply and economic efficiency of the network. Imposition of financial penalties on the ISO is likely to be a poor incentive mechanism as ISO revenues are likely to be small relative to the welfare losses arising from poor performance in operating the system. Instead, well-designed management incentives may be needed.

The ISO model is prevalent in North and South America. Chile, Argentina and Peru were early adopters of the ISO model. There are a large number of ISOs in the USA, each covering a transmission network.

\section{(2) Strategic transmission planning}

The design of new transmission investment is a complex process and requires strategic planning. Specific challenges are the uncertainty in volume and location of future demand; the coordination problem facing generation and network investors; and the large number of possible transmission investments. These challenges can be mitigated by strategic planning. Key characteristics of strategic planning include:

- Define the objectives of new transmission investment. Transmission planning is more effective when the objectives of new investment are clearly defined. These include reliability (security and adequacy of supply) and 
economic efficiency (reduction in the total cost per unit output). Defining these criteria allows the benefits of new transmission infrastructure to be measured.

Estimate and compare the benefits of each proposed investment. Cost-benefit analysis is a key planning tool to identify proposals that meet investment objectives. Reliability and economic efficiency can be assessed with electricity system modelling, and modelling of multiple scenarios can help identify least regrets infrastructure investment under uncertainty. If available, locational pricing provides a clear signal of congestion costs, and can substantiate the economic benefits of new network infrastructure.

Consult all relevant stakeholders. As the costs of investments are borne by network users, they have incentives to ensure that only the most valuable network infrastructure is developed. Stakeholder consultation can elicit views from generators, consumers (municipalities, consumer interest groups), and connected transmission and distribution systems to inform the cost-benefit analysis.

\section{(3) Appropriate level of locational pricing}

Investing in networks efficiently requires an understanding of current network congestion. New network investments that relieve significant network congestion are particularly valuable.

Many electricity systems operate a system of uniform transmission pricing, which does not signal network congestion. Under a system of uniform pricing, the price of electricity is the same at every network connection, regardless of the degree of congestion. It does not signal the need to invest in solutions to relieve network congestion, such as new network investment, generation, or non-network alternatives to new transmission assets, such as electricity storage and demand-side response. While, in principle, the system operator can signal the need to invest through location-specific transmission charges, the rate of these charges is difficult to determine if the electricity price does not signal network congestion. Furthermore, uniform pricing results in re-dispatch costs, where some plant that is scheduled to generate is compensated for curtailment if the network is revealed to be congested.

Nodal pricing can help signal network congestion. Nodal pricing, or locational marginal pricing, is a price mechanism that reflects the cost of supplying additional electricity at a given network connection (node), given the demand for electricity, transmission constraints and options for local generation at that node. When there is no network congestion, overall demand is met at least cost and all nodal prices are the same. When network congestion occurs, demand is met by costlier local generation rather than cheap generation from another node, raising prices at congested nodes. Nodal pricing therefore signals the need to invest in solutions to relieve network congestion, such as new network investment, new local supply and non-network alternatives to new transmission assets, such as electricity storage and demand-side response. Nodal pricing is briefly illustrated in Box 3 .

\section{Box 3: Nodal pricing}

Figure 68 provides a simple example of balancing an electricity system under nodal pricing. In this example, a system operator balances a system of two cities interconnected with a capacity-constrained transmission line under nodal pricing. The numbers in green, blue and purple are the inputs for the system operator's balancing problem. The numbers in red are the outputs.

In City A, generators can produce up to 150 MW. Generation costs \$10/MWh. Consumers demand 50 MW. In City B, generators have $50 \mathrm{MW}$ capacity. Generation costs \$20/MWh. Consumers demand $90 \mathrm{MW}$, exceeding the local generation capacity. Consumer demand in both cities is price-inelastic. In other words, consumer demand is constant and does not change with price. The interconnection between City A and City B can carry up to $80 \mathrm{MW}$. 


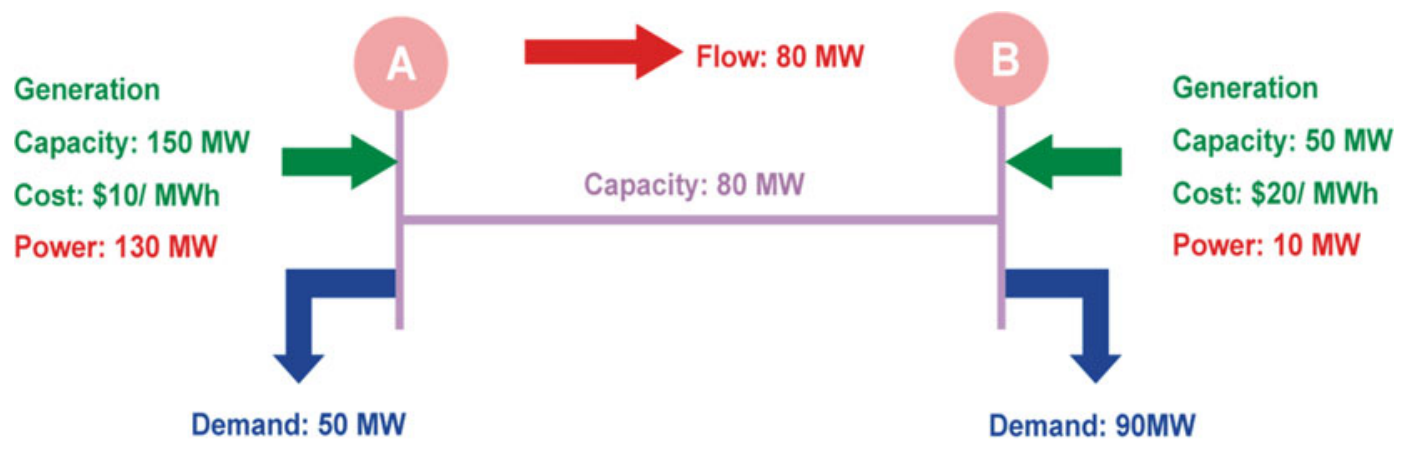

\section{System price: $\$ 20 / \mathrm{MWh}$ \\ Total cost: $\$ 2800$}

Fig. 68 Nodal pricing reflects the cost of supplying additional electricity at a given node. Source Vivid Economics

To minimise the total cost of the system, the system operator first uses the cheap generation in City A. Generators in City A serve the local demand (50 MW). That is why the nodal price in City A equals the local generation cost (\$10/MWh). Generators in City A also export $80 \mathrm{MW}$ to City B. Since the capacity of the interconnection is fully utilised, expensive generators in City B serve the rest of the local demand (10 MW). As a result, the nodal price in City B equals the local generation cost $(\$ 20 / \mathrm{MWh})$. The total cost is $\$ 1,500 \quad(=140 \mathrm{MW} * \$ 10 / \mathrm{MWh}+$ $10 \mathrm{MW} * \$ 20 / \mathrm{MWh}$ ).

However, nodal pricing has disadvantages as well as advantages. First, vulnerability to market power may arise because the segmentation of the electricity market into smaller locational markets increases the concentration of generators at each node with a supply deficit. Some authors challenge this view and argue that the network architecture is the main driver of market power, instead of the pricing mechanism. Nodal pricing can also reduce liquidity in long-term contracting, such as financial transmission rights and contracts for differences. This problem is addressed in the USA by averaging nodal prices into trading hub prices to provide liquidity to market participants.

Zonal pricing, another form of locational pricing, may provide a useful compromise between uniform and nodal pricing. Zonal pricing addresses the complexity introduced by large numbers of nodes by aggregating nodes into zones. Similar to dispatch under nodal pricing, the system operator first dispatches generation, given transmission constraints between zones. If transmission lines in a given zone are congested, the system operator has to re-dispatch generation in that zone to alleviate congestion. As a result, zonal pricing provides some of the benefits of nodal pricing in terms of signalling network congestion but does not fully eliminate the re-dispatch costs associated with uniform pricing.

Locational pricing may be considered once time-of-use pricing is fully implemented. Wider changes to improve the flexibility of the electricity system through electricity storage and demand response are expected to reduce demand and generation peaks, which would automatically reduce network congestion relative to an inflexible system. These changes require time-of-use pricing to be fully implemented across all system resources (including end users) to be fully effective. 


\section{(4) A regime for merchant investments}

The entry of merchant investors has the potential to deliver greater adequacy of investment than a single-owner network. Merchant transmission investors are third-party developers of transmission projects. If locational pricing is implemented, a merchant transmission investor has the incentive to invest in a new transmission link when the revenues from use of that link are greater than the investment cost. Therefore, in principle, merchant competition offers the potential to increase the adequacy of the transmission infrastructure by investing where an incumbent is not willing to do so. This might be the case if the incumbent is an unregulated monopoly, or a poorly regulated TSO.

Other attractive properties of the merchant model are the ability to include non-network alternatives to new transmission assets in planning processes, reduce the risk for consumers and minimise investment costs. In liberalised power markets, potential merchant investors could invest in new transmission capacity, or enter the generation market to supply local generation to a node that is served by a congested transmission link. Investment risk is transferred from regulated transmission owners and consumers to the merchant. As the merchant is the beneficiary of any cost saving, construction costs may also be minimised.

However, merchant investment alone is not sufficient to ensure overall adequacy of the network, underscoring the importance of a well-designed institutional model. Transmission investments exhibit economies of scale, where large-capacity investments carry only a small cost premium relative to small investments. As large-capacity investments offer significant additional benefits at little additional cost, they are socially desirable; however, as these additional benefits are reflected in lower locational prices (due to lower congestion), they are less desirable for private investors. In this setting, merchants will tend to underinvest in new network capacity. Alternatively, with an ISO institutional model, the ISO can also ensure overall network adequacy by planning new network capacity and delivering new investment at minimal cost by running competitive tendering processes.

Merchant transmission investments have been implemented in the USA, Australia and Argentina. In the USA, merchant investment is promoted by the FERC Order 1,000, and a number of projects are in progress or have been completed in recent years. Nearly all merchant-led investments have been on interconnectors, that is, links between distinct networks. Here merchants alleviate coordination and cost allocation issues between different system operators.

\subsubsection{Network Arrangements to Address Future Challenges}

This section discusses new arrangements to address the future changes of decarbonisation and decentralisation. They comprise:

- Strategic generation zones: Strategic generation zones coordinate investment in transmission and generation assets and connect remote renewable energy resources to large population centres.

- Markets for flexibility services: Flexible resources, such as electricity storage and demand response, can substitute for new network investment, as well as providing a range of different system services. A simple set of markets for each system service can reward flexible resources and avoid underinvestment.

- System for controlling decentralised resources: While distribution networks today are largely passive, they will need to become active to accommodate distributed resources. Distributed resources increase the complexity of the electricity system. If the system is too complex for a single system operator to balance, a hierarchy of resource control will be needed, with intermediaries such as virtual power plants and distribution system operators interacting with the transmission system operator. The hierarchy of resource control may reflect computational requirements, institutional characteristics and operational vulnerability. 
- Coordinated investment in decentralised resources: Investment in generation and storage resources should meet the needs of the whole electricity system. A decentralised electricity system may not provide adequate information to investors on system needs, raising the risk of inefficient investment. A coordinated approach to investment can mitigate this risk.

- Open-access, public data on system conditions and resources: Market participants need a degree of access to market information to facilitate a level playing field for competition. A data exchange could be part of an efficiently functioning energy system, but would need to be both secure and accessible.

- Accommodating future innovations: Innovations in electricity networks include new network structures and peer-to-peer electricity trading, which may offer significant benefits. These innovations can be facilitated through pilots and early-stage funding.

\section{(1) Strategic generation zones}

The decarbonisation of electricity generation and the wider energy system heightens the challenge of planning and delivering network infrastructure. The capacity of new transmission investment will be more difficult to determine due to greater uncertainty over the level of total electricity demand (due to electrification of end-use sectors and improvements in the efficiency of electrical appliances) and peak demand, as flexible resources contribute to smoother generation and consumption profiles. The degree to which generation will be centralised - that is, connected to the transmission network-will be difficult to forecast.

In many countries, renewable energy resources are located in areas that are distant from large population centres, and thus require large-scale transmission investment. For example, in the UK, the majority of electricity demand is located in the south of England, while a large proportion of onshore wind resources are located in Scotland and offshore wind resources in the North Sea.

In a liberalised electricity system, investors in generation and network investment face a coordination problem. While vertically integrated utilities are able to plan generation and network investment simultaneously, in a liberalised electricity system, generation and network investment are carried out by different institutions. This gives rise to a coordination problem, where generation investors face the risk that their revenues may be reduced due to inadequate network investment, and network investors face the risk that generators will underutilise their new investments. This can lead to underinvestment.

This coordination problem can be mitigated with strategic generation zones. If a strategic decision is made to exploit a large renewable resource that is distant from large population centres, generation investors may be given incentives to invest there. This may require an overarching strategic plan to be developed by an institution, such as a government agency, with sufficient authority to determine the location of both transmission and generation investment. It may also require a credible, long-term regime for network connection to be developed to reduce stranded asset risks for generators. For example, in the UK, nine offshore wind farm zones of varying size were identified within UK waters to deliver $33 \mathrm{GW}$ of potential offshore wind capacity. The Crown Estate, the statutory owner of seabed rights, asked renewable energy developers to bid for exclusive rights to develop offshore wind farms within the zones. The Electricity Networks Strategy Group, a high-level forum bringing together key stakeholders in electricity networks, including the Crown Estate, then identified key transmission investments needed to meet future demand, given the expected location of future generation. The areas identified by this exercise are shown in Fig. 69. 


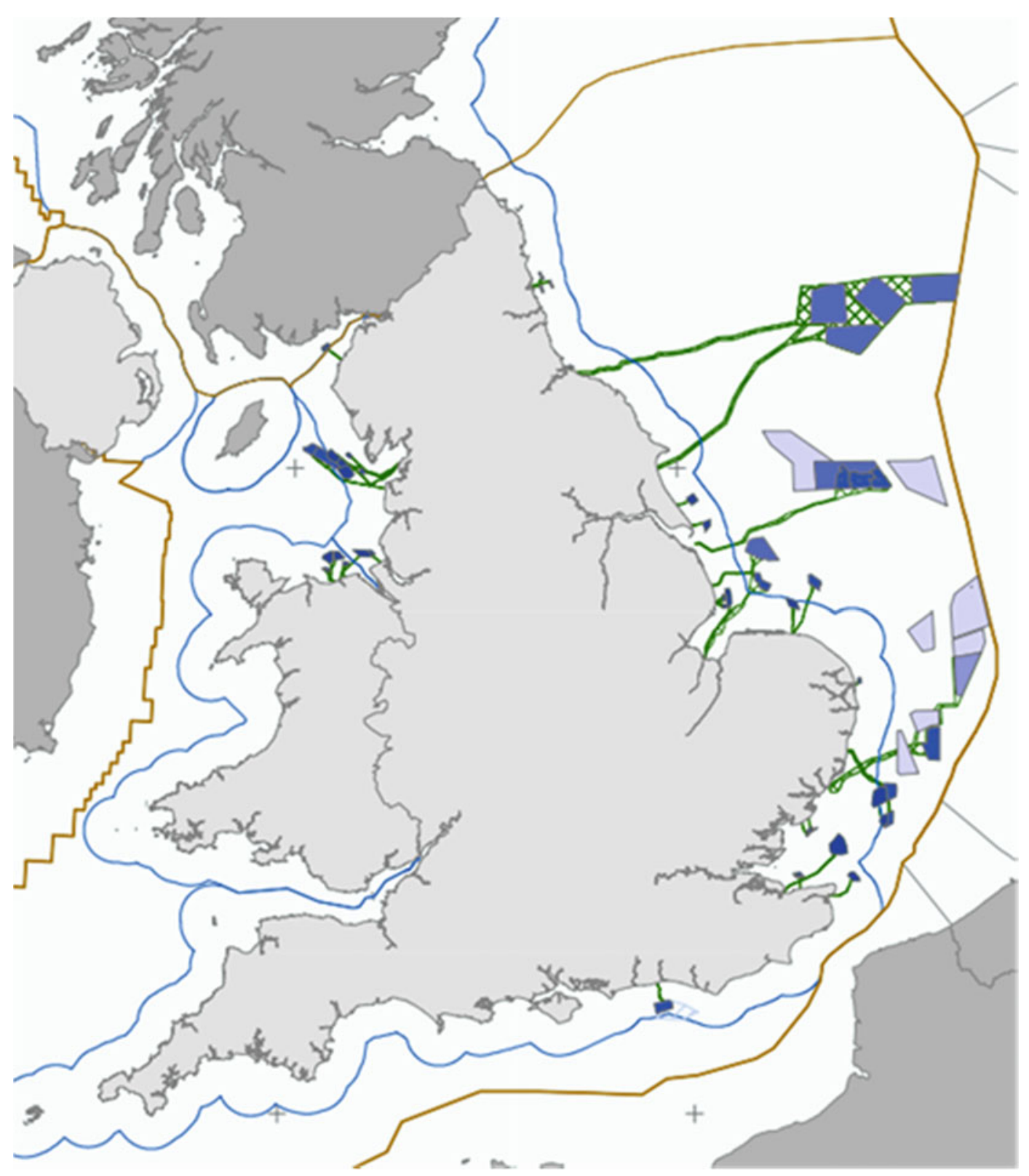

Fig. 69 UK offshore wind farm zones identified for development of renewable energy capacity. Source The Crown Estate (2017)

\section{(2) Markets for flexibility services}

Decarbonisation will require flexible resources, electricity storage and demand response, which offer non-network alternatives to new transmission assets. Electricity networks are costly, long-lived assets and investments are made in the presence of uncertainty over the future spatial and temporal profile of generation and demand. It will be increasingly valuable to enable flexible resources, such as electricity storage and demand response, to substitute for new network investments where possible, or defer new network investments until the future profiles of generation 
and demand are better understood. As discussed above, nodal pricing provides a locational signal for non-network alternatives.

Flexible resources provide a range of system services, which may each be rewarded. As well as substituting for or deferring new network investments, services provided by flexible resources include balancing and system stability. To provide balancing services, electricity storage can hold surplus energy until it is needed, and demand response can shift demand to when electricity is being generated. To provide system stability, electricity storage and demand response can adjust system voltage and frequency. In order for flexible resources to deploy at volumes that bring the greatest benefits, mechanisms exist to reward them for the system services they provide.

A simple set of markets for each system service allocates existing flexible resources and signals investment need. Storage and demand response are already actively engaged in balancing supply and demand in several wholesale markets. However, markets for system stability are typically not developed enough to allow flexible resources to participate to their fullest extent. Procurement mechanisms for system services typically specify these services in terms of the properties of the thermal generators that historically provided them, which often closes these mechanisms to new, low-carbon flexible resources. Recent attempts to create procurement mechanisms for flexible resources have resulted in a patchwork of complex and mutually inconsistent set of mechanisms. For example, in Great Britain, electricity storage facilities providing a short-term ancillary service called enhanced frequency response are not allowed to participate in the capacity mechanism. A set of simple markets to reward all system services provided by flexible resources is needed to ensure adequate investment to provide non-network alternatives.

\section{(3) Model for control of decentralised resources}

While distribution networks today are largely passive, they will need to become active to accommodate distributed resources. As demand on the distribution network is typically inflexible, generators on the transmission system operate flexibly to meet demand and maintain system security. As decentralised electricity resources (distributed generation, storage and demand response) are deployed in the distribution network, these resources will also need to operate flexibly.

Distributed resources increase the complexity of the electricity system. The optimisation of electricity system operation involves finding the optimal volume of output and consumption of every resource in the power system. A conventional, centralised electricity system typically includes a limited number of large transmission-connected generators, suppliers and large industrial consumers with flexible demand. However, a decentralised electricity system will include a very large number of small decentralised resources. The number of resources to be optimised might increase by a factor of several million.

A similar increase in computational demand would occur if the temporal resolution at which resources are controlled increases. For example, shifting from hourly to real-time (second-bysecond) settlement of all dispatch and consumption actions would increase the computational demands of optimal system balancing by a factor of 3,600 .

If the system is too complex for a single system operator to balance, a hierarchy of resource control will be needed. A full optimisation of a decentralised electricity system would have very significant computational requirements. If computing technology is not able to meet these requirements, then control of the system will be distributed.

Virtual power plants (VPPs) and distribution system operators have a role to play in a hierarchy of resource coordination. VPPs, also known as aggregators, could coordinate (aggregate) decentralised resources and coordinate them individually to present the system operator at the transmission level with a level of net generation (or consumption). If the system is complex, more than two levels of resource coordination might be 
needed, with some VPPs coordinating the activity of smaller VPPs further down the hierarchy. Distribution system operators are VPPs that coordinate all resources in a given distribution system, either directly or via intermediate VPPs.

Hierarchies of resource control provide only partial optimisation of the electricity system. In order to optimise the whole electricity system, a single optimising agent must know the demand and supply curves for each system resource. Where no single agent has this information, only partial optimisation is possible, as groups of resources for which information is available must be optimised separately. Markets between groups of resources will be required to coordinate their operation to balance the whole system. However, supply and demand curves in electricity systems change in real time, while the process of price discovery in decentralised markets takes place over time through multiple iterative trades. Therefore, markets between multiple levels of resource coordination can provide only a partial optimisation of the electricity system.

A decision has to be made about how distributed resources will be coordinated, with several possibilities available. Four possible models for operating distributed system resources are currently being discussed in the literature and are illustrated in Fig. 70. These models are:

- Whole-system operator. This model involves only one level of control. The TSO carries out constrained dispatch of the whole electricity system. In other words, it carries out least-cost dispatch across all system resources at the transmission and distribution system levels, taking capacity constraints at both network levels into account. In this model, distribution network operators retain their current, minimal functions of basic planning and operation of the distribution network.

- Whole-system operator with distribution system operator. This model has two levels of control. First, the TSO carries out economic dispatch of the whole electricity system, including constrained dispatch of the transmission system. In other words, it carries out least-cost dispatch across all system resources at the transmission and distribution system levels, but only takes capacity constraints at the transmission network level into account. Second, distribution system operators (DSOs) modify the operation of distributed resources

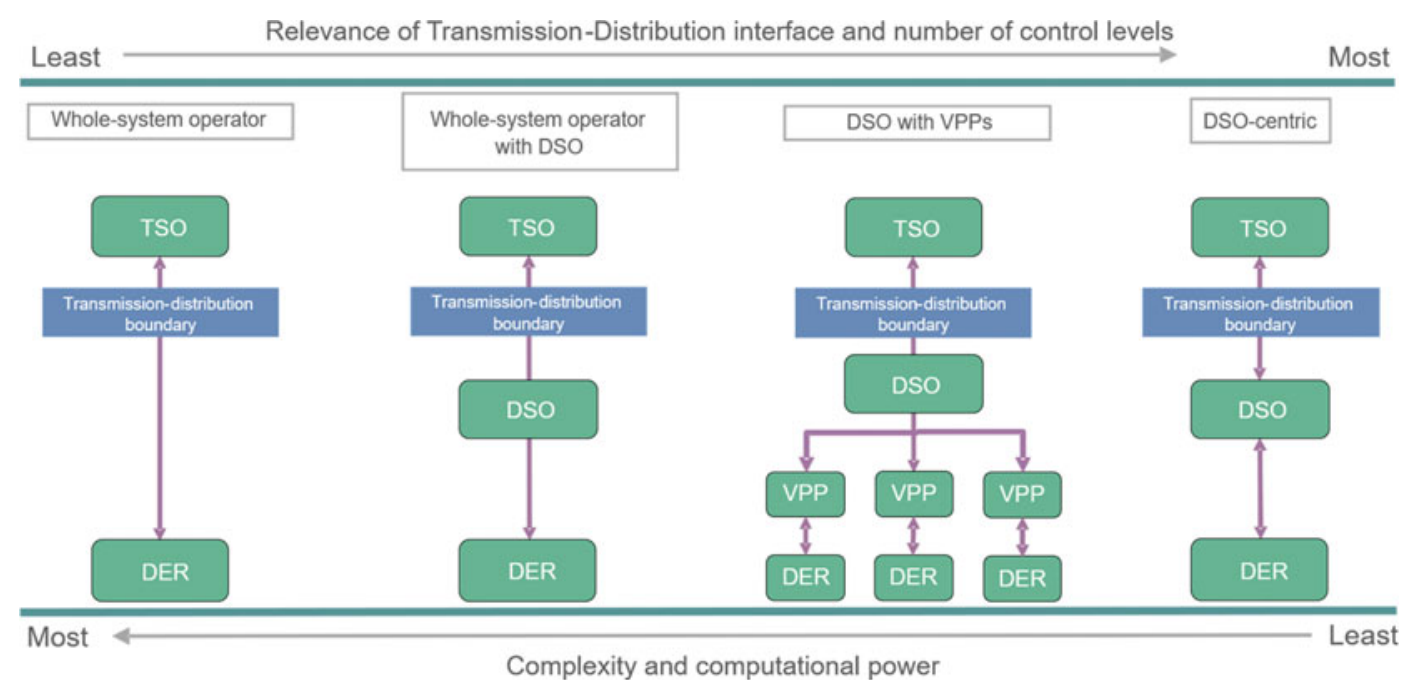

Fig. 70 There are several possible models for coordinating distributed energy resources. Note TSO = transmission system operator; DSO = distribution system operator; DER = distributed energy resources; VPP = virtual power plant.. Source Vivid Economics 
to take into account capacity constraints at the distribution network level.

- Virtual power plants with distribution system operator. This model involves three levels of control. First, VPPs provide the transmission-level system operator with offer curves for generation or demand reduction for the resources they operate. Second, the transmission-level system operator carries out constrained dispatch of the transmission system. Third, DSOs modify the operation of distributed resources to take into account capacity constraints at the distribution network level.

- Distribution system operator. This model involves two levels of control. First, DSOs act as sole distribution-level VPPs, controlling all system resources at the distribution level, and carry out constrained dispatch of the whole distribution system. DSOs provide the transmission-level system operator with bid or offer curves for the generation and demand resources they operate. Second, the transmission-level system operator carries out constrained dispatch of the transmission system.

Key criteria in this decision are the computational requirements, institutional characteristics and operational vulnerability of each model. As explained above, systems with high computational requirements, or small improvements in computing technology, will require more levels of resource coordination, while systems with low computational requirements, or large improvements in computing technology, will require fewer levels of resource coordination, and-with sufficiently developed computing technologypotentially a whole-system operator. Preferences for particular institutional characteristics are also relevant. For example, the whole-system operator and distribution system operator models involve coordination of resources by a single operator. Consumers may or may not have concerns over price, quality of service and privacy. If they have concerns, they might prefer a model involving control of resources by VPPs, which compete to meet customer requirements. Finally, the models may have different degrees of vulnerability to failures in information and communications technologies (ICT), such as those caused by cyberattacks.

Hierarchies of resource control may be needed until ICT capabilities are sufficiently developed. While in the near term a single operator may be able to optimise the electricity system with relatively low volumes of distributed resources, once sufficient volumes of distributed resources are deployed, the task of optimisation may be too great for a single operator. Hierarchies of control may be established early to ensure that increasing volumes of distributed resources can be accommodated if improvements in computing technology fail to keep pace with increases in computational requirements. Even if computing technology improves to the point where a fully distributed system can be optimised by a single operator, an increase in the temporal resolution of system control (for example, from half-hourly settlement towards real time) would result in significant further increases in computational requirements. A shift from hierarchies of control to a whole-system operator model would only be viable if improvements in computing technology are sufficient to meet the requirements of optimising a fully distributed system in real time.

\section{(4) Coordinated investment in decentralised resources}

Electricity systems with largely centralised resources provide adequate information to investors on system needs. Electricity systems periodically require investment in new resources, such as new generation plants. In theory, developers invest in new resources in response to a price signal in the wholesale market. These new investments are typically large. In principle, this leads to a coordination problem, whereby either several investors might plan to develop a similar resource (overinvestment) or investors might not invest in required resources due to the risk that other investors might do so (underinvestment). In practice, these risks are minimised because the transmission system operator knows which resources are under development and awaiting 
grid connection and is able to make this information public.

However, a decentralised electricity system may not provide adequate information, risking inefficient investment. As resources shift to the distribution system level, the same coordination problem may arise. This is because, unless adequate procedures are introduced, no single market participant knows which resources are under development and awaiting grid connection across all electricity networks in the system. The consequence is, again, inefficient investment: overinvestment, underinvestment, a poor technology mix or a poor spatial distribution of resources.

The risk of inefficient investment can be mitigated through a coordinated approach to planning new assets. As set out in Fig. 71, this could be achieved either through formal processes for resource planning and decisionmaking, or through provision of information.

Formal processes for resource planning and decision-making by system operators at the transmission and distribution system levels have been introduced in Spain and Ireland. Processes include formal collaboration, with the TSO and
DSOs planning infrastructure and generation investment together. For example, in Spain, some regional administrations founded evaluation boards. In these boards the administration, TSO, DSO and developers coordinate investment plans and grid connection requests. The TSO and DSO analyse and approve investment plans together. Thereby, the TSO and DSO minimise the network development and project costs as well as project risks. In Ireland, under the group processing approach, investment plans of developers are collected in batches and then submitted to the TSO and DSO for consideration. Then, the TSO or DSO process the plans that are most suited to their system. This approach coordinates the development of the transmission and distribution systems and efficiently allocates scarce capacity.

An alternative approach is to provide adequate information. For example, compulsory registration in a publicly available database on application for planning or grid connection consent would provide investors with an understanding of the pipeline of future resources, and allow them to evaluate potential investments against the expected system requirements.

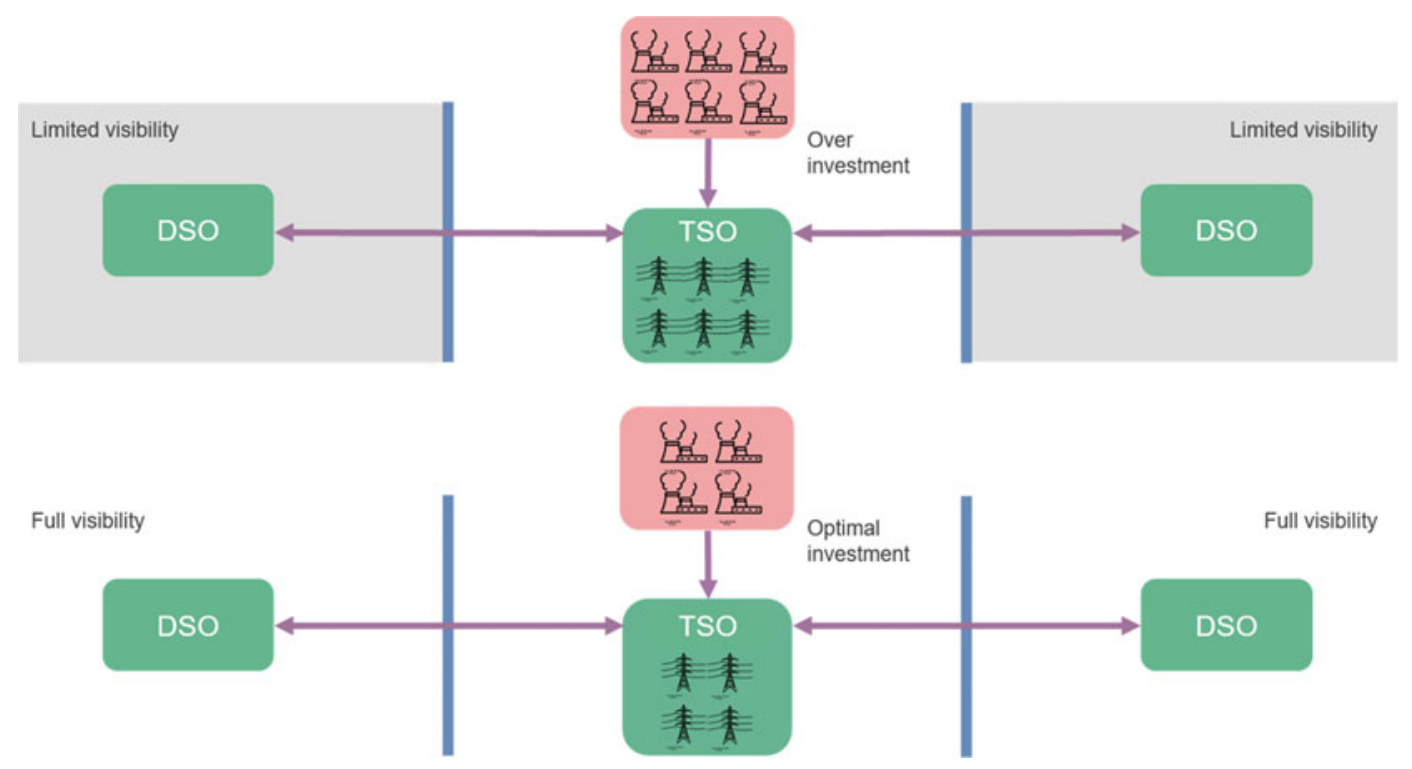

Fig. 71 A coordinated approach can ensure efficient investment in electricity system resources. Note TSO = transmission system operator; DSO = distribution system operator. Source Vivid Economics 


\section{(5) Open-access, public data on system con- ditions and resources}

The development of ICT infrastructure is expanding the amount of data and information available. Smart meters in buildings track the profile of energy consumption every second, offering a new source of information on energy consumption and user behaviour. On the electricity grid, sensors and wide area networks monitor the reliability of electricity grids, providing real-time information on network conditions.

Market participants need a degree of access to market information to facilitate a level playing field for competition. The Council of European Energy Regulators, for example, has identified limited access to information as a key barrier to entry for new market participants. Access to information about distributed resources and network conditions may also grow in importance in the future. This information may also provide a foundation for new opportunities for system balancing, as new participants could enter the market and find more efficient balancing solutions.

A data exchange could be part of an efficiently functioning set of future energy networks but would need to be managed carefully to mitigate risks while being accessible. A data exchange is a secure store of data, for example, on customer use patterns, available distributed resources, local prices and network conditions. The availability of this data raises privacy concerns and a balance would therefore need to be struck between accessibility and protection. Use of data exchanges will require adequate institutional arrangements. For example, if DSOs, who participate in markets for electricity system services, ran data services then gave themselves preferential access. In the long term, ICT developments may make operation of data exchanges by centralised authorities unnecessary, particularly if the trading of electricity shifts towards a peer-to-peer level.

\section{(6) Accommodating future innovations}

Innovations in electricity networks include new network structures and peer-to-peer electricity trading, which may offer significant benefits. New network structures, including microgrids and fractal grids, have the potential to make electricity systems more resilient to failure, as discussed above. Peer-to-peer trading through a distributed data management platform, such as blockchain, offers the potential to lower transaction costs and reduce the role of intermediaries in electricity markets.

These innovations can be facilitated with arrangements required to deliver efficient networks, today and in the future. Most fundamentally, liberalised electricity markets provide a supportive environment for the development, demonstration and adoption of innovations. More specifically, an institutional model that aligns system operator incentives to public policy objectives will be needed to mitigate any incentive for incumbents to block the spread of innovations. A model for control of decentralised resources will also be needed to allow innovations such as new network structures and peer-to-peer electricity trading the opportunity to participate in electricity markets.

It is possible that over time these and other innovations will drive or enable larger changes that have the potential to restructure the electricity system more significantly. It will be worthwhile monitoring new technologies and business models so that policy and regulation can respond appropriately, to realise value and address risks.

\section{(1) New network architectures}

Microgrids and fractal grids are innovative network architectures. Both of these new network architectures provide greater resilience than the radial links of conventional distribution networks. Microgrids achieve resilience through redundancy in generation, while fractal grids 
achieve resilience through redundancy in network infrastructure.

A microgrid is a small-scale, partially self-sufficient network incorporating both generation and demand sources. Microgrids may be connected to the local distribution network, importing or exporting electricity according to system conditions, but may also disconnect from the distribution network and operate as an island. As a microgrid can meet a degree of its own demand, it is more resilient to wider system failures, caused by a fault or cyberattack, than a radial network, and is well suited for critical functions such as healthcare, military installations or data centres. As microgrids are self-sufficient, they may require more on-site generation than conventional networks. The deployment of on-site generation in microgrids may result in a larger total volume of generation assets in the wider electricity system, implying a degree of asset redundancy and an increase in costs. In principle, the redundancy can be mitigated if sufficient generation is deployed to serve only essential loads when islanded. A microgrid can aggregate its resources like a virtual power plant to coordinate electricity trading with the wider power system. This aggregation can be accomplished by a central controller, or potentially by peer-to-peer communication of individual microgrid resources without a central controller. Figure 72 shows the structure of a microgrid with some of these features.

A fractal grid is a new network structure currently at the concept stage. A fractal grid combines the economy of radial networks, where redundancy is minimal, with the resilience of meshed networks, where nodes are connected by multiple links. The fractal grid achieves these properties through use of a fractal, or recursive pattern, where multiple sets of links with the same structure are connected together in a parent-child relationship. Failure of a single link does not prevent power flows between nodes, and the fractal architecture can accommodate microgrids that are able to island themselves in case of wider system failure. Proponents of fractal grids note that most urban spatial areas already have a fractal structure, so a fractal grid system could be easy to develop in cities. There are several fractal grid demonstration projects. For example, CleanSpark's Fractal Grid has a federated structure that connects microgrids in a

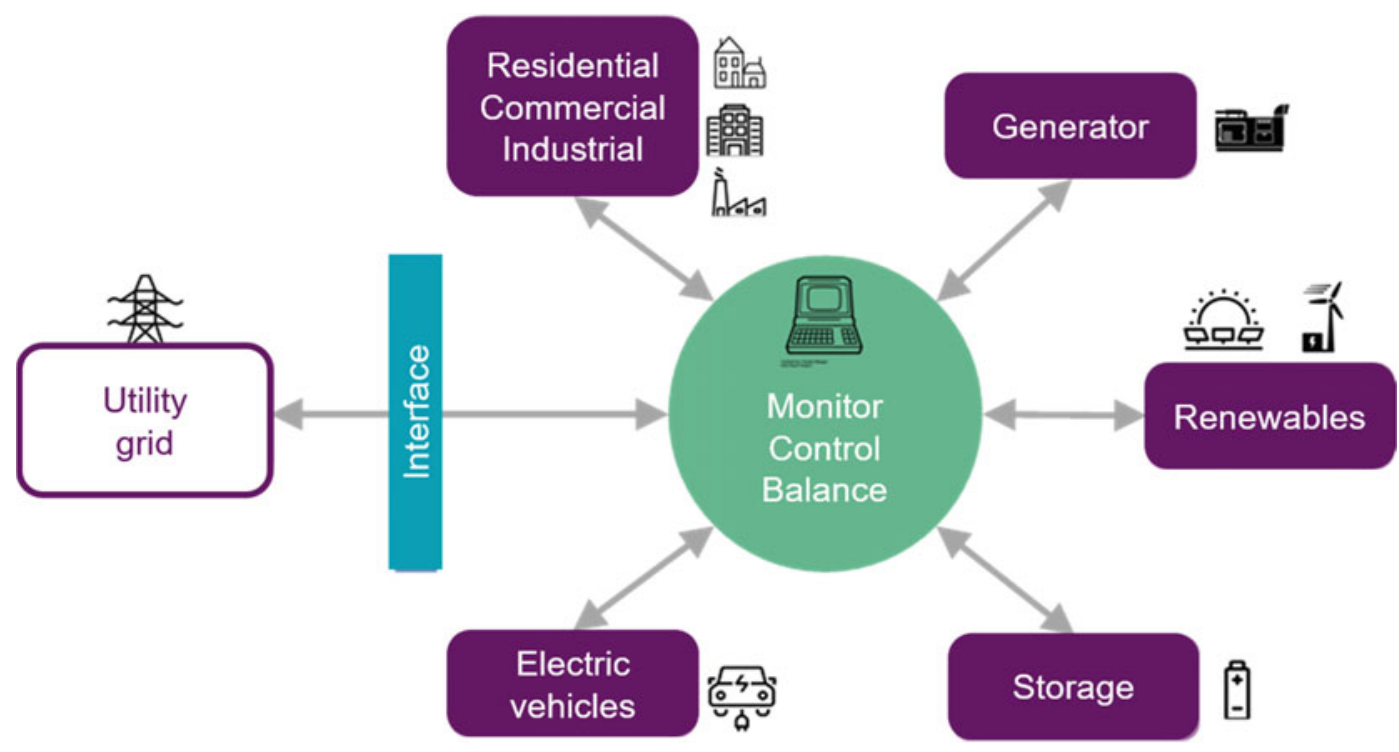

Fig. 72 A microgrid contains generation and flexible resources, as well as sources of electricity demand. Source Vivid Economics 
parent-child relationship. Microgrids in the fractal grid can share their generation and services with other microgrids to shave peak demand and thereby increase the reliability of the whole system, or they can island themselves to manage generation and load independently. The Fractal Grid Demonstration at Camp Pendleton military camp in California and NRECA's Agile Fractal Grid are other examples of microgrids in a parent-child relationship.

\section{(2) Peer-to-peer electricity trading}

Peer-to-peer electricity trading could allow individual owners of small-scale generation, storage and demand resources to participate in electricity markets. Currently, electricity is traded between generators and large electricity suppliers. As discussed above, virtual power plants are also likely to enter the electricity market. In addition, developments in peer-to-peer electricity trading could facilitate individual owners of small-scale generation, storage and demand resources to trade electricity. Peer-to-peer energy trading is being trialled at pilot scale in several small microgrid networks. For example, the Brooklyn Microgrid in New York connects generators, distribution lines, batteries and load sources, with trades and electricity flows tracked though the blockchain distributed ledger.

If peer-to-peer trading is widespread, there may be a reduced role for intermediaries in operating the electricity system. Some commentators suggest that blockchain could automate the active participation of large numbers of distributed resources, such that an intermediary, for example, a virtual power plant, is not required. In future, peer-to-peer electricity trading might take place not only within a microgrid, but between resources at the level of the distribution network, and potentially the transmission network. It is theoretically possible that sufficient automation might reduce the role of system operators at the distribution or even transmission system levels, though it is likely that their core roles, managing network constraints and maintaining system security, will remain.

\subsection{Analysis of Policy on the Reform of State-Owned Energy Enterprises in China}

\subsubsection{The Reform of State-Owned Enterprises Since the 12th Five-Year Plan (2011-15)}

In November 2013, the Third Plenary Session of the 18th CPC Central Committee deliberated and adopted the Decision of the CPC Central Committee on Several Major Issues Concerning Comprehensively Deepening Reform, marking the start of this round of reform of state-owned enterprises. General Secretary $\mathrm{Xi}$ clearly explained the status of state-owned enterprises and the background of the reform in his statement on the Decision: "State-owned enterprises are an important force that promotes the modernisation of the country and safeguards the common interests of the people. After years of reform, state-owned enterprises have, on the whole, been integrated with the market economy. Meanwhile, they need to be further reformed due to the presence of some problems and drawbacks". The key points for further deepening reform are identified in the Decision: "China will perfect the state-owned asset management system, strengthen the supervision of state-owned assets primarily by means of capital management, reform the system of authorised operation of state-owned capital, establish several state-owned capital operation companies, and support the reorganisation of state-owned enterprises into state-owned capital investment companies if conditions permit".

As for important measures for deepening the reform of state-owned enterprises, the Decision sets out that, China will, first: "actively develop a mixed ownership economy", "allow more state-owned sectors, and sectors with other types of ownership, to develop into a mixed ownership economy", "allow non-state capital to participate in state-owned capital investment projects" and "encourage non-public ownership enterprises to participate in the reform of state-owned enterprises, and encourage the development of mixed ownership enterprises held by non-public 
capital"; and second, "impel state-owned enterprises to perfect the modern enterprise system", "accurately define the functions of different state-owned enterprises", "increase state-owned capital investment in non-profit enterprises", "separate national railway network infrastructure from railway passenger and freight transport, and liberalise competitive businesses in natural monopoly industries owned by state-owned capital" and "improve the corporate governance structure to achieve coordinated operation and effective balance".

Since then, General Secretary Xi has talked about the reform of state-owned enterprises on several occasions.

In March 2014, he said in his speech during the deliberation of the Anhui delegation at the Second Session of the 12th National People's Congress that: "the basic policy for the development of a mixed ownership economy has been identified. Detailed rules and regulations are the key to, and decisive factor for, success. The experience and lessons gained from the past reform of state-owned enterprises will be drawn on. The reform of state-owned assets will not be an opportunity for profiteering".

In August 2014, he said at the Fourth Meeting of the Leading Group of the CPC Central Committee for Comprehensively Deepening the Reform that: "state-owned enterprises must be well developed, especially those administered by the central government that dominate the major industries and key sectors and that impact national security and the national economy. They are an important pillar of CPC administration and the economic foundation of socialist state power".

In June 2015, he said at the 13th meeting of the Leading Group of the CPC Central Committee for Comprehensively Deepening the Reform that: "upholding the leadership of the CPC is a unique advantage of the state-owned enterprises of our country" and that China will "make state-owned enterprises bigger and stronger and able to continuously enhance the dynamism, dominance, influence and resilience of the state-owned economy", "prevent loss of state assets" and "accelerate the formation of a state-owned asset supervision system characterised by comprehensive coverage, clear division of labour, coordination and effective restrictions".

In July 2015, he said in a survey in Jilin that: "state-owned enterprises are an important force that promotes the modernisation and safeguards the common interests of the people. China will unswervingly uphold the important role of state-owned enterprises in the development of the country and resolutely develop state-owned enterprises and make them bigger and stronger". "China will deepen the reform of state-owned enterprises, improve the corporate governance model and operating mechanism, truly establish enterprise status as market players and enhance their internal dynamism, market competitiveness and leadership." "The reform of state-owned enterprises will preserve and appreciate state-owned capital, enhance the competitiveness of the state-owned economy and amplify the functions of state-owned capital."

In May 2016, he said at the 13th Meeting of the Financial Leading Group of the CPC Central Committee that: "China will promote the reform of state-owned enterprises". "It should be emphasised that the disposal of 'zombie state-owned enterprises' means the reform of state-owned enterprises and the strategic adjustment of the state-owned economy."

In July 2016, he said in his speech at the National Forum on the Reform of State-Owned Enterprises that: "state-owned enterprises, which are an important force that strengthens the country and safeguards the common interests of the people, must grow bigger and stronger rationally and emphatically and continuously enhance their dynamism, influence and resilience to preserve and appreciate state-owned assets. China will unswervingly deepen the reform of state-owned enterprises, make efforts to innovate systems and mechanisms, speed up the formation of a modern enterprise system, and activate and energise the enthusiasm, initiative and creativity of all kinds of talent in state-owned enterprises".

In October 2016, he said in his speech at the National Working Conference on Party-Building of State-Owned Enterprises that: "state-owned 
enterprises should not just be developed but well developed. China will require all relevant departments and state-owned enterprises in all regions to adjust to the developments and changes in the economy at home and abroad and in accordance with the decisions and arrangements of the CPC Central Committee on the reform and development of state-owned enterprises. They should follow the policies that preserve and appreciate state-owned assets, enhance the competitiveness of the state-owned economy and amplify the functions of state-owned capital, deepen their reform and improve their operational management, strengthen the supervision of state-owned assets and unswervingly make state-owned enterprises bigger and stronger".

In October 2017, he made a concise and systematic exposition of issues concerning the reform of state-owned enterprises in his report to the 19th National Congress of the Communist Party of China (NCCPC): "China will perfect the management of state-owned assets; reform the state-owned capital authorisation system; speed up the optimisation, structural adjustment and strategic restructuring of the state-owned economy; preserve and appreciate state-owned assets; impel state-owned capital to grow bigger and stronger and prevent the loss of state-owned assets; and deepen the reform of state-owned enterprises, develop a mixed ownership economy and foster world-class enterprises with global competitiveness".

Premier Li Keqiang has also spoken many times about the reform of state-owned enterprises.

In March 2016, he said in his government work report that: "China will promote development through reform and tackle firmly the most difficult problems affecting the quality and efficiency of state-owned enterprises; restructure state-owned enterprises, especially those that are managed by the central government, through innovation and mergers; promote equity diversification reform and carry out pilot projects to introduce boards of directors, a professional management system, mixed ownership and employee stock ownership; deepen the reform of enterprise employment systems and explore and establish a compensation system for high-level talent and managers through market-oriented recruitment methods; accelerate the restructuring and formation of state-owned capital investment and operational companies; transform the functions of state-owned asset supervision and administrative institutions by means of capital management, and preserve and appreciate state-owned assets; give greater autonomy to local government with regard to the reform of state-owned enterprises; and accelerate the divestment of those state-owned enterprise functions unrelated to operations, solve problems left over by history, downsize state-owned enterprises and enhance their core competitiveness".

In May 2016, he said at a State Council Executive Meeting that: "China will promote development through reform and will tackle the hardest problems to downsize central government-administered state-owned enterprises and improve their quality and efficiency, and with the courage and determination to make prompt and resolute decisions".

In December 2017, he said at a State Council Executive Meeting that: "China will implement the arrangements identified at the 19th NCCPC, focus on deepening the reform of state-owned enterprises and make efforts to preserve and appreciate state-owned assets".

\subsubsection{Use the 1+N Policy System to Reform State-Owned Enterprises}

In November 2013, the Decision of the CPC Central Committee on Several Major Issues Concerning Comprehensively Deepening Reform was released. On December 30 of that year, the Leading Group of the CPC Central Committee for Comprehensively Deepening the Reform, under the leadership of General Secretary Xi, was formed. In August 2015, the CPC Central Committee and the State Council jointly issued the Guiding Opinions on Deepening Reform of State-Owned Enterprises. Policies on the reform of state-owned enterprises were introduced within the framework of the Guiding Opinions. 
A complete $1+\mathrm{N}$ policy system has been created for the new round of state-owned enterprise reform. " 1 " refers to the Guidance, which is the overall idea behind the policy system. "N" refers to policies that cover such key areas as leadership of the CPC, the state-owned asset management system, mixed ownership, classification of state-owned enterprises, supervision and solving problems left over by history. " $\mathrm{N}$ " includes:

- the Opinions on Rationally Identifying and Strictly Standardising Remuneration and the Business Expenses of Heads of Central Government-Administered State-Owned Enterprises, deliberated and adopted in August 2014;

- the Plan of Reform of the Compensation System for Heads of Central GovernmentAdministered State-Owned Enterprises, implemented in January 2015;

- the Several Opinions on Further Deepening Electricity System Reform, introduced in March 2015;

- the Opinions on State-Owned Enterprises' Development of the Mixed Ownership Economy, introduced in September 2015;

- the Several Opinions on Upholding the Party's Leadership and Strengthening Party Building in Deepening Reform of State-Owned Enterprises, introduced in September 2015;

- the Guiding Opinions on Encouraging and Standardising the Introduction of Non-State-Owned Capital into Projects Invested in by State-Owned Enterprises, deliberated and adopted in September 2015;

- the Several Opinions on Reforming and Perfecting the State-Owned Asset Management System, introduced in October 2015;

- the Opinions on Strengthening and Improving the Supervision of State-Owned Assets of Enterprises and Preventing the Loss of State-Owned Assets, introduced in October 2015;

- the Circular on Printing and Distributing Support Documents for Electricity System Reform, implemented in November 2015 (related support documents are: the Opinions on Promoting the Reform of Power Transmission and Distribution Prices, the Opinions on Implementing the formation of Electricity Markets, the Opinions on Establishing and Operating Power Trading Institutions, the Opinions on the Orderly Liberalisation of Power Generation and Consumption Planning, the Opinions on Implementing Electricity Retail Reform, and the Guiding Opinions on Strengthening and Regulating the Supervision and Administration of Private Coal-Fired Power Plants);

- the Guiding Opinions on the Definition and Classification of Functions of State-Owned Enterprises, introduced in December 2015;

- the Guiding Opinions on Further Regulating and Strengthening the Management of State-Owned Assets of Administrative Institutions, introduced in December 2015;

- the Interim Procedures for the Administration of Stock Ownership and Dividend Incentives of State-Owned Scientific and Technological Enterprises, implemented in March 2016;

- the Circular of the State Council on Printing and Distributing the Work Plan for the Divestment of Functions Unrelated to the Operations of State-Owned Enterprises and for Solving Problems Left Over by History, introduced in March 2016;

- the Regulations on the Supervision and Administration of Transactions of State-Owned Assets of Enterprises, implemented in July 2016;

- the Guiding Opinions on Restructuring and Reorganising Central Government-Administered State-Owned Enterprises, implemented in July 2016;

- the Opinions on Establishing an Accountability System for Illegal Operations and Investments by State-Owned Enterprises, implemented in August 2016;

- the Opinions on the Employee Stock Ownership Pilot Project of State-Held Mixed Ownership Enterprises, introduced in August 2016;

- the Implementation Plan for Improving the Functional Classification Assessment of 
Central Government-Administered StateOwned Enterprises, implemented in August 2016;

- the Review of Policies and Suggestions on Supporting Reform of State-Owned Enterprises, introduced in August 2016;

- the Circular on Doing a Good Job of Stock Ownership and Dividend Incentives of Central Government-Administered Scientific and Technological Enterprises, implemented in October 2016;

- the Opinions on the Pilot Implementation of the Functions and Powers of Boards of Directors for Central Government-Administered State-Owned Enterprises, deliberated and adopted in December 2016;

- the Guiding Opinions on Innovating Government's Resource Allocation Methods, introduced in January 2017;

- the Regulations on the Supervision and Administration of Investment by Central Government-Administered State-Owned Enterprises, introduced in January 2017;

- the Plan of the State-Owned Assets Supervision and Administration Commission of the State Council (SASAC) for Transforming Functions by Means of Capital Management, introduced in April 2017;

- the Guiding Opinions of the General Office of the State Council on Further Improving the Corporate Governance Structure of State-Owned Enterprises, introduced in April 2017;

- the Circular on Doing a Good Job of Declaring and Liquidating State-Owned Capital Operation Budgets for the Divestment of the Central Government-Administered StateOwned Enterprise Functions of Water, Power and Heat Supply and Property Management for Employee Residential Areas in 2017, introduced in April 2017;

- the Several Opinions on Deepening Oil and Natural Gas System Reform, introduced in May 2017; and

- the Implementation Plan for the Transformation of Central Government-Administered State-Owned Enterprises into a Corporate System, introduced in July 2017.

\subsubsection{Steady Progress in Priorities}

First, the Ten Reform Pilots have been implemented since 2016. The 10 pilots were carried out at central government-administered stateowned enterprises to create experience that can be extended into other companies. The 10 pilots had the following objectives:

\section{(1) Reform the state-owned asset manage- ment system}

State-owned capital investment and operational company reform pilots: China National Cereals, Oils and Foodstuffs Corporation (COFCO), State Development \& Investment Corporation (SDIC), Shenhua Group, Baosteel, Wuhan Iron and Steel Corporation (WISCO), China Minmetals Corporation (CMC), China Merchants Group (CMG), China Communications Construction Company (CCCC), China Poly Group (state-owned capital investment company reform pilot) and China Chengtong and China Reform Holdings Corporation (CRHC, state-owned capital operation company reform pilot).

Central government-administered state-owned enterprise merger pilots: China State Construction Engineering Corporation (CSCEC) and China National Materials (Sinoma), China Ocean Shipping Company (COSCO) and China Shipping Container Lines (CSCL), and China Power Investment Corporation (CPI) and State Nuclear Power Technology Corporation (SNPTC).

\section{(2) Develop mixed ownership}

Pilot mixed ownership reform in several key sectors: power, oil, natural gas, rail, civil aviation, telecommunications and the military.

The first batch comprises nine pilots, the second batch consists of 10 pilots and the third batch comprises nine. The 28 pilots include China Unicom, China Telecom, China Railway Group (CREC), China Railway Construction Corporation (CRCC), China Railway Corporation (CRC), China National Aviation Holding Company (CNAH), China Eastern Airlines, China Southern Airlines, State Grid Corporation of China (SGCC), China Southern Power Grid 
(CSG), POWERCHINA, China Nuclear Engineering \& Construction Corporation (CNEC), China Energy Engineering Corporation (CEEC), State Power Investment Corporation (SPIC), Harbin Electric Corporation (HE), China National Petroleum Corporation (CNPC), China National Offshore Oil Corporation (CNOOC), China Petroleum \& Chemical Corporation (Sinopec), China State Shipbuilding Corporation (CSSC), China North Industries Group Corporation (CNGC), China South Industries Group Corporation (CSGC), China Shipbuilding Industry Corporation (CSIC), Aero Engine Corporation of China (AECC), China Aerospace Science \& Industry Corporation (CASIC), China Aerospace Science and Technology Corporation (CASC), Aviation Industry Corporation of China (AVIC), and China National Building Material (CNBM).

Pilots of employee stock ownership of mixed ownership enterprises comprise third-level subsidiaries of Shenhua Group, China National Machinery Industry Corporation (Sinomach), China Baowu, COSCO, COFCO, CMG, China Energy Conservation and Environmental Protection (CECEP), CNBM, China Academy of Building Research (CABR), and CREC.

\section{(3) Improve the modern enterprise system}

Pilot to implement the functions and powers of boards of directors: CECEP, CNBM, Sinopharm, Xinxing Cathay International Group, China Baowu, SDIC and China General Nuclear Power Group (CGN).

Pilot for the market-based selection and employment of managers: Baosteel, Xinxing Cathay International Group, Sinopharm, CECEP, SDIC and China Railway Signal \& Communication Corporation (CRSC).

Pilot to recruit professional managers: China Baowu Group, Xinxing Cathay International Group and CNBM.

Pilot to reform emolument differentiation in enterprises: Scheduled for launch in 2018 by the Ministry of Human Resources and Social Security (MOHRSS).

\section{(4) Prevent the loss of state-owned assets}

Pilot for state-owned enterprise information disclosure: COFCO, CSCEC, SPIC and China Southern Airlines.

\section{(5) Solve the problems left over by history}

Pilot the divestment of state-owned enterprise functions that are unrelated to operations and solve the problems left over by history: This will be carried out in selected provinces and cities.

Second, the merger and reorganisation of central government-administered state-owned enterprises is an important measure to optimise the distribution of state-owned capital and adjust the industrial sector. It is just one of the Ten Reform Pilots mentioned above. Six pilot enterprises have completed their merger and reorganisation. They include CSCEC-Sinoma (China National Building Material, CNBM), COSCO-CSCL (China COSCO Shipping Group) and CPI-SNPTC (State Power Investment Corporation). In recent years there have been other mergers and reorganisations of state-owned enterprises, such as CSR-CNR (CRRC), MCC-CMC, Sinotrans and CSC-CMG, HKCTS-CITS (China National Travel Service Group Corporation), Sinolight-CNACGC (Poly Group), Baosteel-WISCO (China Baowu) and Shenhua Group-China Guodian (National Energy Investment Group).

Third, excess capacity in the coal industry is being resolved. Capacity cutting by state-owned coal enterprises is an important part of supply-side structural reform. In July 2016, the State-Owned Assets Supervision and Administration Commission of the State Council (SASAC) identified the tools for solving excess coal capacity in central government-administered state-owned enterprises. SASAC proposed that: (i) central government-administered state-owned enterprises should cut capacity by $15 \%$ within five years and $10 \%$ within two years; and (ii) central government-administered state-owned enterprises involved in the coal industry on a non-core basis should withdraw from the 
industry - only professional coal enterprises and coal power integration enterprises should remain. All the central government-administered coal enterprises achieved their capacity-cutting targets for 2016 and 2017. SDIC and Poly Group have transferred their coal businesses to China Coal Group. In addition, local governmentadministered state-owned coal enterprises are actively cutting capacity and have achieved their capacity-cutting targets for 2016 and 2017.

\subsection{The Reform of State-Owned Energy Enterprises}

\subsubsection{The Idea Behind the Reform}

Based on a review of the speeches and policies on the new round of state-owned enterprise reform, the basic idea behind the reform can be summed up in the following six points:

First, ensuring national energy security wlll continue to be an important goal. China is a major energy producer and consumer, with a balanced structure of supply and demand. Total demand is large and has been relatively stable following the economic downturn, with low growth expected in the years to come. There are objective constraints, such as local resource endowment and long-distance transport. Seasonal and partial shortages are, therefore, difficult to avoid. Ensuring national energy security remains an important goal of this round of reform of state-owned energy enterprises. In the future, China's energy supply system will be continuously optimised on the basis of local conditions to ensure that the foundation of national energy security will not change.

Second, state-owned enterprises will become bigger and stronger. General Secretary $\mathrm{Xi}$ has continually emphasised that China will make state-owned enterprises and state-owned capital grow bigger and stronger. Scale is one of the characteristics of state-owned energy enterprises and will remain so in the future. According to data from the National Bureau of Statistics, in 2015 state-owned enterprises in the coal, petroleum, chemical and power sectors accounted for $47.2 \%$ of state-owned industrial enterprise assets and $40.2 \%$ of their employees. The aggregate assets of state-owned energy enterprises amounted to $18.03 \%$ of the total assets of all industrial enterprises. Central government-administered energy enterprises include China National Petroleum Corporation (CNPC), China Petroleum \& Chemical Corporation (Sinopec), China National Offshore Oil Corporation (CNOOC), National Energy Investment Group (renamed after the Shenhua Group-China Guodian merger), China Coal Group, SPIC (after the CPI-SNPTC merger), China Huaneng Group (CHNG), China Huadian Corporation (CHD) and China Datang Corporation (CDT), as well as many local government-administered state-owned energy enterprises that are a pillar of their local economy. These enterprises have good industrial foundations and advantages of scale, technology and market, reflecting the strategic pattern of state-owned capital in the energy industry. In the future, the issues of how to make central government-administered energy enterprises stronger and bigger will be the focus of their reform and development. The smooth progress of the pilots to improve central governmentadministered energy enterprises is an example for the reform and improvement of local government-administered state-owned energy enterprises.

Third, the roadmap for improving state-owned capital in state-owned energy enterprises will be created. The Guiding Opinions on Restructuring and Reorganising Central GovernmentAdministered State-Owned Enterprises, which was implemented in July 2016, stipulates that these enterprises "will significantly improve their support capabilities in the sectors that impact national security, such as national defence, energy, transport, food, information and ecology", and that they will "enhance their dominance in the key industries that affect the national interest, people's livelihoods and the national economy, such as major infrastructure, key resources and public services", and that they will 
"drive industries like new energy, new materials, aerospace and intelligent manufacturing". Specifically, the following efforts will be made:

(1) China will implement sole proprietorship or shareholding in fields like: water conservation, hydropower and navigation-hydropower integration hubs in important river basins; natural monopolies like oil and natural gas trunk pipeline networks, power grids and nuclear power; and reduce excess capacity in the coal industry;

(2) China will encourage central governmentadministered state-owned enterprises in power, new energy and oil and gas pipelines to fund specialist joint-stock platforms; and

(3) China will reorganise central governmentadministered state-owned enterprises in the upstream and downstream coal, power and metals industries, which will provide a model for state-owned capital in the energy sector.

Fourth, state-owned energy enterprises will be reorganised into state-owned capital investment companies. The function of these companies will be to optimise the distribution of state-owned capital through the entry or withdrawal or flow of state-owned capital in the energy industry, and to pool the advantages of state-owned energy enterprises and enhance their operational efficiency and international competitiveness. The state-owned capital investment company reform pilot is at SDIC and the Shenhua Group. The goal of the Guiding Opinions on Restructuring and Reorganising Central Government-Administered State-Owned Enterprises is to "create a mechanism for the entry or withdrawal or flow of state-owned capital" and to "reorganise central government-administered energy enterprises into state-owned capital investment and operational companies". Some local governments have identified the reform pilot of reorganising provincial government-administered energy enterprises, such as those engaged in the coal business, into local state-owned capital investment companies.

Fifth, state-owned energy enterprises will be encouraged to develop mixed ownership. The development of mixed ownership is an important measure to reform the state-owned capital management system and the internal mechanisms of state-owned enterprises. The $1+\mathrm{N}$ policy system includes special policy arrangements, such as the Opinions on the Development of the Mixed Ownership of State-Owned Enterprises, which was introduced in September 2015, and the Opinions on the Employee Stock Ownership Pilot of State-Held Mixed Ownership Enterprises, which was launched in August 2016. The mixed ownership reform of state-owned enterprises is described in other documents as well. The Guiding Opinions on Restructuring and Reorganising Central Government-Administered State-Owned Enterprises emphasises that China will maintain state-owned capital's control of key industries and sectors, while supporting the participation of non-state-owned capital. The Opinions on Deepening Electricity System Reform, introduced in March 2015, states that China will "steadily reform, liberalise and open electricity retail to private capital in an orderly manner", "encourage private capital to invest in power distribution" and "gradually open power distribution investment to market participants that meet requirements, and encourage the development of distribution businesses based on mixed ownership". The Opinions on Deepening Oil and Natural Gas System Reform, introduced in May 2017, states that China will "improve the corporate governance structure of state-owned oil and gas enterprises and encourage them to diversify their ownership structure and allow mixed ownership, if conditions permit". In the coal sector, Shenhua Group has been identified as one of the pilots for mixed ownership reform of central government-administered state-owned enterprises.

Sixth, the supply-side structural reform of state-owned energy enterprises will be deepened. Downsizing state-owned energy enterprises is a key element of supply-side structural reform. At present, it primarily involves three aspects.

(1) Tackling the hardest problems in the reform of state-owned energy enterprises. This primarily refers to deepening electricity and oil 
and natural gas system reform. Relevant government departments have produced support documents like Opinions on Further Deepening Electricity System Reform in March 2015 and Opinions on the Reform of Power Transmission and Distribution Prices, Opinions on Creating Electricity Markets, Opinions on Implementing and Operating Power Trading Institutions, Opinions on the Orderly Liberalisation of Power Generation and Consumption Planning, Opinions on Implementing Electricity Retail Reform, Guiding Opinions on Strengthening and Regulating the Supervision and Administration of Private Coal-Fired Power Plants, and Opinions on Deepening Oil and Natural Gas System Reform.

(2) Steadily implementing capacity cutting in the coal and coal-fired power industries. China has intensified capacity cutting in the coal industry since 2016. Resolving excess coal production has become one of the key tasks in the reform of state-owned energy enterprises. In February 2016, the State Council issued Opinions on Resolving Excess Capacity to Stop Losses and Develop the Coal Industry. Since then, support documents on human resources, finance, safety supervision, land, quality inspection, taxation and environmental protection have been published, and major coal-producing provinces, municipalities and autonomous regions have identified their capacity-cutting targets, plans and measures. The Guiding Opinions on Restructuring and Reorganising Central Government-Administered State-Owned Enterprises of July 2016 stipulates that China will "reduce excess capacity and speed up the elimination of outdated capacity" in industries like coal. In July 2017, 16 ministries and commissions jointly issued Opinions on Promoting Supply-Side Structural Reform to Prevent and Resolve the Risk of Excess Coal-Fired Power Capacity, which started capacity cutting in the coal-fired power industry. The document states that China will ensure power security while "eliminating outdated capacity", "shutting down illegal projects" and "strictly controlling the scale of new capacity"; and that China will "encourage large power generation groups to reorganise and integrate upstream and downstream enterprises in coal and power to unlock synergies". The coal-fired power industry has identified its capacity-cutting targets for the 13th Five-Year Plan (2016-20). These include stopping or suspending the construction of $150 \mathrm{GW}$ of coal-fired power generation and eliminating outdated capacity of more than $20 \mathrm{GW}$.

(3) Solving problems left over by history and divesting state-owned enterprises of functions unrelated to their operations. In March 2016, China introduced the Circular of the State Council on Printing and Distributing the Work Plan for Accelerating the Divestment of State-Owned Enterprise Functions Unrelated to Their Operations and Solving Problems Left Over by History. The circular also identified these two issues as one of the Ten Reform Pilots.

\subsubsection{Major Progress}

Progress has been made in the reform of state-owned energy enterprises that have been conducted in an orderly manner and in accordance with the six aspects of the basic idea, as summarised in Table 18.

\subsection{Three Conclusions on the Reform of State-Owned Energy Enterprises}

\subsubsection{The Key to the New Round of Reform of State-Owned Energy Enterprises Is to Improve the Efficiency of State-Owned Capital Investment in the Energy Industry}

This round of reform of state-owned enterprises focuses on the state-owned capital management system. Specifically, for state-owned energy enterprises, the goal is to increase the efficiency 
Table 18 Summary of progress in the reform of state-owned energy enterprises

Aspect
Ensuring national energy security
Making state-owned energy enterprises
grow bigger and stronger

Optimising the distribution of state-owned capital

\section{Reorganising}

state-owned energy enterprises into state-owned capital investment companies

Carrying out mixed ownership reform

Deepening supply-side structural reform

\section{Progress}

The responsibility of ensuring energy supply and energy and technological reserves has been fulfilled

(1) The state-owned energy enterprises that have reorganised are operating stably

(2) Reorganisation of central and local government-administered state-owned energy enterprises will continue

(3) Integration across the value chain has taken place, which represents a transformation of the industry

(4) State-owned energy enterprises have been downsized through measures like streamlining the business, eliminating outdated and inefficient production capacity and divesting state-owned enterprises of unrelated operations

(5) The modern enterprise system has been improved; the role of the Party has been activated and loss of state-owned assets prevented

(1) The idea of state-owned capital investment in different energy fields has been identified

(2) Horizontal and vertical integration and the reorganisation of state-owned energy enterprises, such as the merger of Shenhua Group and China Guodian, have started

(3) SDIC and Poly Group have transferred their coal operations to China Coal Group - a result of the policy of withdrawing central government-administered state-owned enterprises from coal if it is not their core business

(1) Two central government-administered state-owned enterprises, SDIC and Shenhua Group, are in the state-owned capital investment company reform pilot

(2) Some local government-administered state-owned energy enterprises are also involved in local state-owned capital investment company reform pilots

Mixed ownership reform has been carried out to varying degrees at second- and third-level subsidiaries of state-owned energy enterprises

(1) The documents on deepening electricity system reform and on oil and natural gas system reform have been introduced and a roadmap for marketisation has been released

(2) The annual capacity-cutting plan for state-owned energy enterprises in the coal industry has been oversubscribed for two years in a row

(3) Capacity cutting has been promoted in the coal industry

(4) Solving problems left over by history and the divestment of state-owned enterprise functions that are unrelated to operations have been accelerated. Some state-owned energy enterprises have already completed this work. For example, the initiative for CNPC and Sinopec to divest unrelated operations affects more than 2 million households near the oil fields. In terms of the workload needed to divest water, power and heat supply and property management for employee residential areas, CNPC and Sinopec account for a third of the total of all the central government-administered state-owned enterprises. The provincial government-administered state-owned energy enterprises have produced a schedule for this work. Some state-owned energy enterprises in Shandong, Henan, Hebei and Shaanxi have achieved their targets 
of state-owned capital investment in the energy industry. Under the new management system, the border between the government and enterprises is clearer. As a contributor of state-owned capital, the government is not engaged in managing asset operations, which is the business of the enterprises, but in managing capital and continuously optimising the distribution of state-owned capital by leveraging liquidity and improving the return on state-owned capital. The reform addresses three levels:

- the responsibility of government departments for state-owned enterprise regulations, and the relationship between the government and state-owned enterprises, should be optimised;

- the corresponding internal reform of state-owned enterprises should be deepened; and

- government should delegate some management and investment powers to state-owned enterprises, which in effect means decentralising some power. Specifically, for state-owned energy enterprises, the government should optimise the distribution of state-owned capital in the energy industry through guarantees of state-owned capital for key and strong sectors and withdrawal from inefficient areas to improve the return on capital.

As part of the reform of the state-owned capital management system, state-owned energy enterprises need to carry out internal reforms, such as reorganising themselves into state-owned capital investment companies, establishing a modern enterprise system with internal mechanisms and opening up to mixed ownership. The necessity of reorganising state-owned energy enterprises into state-owned capital investment companies should proceed on a case-by-case basis. In the reform pilot of turning central government-administered state-owned enterprises into state-owned capital investment companies, only two energy enterprises (SDIC and Shenhua Group) are involved. For those state-owned energy enterprises that transition into state-owned capital investment companies, their internal systems and mechanisms should be reformed in accordance with the new state-owned asset management system. The reason for this is that the goal of the reform of the state-owned capital management system is to improve the return on investment of state-owned capital. The mixed ownership system reform pilot involves CNPC, Sinopec and central government-administered state-owned enterprises in the power industry.

\subsubsection{State-Owned Energy Enterprises Should Become Bigger and Stronger}

Making state-owned energy enterprises bigger and stronger is a realistic requirement for national energy security and social stability. China is a major energy consumer, working in close cooperation with the global supply market in the three major fossil energy areas: oil, natural gas and coal. It should be emphasised that energy supply is not only an economic issue but also a social responsibility. First, state-owned energy enterprises shoulder the social responsibility of ensuring energy supply. Second, since state-owned energy enterprises have large workforces and the areas where they are located are often endowed with energy resources, they shoulder the social responsibility of stabilising employment and promoting regional industrial restructuring. Bearing this dual (economic and social) responsibility, state-owned energy enterprises need to become bigger and stronger. Through years of development, they have laid a good foundation for growing bigger and stronger.

Growing stronger comes before growing bigger, which suggests that the former is harder. State-owned energy enterprises have already been big, but this does not mean they are strong. Generally, they are subject to heavy historical burdens, high interest rates on debt, poor use of resources and low profit margins. Improving return on investment of state-owned capital in the 
energy industry means that the operational efficiency of state-owned energy enterprises must be improved.

Therefore, the key to this round of reform of state-owned energy enterprises is to optimise their internal structure in business, staffing, assets and capital, and strengthen their capabilities in management, operation and investment to help them become bigger. Through optimisation and strengthening, state-owned energy enterprises can use their scale and industry advantages to develop gradually into internationally competitive energy enterprises.

\subsubsection{Many Difficulties Remain in the Reform of State-Owned Energy Enterprises}

This round of reform of state-owned enterprises, which focuses on improving the state-owned capital management system, is steadily making progress. Despite some achievements, considerable difficulties remain.

First, there are institutional barriers to withdrawing state-owned capital from inefficient energy assets. Characterised by their large size and diversified operations, state-owned energy enterprises have varying degrees of inefficient assets. The losses made by state-owned energy enterprises in these inefficient assets can be stopped by the state withdrawing its capital. Relevant support policies for system reform (by means of capital management) and supply-side structural reform (through capacity cutting) are in place. However, withdrawing state-owned capital from inefficient state-owned energy assets is difficult. The difficulties include resettling employees, repaying debt and preserving assets. Once inefficient assets are removed, the repositioning and resettlement of employees and debt repayment should be handled in a timely manner. Thanks to the central government, local government and state-owned enterprises, the repositioning and resettlement of employees is being addressed through various channels. However, the problem of debt repayment remains a difficulty. A debt may be shelved or borne by the parent company. But this also involves the debt-owning banks, which makes institutional progress difficult. Besides, a market-based valuation of assets is hard to make. The value of inefficient assets is low and they often create huge losses for state-owned energy enterprises. However, the government requirement to preserve and appreciate the value of state-owned assets means that their estimated value rarely equals their market value, and their estimated value is unacceptable to private capital.

Second, electricity system reform and oil and natural gas system reform are slow-paced. Although both are industrial management system reforms, they are closely related to the reform of state-owned enterprises because both industries are dominated by state-owned capital. Both involve the liberalisation of some business areas. The mixed ownership reform pilot involves central government-administered state-owned enterprises in these two industries. The slow pace of the two industry reforms is driven primarily by three factors: (i) market liberalisation has an impact on energy security; (ii) the influence of the existing benefits structure on traditional enterprises has been broken; and (iii) the Chinese market system still requires continuous improvement. These three factors are difficult to change quickly and the implementation of the reforms will take time and government determination.

Third, state-owned energy enterprises lack the ability to manage investment. State-owned energy enterprises were historically industrial groups focused on production. Under the new state-owned capital management system, they are required to maximise the investment function of state-owned capital. However, they lack not only human resources for and experience in capital investment, but also the requisite internal management system. An organisational structure can be gradually established and optimised, but reforming investment mechanisms is difficult.

Releasing the dynamism of state-owned energy enterprises is an important means to improve operational efficiency. Internal mechanism reform and large system reform complement each other. Since the reform of the state-owned capital management system has yet 
to be fully implemented, the reform of state-owned enterprises is difficult to implement. Reform involves defining the responsibility of state-owned asset administrative departments, the division of labour between government departments, and the government's authorisation to delegate power to state-owned enterprises.

Fourth, mixed ownership reform is difficult to implement. The reform pilot for mixed ownership of state-owned energy enterprises involves second- and third-tier non-core subsidiaries and is difficult to roll out at scale. The mixed ownership reform aims primarily to make state-owned capital open to private capital, creating a mix of state-owned and private capital. Such a mix is not simply adding or subtracting capital but integrating different governance mechanisms. Private enterprise might reject the capital management system and mechanisms of state-owned enterprises, while state-owned enterprises might not accept the management system of private enterprise. As things stand, institutional integration is the biggest obstacle. Questions such as "Which businesses should be open to private capital?" and "How should state-owned assets be valued and priced?" are still unanswered. The businesses favoured by private enterprise are not necessarily open to them, while those open to them are not necessarily attractive to them. The asset prices, which are based on the government policy of preserving and appreciating state-owned assets, are likely to be higher than the expectations of private capital. These are the real problems underlying mixed ownership reform.
Open Access This chapter is licensed under the terms of the Creative Commons Attribution 4.0 International License (http://creativecommons.org/licenses/by/4.0/), which permits use, sharing, adaptation, distribution and reproduction in any medium or format, as long as you give appropriate credit to the original author(s) and the source, provide a link to the Creative Commons license and indicate if changes were made.
The images or other third party material in this chapter are included in the chapter's Creative Commons license, unless indicated otherwise in a credit line to the material. If material is not included in the chapter's Creative Commons license and your intended use is not permitted by statutory regulation or exceeds the permitted use, you will need to obtain permission directly from the copyright holder. 